Illinois State University

ISU ReD: Research and eData

Theses and Dissertations

6-21-2016

\title{
Secondary Mathematics Teachers' Learning Through Practice: The Case of Rudy
}

Theodore John Rupnow

Illinois State University, ted.rupnow@gmail.com

Follow this and additional works at: https://ir.library.illinoisstate.edu/etd

Part of the Educational Sociology Commons, Science and Mathematics Education Commons, and the Teacher Education and Professional Development Commons

\section{Recommended Citation}

Rupnow, Theodore John, "Secondary Mathematics Teachers' Learning Through Practice: The Case of Rudy" (2016). Theses and Dissertations. 633.

https://ir.library.illinoisstate.edu/etd/633

This Dissertation is brought to you for free and open access by ISU ReD: Research and eData. It has been accepted for inclusion in Theses and Dissertations by an authorized administrator of ISU ReD: Research and eData. For more information, please contact ISUReD@ilstu.edu. 


\title{
SECONDARY MATHEMATICS TEACHERS' LEARNING THROUGH PRACTICE: THE CASE OF RUDY
}

\author{
Theodore J. Rupnow
}

\section{Pages}

In this study I investigated teachers' learning through practice. Teachers learn in teacher preparation programs and in professional development, but the most personal learning occurs in practice. Teachers spend much of their time isolated from colleagues, participating in classroom communities instead of professional communities. If teacher educators want to understand the potential for learning in the space where teachers spend much of their time it is necessary to investigate the learning that is occurring in classroom practice. To pursue this end, I explored one secondary mathematics teacher's learning in practice. I observed and video-recorded this teacher's classroom practice for one unit of instruction in two sections of the same course. I conducted interviews before and after the observations, asked him to record reflections about his planning and teaching, collected all of his lesson plans and materials, and observed his interactions with colleagues on a teacher inservice day. I analyzed the results qualitatively (Miles, Huberman, \& Saldaña, 2014) with Wenger’s (1998) Communities of Practice (CoP) framework. Using the CoP framework, I posited the teacher's practice as the driving force for coherence in communities, for the negotiation of meaning in experience, and for identity formation. 
Thus, in characterizing the teacher's communities of practice, negotiation of meaning, and identity I painted a picture of the teacher's practice. Through this picture of practice, I viewed learning as belonging in community, learning as experiencing meaning, and learning as becoming a particular type of person. My analysis revealed five important ideas. First, engagement in collegial communities is important for the development of practice. This was revealed in the minimal engagement with mathematics teachers that stifled the teacher's learning. However, it was also demonstrated by the safe haven and significant learning in the teacher's coaching community. Second, teachers can leverage opportunities for professional learning through practice, but may need assistance to recognize the potential for change. The teacher in this study learned through his participation with his fifth hour class, but also failed to leverage the opportunity for optimal growth. Third, learning through practice may best be accomplished through a process that combines reflective and projective participations. When the teacher reflected on his participation with students and projected that onto a hypothetical participation from the student's perspective he produced significant learning. Fourth, the work of identity formation in teaching is significant, difficult, and emotional. This implies the need to focus educational efforts on supporting identity transformations. Finally, learning through practice is significant. This implies the need to focus educational efforts on helping teachers learn through practice and positively leverage the opportunities for professional growth presented in their own practice.

KEYWORDS: Learning in Practice, Teacher Learning, Communities of Practice, Teacher Identity, Case Study, Secondary Mathematics Teaching 
SECONDARY MATHEMATICS TEACHERS’ LEARNING THROUGH PRACTICE:

THE CASE OF RUDY

THEODORE J. RUPNOW

A Dissertation Submitted in Partial

Fulfillment of the Requirements

for the Degree of

DOCTOR OF PHILOSOPHY

Department of Mathematics

ILLINOIS STATE UNIVERSITY

2016 
Copyright 2016 Theodore J. Rupnow 
SECONDARY MATHEMATICS TEACHERS’ LEARNING THROUGH PRACTICE:

THE CASE OF RUDY

THEODORE J. RUPNOW

COMMITTEE MEMBERS:

David Barker, Chair

Jeffrey E. Barrett

Craig J. Cullen

Beth Hatt

Tami S. Martin 


\section{ACKNOWLEDGMENTS}

I would like to thank David Barker first. You have done more than help me write a dissertation, you have helped me learn to research. You mentored me through collaborative work on teacher decision making, letting me in on the entire research process. I appreciated being treated as a colleague and not only a student. You mentored me as I observed your classes and learned to teach college level coursework. On this dissertation you have spent many hours helping me navigate the IRB process, copyright permissions, and participant recruitment. You have helped me in unfamiliar territory in all of these areas. You worked with me to understand a theory that neither of us knew very well at the beginning and apply it to the analysis of this project. You read my work and gave me meaningful feedback. You have spent more hours on this project than you probably ever intended and I am extremely grateful.

I would also like to thank Craig Cullen and Jeff Barrett. Working with you prior to this dissertation taught me as much about research as any other part of the program at ISU. I am grateful for the things that I learned in my time working with you and how I could apply those elements in a different form of research. I appreciate the amount of responsibility and freedom you gave me and the support you provided so that I could carry out those responsibilities. I also appreciate your work on my committee. You have provided me with exceptional advice to improve this product.

I would like to thank Tami Martin and Beth Hatt for the ways I learned in your 
classes. You each provided me a solid foundation for research in the courses you taught. You also provided me with feedback that has been integral to the success of this project. You have dealt with all of the changes to this study with wisdom and support. Thank you.

I would like to thank Cindy Langrall and Edward Mooney for pushing me toward studying practice instead of knowledge. Your comments, suggestions, and gentle prodding in class helped me develop a better study. You also created a more powerful learning experience for me by pushing me to study teachers’ learning through practice.

I would like to thank my fellow Doctoral students (even though they will not read this) for spurring me on, supporting me, and helping me to grow as an educator and researcher. The strength of engagement in this community at ISU has helped me understand the power for learning in communities of practice. It is my hope that the years we have spent engaged with one another here will continue into our professional lives.

I would like to thank my family. You have always encouraged me in my academic pursuits. You instilled in me the value of education and have always helped me learn inside and outside the classroom. You have supported me through every stage of my education and educating. I am who I am because of all of you.

Finally, I would like to thank Kara Rupnow. You encouraged me to pursue this professional goal. You moved here with me as I pursued it. You have stood by me through three years of many late nights, and always strange hours. You have supported me at all times. You have encouraged me in countless ways and this would not have been such a positive learning experience without you by my side. I am excited to continue into the next stage of our life together.

T. J. R. 


\section{CONTENTS}

Page

ACKNOWLEDGMENTS $\quad$ i

CONTENTS iii

TABLES $\quad \mathrm{X}$

FIGURES $\quad$ xii

\section{CHAPTER}

I. PROBLEM STATEMENT 1

Teacher Learning $\quad 2$

I Am Not Alone 3

Why Jump off the Cliff?

I Am Not Just Reminiscing $\quad 5$

Professional Development Experiences 6

Knowledge as the Object of Learning 6

Collegial Communities of Practice as the Context of Learning 7

$\begin{array}{ll}\text { I Am Moving Forward } & 7\end{array}$

Research Questions $\quad 8$

Communities of Practice $\quad 9$

Meaning 11

Community 12

Identity 13

Learning in Practice $\quad 14$

II. REVIEW OF LITERATURE 17

$\begin{array}{ll}\text { Communities of Practice } & 18\end{array}$

From Social Constructivism to Communities of Practice 18 
Why Communities of Practice $\quad 20$

Didactical situations in mathematics. 20

Commognition. 21

Critiques of CoP. $\quad 22$

Building on Communities of Practice 24

Jean Lave. $\quad 24$

Etienne Wenger. $\quad 25$

More situated learning. $\quad 28$

$\begin{array}{ll}\text { Teacher Learning } & 28\end{array}$

Teacher Knowledge $\quad 29$

From Knowledge to Professional Development 31

The Teacher Research Boom 34

Teachers’ Learning in Practice 35

Professional communities. $\quad 36$

Reflection. $\quad 37$

Knowledge. $\quad 38$

Identity. $\quad 39$

Change. $\quad 40$

Time to Move Ahead 42

$\begin{array}{ll}\text { III. METHODS } & 43\end{array}$

Research Questions $\quad 43$

Paradigm 43

Positionality 44

Research Methods $\quad 45$

Participant Selection 46

Research Setting $\quad 47$

Data Collection and Instruments 47

Data Analysis 51

Stage one. $\quad 52$

Stage two. 55

Stage three. $\quad 56$

Stage four. $\quad 56$

Ethical Issues $\quad 57$

$\begin{array}{ll}\text { Continuing } & 58\end{array}$ 
$\begin{array}{lll}\text { IV. RUDY } & 59\end{array}$

Setting the Stage $\quad 60$

$\begin{array}{ll}\text { The Return } & 60\end{array}$

The Classroom 61

The Students 62

The Curriculum 64

Initial Interview $\quad 65$

The Curriculum 65

The Difficulties of Transition $\quad 66$

Rudy’s Teaching Philosophy $\quad 67$

Rudy's Collegial Relationships $\quad 69$

Rudy's View of Mathematics 70

$\begin{array}{ll}\text { Teacher Inservice } & 71\end{array}$

Rudy's District Context $\quad 71$

Rudy's High School Context $\quad 72$

Rudy’s Lesson Plans as Content Oriented 75

The First Lesson $\quad 77$

$\begin{array}{ll}\text { Fourth Hour } & 77\end{array}$

Warm up.

Notes. $\quad 80$

Homework. $\quad 86$

$\begin{array}{ll}\text { Fifth Hour } & 87\end{array}$

Rudy's unrelated story. $\quad 88$

Warm up. $\quad 90$

Notes. $\quad 92$

George's influence on fifth hour. $\quad 96$

Greater content coverage in fifth hour. $\quad 99$

Homework. 101

The Second Lesson 102

Fifth Hour 102

One form of homework feedback. 103

Another form of homework feedback. 106

Notes. 108 
Different homework feedback for fourth hour.

The Third Lesson

Fourth Hour

Combining questioning and direct instruction.

Combining questioning and direct instruction.

Homework feedback and grading.

Using prior lessons to build mathematics as a system of procedures.

Homework feedback and grading.

Using prior lessons to build mathematics as a system of procedures.

Rudy's Form of Authority

Rudy's Perception of My Impact as a Researcher

Rudy's Self-Described Learning 
Communities of Practice

Classroom Communities

Mutual engagement.

Joint enterprise.

Shared repertoire.

Professional Communities

Mathematics teachers at Valley View High School. 212

Mathematics teachers beyond Valley View High School.

Coaches at Valley View High School. 217

Rudy’s Boundary Encounters 219

$\begin{array}{ll}\text { Negotiation of Meaning } & 221\end{array}$

Rudy’s Participation in Practice $\quad 221$

Mathematical telling and questioning. 226

Directing, evaluating, and using humor. 229

Story telling, using a nickname, allaying fears, and motivating.

Answering, facilitating peer-to-peer engagement, facilitating self-evaluation, hinting, coordinating logistics, undefined forms of participation, and withdrawing.

Participation in other communities.

Reification and Reifications of Rudy’s Experience

Mathematical objects.

Homework, notes, quiz, test, and warm up. $\quad 256$

Social norm, schoolwide, technology, undefined. 261

Textbook, CCSS-M, lesson plan, lesson objective, course, schoolwide.

The Interplay of Reification and Participation for Meaning 265

Identity

Community Memberships and Learning Trajectories 
Rudy's membership in the classroom community.

Rudy's membership in the mathematics teacher community.

Rudy’s position as coach.

Experiencing Meaning

Patterns of participation.

Multimembership

The Local and the Global

Learning as Belonging

Mutual engagement.

Joint enterprise.

300

Shared repertoire.

302

Trajectories.

306

Learning as Experience

Experimental participation.

Reificative participation.

311

Vicarious participation.

Learning as Becoming

Engagement.

Alignment. 
Teachers’ Learning in Practice 335

Professional communities. 335

Reflection. 336

Knowledge. $\quad 337$

Identity. $\quad 338$

Change. $\quad 340$

Limitations and Validity $\quad 341$

Implications 344

Lesson One $\quad 344$

Lesson Two 346

Lesson Three $\quad 347$

Lesson Four $\quad 348$

Lesson Five 349

Future Research 350

Methodological Implications $\quad 350$

Continuing Studies 353

Not the End $\quad 354$

References $\quad 355$

APPENDIX A: PRINCIPAL EMAIL 365

APPENDIX B: TEACHER EMAIL 366

APPENDIX C: LESSON PLANNING THINK-ALOUD PROTOCOL 367

APPENDIX D: REFLECTION PROTOCOL 368

APPENDIX E: INTERVIEW PROTOCOLS 369

APPENDIX F: CODE DEFINITIONS 371

APPENDIX G: TEACHER LETTER AND CONSENT FORM 390

APPENDIX H: RUDY'S LESSON PLANS 392

APPENDIX I: RUDY'S THINK-ALOUD RESPONSE 395 


\section{TABLES}

Table

Page

1. Data Accounting Log 48

2. Progression of Percentage of Agreement in Coding Observation Data 55

3. Mutual Engagement Codes 159

4. Instances of Mutual Engagement Codes for Rudy’s Sources 161

5. Participation Codes (Abbreviated) 164

6. Teacher-Class Engagement Instances Coded at Participation 165

7. Teacher-Student Engagement Instances Coded at Participation 174

8. Individual Work Engagement Instances Coded at Participation 181

9. Joint Enterprise Codes 189

10. Instances of Negotiating Coded at Products and Responsible Parties 190

11. Instances of Negotiating Coded as Products and Responsible Parties 191

12. Accountability of Students and Teachers to Communities 197

13. Shared Repertoire Codes 202

14. Elements Coded at Shared Repertoire for Rudy’s Sources 204

15. Overlapping Content and Stage Codes for Shared Repertoire 205

16. Procedural Analogues From Prior Units for Procedural Elements of the Emerging Mathematical Shared Repertoire 208

17. Participation Codes 223

18. Instances of Participation Codes for Rudy’s Sources 224

19. Mathematical Telling and Questioning in Mutual Engagement as Percent of Instances Coded as Participation 
20. Mutual Engagement Codes as Percentage of all Instances Coded at Mathematical Telling and Questioning

21. Directing, Evaluating, and Using Humor in Mutual Engagement as Percent of Instances Coded at Participation

22. Mutual Engagement Codes as Percentage of all Instances Coded at Directing, Evaluating and Using Humor

24. Instances of Reification Codes for Rudy’s Sources 


\section{FIGURES}

Figure

Page

1. Converging strophoid learning trajectories in the classroom community of practice.

276 


\section{CHAPTER I}

\section{PROBLEM STATEMENT}

As an elementary student I thought my teachers knew everything, maybe even more than my parents. As I grew up I found that my teachers were not omniscient, but I admired them nonetheless. Despite my admiration it never crossed my mind that I might one day become a teacher. A career path filled with the monotonous drone of course upon course, year after year, was not the life for me. I needed change, and although I would not have used this word, I needed to learn. But by my second year of college this path that seemed unlikely to satisfy my need for change became reality.

For the next three years of college I eagerly sought the knowledge of the teaching profession, and by the end of my time I was ready to face a classroom full of students. My learning was complete. My students would be awed by my grasp of mathematics and my eloquent and engaging teaching style. They would love learning mathematics because I loved mathematics. Then, I met my students.

It was not long before I began exploring other professions. Surely there was a better way to use my knowledge of mathematics for the good of humanity. The students in whom I was trying to instill a love of learning, and a love of mathematics, seemed to glean nothing from my teaching. It was not that I thought they were hopeless, I thought I was hopeless. Someone else, with more knowledge of teaching, a better understanding of students, and more experience could do a much better job than I could. I was not fit for 
this role. Yet, somehow, my students learned a little bit of mathematics, and I decided to teach for one more year. Something was different about me by the end of my first year of teaching. I had learned something.

The funny thing was, no one had taught me. Everything I learned in that sink-orswim, just-keep-your-head-above-water, try-not-to-kill-any-of-your-students, first year of teaching was a product of my experience. In the years that followed, despite my early impressions that teaching was a profession of monotony, I continued to learn. I learned from colleagues, professional development experiences, and coursework, but my most profound learning continued to be the product of experience. Those lessons I learned in my classroom, standing in front of my students, have had, perhaps, the greatest influence of any learning experience on my teaching and learning of mathematics.

\section{Teacher Learning}

As a result of my own experiences learning as a teacher, this study was about teachers’ learning. In particular, I was interested in one teacher’s learning through practice. I call this teacher Rudy. Most teachers or former teachers would probably not need convincing that this is an important topic to study. They know firsthand that what we, as teachers, learn through experience is more than abstract knowledge, it is lived experience and intensely personal. It has come by trial and toil, and it transforms who we are as people, and as mathematics teachers.

Even so, I will provide a rationale for my interest in Rudy’s learning in practice. I will show that I am not the only one interested in the topic, that I am not merely reiterating what many have said before, and that the outcome of this study is useful for our community of mathematics educators. Before I describe my study, I will establish it 
on these three assurances: I am not alone, I am not rehashing old memories, and I am moving forward.

\section{Am Not Alone}

I had to look no further than a couple mathematics education research handbooks to find that research about teachers' learning is a predominant topic. In the Third International Handbook of Mathematics Education the editors Clements, Bishop, KeitelKreidt, Kilpatrick, and Leung (2013) devoted two chapters and more than 60 pages to topics related to teacher learning. The authors of the chapters cited almost 200 sources related to their respective topics. In the Second Handbook of Research on Mathematics Teaching and Learning, Lester (2007) devoted an entire chapter of nearly 70 pages to “The Mathematical Education and Development of Teachers.” Sowder (2007) cited over 250 sources about teacher education and development in writing the chapter.

Furthermore, the fifteenth study of the International Commission on Mathematical Instruction (ICMI) was devoted entirely to The Professional Education and Development of Teachers of Mathematics. In the resultant Springer publication, the editors, Even and Ball (2009), devoted an entire section and nearly 100 pages to discussing "Learning in and from Practice.” This ICMI study was the result of a review of the field of research about mathematics teacher education by Adler, Ball, Krainer, Lin, and Novotna (2005). In their review they claimed, "We know much less than we should what teachers learn from experience, whether teachers learn from experience, and what supports learning from experience” (p. 376). Thus, it is no surprise that Ball provided space for studies that helped address this identified deficiency in the fifteenth ICMI study.

It is clear that I am not alone in studying teacher learning. Furthermore, I am not 
alone in studying teachers' learning in practice. However, the argument that everyone else is doing it was never sufficient to convince my mother. As the saying goes, if everyone jumped off a cliff would you? Of course, the answer is not an immediate no, the answer depends on the surrounding context. Why is everyone jumping off the cliff? Is the water at the bottom of the cliff deep enough that I would not sustain injuries from the fall? So, I will look at why everyone is jumping off the cliff.

\section{Why Jump off the Cliff?}

The basic argument for research on teachers' learning in practice, whether stated in full or left implicit, is this: (a) student learning is important, (b) teachers can have a significant impact on student learning by providing high quality instruction, (c) teachers can improve their instruction through learning, and (d) teachers' practice is a significant element in their learning. The first point can be established based on a number of different arguments including humanitarian, religious, political, economic, and social arguments, but I will claim this as my foundational assumption.

The second point brings only slightly more contention. I could quote the statistics presented in process-product studies (Biniaminov \& Glasman, 1983; Rowley \& Leckie, 1977) that have demonstrated time and again that teaching is a fundamental variable in learning, or the descriptive studies that demonstrate learning without guidance is often misdirected (e.g., Erlwanger, 1973), but these may not convince the true skeptic. For the true skeptic, the traditional products of education are under scrutiny. The skeptic suggests that internalized knowledge is not the learning that is important and the results just mentioned are insignificant. But the alternative to learning as internalization is learning as a social process. With a mere description of social learning, the skeptic will accept that 
a student does not learn in isolation. Thus, a teacher, though differently imagined than the traditional instructor, may produce better learning results if she can orchestrate social situations conducive to a student's learning.

Although I could, once again, cite research that demonstrates improved teaching leads to improved learning outcomes (e.g., Fennema et al., 1996; P. L. Peterson, Carpenter, \& Fennema, 1989), the third point is not much more than a logical extension of the second point. If some teaching is better than other teaching and if learning is possible, then learning to teach better should be possible.

The final point is certainly the most contentious in all the argument, but it may help to simply state that the learning outcomes of practice do not have to be positive to be significant. If teacher educators hope to improve teaching through teachers’ learning they will need to understand how various factors influence teacher learning for better or for worse. And as Brodie and Shalem (2011) suggested, educators are well aware from professional development research that practice should be a focus of professional development (Borko, 2004) because practice, including the production of artifacts for practice (e.g., Horn, 2005) and reflection on practice (e.g., McDuffie, 2004), is a significant part of teachers’ learning.

\section{Am Not Just Reminiscing}

Now that I have established the importance of research about teachers' learning in practice, I have yet to establish that I am bringing something new to the conversation. This study fills a new role that I will highlight in the following description of prior research about mathematics teachers' learning in practice. I will use three illustrative studies to demonstrate the important role this study will play. Chapter II will provide a 
more thorough review of how my study relates to the existing research.

\section{Professional Development Experiences}

In studies on cognitively guided instruction (Fennema et al., 1996; Franke, Carpenter, Fennema, Ansell, \& Behrend, 1998; P. L. Peterson et al., 1989) researchers leveraged teachers' experiences in practice for professional growth. Teachers' experiences were used in conjunction with professional development workshops to confirm ideas about student thinking and to develop practices focused on student thinking. Mentors were provided at each school to assist practicing teachers in their implementation of ideas presented during the professional development. Thus, teachers' classroom experiences were a conduit for teachers’ knowledge construction.

In this study, I also investigated how a teacher learned in his practice and from his students, but this learning occurred in the absence of an intervention. My discussion is aimed at the more natural process of teacher learning apart from professional

development experiences. This focus is important because teachers spend significant time in isolation with their students. However, the professional development studies are important because one cannot assume that teachers can develop effective practice apart from the expertise of other practicing professionals. Educators must understand both how teachers learn from practice and through intervention.

\section{Knowledge as the Object of Learning}

Margolinas, Coulange, and Bessot (2005) investigated teachers’ learning in practice without interventions like professional development or elements of a teacher education program. They viewed teachers' learning experiences through a didactical situations lens, and focused on teachers' development of a very specific type of 
knowledge they termed observational didactic knowledge (ODK). Didactic knowledge was defined as a form of subject specific knowledge for teaching, but they narrowed the scope of didactic knowledge by focusing on that which related to teachers' observations of student activity. Their study is illustrative of a pervasive focus on knowledge in teacher learning studies. The CGI studies mentioned above are another illustration of the common focus on knowledge as the object of learning. These studies are important because cognitive theories of learning should be juxtaposed against social theories of learning like Communities of Practice (CoP) (Wenger, 1998). In this study I use the CoP framework to analyze a teacher's learning through practice. Together, studies focused on knowledge and those focused on social practice provide a more complete perspective on teacher learning than either could provide independently.

\section{Collegial Communities of Practice as the Context of Learning}

Horn (2005) focused on two teachers in high schools that were undergoing serious mathematics reform efforts. She collected data on these teachers' natural experiences, both in the classroom and in conversation with colleagues. Her main goal was to understand how the larger school context and collegial relationships influenced teachers' learning. Her study is important because the CoP framework was central to her analysis. My study also draws on the CoP framework, but I have posited the classroom community as central to the teacher's development as opposed to the collegial community of practice.

\section{Am Moving Forward}

These three studies illustrate how this study builds on the past without rehashing what has already been studied. I have taken a position that will move the mathematics education field toward a deeper understanding of teacher learning from a social 
perspective. This position will supplement the existing research about how teachers develop knowledge through practice, develop practice through interventions like professional development, and develop practice through collegial relationships. I am taking a step back to understand the natural process of teacher learning through practice. Just as athletes who seek to improve physical performance, first must understand the natural processes involved, if I want to improve learning, I must first understand the natural processes involved. Understanding this natural process of teacher learning through practice may move us, as mathematics educators, forward to enhance the positive aspects of teachers' learning through practice and eliminate the negative aspects of teachers' learning through practice. This is an important perspective because it may have significant implications in the areas of teacher preparation, teacher induction, and professional development. If we understand how teachers learn from their practice, we can better leverage preservice teachers' experiences in practice for the improvement of practice. We may do the same for early career teachers, which in turn will improve the induction process. Still, late career teachers do not cease to practice, so we may also assist late career teachers in the continued process of learning from their own practice. At any point in their career teachers spend much of their time in isolated classroom practice. The results of this study may help educators leverage one of teachers' most prevalent resources for learning.

\section{Research Questions}

I have established that understanding teachers' learning is crucial. Furthermore, teachers' learning in practice is unique and profoundly important. However, Adler et al. (2005) have suggested that our understanding of teachers' learning in practice is lacking. 
Therefore, the purpose of this study is to investigate teachers' learning in the secondary mathematics classroom context. To accomplish this purpose, I have begun to address the following questions:

1. What are the characteristics of Rudy's communities of practice?

2. How did Rudy negotiate meaning in practice?

3. What characterized Rudy's identity in practice?

4. In what ways did Rudy learn through practice?

Several terms in these questions require that we agree on a common definition. I define practice, learning, communities of practice, negotiation of meaning, and identity in relation to Wenger's (1998) theory of Communities of Practice, which is detailed in the following section. Furthermore, I define practice to be confined to any situation in which the teacher is focused on the planning of, implementation of, or reflection about a particular instance of instruction. Thus, practice is directly connected with specific classroom experiences.

\section{Communities of Practice}

To define learning I turn to the work of Etienne Wenger (1998). His theory of learning developed out of the social learning theory tradition, which has its roots in the work of Lev Vygotsky (e.g., 1934/1999). Wenger's theory is a more direct extension of the work of Jean Lave (1988). Lave and Wenger's (1991) Situated Learning provided a foundation for Wenger's (1998) Communities of Practice. Communities of Practice is an appropriate framework for analyzing most learning, but particularly in the case of teacher learning. Many theories of learning focus specifically on the cognitive aspects of knowledge, but teachers' learning is intimately connected with their practice within a 
community. Lave and Wenger (1991) argued that cognitive theories of learning focus on the person in a narrow sense and create a non-personal view of knowledge and activity. Their more personal view posits a holistic understanding of learning as a process of social participation, thus keeping a focus on the learner as a part of community. They wrote, Learning involves the whole person; it implies not only a relation to specific activities, but a relation to social communities—it implies becoming a full participant, a member, a kind of person. In this view, learning only partly—and often incidentally_-implies becoming able to be involved in new activities, to perform new tasks and functions, to master new understandings. (Lave \& Wenger, 1991, p. 53)

In Lave and Wenger's (1991) holistic view, learning cannot be defined categorically. That is not to say that a concept of learning cannot be established, but it is intertwined with the concepts of meaning, identity, practice, and community in ways that do not allow for precise categorical distinctions. Thus, in what follows I will attempt to summarize the operational definition of learning set forth in Wenger's (1998) Communities of Practice. It will be hard, in such a short space, to do justice to the complexity of learning, so I will try to focus on the aspects that I find most poignant for teachers' learning in practice.

Learning coexists in a complex relationship with meaning, identity, practice, and community (Wenger, 1998). To study learning without attending to negotiating meaning, transforming identity, changing practices, and evolving communities would be irresponsible. However, the teacher's changing practices are the aspect of learning I am addressing in my research question, so I will set a heavy focus on practice, or learning as 
doing.

To help his readers understand learning, Wenger (1998) first explored practice and then discussed identity. Within the concepts of practice and identity he explored the interrelations of community and meaning. Although additional aspects of the theory will become important throughout my analysis, the aspects of practice, community, meaning, and identity will serve as the foundation. Therefore, I will focus solely on these elements here and leave additional details until a more concrete understanding of how this theory is being applied in my analysis has been establish.

\section{Meaning}

Wenger (1998) was very careful in his description of practice as the negotiation of meaning. He stated, "Practice is about meaning as an experience of everyday life" (p. 52). As humans, we experience our world in meaningful ways. That meaning is derived in practice primarily through two processes. Wenger calls these processes participation and reification. Participation can be understood in the general sense of the term. Participation is living in the world, membership, acting, interacting. Reification is the concretization of meaning. Reification exists in documents, forms, monuments, and instruments as well as the less concrete projections, and points of emphasis. Reification helps us organize our experiences and refers to both the process of concretization and the product of that process. Participation and reification are not categorical, opposites, substitutes for one another, ends of a spectrum, or translations of one another. They are a duality, describe an interplay, interact and imply one another, and transform their relation with one another. 


\section{Community}

When Wenger (1998) used the term community he was referring to a community of practice, not a culture, social structure, or an activity. Practice provides a sense of coherence for these communities through mutual engagement, a joint enterprise, and a shared repertoire. Mutual engagement occurs when members participate in practice together, but it involves more than work proximity, networking, or a formal group membership. Mutual engagement involves dense relations around significant practice. The joint enterprise that characterizes a community of practice is the result of "a collective process of negotiation” (Wenger, 1998, p. 77). The joint enterprise is simultaneously defined by, and pursued by, the members of the community. It is more than a defined objective; it creates a source of accountability that adheres the community. In the pursuit of this enterprise the community "creates resources for negotiating meaning” (Wenger, 1998, p. 82) called a shared repertoire. This repertoire may include "routines, words, tools, ways of doing things, stories, gestures, symbols, genres, actions, or concepts” (Wenger, 1998, p. 83). These sometimes seemingly unrelated elements are held together in coherence by the joint enterprise of the community. Communities of practice may or may not be reified groups with formal structure. Moreover, a formal group may not form a true community of practice.

I must reiterate at this point that the focus of my study is teachers' learning in practice. This has evolved out of and it informs my use of Wenger's theory. I have described how practice gives rise to meaning and community in a teacher's experience. Wenger also describes identity as a development of practice through the mediation of community and meaning. Although this is not a comprehensive view of identity, these 
two aspects of identity will establish a foundation for my analysis of identity.

Furthermore, I will illustrate how community, meaning, and identity influence and are influenced by learning.

\section{Identity}

Wenger (1998) described "identity as negotiated experience. We define who we are by the ways we experience our selves through participation as well as by the ways we reify our selves” (Wenger, 1998, p. 149). What others think and say about us, and what we think and say about ourselves, are reifications that play out in our everyday participation. Who we are, as people, is both a reflection of these reifications and a reality of our participation in the world.

Simultaneously, community membership defines identity. Community membership translates into identity primarily as a form of competence. A community member's level of competence determines and is determined by his or her level of engagement with other community members, his or her role in pursuing the joint enterprise, and the degree to which he or she shares in the repertoire of knowledge and tools of the community. The member's identity may shift over time as he or she progresses from the periphery of a community into full membership in the community. Thus, the member's identity may also be seen as a trajectory, or a set of trajectories in several communities. These trajectories may be inbound (driving him or her into full membership), outbound (helping him or her exit a community), peripheral (keeping him or her out of full membership in a peripheral role), insider (continuing the learning of a full member), or boundary (allowing him or her to link two communities). 


\section{Learning in Practice}

Once again, I must refocus the discussion of this theory back to learning in practice. I have described how practice gives form to communities, gives rise to meaning, and informs identity through meaning and community. Learning in practice, then, takes place in the development of community, through the negotiation of meaning, and as a transformation of the identity of practice. In terms of community, the central aspect of practice as learning is legitimate peripheral participation. This occurs as a new member participates in the community in mutually beneficial ways. Legitimate implies that this member's participation is contributing to the joint enterprise of the community, but peripheral implies that he or she is not participating fully in all aspects of the community. The peripheral participant has not reached the extent of mutual engagement that a full member has and does not understand the full extent of the shared repertoire of the community. In this perspective reification and participation are forms of memory and sources of continuity and discontinuity. In other words, participation and reification make some people members of a community and keep others out. For the legitimate peripheral participant, participation and reification act as memory that helps him or her move toward full participation in the community of practice. Simultaneously, the participation and reified objects of this peripheral member are sources of evolving practices for the community. As the peripheral participant increases mutual engagement he or she begins to experience and contribute meaningfully to the joint enterprise. He or she is also introduced to the shared repertoire and begins to understand the language and meanings of the community.

Although legitimate peripheral participation is the primary position of learning in 
a community of practice, the peripheral member is not the only learner in the situation. The community of practice is changed by the contributions of any new member, or in many cases an already existing member. Thus, what Wenger (1998) called generational discontinuities also create new continuities. This perspective suggests that not only does learning occur in the experiences of the legitimate peripheral participant, but also in the experiences of full participants, as the peripheral participant influences the structure of the community.

Although this picture of Wenger's framework is utterly incomplete, allow me to provide a single helpful exercise in thought before I proceed to the review of literature in Chapter II. Picture yourself on your very first day in your very first job. I don’t mean your first career job; I mean your first plain-old-job job. Now, think about your first attempts at whatever tasks you were asked to do on that first day of work. Then, try to recall how it was you came to build competence at the tasks you were assigned in subsequent days. Think about your engagement with coworkers, and the ways you worked together to accomplish the work of your station (the joint enterprise). Think about the ways you as a worker defined the enterprise despite the external mandates of what you were required to accomplish. Think about the language you developed, the skills you acquired, and the tools you learned to use in the process of accomplishing the tasks you were assigned to (shared repertoire). Think about how you found meaning in your work-how your participation with your coworkers or clients helped define your experience as meaningful. Think about the ways concrete elements of your environment shaped your participation and brought little bits of meaning to your existence. Think about how your membership in that community, even for a short period of time, has 
become a part of who you are today—how it shapes your identity even as you participate in this conversation. And think about how your learning in that first job was about so much more than knowledge. It was about belonging to a particular group of people (community). It was about experiencing your world in a particular manner (meaning). It was about doing a particular kind of work (practice). It was about becoming a particular kind of person (identity). 


\section{CHAPTER II}

\section{REVIEW OF LITERATURE}

The review I am setting out to establish as the foundation for my work represents a history of learning in several fields. The review represents a form of memory of a landscape of practice. The research studies in the next several pages are reifications that serve as a form of memory and partially constitute a history of learning for the communities of practice out of which they arose. These reifications serve as boundary objects that link the various communities of practice represented by each study. These studies provide windows into the communities that, together, constitute the landscape of practice of mathematics educators, sociologists, education researchers.

As I bring insights from various communities of practice into my own practice I am not attempting to be comprehensive in my review of the related fields. The breadth of topics that bear mentioning in this discussion could lead to a review that would span thousands of pages and decades of academic writing. Instead, I am attempting to accomplish three less prodigious goals: (a) to acknowledge the history of learning that has given rise to my study, (b) to illuminate a context in which to interpret my conclusions, and (c) to illustrate the nexus of community competence that supports my analysis.

In light of these objectives I think it will be most appropriate to begin by tracing the genesis of Wenger's (1998) CoP framework backward through time. This will help 
me describe the underpinnings of the theory and the important roles of practice and socialization in learning. Then, I will illumine the current position of the CoP framework by investigating a few of the avenues of application since its introduction. The remainder of the review will consist of a description of research about teachers. I will begin this part of the description with a historical perspective on the development of research on teachers' learning and I will conclude with a pointed analysis of a few pertinent studies about teacher preparation, professional development, and teacher identity.

\section{Communities of Practice}

Communities of Practice as a theory of learning is most often associated with Wenger (1998) and his work by the same title. However, the concept was first developed in the collaborative work of Situated Learning (Lave \& Wenger, 1991). The primary concept in Situated Learning was legitimate peripheral participation, which was upheld as the standard mechanism of learning. Communities of practice provided the context for legitimate peripheral participation. In the opening chapters of Situated Learning, Lave and Wenger (1991) explained how the concept of legitimate peripheral participation grew out of apprenticeship research, but significant advances in the understanding of learning as situated can be traced back through the work of Pierre Bourdieu (e.g., 1977) and at least to Lev Vygotsky (e.g., 1934/1999).

\section{From Social Constructivism to Communities of Practice}

Social constructivism has evolved into a plethora of theories so diverse in conceptualizations that it can be difficult to recognize the connections with their common origin in Vygotsky. However, CoP, commognition (Sfard, 2008), and didactical situations in mathematics (Brousseau, 1997), just to name a few, all have roots in the 
seminal works of Vygotsky (e.g., 1934/1999). Two concepts in social constructivism are fundamental to the $\mathrm{CoP}$ framework. First, learning occurs through social communication (Vygotsky, 1934/1999). Second, learning is not a product of acquisition from these social interactions, but an individual construction through participation. Social interactions extend a person's possible realm of understanding in a zone of proximal development. This zone is the extent to which a person's capabilities can be extended by participation in community. As a learner's capabilities are extended learning occurs as a function of social interaction with more knowledgeable others. These two fundamental concepts pervade social learning theories, but research in other areas has influenced each of the modern theories of social constructivism to differentiate one from another. Communities of practice, for example integrates practice research as important to understand learning. Bourdieu (1977) was one of a few researchers in the 1970s to begin breaking the barrier between internal cognition and an external world. He posed an integrated view that cognition, interaction, activity, knowing are all interdependent. Although Bourdieu's focus was not on learning in particular, his influence was clear in Lave’s (1988) Cognition in Practice as she developed an argument that prevailing psychological and anthropological perspectives were incomplete. In terms of learning, the common theories, including Vygotsky's social constructivism, maintained that learning was a process of internalization. Lave (1988) suggested cognition does not merely influence practice, nor does practice only influence cognition, rather cognition is situated within practice.

Lave and Wenger (1991) claimed precisely the same thing for learning by means of legitimate peripheral participation. They built an argument out of apprenticeship research to demonstrate how learning occurs in practice. Note, they do not mean learning 
is a result of practice, but practice is learning. That is not to say that practice and learning are synonymous. Learning consists not in the internalization of a concept or skill, but in the participation of apprentices in genuine practice.

\section{Why Communities of Practice}

Practice as learning is one of the aspects of CoP that I believe separates it from other social theories of learning that might seem applicable as a theory of analysis for this study. Allow me to take the following two sections to describe why I found CoP to be the more meaningful theory as compared to two others that could have been useful. In addition, I will take the opportunity to answer a few critiques that have been leveled against CoP. After this short diversion I will return to CoP and how it has carried on since the publication of Situated Learning (Lave \& Wenger, 1991).

Didactical situations in mathematics. Brousseau initiated the development of the theory of didactical situations in mathematics in the 1960s (Artigue, Haspekian, \& Corblin-Lenfant, 2014). Brousseau's (1997) theory is specifically focused on mathematics teaching and learning. Brousseau organized his theory around situations and was particularly interested in those situations that were didactic in nature. In any situation a learner interacts with his or her milieu, which consists of external environmental factors. These interactions occur in situations of action, situations of formulation, and situations of validation. These situations influence student learning through the cognitive processes of adaptation and acculturation. The theory has been applied to research on student learning since its origination, but has more recently been applied to situations involving teachers' learning.

Margolinas et al. (2005) proposed and demonstrated a theory modeling the 
evolution of a teacher's observational didactic knowledge. They drew principles from the theory of didactical situations in mathematics to explain the teacher's learning. With the antagonistic milieu principle, they suggested that the teacher learned through interaction with a milieu, which includes students, the problem situation, and essentially anything external to the teacher. With the reflection principle, they stated that learning required reflection. With the usefulness principle they suggested that a proposition was retained if it was deemed useful. With the awareness of ignorance principle, they stated that learning was predicated on the learner's awareness of his or her own ignorance. These four principles helped illuminate how the teacher learned from observation and reflection in didactical situations.

Although the theory of didactical situations is clearly applicable in studying teachers' learning through practice, it differs significantly from the CoP framework in one crucial aspects. It is an internalization theory of learning. I am not suggesting internalization theories of learning are not useful, but they offer a very different perspective on the relationship of learning and practice. The CoP framework represents a potential for understanding teachers' learning in practice in powerful ways beyond the internalization of concepts and skills for teaching.

Commognition. In the introduction to her book Thinking as Communicating Anna Sfard (2008) described Vygotsky as one of two sources of inspiration for her theory of commognition. Sfard used the term commognition to accentuate her stance that cognition and communication are inseparable. Her stance that cognition is communication is a turn away from internalization theories of learning. She also described learning as changing practice, a similar concept to that put forward by Lave 
and Wenger (1991).

Sfard's theory of commognition has been applied in mathematics education research ranging in topics from integers (Sfard, 2009; Wessman-Enzinger, 2015) to calculus (Park, 2013, 2015) and proof (K. S. Remillard, 2014). It has proven useful in these contexts and could be applied effectively to teacher learning. However, the strength of Sfard's theory is in analyzing communication so it lacks the strong focus on practice presented by CoP.

Critiques of CoP. I have found CoP to be a strong theory that is useful for interpreting the teacher learning that is at question in this study, and many others have found the theory useful in analyzing a host of other concepts in many different disciplines. However, CoP has not escaped the critical eye of academics or that of practitioners applying the theory toward productivity of one variety or another. Wenger (2010) addressed some of these critiques in a chapter in Blackmore’s (2010) Social Learning Systems and Communities of Practice.

One of the common critiques of CoP is that it does not give enough attention to issues of power (Wenger, 2010). Wenger (2010) acknowledged that power is not the central concept of the theory because it is "a learning theory, not a political theory” (p. 189). However, he also suggested that CoP leaves space for a focus on power in several ways. First, power is inherent in the economies of meaning that develop in communities of practice. Access to the community, who qualifies as competent, and what counts in accountability to the enterprise are claims of power. Wenger concedes these relations of power are more typically worked out in horizontal relations of accountability and less reliant on traditional vertical forms of power. However, these horizontal relations can be 
projected across a landscape of practice. Wenger (2010) claimed that what different practices in the community

produce has different value in the 'market' of knowledge, where for historical reasons, some practices have developed a greater ability to influence the landscape (e.g., management, government), to colonise an area of the landscape (e.g., engineers having a history of building bridges that don't collapse), or to make people accountable to their competence (e.g., math as a core subject for all kids). (p. 189)

The second way power plays into the CoP framework is through identification. Wenger (2010) explained that identity as a member of community makes the individual accessible to power structures. For example, power that plays out in an attack on competence is reliant on identification with a community where that competence is valued. If an individual does not value the form of competence being attacked, then the attack issues no power.

The third way power is treated in $\mathrm{CoP}$ may be critiqued as overoptimistic. Wenger (2010) suggested that CoP implies locally negotiated production in participation, even in the face of the most oppressive forces. Some would suggest that this gives too much agency to the production of practices locally and inauthentically limits the application of power. However, Wenger (2010) suggested that CoP is consistent with other research in claiming "the creation of a practice takes place in response to power, not as an outcome of it” (p. 190).

Another critique of the CoP framework is that it is presented ahistorically. However, I think I have presented it situated historically here. Critics claim that the theory may have no relevance outside the realm of developing craft knowledge in apprenticeship type situations. Wenger (2010) claimed the goal of capturing something fundamental about learning in these contexts should allow the theory to evolve in 
different societal contexts. On a related note, some criticize the theory as too focused on community in neglect of networks and other forms of social organization inherent to a more global system. This critique is not relevant to my work here because I am not trying to analyze systems that extend beyond communities of practice.

A final critique of $\mathrm{CoP}$ involves its extensive application as a productive framework as opposed to an analytical framework. Critics claim that the use of the framework to inform development and produce learning has diluted the theory over time. Although Wenger (2010) conceded the disadvantages of the practical use of the theory, he also claimed that this form of use developed the theory in positive ways that would not have been possible were it merely applied as an analytic framework. I have attempted, in my application of $\mathrm{CoP}$ to attend specifically to the framework as an analytical theory, taking the majority of my conceptualization from Lave and Wenger's (1991) original conceptualization and Wenger's (1998) work that followed.

\section{Building on Communities of Practice}

Having described what gave rise to communities of practice, I not turn to that which has arisen from communities of practice. The most logical place to start is with the work of those who developed the theory. First, I will briefly explore the ongoing work of Lave. Then, I will turn to the work of Wenger. I will also mention some CoP and situated learning research in other domains before proceeding to teacher research.

Jean Lave. The social anthropologist has continued to research social practice

theory (Lave \& Chaiklin, 1993), but has also published ethnohistorical research (Herring \& Lave, 2001). However, her work most relevant to my review is "Teaching, as Learning, in Practice” (Lave, 1996). Allow me to detail the relevant ideas from 
“Teaching, as Learning, in Practice.”

Lave (1996) began her argument for a social theory of learning on the grounds that a purely cognitive perspective impoverishes learning and leads to social inequalities by blaming the marginalized for their marginalization. Not only did she make the case that a social theory of learning is the way to move forward in overcoming social inequalities, she suggested that social practice theory is the most fertile ground for growing our theory of learning. After briefly describing some contributions of apprenticeship research to the development of learning theories, Lave turned to a critique of modern schools and education research. She called for a focus on students as learners, claiming that research on learning mistakenly investigates teaching. She suggested that teaching is not necessary for learning and if researchers want to discover how teaching can make learning more effective we must start with a more direct focus on the learner. In making this point she emphasized a broader view of learning than the cognitive development of the learner, focusing instead on the identity transformation of students. She also suggested that to comprehensively study learning in schools researchers must also focus on the teacher as learning from his or her own teaching. Twenty years after her suggestion I am taking up the call.

Etienne Wenger. After Situated Learning (Lave \& Wenger, 1991), Wenger published Communities of Practice (Wenger, 1998). The framework I outlined in Chapter I was derived directly from Communities of Practice. Wenger went on to write Cultivating Communities of Practice with McDermott and Snyder (2002). These works are characteristic of Wenger's ongoing work with communities of practice. He has continued to develop both the theoretical framework established in Communities of 
Practice and practical applications of the theory laid out in Cultivating Communities of Practice.

Wenger, McDermott, and Snyder (2002) focused their efforts on describing how communities of practice could be purposefully developed in ways that would benefit organizations. Although their principles for development are not relevant for my study, their characterization of the structural elements of a community of practice bears mentioning. They claimed that a community of practice consists of "a domain of knowledge, which defines a set of issues; a community of people who care about this domain; and the shared practice they are developing to be effective in their domain” (Wenger et al., 2002, p. 27). This alternate characterization of the community complements Wenger’s (1998) earlier characterization of mutual engagement, joint enterprise, and shared repertoire. At first these seem to imply a direct correspondence (domain with repertoire, community with engagement, and practice with enterprise). However, domain implies a more global set of problems and understandings that spans multiple communities. Community implies belonging as identity as much as engagement in practice. Practice implies the use of tools and common language to approach the concerns of the domain.

The concept of domain is extended even further in Learning in Landscapes of Practice (Wenger, Fenton-O'Creevy, Hutchinson, Kubiak, \& Wenger-Trayner, 2015). In the first chapter of this book Wenger-Trayner and Wenger-Trayner (2015) described the analogy of a landscape as conjoining communities that produce a body of knowledge for a profession. They also introduced knowledgeability in the statement, "Whereas we use competence to describe the dimension of knowing negotiated and defined within a single 
community of practice, knowledgeability manifests in a person's relations to a multiplicity of practices across the landscape” (Wenger-Trayner \& Wenger-Trayner, 2015, p. 13). Because I am focusing on a teacher's practice as confined to situations directly connected to the classroom, this construct of a landscape of practice was not pursued in the data collection. However, the knowledgeability of the teacher in this study, and his relations within the landscape of practice, were manifested in the data. The following ideas from this book will become pertinent in the later analysis.

In the second chapter Fenton-O’Creevy, Dimitriadis, and Scobie (2015) recounted the emotional struggles of identity transformation at the boundaries of communities. Each author presented his or her story of transition at the boundaries of multiple communities of practice. In their experiences of struggle and failure they found that the "work of reconciling different aspects of our identities is not just a feature of transitions; it is a consequence of multimembership” (Fenton-O'Creevy et al., 2015, p. 33). FentonO’Creevy's experience as a beginning lecturer led him to retreat to a different identity of competence in research. Scobie's struggle to transition into a new school district as a high school teacher led to disconfirmation of a key aspect of her identity: competence as a teacher. In situations like Scobie’s this disconfirmation can lead us to change our behavior to try to get confirming responses from others in the community; seek to convince others to accept our behaviour and the meaning it implies; or withdraw from the situation. We may also...de-emphasize the importance of [the] disconfirmed aspect of identity. (Fenton-O'Creevy et al., 2015, p. 37)

Dimitriadis's story of constant multimembership in teaching, research, and technical 
communities revealed "not only a story of shifting intellectual engagement but of shifting emotional investment” (Fenton-O'Creevy et al., 2015, p. 41). In all of these cases, identity was a key aspect of boundary relations and the struggle involved was intensely emotional.

More situated learning. Beyond the research of Lave and Wenger, many others have taken up the frameworks of situated learning and communities of practice in the past two to three decades. For example, Anne Watson has been instrumental in the publication of two books containing 24 different research studies using situated learning theory (Watson, 1998; Watson \& Winbourne, 2008). These studies ranged across a variety of mathematics content areas from geometry (Boaler, 1998) to calculus concepts within vocational courses (Pinto \& Moreira, 1998). In Communities of Practice: Fostering Peerto-Peer Learning and Informal Knowledge Sharing in the Workplace Hara (2009) shared extensive research on communities of practice in the public judicial sphere. Hughes, Jewson, and Unwin (2007) edited Communities of Practice: A Critical Perspective as a collection of theoretical critiques and applications of CoP and practical research employing CoP. Although I could take the time and space to provide detailed accounts of the findings presented in these books and dozens of additional articles, I would like to keep focused more directly on what applies to my study, so I continue with research about teachers’ learning.

\section{Teacher Learning}

I do not claim to be starting at the beginning, but 1982 seems to be a reasonable year in which to begin my review about the development of current research on teacher learning in mathematics education. I chose this year because two studies that had the 
potential to direct teacher research toward learning were published in 1982. Yonemura (1982) studied the potential of collegial conversations as a source of professional growth. She suggested that experienced teachers deployed what she called theories-in-use that she described as giving teachers "a way of coping with the complexity of decision-making in real-life conditions” (Yonemura, 1982, p. 240). Yonemura's suggestion that these practices might be passed on through generational encounters in communities certainly hints at the ideas we saw in later years as CoPs were applied in teacher research. In the same year, Little (1982) published the results of a study of workplace conditions conducive to learning on the job. She found that collegial relationships and professional conversations were significant factors in developing these desirable workplace conditions. Perhaps the community was not prepared to build on these studies, but it seems that an opportunity to push forward the collective understanding of teacher learning was overlooked. These significant results about learning through experience seem to have been overshadowed by research about teacher knowledge.

\section{Teacher Knowledge}

Freema Elbaz first wrote about practical knowledge in 1981. In addition to curricular and subject matter knowledge, Elbaz (1981) found

There was a "practical" aspect to the teacher's knowledge, i.e., that teachers have knowledge, derived from practice, of instructional routines, classroom management, student needs, and the like. There was a "personal” aspect, i.e., teachers have self-knowledge and they work toward personally meaningful goals in their teaching. And finally there was an "interaction" aspect, which refers to the fact that teachers' knowledge is based on, and shaped by, a variety of interactions 
with others in their environment—-teachers, students, administrators, the prevailing social ethos, and encounters with researchers, such as occurred in this study. (p. 47)

Not only do these ideas of knowledge hint at some of the ideas of situated learning, but her

Intention was to argue for a view of the teacher as an autonomous agent in the curriculum process by demonstrating the teacher's knowledge as something dynamic, held in an active relationship to practice and used to give shape to that practice. (Elbaz, 1981, p. 48)

In my view, it is unfortunate that Elbaz's (1981) formulation of teacher knowledge was overshadowed in mathematics education research, if not across the spectrum of education research, by Lee Shulman's (1986) pedagogical content knowledge (PCK). That is not to suggest that PCK has not had a significant and positive influence in research on teaching over the past three decades. However, the applications of PCK have allowed the research and teacher education communities to retain a primarily internalization view of learning. I think Elbaz's formulation would have pushed the conversation toward a situated view of learning, which I think is necessary to drive teacher preparation programs toward a learning in practice framework for teacher education.

Although Shulman’s $(1986,1987)$ formulation of teachers' knowledge was not as oriented toward practice as that of Elbaz $(1981,1983)$, he made a different and significant contribution to our understanding of what teachers learn in practice (although he did not put it in those terms). Shulman (1986) claimed research on teaching in the 1970's had 
focused primarily on content knowledge and in the early 1980s had focused primarily on matters of pedagogy. To find evidence for this critique we need to look no further than Elbaz (1981, 1983) and Diorio (1982). However, Shulman (1986, 1987), Lienhardt, and Smith (1985), Lienhardt, and Greeno (1986), and likely others began to take a middle road between content knowledge and pedagogical knowledge. As mentioned, Shulman called this amalgamation of knowledge between content and pedagogy, pedagogical content knowledge. Shulman's formulation of teacher knowledge became prevalent in research about teacher knowledge across various disciplines. Ball (2008) recorded that Shulman's $(1986,1987)$ pieces had been cited over 1,200 times in over 125 different journals. Clearly, Shulman's work was seminal in the field of teacher knowledge, but it also influenced research on mathematics teacher learning.

\section{From Knowledge to Professional Development}

Peterson, Carpenter, and Fennema (1989) began researching an approach to teaching, and professional development, they called cognitively guided instruction (CGI). Although Peterson et al., like other researchers in the 1980s, were researching teachers' knowledge (one of many aspects of their research agenda), they carved out a distinct place of their own. Although Shulman focused most of his work on PCK and Peterson et al. were focused on teachers' knowledge of students' knowledge, Shulman's influence was acknowledged. I would like to say that CGI ushered in a new era in research on mathematics teaching and learning, but researchers did not initially follow the CGI researchers in their inclusive approach to researching student thinking, teacher knowledge, professional development, and student outcomes. Even professional development research was only beginning to gain popularity through the 1990s and 
research that focused specifically on teachers' learning was still yet to come.

Research in the 1990s shifted from the teacher knowledge focus of the 1980s to teacher change and professional development. Wilson and Berne (1999) noted at the beginning of their chapter in the $24^{\text {th }}$ volume of the Review of Research in Education In the past 10 years, the calls for a commitment to teacher learning have increased exponentially, most likely from a confluence of forces. The standards movement is one such force... Mounting efforts to increase the professionalization of teaching constitutes yet another force. (p. 173)

Clearly, these factors began to influence mathematics education research through the 1990s because more research about teachers was conducted in the 1990s than in the 1980s. But in the early 2000s researchers published even more studies on professional development, teacher education, and teacher change than in the 1990s.

In their synthesis of research "related to the professional learning of practicing teachers of mathematics” (p. 5) from 1985 to 2008 Goldsmith, Doerr, and Lewis (2014) reviewed 106 articles, two from the 1980s and 23 from the 1990s. The majority of the research on teacher change in the 1990s was directed at changes in identity, beliefs, dispositions, and practices. Fennema et al. (1996) and Franke, Carpenter, Fennema, Ansell, and Behrend (1998), although interested in facilitating changes in teachers' knowledge of students, primarily took the approach of changing teachers' instructional practice in one key area: they asked teachers to listen to their students. Bright and Prokosch (1995) studied teachers' changes in the use of technology in their classrooms. Brown, Stein, and Forman (1996) described an effort to institute a theory of assistance as reform in a mathematics classroom. Chazan, Ben-Chaim, and Gormas (1998) reported 
about how team teaching changed mathematics teachers' practices. Edwards and Hensien (1999) described how action research can change practice. Chapman (1999), who attempted to facilitate teacher change by capitalizing on teachers' own classroom experiences, investigated the changes in teachers' self-perception regarding problemsolving. The list could continue with Gersten and Kelly (1992), Grant, Peterson, and Shojgreen-Downer (1996), Jaworski (1998), and Senger (1998), but the conclusions of these researchers are less relevant for my study than the direction in which they drove the community.

The research on teacher change was an inevitable result of reform efforts focused on changing instructional practices. Mathematics educators conducting professional development and teaching university courses took the opportunity to assess their interventions. As a result, research in the 1990s included studies that were more processproduct oriented than the typically descriptive studies of the 1980s. Although qualitative methods like case study (e.g., Connelly, Clandinin, \& He, 1997; Schifter, 1998; Yonemura, 1982), narrative (e.g., Clandinin \& Connelly, 1986), and ethnography (e.g., Little, 1982) were prevalent in both decades, the theoretical approaches and aims of the research were very different. Researchers in the 1980s wanted to describe teachers' knowledge and learning, but many researchers in the 1990s sought to evaluate their efforts to change teachers. In the 1990s researchers in the community focused on teacher changes in areas like practice and identity, but researchers did not follow Elbaz (1981) or Lave and Wenger (1991) in espousing an integrated view of learning in practice. 


\section{The Teacher Research Boom}

At the dawn of the new millennium research on teachers became exceptionally prevalent. Researchers studied teacher knowledge, teacher beliefs, professional development, teacher preparation, and the list goes on. I think the prevalence of teacher research stemmed from the standards and professionalization that Wilson and Berne (1999) cited, but also from the political pressure to keep teachers accountable through evaluation.

Between 2000 and 2016 many researchers investigated teacher learning (e.g., Boston, 2013; Boylan, 2010; Boyle, Lamprianou, \& Boyle, 2005; L. Brown \& Coles, 2010; Chapman \& Heater, 2010; Doerr \& English, 2006; Drake, Spillane, \& HufferdAckles, 2001; Goos \& Geiger, 2010; Hiebert, Morris, \& Glass, 2003; Hodgen \& Askew, 2007; Jaberg, Lubinski, \& Yazujian, 2002; Kazemi \& Franke, 2004; Liljedahl, 2010; J. T. Remillard, 2000; Ross \& Bruce, 2007; Sherin \& Han, 2004; Vithal, 2003; Warfield, Wood, \& Lehman, 2005). Hiebert, Morris, and Glass’ (2003) study of teachers learning to learn to teach is an illustration of how many of these studies related to teacher learning, were, in reality, focused more on a program designed to improve teaching and the applications of the program. These studies rarely included genuine substance about teachers' learning. Studies that contained more substantial analyses of teachers' actual learning often focused on internalized knowledge, but some focused on changing practices.

Boston's (2013) study is an example of the knowledge focus. She investigated connections between teachers’ changing knowledge and a particular professional development experience. Boston and others were likely influenced by the prevalence of 
researchers adapting, extending, amending or otherwise utilizing Shulman's PCK (e.g., Agyei \& Voogt, 2012; Ball et al., 2008; Guerrero, 2010; Handal, Campbell, Cavanagh, Petocz, \& Kelly, 2013; Hill, Ball, \& Schilling, 2008; Hill, Dean, \& Goffney, 2007; Kilic, 2011; Koh, Chai, \& Tsai, 2014; Mishra \& Koehler, 2006; Niess, 2013; O'Hanlon, 2012; Polly, 2011). Although Boston did not refer to these knowledge structures, she applied a view of internalized knowledge as the product of professional development that is consistent with the research on teacher knowledge.

As an example of the practice focus take Boylan (2010). He described the process of change in practices of a veteran teacher involved in teacher-led professional development. He used actor-network theory for analysis and found that "it is important to investigate, firstly, the relationship between stabilizing factors, which do not change but may contribute to change and, secondly, the ways changes in different relationship themselves interrelate” (Boylan, 2010, p. 393). He cautioned that a complex set of social variables may influence change in unpredictable ways. This study illustrates how practice focused research often takes into account a more complex set of variables associated with teacher learning instead of reducing teachers' practice to a function of knowledge application. Before I conclude this review, I will discuss the applications of a few more of these types of studies for my research.

\section{Teachers' Learning in Practice}

In this final section I will discuss the relevant conclusions from several studies focused specifically on teachers' learning in practice. These studies can be divided into five different emphases based on the products of learning and the stimulus for learning. The first set of studies defined the stimulus for learning as professional communities. The 
second set of studies defined the stimulus for learning as reflection. The remaining studies either did not define the stimulus for learning specifically, defined it variably within the study, or were primarily concerned with the products as opposed to the stimulus of the learning. Thus, the third set of studies defined the product of learning as knowledge internalization. The fourth set of studies defined the product of learning as identity transformation. The fifth set of studies defined the product of learning as general change.

Professional communities. In a study of teachers’ learning Graven (2004) drew heavily on Lave and Wenger’s (1991) situated learning and Wenger’s (1998) CoP frameworks. In this study she used CoP to investigate secondary mathematics teachers’ learning in professional communities established as part of a professional development program in South Africa. She found that teachers experienced significant learning in this context, and confidence played a critical role in mediating the learning. She suggested that confidence as an overarching variable should be appended to CoP to better explain learning. She used the term confidence because it arose in the teachers' discussion, but I claim that the concept is already a component of the CoP framework that was not recognized. I am suggesting that confidence is a self-perception of competence. Thus, this confidence would play a role as an aspect of a teacher's self-identification with his or her competence in a community.

Horn (2005) also used Wenger’s (1998) communities of practice to investigate secondary mathematics teachers' on-the-job learning in two schools promoting mathematics education reform. Although one school presented a more productive environment for teacher learning and change, she found three key factors productive of 
reform efforts in both schools. First, teachers used "artifacts as tools to bootstrap their understandings of, and ultimately learn about, practice” (Horn, 2005, p. 217). Horn described the interplay of reifications as artifacts to convey meaning for participation among colleagues. Second, "teachers learn via the informal classification systems that are a part of their workplace” (Horn, 2005, p. 221). The primary example was teachers’ categorization of students, which at one of the schools involved an implicit twodimensional sorting along axes of motivation and ability. Third, "teachers learn about classroom practice by the ways it is (and is not) rendered in collegial conversations" (Horn, 2005, p. 221).

In the final study that investigated professional communities as the stimulus for learning, Brodie and Shalem (2011) investigated the use of communities of practitioners in a professional development program. They found themes of solidarity and challenge that supported productive accountability conversations in those communities. From a $\mathrm{CoP}$ perspective this would be interpreted as the mutual accountability necessary for the productive pursuit of the joint enterprise.

Reflection. McDuffie (2004), Scherer and Steinbring (2006), and Ticha and Hospesova (2006) all began their research about teacher learning with the same basic assumption that reflection is necessary for significant learning from practice. Based on this assumption, each set of researchers purposefully intervened to elicit particular types of reflections from the study participants. McDuffie’s (2004) investigation of two preservice elementary teachers revealed that in-the-moment reflections were rarely observed and did not yield significant learning. Reflections that were removed from the immediate situation and focused on long-term growth, however, were a significant source 
of learning. Her conclusions left open the possibility that immediate reflections may be more prevalent and more beneficial for experienced teachers.

Scherer and Steinbring (2006), in a joint research project with elementary teachers, investigated how joint reflections on teaching practice influenced teachers' change. They found that professional reflection was important and should be incorporated as a natural part of professional practice, but change happens only as part of a long-term process. Ticha and Hospesova (2006) corroborated the power of joint reflections on professional practice. In addition, they chronicled teachers' development in competent reflection. Teachers' early reflections involved discussion based primarily on intuition, but developed to a pursuit of effective methods, and finally to an in-depth analysis of the mathematics instruction. These three studies point to the fruitful ground of reflection for teacher learning.

Knowledge. In terms of the products of learning, knowledge is the most traditionally expected product. Margolinas, Coulange, and Bessot (2005) investigated teachers learning from experiences with their students. First, they posed a model of didactic situations, then, used their model as a framework to investigate teachers' observational didactic knowledge (ODK). This observational didactic knowledge may be loosely described as a mixture of teacher noticing and PCK. Margolinas et al. were interested in how teachers observed and responded to their students' thinking about mathematics. They found that teachers could develop ODK but it tended to be more powerful with external intervention. They suggested that teachers' experiential learning is not a significant source of learning, but should be coupled with outside input.

Sherin (2010) investigated mathematics teachers' learning, particularly in the area 
of content knowledge, through the implementation of mathematics education reform. She built on the work of Shulman (1986) and Ball et al. (2008), but investigated knowledge use in practice. She found that negotiations between different types of content knowledge occurred within a lesson to produce learning. Sherin’s findings suggest the possibility of experienced teachers learning from immediate reflection left open by McDuffie (2004) is more than a possibility; it is a reality. Although internalized knowledge is not the product of learning I sought in this study, Sherin's results gave me hope that I would possibly find evidence of learning in practice even if Margolinas et al.’s (2005) results implied the learning would be menial.

Identity. Goos (2005), Walshaw (2004), and Lloyd (2005) investigated teacher learning as identity transformation with preservice teachers. Goos (2005) chronicled the identity formation, in terms of pedagogical practices and beliefs regarding technology implementation, of one preservice teacher into his first years as a secondary mathematics teacher. Goos found that the sociocultural analysis...revealed how Geoff was an active agent in his own development as a teacher, not simply reproducing the practices he observed nor yielding to environmental constraints, but instead re-interpreting these social conditions in light of his own professional goals and beliefs. (p. 55) Walshaw (2004), in her study on the identities of preservice elementary teachers, suggested "a rethinking of the notion of the pre-service teacher who has teaching experience towards conceptualizing the pre-service teacher as constituted through experience" (p. 80). And in a similar manner to Goos (2005) she contended "the concept of teacher identity, then, is best thought of as complex and multiple, developed in 
response to other identities that are sometimes held in opposition” (Walshaw, 2004, p. 80).

Lloyd (2005) investigated the identity transformation of a secondary mathematics student teacher as changing roles throughout his student-teaching internship. He found that the student-teacher attempted to develop teaching practices that allowed him to take on teaching roles that aligned with his beliefs about mathematics teaching and learning. Although his cooperating teacher did not share the same beliefs about the teacher's role in a mathematics classroom, Lloyd suggested that the dissonance may have provided learning opportunities in some ways while stifling learning in others.

Change. The final four studies about teacher learning detailed teacher change. First, Doerr and English (2006) investigated the influence modeling tasks could have on teacher change. They found that the features of the tasks allowed the teachers to learn in three ways. The teachers developed new mathematical understandings. They shifted their roles when interacting with students in the problem context. They shifted the role of evaluating onto students. This study suggests that even mathematical tasks influence teachers’ change, given the appropriate context.

Contrary to commonly held beliefs about teacher change as a long-term and sustained process, as espoused by Scherer and Steinbring (2006), Liljedahl (2010) contended that there are five types of rapid teacher change (conceptual change, accommodating outliers, reification, leading belief change, and push-pull rhythm of change). He admitted that instances of these rapid and profound changes in teachers are rare, but he also claimed that these changes can be genuine.

Boylan (2010) chronicled the change of a veteran secondary mathematics teacher 
through the process of a "teacher led, teacher-educator-supported professional development project” (p. 383). He found the teacher’s participation in professional community influenced his teaching in several ways that he described with three conceptual tools borrowed from actor-network theory: relationality, fluidity, and translation. In terms of relationality the teacher adjusted his relation to himself and his students. In the CoP framework this might be described as identity transformation through changing participation in the community. Translation is a much more involved concept but essentially boils down to the complex interaction of a system of actors working out influence in varying contexts for different purposes that come together in a single process. In this case the influences of professional development and research coordinators came to play a significant role in this teachers changing identity, commitment, and actions. In terms of fluidity, the use of a dynamic computer geometry software (a fluid tool adaptable to various environments), was crucial in the teacher's process of change.

Finally, Chapman and Heater (2010) described a teacher's self-initiated journey of change to an inquiry-based teaching approach. She described an iterative four-stage process that yielded three types of change. The four stages were experiencing cognitive and emotional tension, attending to the tension, problematizing the tension, and resolving the tension. For the teacher in the study these stages resulted in instrumental change, conceptual change, and foundational change. Chapman described them in this way: Instrumental change focuses on what and how...It consists of new techniques or activities the teacher learned and can adapt to her teaching, but limited only to those situations...for which it was learned...Conceptual change includes a change 
in understanding of why a technique works and when and how to apply

it...Foundational change involves a change in orientation of self (identity) and practices (actions). (p. 456)

Chapman's work on change should be encouraging to any educator. She found that teachers can change. Not only can they change, but they can also change of their own volition and within the realm of their own practice. But, the impetus for this change, we must recall, is a tension that arises within the teacher's practice. Many teachers, unfortunately, do not often feel a strong enough tension to elicit real change.

\section{Time to Move Ahead}

In this description of the landscape of practice I have demonstrated that the history of social learning theory has positioned CoP as a theory of learning that holds great promise for investigating teacher learning. I have also shown that the development of research on teacher knowledge has positioned me to investigate learning in practice using the CoP framework. Before I move on to present the methods of this study I would like to clarify that the critiques I have levied toward some of these studies are not meant to denigrate their findings. I simply hold them in tension with where they have positioned me as a newcomer to the landscape of practice. It is my desire, as one entering into the field, to provide the discontinuities of generational encounters that will yield the productive tensions that occur in boundary relations across a landscape of practice. 


\section{CHAPTER III}

\section{METHODS}

Now that I have examined the histories of learning for the intersecting communities at play in this study, I will turn back to the primary focus of my writing. In this chapter I will restate my research questions and provide a statement of my research paradigm and positionality. Then, I will provide a thorough description of the methods I employed. This will include the context and participant selection procedures, the data collection and analysis process, and ethical considerations.

\section{Research Questions}

Recall that the purpose of the study was to investigate teachers' learning in the secondary mathematics classroom context. To accomplish this purpose, I sought to address the following questions:

1. What are the characteristics of Rudy's communities of practice?

2. How did Rudy negotiate meaning in practice?

3. What characterized Rudy's identity in practice?

4. In what ways did Rudy learn through practice?

\section{Paradigm}

For the purposes of this study, I have positioned my analysis within the interpretivist paradigm. According to the interpretivist paradigm, the reality of the educational world is a co-constructed and shared reality with multiple perspectives 
(Glesne \& Peshkin, 1992). Each teacher, student, administrator, parent, and in this case researcher, contributes to the construction of the social world of education in which he or she shares. Yet, the individual experiences within this shared reality are variously interpreted by those involved.

The interpretivist paradigm has specific implications for this study. First, as a coconstructor of reality, my research will inevitably influence Rudy’s learning experiences. As a result, I will need to be cognizant of this fact and acknowledge my contributions to his experiences, and subsequent learning, as I analyze and write about the data.

Second, as co-constructors of reality, Rudy has a specific story to tell. I must seek to present his reality, as best I can in my analysis and writing. Understanding that I interpret his reality through my own, I will not seek objectivity but a form of subjectivity that presents Rudy’s authentic perspective as interpreted by a co-constructor of our shared reality.

Third, as co-constructors of reality, Rudy's students are integral elements of the research process. These students are perhaps the most influential co-constructors of Rudy’s daily reality. As such, my data collection, analysis, and reporting must include a thorough investigation of the students and their role in Rudy's classroom experience.

\section{Positionality}

I am a white, male, mathematics educator, former teacher, current researcher, $\mathrm{PhD}$ student, and outsider to the school context of the teacher with whom I worked. Several of these aspects influenced the initiation of this study. For example, as a teacher I found that I learned as much from experience as I did from my teacher preparation. Now, as a researcher and Ph.D. student I have found little research that addresses how teachers 
learn from their own practice as teachers. Because I am in a position to conduct research, I want to bring to light what I have found to be an important part of my growth as an educator.

I grew up in a rural farming community and attended a high school similar to Valley View High School, which served as the setting for this study. My positive experiences in environments similar to the context of this study have played a role in my interpretation of the school context and the relational dynamics among teachers and students.

\section{Research Methods}

I have taken a case study approach to help address my research questions. Case studies are differentiated from other types of qualitative research because they are intensive descriptions and analyze a single unit or bounded system (Smith, 1978). The purpose of my research study was to gain a deep understanding of how one high school teacher learned from his practice. The purpose was not to claim generalizability, but to intensively describe the learning of one teacher within the context of his communities of practice. Each individual's experiences of meaning and roles in his or her communities of practice are different, and a case study will attend to the individuality of the teacher's classroom experiences. Although investigating teacher learning does not imply a bounded phenomenon, investigating a teacher's learning in a specific situation, his communities of practice, does imply a bounded phenomenon. In this study, the bounded systems, as described by Smith (1978), were the communities of practice for which Rudy was a member and where his learning took place. The teacher had a finite number of communities of practice in which he participated, establishing a boundary for the 
teacher’s learning.

My decision to approach the research questions through case study was also influenced by the CoP perspective that learning is intricately connected with meaning, community, practice, and identity. As Merriam (1998) stated, “case study offers a means of investigating complex social units consisting of multiple variables of potential importance in understanding the phenomenon” (p. 41). Given the complexity of learning, case study provides a means to describe this complexity. In addition, case studies are useful when "the boundaries between phenomenon and context are not clearly evident" (Yin, 2003, p. 13). The CoP framework is social in nature, the boundaries between social interaction and individual learning are intimately connected. Hence, the use of case study methodology will be helpful in uncovering and describing these interactions.

\section{Participant Selection}

I recruited participants from practicing secondary mathematics teachers in the Midwest. I contacted all secondary schools within a reasonable driving distance of my residence at the time of data collection by emailing principals (see Appendix A for the principal email). I requested permission to contact teachers who were teaching multiple sections of a course that was new to their teaching load and emailed those teachers (see Appendix B for the teacher email). I wanted a teacher who had multiple sections of the same course so that I could observe differentiated participation in the two course without the intervening variable of different mathematical content. The search resulted in one teacher, Rudy, who was willing to participate in the study. Rudy was teaching three sections of a Math II course (this course will be described in Chapter IV in the section The Return). He was not teaching the course for the first time, but the school had recently 
transitioned to an integrated curriculum. For this study I analyzed two sections of the course, fourth hour and fifth hour. Because Rudy presented the only willing participant whose teaching load resembled the desired qualifications he became my only participant.

\section{Research Setting}

This study took place in the context of Rudy's everyday work life at Valley View High School. In particular, the majority of data collection occurred in Rudy's classroom, although additional data was collected from other locations within Valley View High School. For this reason, I now provide a short description of Rudy and Valley View High School. I will include a fuller description of both in the findings of this study, but I provide a brief overview here to illuminate the setting of the study.

Valley View High School was a small (enrollment under 300) rural school in the Midwest. Rudy had been teaching mathematics at Valley View for $6 \frac{1}{2} 2$ years at the time of observation. He started at Valley View immediately after completing college, at the age of 23, when he was hired to teach geometry and coach wrestling. At the time of observation, he was the head wrestling coach and one of several baseball coaches. Rudy fit in at Valley View because he cared about his relationships with his students. Rudy and two other mathematics teachers taught at Valley View, but they did not spend much time collaborating.

\section{Data Collection and Instruments}

I collected data from the planning, implementation, and reflection stages of teaching. Table 1 is a data accounting log (Miles, Huberman, \& Saldaña, 2014) that includes all of the forms of data I collected as well as the dates on which the data was collected. 
Table 1

Data Accounting Log

\begin{tabular}{|c|c|}
\hline Data type & Date(s) of collection \\
\hline Initial interview & December 16, 2015 \\
\hline Informal observations & December 10, 11, 14, and 16, 2015 \\
\hline Inservice observation & January 4, 2016 \\
\hline Lesson plans & January 4, 2016 \\
\hline Lesson planning think aloud & January 4, 2016 \\
\hline \multicolumn{2}{|l|}{ Lesson materials } \\
\hline Textbook & December 16, 2016 \\
\hline Imaginary numbers worksheet & January 5, 2016 \\
\hline Complex numbers worksheet & January 5, 2016 \\
\hline Quiz & January 15, 2016 \\
\hline Lesson 1 observation & January 5, 2016 \\
\hline Lesson 2 observation & January 6 and 7, 2016 \\
\hline Lesson 3 observation & January 11, 2016 \\
\hline Lesson 4 observation & January 12, 2016 \\
\hline Lesson reflections & January 12 and 15, 2016 \\
\hline Follow-up interview & March 6, 2016 \\
\hline
\end{tabular}

From the planning phase I collected all lesson plans and additional instructional materials. I also asked Rudy to record a think aloud during his lesson planning. The think aloud was intended to focus Rudy on the learning that occurred in the lesson planning process (see Appendix C for think-aloud protocol). However, Rudy did not follow the recommended protocol. The lesson plans allowed me to see Rudy’s goals, some aspects 
of his plans for participation, and the elements he hoped to introduce into the community shared repertoire. These aspects helped me to determine the joint enterprise of both his mathematics teaching community and classroom communities. The lesson plans and materials also helped me analyze how he turned these plans into his participation in the classroom to produce meaning. Finally, they illuminated some aspects of the shared repertoire as Rudy desired to introduce them to the community. Because Rudy did not follow the think-aloud protocol, his think-aloud reflections provided information about how he adjusted external obligations for use in his classroom and how he adjusted his plans as he taught. These elements informed me about the enterprise in Rudy's teaching community and about how he produced learning in the negotiation of reifications and participation.

During the implementation phase of teaching I was present for, and videotaped, all lessons, except one day when Rudy was absent. I did not take detailed observation notes because I was attending to the recording of the lessons. However, I recorded an observation reflection immediately following each observation that included a brief summary of the observation and my initial analytic reflections. These observations occurred on January $5^{\text {th }}, 6^{\text {th }}, 7^{\text {th }}, 11^{\text {th }}$, and $12^{\text {th }}$ of 2016 . I observed two 45 minute classes on the $5^{\text {th }}, 11^{\text {th }}$, and $12^{\text {th }}$. On January $6^{\text {th }}$ I observed fifth hour in a 90-minute session, and on January $7^{\text {th }}$ I observed fourth hour in a 90-minute session. On January $8^{\text {th }}$ Rudy was not in class. I also observed in Rudy's classes for one week prior to the school's winter break in order to give Rudy and his students time to adjust to my presence in the classroom. I recorded a reflection following each observation that directed my thinking in the direction of analysis, but these reflections were not included in the current analysis. 
The observations provided me with the most significant source of information to address each of my research questions. The video-recordings were the primary form of data used to reveal Rudy's engagement with his students, the work involved in the classroom enterprise, the shared repertoire of his community, the ways he produced meaning in his participations, his use of reifications in the classroom, his identity as a teacher, and his learning across all of these dimensions. I analyzed these observations because they constituted what Rudy deemed a unit of instruction. I chose a unit so that it would have a consistency of content and I could observe Rudy on consecutive days that would allow me to observe the immediate context of Rudy's practices for those days. I observed additional days for the possibility of a greater breadth of analysis, but later restricted my analysis in favor of consistency of content in analyzing one unit for the present study.

I asked Rudy to record a reflection orally, or in writing, at the end of each day (see Appendix D for reflection protocol). He did not follow the prompts for his reflections and did not reflect at the end of each day. In total, Rudy provided me with four reflections that were focused primarily on his choice of content for the unit of instruction.

In addition to these data, I conducted interviews before and after the period of observation (see Appendix E for interview protocols). The interviews were semistructured opportunities to address the teacher's overall change. In the pre-study interview I asked questions to help characterize Rudy’s communities of practice, participation in those communities, and teaching practices. In the post-study interview I asked similar questions that accentuated any changes in practices, participation, or community membership and elicited answers to questions I developed from my 
observations. The date from these interviews supplemented the data from the observations and the fieldnotes I will describe next. Prompts such as, "Please describe your teaching practices, the ways you engage with students, how you approach mathematical content," helped me to characterize Rudy’s engagement in the community and his participation in teaching. Prompts such as, “describe how your relationships with colleagues impact your teaching,” helped me to characterize his engagement in community with other mathematics teachers and provided a historical perspective on Rudy’s learning in community.

Finally, I took fieldnotes during a districtwide teacher inservice day on January $4^{\text {th }}$. This was the only time I was able to observe Rudy's collegial interactions. He did not eat lunch with colleagues regularly because he spent the time working on coaching responsibilities. He was required to attend weekly meetings with the high school staff, but I was not able to attend these meetings for logistical reasons. The meetings focused on training related to a reading initiative.

\section{Data Analysis}

Following completion of data collection and transcription, I retrospectively analyzed the data using a data reduction approach in accordance with methods outlined in Miles, Huberman, and Saldaña (2014). These methods were adapted to the communities of practice framework. I accomplished the analysis with the assistance of Nvivo, a qualitative data analysis software. As recommended, the beginning stages of analysis occurred during the data collection phase as I reflected on my observations and transcribed the video-recordings.

I analyzed the data in four stages. In the first stage I developed, checked, and 
utilized an initial coding scheme regarding communities of practice and the negotiation of meaning. In the second stage I analyzed themes and patterns based on the first stage of coding and used the themes to describe Rudy's communities of practice and negotiation of meaning. In the third stage I used the themes and patterns from stage two to describe Rudy's identity in practice. In the fourth stage I used the themes and patterns from stage two and the identity analysis in stage three to describe Rudy's learning in practice.

Stage one. The first stage involved three sub-stages across two different coding categories (communities of practice and negotiation of meaning.) In the first sub-stage I developed codes for communities of practice and negotiating meaning. In the second substage Dr. David Barker and I checked intercoder reliability to $85 \%$ agreement, as suggested by Miles, Huberman, and Saldaña (2014), in each of the coding categories for both communities of practice and negotiation of meaning. In the third sub-stage I coded all data sources using the finalized coding categories.

Sub-stage one. In this sub-stage I developed initial coding schemes through coding and categorizing. I will describe this process for both coding categories. I would encourage you to suspend your evaluation of the coding scheme until Chapter IV. I have not included the coding definitions here (they can be found in Appendix F) because I want to focus on the process. I have included more details of my analysis in the results, including complete tables of coding definitions, because the emerging codes are intricately connected with the results. As emerging codes, they are a form of results. Thus, the codes will take on more meaning for you as we discuss the data from which I derived their meaning for me.

The end goal for the communities of practice coding scheme was threefold: (a) to 
characterize Rudy’s communities of practice, (b) to describe Rudy's community memberships in a way that would demonstrate his identity, and (c) to illuminate the learning that occurred in practice. With this in mind, my coding scheme began with the three ways in which Wenger (1998) claimed practice is a source of community coherence: mutual engagement, joint enterprise, and shared repertoire. You can refer back to Chapter I for a description of mutual engagement, joint enterprise, and shared repertoire. As I began to code parts of lesson transcripts as evidence of mutual engagement, joint enterprise, and shared repertoire I also developed sub-codes for each of the three categories. The unit of analysis varied by code. For example, I often applied the subcodes for joint enterprise a long portion of an observation transcript that was indicative of the activity aimed at accomplishing the goals of the community. But I often applied the subcodes for the shared repertoire to individual words or sentences that described shared language or tools. The list of sub-codes and operationalized definitions for mutual engagement, joint enterprise, and shared repertoire are provided in Appendix F. Note the use of any sub-code also implied a coding reference for the primary code. As I worked through all of the data sources I continued to adjust the list of sub-codes used to characterize mutual engagement, joint enterprise, and shared repertoire. I also met with Dr. David Barker to ensure that the code definitions were consistent with the CoP framework and the codes were well-defined operationally. I considered sub-stage one complete once I had coded all of the sources with the initial scheme.

Simultaneously, I performed the identical process for the negotiation of meaning coding scheme. I coded a single source with the emerging communities of practice codes and then coded that source with the emerging negotiation of meaning codes. The goal for 
the negotiation of meaning coding scheme was threefold: (a) to characterize how Rudy ascribed meaning to his experience, (b) to describe Rudy's patterns of negotiation in a way that would demonstrate his identity, and (c) to illuminate the learning that occurred in practice. With this in mind, my coding scheme began with reification and participation, the two interacting elements that give rise to meaning in experience. You can refer back to Chapter I for a description of reification and participation.

Sub-stage two. In this sub-stage I sought $85 \%$ agreement on intercoder reliability. Dr. David Barker and I discussed and adjusted the coding definitions I had developed in sub-stage one by coding one transcript together for each code category. Then, we each coded a lesson observation transcript individually using a single category of codes (mutual engagement, joint enterprise, shared repertoire, reification, or participation) and checked whether we had coded the transcripts in the same way. I counted all codes as one reference, regardless of the length of text coded. I counted the number of references in the whole document without double counting a reference we both coded, but counting any reference coded by either of us. I counted any reference as an agreement if we both coded the reference and we used the same code. To find the percent of agreement I divided the number of reference agreements by the total number of references and multiplied by 100 . In the case that our agreement was less than $85 \%$ we resolved our discrepancies, adjusting operationalized definitions of codes as necessary, and proceeded to code another transcript or observation until we reached $85 \%$ agreement. In each coding category we coded at most two transcripts to reach $85 \%$ agreement. Note that analysis began with a larger data set than is described in this study so some of transcripts used in check coding are not part of these results. Table 2 provides the progression of agreement 
on successively coded transcripts until the $85 \%$ agreement was reached. The percentages reported for the first transcript indicate the level of agreement before discrepancies were resolved. The percentages reported for the second transcript, where necessary, indicate the level of agreement on a different transcript than the first transcript.

Table 2

Progression of Percentage of Agreement in Coding Observation Data

\begin{tabular}{lccccc}
\hline \multicolumn{1}{c}{ Coding category } & $\begin{array}{c}\text { Mutual } \\
\text { engagement }\end{array}$ & $\begin{array}{c}\text { Joint } \\
\text { enterprise }\end{array}$ & $\begin{array}{c}\text { Shared } \\
\text { repertoire }\end{array}$ & Participation & Reification \\
\hline First transcript & 65 & 85 & 64 & 53 & 80 \\
Second transcript & 93 & & 86 & 86 & 87 \\
\hline
\end{tabular}

Sub-stage three. When we reached $85 \%$ agreement in a coding category (mutual engagement, joint enterprise, shared repertoire, reification, or participation) I began the process of final coding. I used the final, refined operational definitions for the category in which we had agreement and revised my coding for all sources. I conducted the final coding for each subcategory as soon as we had agreement. In this manner I ensured the highest level of fidelity between the operational coding definitions used to reach agreement and my application of those definitions in the final coding.

Stage two. When I completed the final coding for each category I began looking for patterns and themes among the coded references. I used the capabilities of a qualitative analysis software to help identify themes and patterns. For example, I used matrices to compare the overlap of different codes and to describe the teacher's activity. I cross referenced the teacher's mutual engagement codes with his participation codes to 
help analyze how the teacher engaged with students and how this influenced his or her participation in classroom activity. The variety of ways in which I sought patterns in stage two will be more apparent in the description of results in Chapter IV, but it would be relatively meaningless to describe the methods in this section when disconnected from the results.

Stage three. In the third stage I developed a description of teachers’ identity. The teacher's identity is largely indicated by the community membership and patterns of negotiation of meaning in practice. Therefore, this analytic stage developed directly out of the coding schemes of stage one and the patterns of stage two. These patterns were developed into a rich description of each teacher's identity in practice. More specifically, I used the descriptions of Rudy's communities to develop his forms of membership in those communities. His engagement, his role in the enterprise, and his access to the shared repertoire were evidence for his identity as a member of the community and his learning trajectory within the community. Then, I analyzed his experience of meaning in relation to these forms of membership. I looked for indications of consistency and inconsistency in how he developed meaning and his forms of membership and described both the continuity and discontinuities in identity.

Stage four. The coding schemes from stage one and patterns from stage two also played into the analysis of learning in stage four. In this stage I searched for evidence of learning. I reinterpreted the objects of reification and instances of participation as forms of memory. Evidence of learning was found in a teacher's “evolving forms of mutual engagement” (Wenger, 1998, p. 95). It showed up as Rudy adjusted his enterprise and developed an understanding of the joint enterprise of the community. Evidence of 
learning was found in the development of a shared repertoire and the renegotiation of meaning of various elements of the community's shared repertoire. Additionally, I investigated transformations in identity. In all of these areas I sought evidence of a history of learning as well as evidence of learning during observations.

\section{Ethical Issues}

There were a few ethical issues that I took into consideration for this study. First, I considered issues of the teacher as direct participant. I provided him with a letter explaining the details of the study and a consent form with no form of obligation to participate (see Appendix G). The letter explained that his identity would be kept confidential, which is why I used the pseudonyms Mr. Ruettiger, Mr. Rudy, and Rudy throughout this writing (all other names of locations, schools, students, teachers, and administrators are also pseudonyms). I also offered him reciprocity. I offered to teach a class period or perform clerical work for Rudy, but he declined any form of reciprocity except an $\$ 80$ stipend.

Prior to the study I was concerned about possible ethical issues that could arise if, in my estimation, the teacher was teaching mathematically incorrect material or using methods detrimental to student learning. In the course of the study I was not confronted with significant ethical dilemmas regarding these scenarios. The only instance I found Rudy presented incorrect mathematics was a misuse of vocabulary. He used the term rationalize to indicate a mutually exclusive procedure from that indicated by the use of the complex conjugate. In reality, the complex conjugate may be used in the process of rationalizing. Because this was merely a poor use of terms I did not inform Rudy of the incorrect use of the terms until after the study was complete. This was ethically 
appropriate because the students' understandings of the mathematical concepts were adequate, despite the limited nature of their definition of rationalization. Although Rudy used methods that I would not describe as being in the best interest of his students, all the methods he employed were within standard educational practices that are not considered detrimental to students.

\section{Continuing}

As I continue into the results from the methods of data collection and analysis I just described I will provide a brief roadmap for the coming chapters. In Chapter IV I will provide a rich description of my time with Rudy and his class. I will take a narrative approach to Chapter IV that I hope will help you get a genuine feeling for the school environment in which Rudy participated, who Rudy was as a teacher, and what the classes were like on the days that I observed. In Chapter V, I will share my analysis through the CoP framework. First, I will detail Rudy’s communities of practice including the mutual engagement, joint enterprise, and shared repertoire that characterizes each community. Second, I will describe how he negotiated meaning in his pedagogical practice through participation and reifications. Third, I will build on the prior two sections to illustrate his identity, particularly in relation to practice. Finally, I will characterize his learning through practice as revealed in community, meaning, identity, and practice. In Chapter VI, I will draw out the significant conclusions from this study, the limitations, and the significance it has for the broader conversation within our landscape of practice. 


\section{CHAPTER IV}

\section{RUDY}

The parking lot was wet from the rain and the sky shrouded in gray clouds as I pulled into the parking lot of Valley View High School. I was surprised by the size of the building that sat on the edge of this town of only 1,000 residents nestled in the hills overlooking a river valley in the rural Midwest. As the door clicked open, I stepped into the office and was greeted by a polite young man, a senior at Valley View, who sat at the front desk greeting visitors to the school. When I explained that I would be meeting Mr. Ruettiger, clarifying that I pronounced the name correctly, he offered to show me to his room. I politely declined as I was a little early and Mr. Rudy, as the students called him, had agreed to meet me in the office. While I waited, I looked over the years of pictures of graduating classes waiting to be hung, or recently taken down (I could never tell which because they never moved from their stacks against the walls over the months I observed at Valley View).

When Rudy, as the teachers called him, came into the office he greeted me with a firm handshake. I could tell from his appearance that he was indeed the wrestling coach who agreed to participate in my study. We left the office and headed to his room through the main commons that also served as the school cafeteria. The school design was classic 1970s. The multipurpose cafeteria fed into hallways lined with lockers and classrooms clustered in groups of four, some of which were separated from one another by old 
yellow curtains that now served as “permanent” walls. Rudy’s classroom was average size with a window in the corner by his desk, chalkboards on three walls, and one of those yellow curtains as the fourth. I sat down in one of those school desks that looks like it has a stone top and seat, but you know it is really plastic. Rudy rolled over the chair from behind his desk and listened as I explained my study and how he could be involved. He did not hesitate to agree to participate and welcomed me back as soon as I could work out the logistics.

\section{Setting the Stage}

In this chapter I will present Rudy's story through a narrative description of his communities of practice and his participation in those communities. I proceed chronologically through the data sources while presenting themes in Rudy's practice, which provide an in-depth look at Rudy and the context for the analysis that follows. In Chapter V I will present a rigorous analysis using the Communities of Practice (CoP) framework to further describe his interactions within these communities.

\section{The Return}

It was two and a half weeks before all the permission and logistics were worked out and I could return to Valley View to observe Rudy’s Math II classes. As I looked over the building for the second time I recognized the various additions that, according to my research, had brought the elementary school, middle school, and high school together under one piecemeal roof. It took the young man in the office a moment to recall who I was, but he was as pleasant as the first time we met and offered to direct me to Rudy's room again. I assured him that I could find my way and proceeded through the cafeteria down the hall to Rudy's classroom. The bell had just rung and the halls were filled with 
students, but they were not packed like some schools. I did not feel the typical urge to wait in a corner until the second bell and traverse the halls without the threat of being trampled by eager freshmen, worried about being tardy to class.

Rudy’s students eyed me quizzically as I greeted Rudy and made my way to the back of the classroom and took a seat in a chair Rudy had placed there just for me. I waved hello when Rudy introduced me as the researcher who would be observing their classes for the next several weeks, but that was the only time the students acknowledged my existence on that first day. As I settled in to get my first taste of the classroom atmosphere I took note of the learning environment.

\section{The Classroom}

Although the school was dated, it was clean and Rudy's room was somewhere between tidy and unkempt. Rudy's desk sat at the front left of the room and the door at the right. In the middle, a projector mounted to the ceiling illuminated the interactive whiteboard fastened to the wall over the right half of an old chalkboard. To the left of the chalkboard and behind Rudy's desk hung a set of oversized geometric drawing and measurement tools intended to be used with chalk (I never saw them leave their hooks). Rudy’s desk was organized but held stacks of papers, a laptop, a desktop computer, a stack of textbooks and a variety of "decorative" items including a mug with the logo of his favorite baseball team, a miniature ceramic toilet, and a metronome. The front and side of his desk displayed student artwork and photos that appeared as if they might have been placed there years before.

In the back left corner was a bookshelf and table holding a computer. The computer appeared to be left from a bygone initiative to get computers in the classroom, 
and the only use it ever got was students using the USB ports to recharge their phones. The birthday cards that hung on the bulletin board above the computer appeared to be as old as the student artwork and photos taped to the front of Rudy’s desk. In the back right corner of the room was a large cabinet that was never opened, much like the filing cabinets that sat next to the door and covered the place where the curtain would open were it not being used as a wall.

From the classroom picture one might expect Rudy to be an old veteran of the school known as well for his strong hand in the wrestling room as his rigid style in the mathematics classroom. However, the man who stood at the front of the room was a young teacher, unassuming in demeanor, and overflowing with a sarcastic, dry sense of humor. Rudy had been teaching at Valley View High School since he graduated college nearly seven years prior. He had also been the head wrestling coach since his first day on the job. I describe Rudy before his students because in his classroom, you paid attention to him first. That is not to say he was gregarious, nor was he authoritarian. He did not exactly command your attention, but his quiet and controlled manner kept the attention of his class, including me, on the task at hand.

\section{The Students}

The first students I met in fourth hour Math II were all grade ten students who I imagine were more ready for the winter break than I was. It was December 9 and reviewing for their semester finals did not seem to be the most pressing thing on their minds. That is not to say they were disruptive, or unruly, but they were a little more distracted than would prove to be the norm in Rudy's class. Over the coming weeks I would find that the students all knew each other well and interacted as friends, at least in 
Rudy's classroom. This was, at least in part, the result of an enrollment of only 296 students in grades 9-12. Any classroom of students would have likely known each other, even on the first day of school. However, I am certain I did not get a full sample of the conflicts that could arise within the student body. My experience in fifth hour Math II proved to be much the same aside from one relatively friendly rivalry between two young men who seemed to be vying for the "smartest-kid-in-class" title.

As I looked around the room I saw white faces, save one student in fourth hour and another in fifth representing the less than $8 \%$ of the student body who were not White. I could tell I was in a farming community when Rudy asked how many students had been to an auction and all of them raised their hands. However, I would find that not all the jobs in the community belonged to agriculture, a larger town nearby contributed to the economic production of the community by helping to support businesses that required both technical and unskilled labor. These various job markets contributed to a relatively small low-income population of $24 \%$. I would also presume that the job stability contributed to the school's $5 \%$ mobility rate but not the $3 \%$ rate of homelessness, which was up from $1 \%$ the previous year. The small enrollment, which made it difficult for students to remain hidden in the crowd, may have been one factor contributing to the strong 97\% attendance rate. Rudy often asked the present students why certain other students were absent. This kind of accountability to the schooling enterprise is indicative of a strong community atmosphere in Valley View High School.

After my introduction, I sat in the back of the room without as much as a glance from the majority of students, but they would come to acknowledge my presence in the days that followed. I found their communication with me was an indication they were not 
uptight about my presence and could act naturally in the classroom. As much as I wanted to be a fly on the wall, this direct interaction allowed for a more natural participation from students in both classes.

\section{The Curriculum}

As I observed the content of the review on that first day, I recognized the material as atypical for a traditional sophomore level (grade 10) class. It seemed as if the entire first semester had been about quadratic equations, except for one unit about graphing and identifying different types of functions. The typical grade 10 class has been Geometry in the United States but this was definitely algebra content. This abnormal curricular focus was the result of an integration process the school had begun two years prior. The district had decided an integrated approach to mathematics would provide a means to meet the demands of the Common Core State Standards for Mathematics (CCSS-M) (National Governors Association Center for Best Practices [NGA Center] and the Council of Chief State School Officers [CCSSO], 2010). The transition to Math II from Geometry was still a work in progress, as evidenced by Rudy consistently referring to the course as Geometry. The integrated approach meant that geometry, algebra, number and quantity, probability and statistics, functions, and modeling would be integrated throughout three years of high school mathematics. For Math II at Valley View High School this implied quadratics would be studied in the first semester and geometric proofs would be studied in the second semester. I am over-simplifying the scope and sequence in this statement.

In conjunction with the transition to an integrated mathematics curriculum the school had transitioned out of what Rudy described as tracking. That meant every student in Math II was in grade 10 and every grade 10 student was in Math II, except in cases 
when the student had not passed a semester or more of mathematics. Several students with IEP's had been placed in Rudy's fourth hour class, but none were placed in his fifth hour class (note that there was one additional Math II class at the school). I did not seek out the reasons behind this division but it seemed, at least to Rudy, to go beyond the inclusion of students receiving special education services. I will not conjecture on the sources of what seemed to be a de facto tracking system, but the homogenous grouping may have played a significant role in the differences in the classroom communities.

\section{Initial Interview}

On the final day of my informal observations, Rudy allowed me to ask him some questions that served as our initial interview. He talked with me during his planning hour and the interview lasted approximately 30 minutes. One of the first questions I asked was, “Can you tell me what courses you’ve taught?

\section{The Curriculum}

Rudy told me a list of courses that included primarily geometry and algebra courses. His list included several courses specific to his school context that were mostly what he called, "lower track" courses. He took some time to explain the differences in Geometry and Practical Geometry, for example. He also explained that the school had eliminated tracking (and with it courses like Practical Geometry). In order to accommodate for students who needed extra support, after eliminating tracking, they had incorporated extra elective classes that accompanied the standard course for each grade level. For example, all grade 10 students at Valley View took Math II, but some grade 10 students also took another course that was meant to support them in Math II. 


\section{The Difficulties of Transition}

When he brought up these support courses he mentioned that they were instituted when the school switched to an integrated curriculum from a traditional curriculum. This topic clearly stirred up some emotions for Rudy. The difficulties of this transition, and its consequences, are important to understand Rudy and his story. He explained the transition in the following excerpt.

So, the first year that we introduced the integrated, this went against everything I said, but no one really listened to me cause I'm just young and don't know what I'm talking about. The Principal at the time and the other two math teachers wanted all three of us math teachers to teach one class, or each class of each subject. So, I taught Algebra 1 [Math I], Geometry [Math II], Algebra 2 [Math III], and then two different [support classes]. The [support] for Algebra 1, [support] for Geometry. And they kind of did the same thing. I told them all, you're nuts. This is the first year going integrated, changing our curriculum, we don't know our pacing guides. This is going to be way too much. Like, their idea, we need to collaborate more, which I agree with, but that's something to do after we've established pacing guides, curriculum maps.... I told them after a month, two months, after the first quarter you guys are going to agree with me. Sure enough they started complaining after a month of it. Now, I'm just venting. To me, I think that year was kind of a waste because I know myself, I was not a good teacher because I was just trying to plan for the class period before that day. It was hard to go in depth and differentiate and things like that. Last year, finally, I only taught Geometry and Geometry [support]. So I was able to get the pacing down a lot more, help fill some of the gaps. Really, it's kind of a three, four year process. After that three or four years of teaching that same class you have things down more.

In the transition to an integrated curriculum the administration required Rudy and his colleagues to teach a new sequence of courses and required each of them to teach each of the new courses. This transition implied an increased workload. Jean and Julie also perceived a need for increased collaboration during the transition. However, the combination of the increased workload and the perceived need for collaboration seems to have exposed, or created, tension amongst the mathematics teachers.

I decided to continue on what seemed to be a significant topic and asked, "Can 
you talk a little bit about what are the biggest things you learned through that [transition to an integrated curriculum]?” Rudy discussed how the integrated curriculum was chosen to help address the requirements of the Common Core State Standards for Mathematics (CCSSM). He explained that the CCSSM called for an approach that related the material to the students and that used projects. He claimed that the integrated approach helped them cover the content in the CCSSM because the projects could cover multiple content areas allowing for more efficient content coverage.

\section{Rudy's Teaching Philosophy}

In order to determine how Rudy perceived his own teaching I asked, "What are your general teaching practices? How do you engage with students in the classroom?”

He responded,

One of my biggest teaching philosophies is being a good salesman. Not everyone likes coming to math. If, I would say half and half. If the kids are interested. If you can get the kids to buy in, if you can relate it to them, then they're interested. Then, they want to learn. Then, if they're wanting to learn, if they're interested then odds are they're gonna be learning something. If they dread coming to class. If it's aww, it's math class, odds are they're probably not going to learn a whole lot.... I want them to want to come to math class, or not dread coming to math class. And when they leave I want them to be thinking, 'Oh, by golly that is kind of interesting.' End with some interesting topic or something. I like doing multiple examples of different problems or concepts that we're going over so kids can refer back to their notes, back to their homework, putting more responsibility on them. Versus me being a crutch, asking me questions, 'Am I doing this right?' Well, look at your notes we just did an example that's basically the same thing, it's just different numbers different variables. A lot of group work. I think a lot of times kids can learn more from each other than from me. And I've found, and I've heard this so many different areas, the quickest way to learn something is to teach it. So if you get a kid helping another kid out, they're kind of teaching, going through the steps, they're gonna become stronger at that concept also.

It seems that Rudy believed that being a good teacher meant being a good

motivator. Later in the interview, when I asked Rudy about his overarching goals or objectives, he brought up the concept of motivation in his response. His response 
demonstrated that he wanted to make a difference in his students' lives and influence them beyond mathematics. It also illustrated the connections he made between coaching and teaching. He said,

I want them thinking, I don't know this may sound corny, change the world ideas. It could be math, maybe it's something that relates to math, maybe it's something non-math-related at all... What's a holy crap idea that's gonna change the world? Cause there's that out of the box thinking the, them making a difference I guess once they get out of high school. And it keeps them interested. It keeps them motivated. Whether its mathematics or just life in general. With my wrestlers, yeah, do we want to go undefeated, is it about wins, losses. It's nice but it's not all about that. It's a lot about the life lessons that you can take out of just the sport in general. Between the discipline, the mental attitude, all that stuff. A lot of it's the same with math too. As far as just kind of the reasons I gave you earlier. The reasoning, the critical thinking, picking up patterns, things like that.

Immediately following my initial question about his teaching philosophy, I asked

Rudy to describe how he developed his teaching philosophy. In his response, recorded below, he cited the influence of a former teacher, the influence of his students, and the influence of his coaching practice. I asked, "Does this come a lot from, you just kind of figured it out on the job? Is it something that comes from teachers that you had in the past or from your training, or all of it?”

He said,

Kind of everything. The reason I'm a math teacher today is because I had an awesome math teacher in high school. If he were teaching now, he would be a horrible math teacher because it was so traditional, old school. Homework, you went over the homework, you took notes, and you worked on the homework. And that was just everyday. It was clockwork. We never really got into groups. We didn't do projects.

In this response, Rudy demonstrated the tension that had arisen in his practice between a traditional form of teaching, influenced by his high school mathematics teacher, and a contemporary approach to teaching. Some elements of Rudy's practice, such as his use of multiple examples and note taking, seem to have been influenced by this traditional 
teacher, but Rudy claimed that this teacher would have been a horrible teacher at the time of the interview. This identity tension is an important consideration in my analysis in Chapter V. He continued his response discussing the influence of students.

A lot of it comes from the relation, the positive relationships with the kids. We have awesome kids here. I think we talked about it, small school atmosphere, you know everyone on a personal level. So if the kids see me getting amped up... they get excited.... Trying to put myself in the kids' shoes is a lot of it too. If I were sitting there listening to me, am I bored, am I listening, am I understanding. Things like that. Trying to pick up, trying to catch questions, mistakes before they happen so that if a kid asks a question I can read their mind. Oh yeah, I know what you did there, you did this. Oh yeah, okay, I understand that. Things like that.

Rudy claimed that his relationships with his students, understanding his students, and identifying with them are strong influences on his teaching practice. I will describe in Chapter V how Rudy's relations with his students influence his learning in the classroom community. He also described the influence of coaching on his teaching philosophy.

A lot of it comes from the coaching standpoint, motivating the kids. And that's hard because each kid's motivated differently. You have to figure out what, what really gets, eats at them. You can't be too hard on some of them, they'll break so to speak. Some of them you have to be harder on. They can take that and use it positively. As far, that kind of takes care of a lot of the discipline.

Rudy explained that he uses some of the same principles of motivation with his mathematics students and with his athletes. It is important to note that Rudy sees himself as a more valued member of the coaching community as compared to the community of mathematics teachers, which may impact the level of influence of his coaching on his teaching practice.

\section{Rudy's Collegial Relationships}

Rudy described some of the tensions in his relationships with his colleagues when I asked about the transition to the integrated curriculum. When I asked about any further 
influence his colleagues had on his teaching practices he continued to describe the difficulties associated with collaboration. He explained,

I think for me, I would like to collaborate more. I think that you can't collaborate enough. There's been so many changes and I'm young enough, I haven't been teaching long enough where I have things down to where I have enough free time to go around and collaborate. My first year I locked myself in my room. I worked through my preps, my lunches, I'd come in on Sundays, lesson plan, things like that. I didn't have time to collaborate.

Rudy's conception that he did not have time to collaborate reappeared, or continued through, Valley View's transition to an integrated curriculum. Rudy stated, in reference to the state of the transition to integrated at the time of the interview, "I'm trying to keep my head above water.” However, he also expressed a desire to collaborate.

So, I'm gonna try and get with some of them [the other mathematics teachers] and talk about next semester. Talk with the Algebra 1 teacher about what she's gotten through. Do I need to go over parallel lines? How in depth do I need to go over proving them, things like that. Once we all get that down, then it (Our pacing guides, curriculum) we'll be able to collaborate more, and get more in depth.

In addition to his concerns about time constraints, Rudy's responses regarding collaboration may indicate that he hoped to establish a certain degree of competence prior to collaboration.

\section{Rudy's View of Mathematics}

When I asked Rudy about how he thinks of mathematics, he described a paradoxical relationship. He explained that mathematics can be very difficult, but it creates critical thinking that makes those who understand mathematics different than everyone else. He said,

I think math is kind of a love-hate relationship. Thinking back on my more advanced classes in college, my undergrad. There were times when I just wanted to cry cause. I know real analysis, that was the hardest class. Where, so much out of the box thinking. And there are days if it's a shortened class period or half days where I'll do activities or brain teaser type things with the kids that's not really 
math but the concepts behind it is math. Where it's critical thinking, problem solving, things like that. Those type of skills I like because that out of the box thinking makes you different than everyone else...

\section{Teacher Inservice}

After my informal observations, the initial interview, and Valley View High School's winter break, I returned on January $4^{\text {th }}$ for their teacher inservice day. I wanted to gain a picture of the administration and collegial relationships in addition to the students I would see each day in Rudy's classroom. I knew that if I did not attend the inservice day I would likely only observe Rudy in the isolation of his classroom and miss out on the broader context of collegial relationships.

\section{Rudy’s District Context}

I entered a relatively empty school that cold morning and found Rudy alone in his classroom. As soon as I arrived we made our way to the school auditorium for the opening presentations. Rudy greeted a few teachers as we found a seat near the back of the auditorium where the entire district was beginning to gather. Nearly every teacher chose a seat near the back as a Local Park District representative distributed some literature about the programs they offer. Everyone seemed in good spirits as they chatted about Christmas and Fantasy football.

The district superintendent, a middle-aged, white male, spoke first, welcoming the teachers back. He proceeded to give a brief report about upcoming testing before describing the annual "biggest loser" competition that would begin that day. He encouraged everyone to begin their participation with a weigh-in later that day. Then, he handed the microphone to a representative from the Local Park District. She gave a fiveminute presentation about developing partnerships with the school for environmental 
education. The teachers applauded politely as she left the stage.

The district technology director, a young white male, took the stage. His 20minute presentation seemed to be an update, but also as a motivational speech to reach district technology improvement goals together. He detailed their progress on a significant improvement plan and where the next steps would take the district. He explained multiple ways the teachers could help with the progress, including participation in a training workshop that would help teachers build their own class websites.

After the superintendent gave some announcements about the remainder of the day, he shared the obligatory motivational blurb about getting back to work. He referred to the beginning of the spring semester as the most frustrating time of the school year, but encouraged his staff to "rein the kids in" as they came back from their winter break.

\section{Rudy's High School Context}

After the meeting Rudy introduced me to the driver's education teacher (who also taught physical education classes), the health education teacher (who also taught physical education classes), and the physical education teacher. As we walked back to Rudy's room, the health teacher casually mentioned that she had no interest in learning the new technology and that it was all about to do her in (as she was planning to retire soon).

Rudy entered grades from the fall semester before we proceeded to a high school staff meeting in the room across the hall. Rudy sat with four physical education teachers (the three previously mentioned and one other). At this point it was becoming clear to me that these were the colleagues with whom Rudy allied himself. As a coach, he seemed to be a valued member of their community (they were also coaches) and he appeared to value his position in their community. About 21 total teachers plus the Principal and 
Superintendent were in attendance. I noticed that many of the teachers appeared to be young like Rudy, probably in their late twenties.

The principal began the meeting by sharing his professional goals. He explained that he wanted to make his goals known to show that he had similar obligations to the teachers in terms of evaluation. He also wanted to make the motivations of his actions transparent in order to have everyone on the same page. He explained that his goals followed specific performance indicators in accordance with state evaluations because the Danielson model does not apply to administrative work. Many teachers, including Rudy, were viewing the principal's professional goals using google apps tools available on their computers through the school technology initiatives. As the presentation wore on Rudy appeared to shift his attention to his own professional goals that were part of his evaluation at Valley View.

The English department took the remainder of the time to discuss close reading. The four English teachers suggested that everyone open their presentation and follow along; some teachers did. Rudy appeared to continue to work on his professional goals and evaluation documentation. At some point he transitioned to cataloguing wrestling statistics before preparing some lesson plans and responding to emails. The close reading initiative the English teachers were presenting was part of a principal backed initiative that would be the focus of their Wednesday afternoon professional development sessions for the remainder of the year.

Rudy worked on lesson planning in his room for about half an hour before proceeding to the free lunch provided for all teachers. Rudy sat with the two elementary physical education teachers, one of whom coached baseball with Rudy. They talked 
primarily about sports and student athletes, but brought up technology in an effort to include me in the conversation.

In the afternoon, Rudy and I visited the most senior mathematics teacher's classroom. According to Rudy she had been teaching at Valley View High School for at least a few years before he was hired. The two teachers exchanged essentially no greetings and I was not introduced, we waited awkwardly until the third high school mathematics teacher, who had been at the school one more year than Rudy, joined us. Rudy got right to the point and seemed to be in charge of the gathering. He had requested the meeting to ask questions related to scope and sequence. It became apparent that even though Rudy was in control of the topics they discussed he was not in charge. The meeting involved no discussion or negotiation. Rudy took notes as the other teachers stated how he should adjust his scope and sequence for Math II to accommodate what one of them had accomplished in Math I and what the other hoped to accomplish in Math III. When we left the meeting Rudy said they were very hard to work with. This meeting made it apparent that Rudy identified more closely with the community of physical education teachers or coaches rather than the community of mathematics teachers. This meeting with the mathematics teachers concluded the collaborative portions of the inservice day and I left Rudy to finish his lesson planning at the end of the day.

I told this story to provide a description of Rudy’s interactions with his colleagues. I believe the differences in his interactions with coaches and mathematics teachers play an important role in Rudy's story and his learning. In the next section I continue the story by providing an explanation of his lesson plans. 


\section{Rudy's Lesson Plans as Content Oriented}

By the time I left the inservice day Rudy had completed most of his formal lesson planning for the next four days. He had already given me a set of lesson plans (see Appendix $\mathrm{H}$ ) from the prior year and a page of notes about adjustments that he planned for the coming unit (see Appendix I). These notes served as his response to my lesson planning think-aloud prompts. At one point in our conversations he explained to me that he made a lot of in-the-moment decisions in class. He did not do a lot of detailed advance planning, but used a basic outline of problems to guide his moment-by-moment participation in the practice of teaching. Rudy's lesson plans and his notes demonstrate a strong focus on mathematical content in his explicit planning.

The plans Rudy provided began with lesson objectives and associated Common Core State Standards (NGA Center \& CCSSO, 2010). He also referenced the associated section in the textbook at the beginning of the plan. Rudy's objectives for the three days on his lesson plans were: (a) determine the number and type of roots for a polynomial equation, and (b) find the zeros of a polynomial function. According to the plan, the first day was to begin by going over homework, followed with a warm up from the textbook. However, later in the plan was a note that stated, "Start here," next to the heading, "Determining the total number of zeros." This was in the day two lesson plan, but it appears that Rudy planned to move this to the first day during my observations. He also wrote the note, "Only \# of zeros." He described this further in his notes in which he explained that he would not be teaching how to find the number of positive and negative real roots, or the number of imaginary roots. The reason he provided for this change from prior years was that these concepts would be covered in Math III. 
After the warm up, the lesson plan for the first day included the definition of $i$ and examples of how $i$ could be used to simplify square roots of negative numbers. The lesson then included a statement about rationalizing the denominator and two examples thereof. Next, the lesson had statements about adding and subtracting using $i$, multiplying using $i$, and conjugates using $i$. Two examples followed each of these statements. After the examples involving conjugates, Rudy wrote a homework assignment from two worksheets, one titled "Imaginary Numbers” and the other "Complex Numbers.” Rudy stated in his notes that he was moving the section about rationalizing the denominator to after the section about multiplying using $i$.

The second day on the lesson plan began by going over homework and two warm up exercises. The warm ups involved solving quadratic equations that could be solved using square roots. Rudy’s notes stated that he wanted students to, "notice the similarities from what/how they've solved quadratic [equations]...in the past.” This suggests that he wanted to include more exercises like these warm ups that involved solving quadratic equations in various ways. After the warm ups was a statement of the Fundamental Theorem of Algebra followed by the statement that was labeled start here. The remainder of the day two lesson and all of the day three lesson was about Descartes' Rule of Signs, which Rudy mentioned he would not cover in his notes about the lessons. Despite the lesson plans only covering three days, in Rudy's notes he planned for the unit to take four to five days.

These plans show how Rudy focused primarily on the mathematical content of his lesson plans, including examples to be covered, with little explicit recording of pedagogical practices. The plans may have implied certain pedagogical considerations for 
Rudy, but most of those pedagogical choices were not readily apparent to me. It appeared that he made pedagogical choices primarily in his mental planning, or as he participated in classroom activity.

\section{The First Lesson}

On Tuesday, January $5^{\text {th }}$, the day after the teacher inservice day and the first day back from winter break for the students, I conducted my first formal observation. I made my way to Rudy's classroom between third and fourth hour and set up my camera in the back of the classroom as the students entered the room.

\section{Fourth Hour}

This first lesson illustrates the use of a warm-up activity, the typical note-taking experience in Rudy's class, and the typical procedure for assigning homework at the end of class. Notice the content of the lesson because it provides the mathematical context of Rudy's participation. Also, notice Rudy's interactions with the students in his fourth hour class as a baseline to compare with his interactions with fifth hour class. I will refrain from any further comment about the specifics of Rudy's interactions until I present the later lessons.

Warm up. Most of the students chatted with friends as they awaited the bell. I overheard conversations about Christmas gifts, family events, and the social happenings of the break. When the bell rang the students continued their conversations as Rudy took attendance and turned on his projector to reveal a warm up exercise. It appeared that the class only began when Rudy proclaimed, "Let’s open up to our warm ups.” The students finished their conversations as they pulled out five-subject notebooks and opened to whichever section they had designated for their warm ups. 
The students stopped talking when Rudy said,

This warm up should be written down. It's a little confusing. I will help you out. This should get you back into the rhythm of doing some fun math. You guys were probably getting to the point where you were having withdrawals.

Several students murmured apparent disagreement as Rudy read the warm-up exercise aloud,

So, if one fourth is one twelfth of how and if one fourth is one sixteenth of twice of why; find the product of how and why. You want to convert it into an equation or equations. Don't let these two words confuse you.

Rudy drew boxes around the words how and why on the board saying, "They're strictly variables, they're unknowns. What does the word is mean? What does the word of mean? What does the word twice mean?”

The students remained silent as Rudy used red to underline "1/4 is 1/12 of HOW," which was written on the board, stating, "Focus on this one first.” Then, he underlined "1/4 is 1/16 of twice of WHY,” which was also written on the board, in blue and said, “Going, or converting a verbal statement into an equation what are some key words, or what do the words mean? So, what does it mean when it says is?”

Reese answered, “Equal.”

Rudy, “Equal? Okay. What about of? Colton?”

“Product,” Colton replied.

Rudy probed, “And what does product mean?”

“Multiply,” said Colton.

Rudy addressed the class, “So, what I want you to do, come up with, we're making two equations. So what did Reese say is, is? Equal. What about of?” Many students watched and waited while a few worked and Rudy wrote an equal sign on one 
side of the interactive whiteboard and "HOW $\bullet W H Y$ = ?" on the other. Rudy looked at several students' notebooks as he walked between two rows on the right side of the room.

After about a minute Rudy returned to the front of the room and asked,

What do you think about the very end? What is how times why? What did I tell you how and why represent? Variables, unknowns. Let's say how is $x$ and why is $y$. Can we figure out what $x$ times $y$ is?

Without a response, Rudy continued, “We don't know what $x$ and $y$ are. Can you solve for $x$ and $y$ ? That's what you have to do setting these equations up.” Rudy continued to question students as he set up and solved the first equation on the board. When he finished solving, Rudy wrote " $3=H O W$ " as he said, "So, do we know what how is? I will give you 1 minute to do the rest.” Most of the students seemed to take the opportunity to work on the second equation. Rudy told them, "Raise your hand if you think you have an answer.”

Liz and Brady raised their hands immediately. Rudy went over and looked at Liz’s paper. Without commenting he proceeded to look at Brady’s paper. At this point Callie raised her hand and Rudy walked to Callie’s desk and looked at her notebook, again, without commenting on what Brady had done. Then, he checked the work of two more students who had not raised their hands, all without an audible comment. Several students appeared to be finished and began to chat just before Rudy asked the class, "So how am I going to set this equation up? Anyone?” Although Brady raised his hand and Devin did not, Rudy said, "Devin, thanks for volunteering. What's your second equation?”

Devin said, "I got one fourth equals one sixteenth times 2 times $y$. ."

Rudy transcribed Devin's equation on the board and questioned various students 
as he solved the second equation on the board in front of the class. When he finished solving he said, "So, $y$ is going to equal?"

Ryan said, “Two.”

Rudy said, “Two. Three times 2 is?” as he wrote $3 \times 2=6$ under the $\mathrm{HOW} \bullet$ $W H Y=$ ? he already had on the board.

Kate offered, "Six.”

Rudy circled the six he wrote on the board and drew a smile underneath. He added two teeth on the smile as he nodded to acknowledge Brady, who had his hand raised. Brady asked, “Couldn't you just multiply that by the reciprocal?”

“Yep, you could do that,” Rudy replied.

Rudy looked around the room momentarily as if he were anticipating another question. When nobody said anything he switched to a blank page on the interactive whiteboard and said, “Alright, notes.” This lesson provided the only instance of a warm up during my formal observations. However, Rudy attested to the somewhat frequent use of warm ups in his daily lessons, and I was able to observe the use of warm ups during my informal observations.

Notes. The students flipped to a different section in the five-subject notebooks they were using as Rudy stated that the next unit would cover roots and zeros. After writing the title on the board he asked, "Who remembers what a root is? Something that a tree has, right?” Without a response Rudy continued, “Quadratics. Who remembers what a quadratic equation is?” Following another silence, he inquired, “No one remembers what a quadratic is? How do we know if something is a quadratic equation?” Brady guessed, "It has four parts.” 
Rudy replied, "It could have four parts to it. Alright Ryan, you're being tested

here.”

Ryan asked, “Tested? Alright guys, help me out.”

Brady seemed to assure Ryan he would help him answer Rudy's questions. Ryan looked back at the camera, or possibly another student, as Rudy wrote the equation $2 x-$ $4=y$ on the chalkboard. He asked Ryan, "Is that a quadratic?”

“No,” Ryan replied.

Rudy wrote $18^{x}-4 y=0$ and asked, "Is that a quadratic?"

Colton interjected, "No."

Ryan added, “No, I guess no. I thought it was.

Colton said, "I'm gonna look this stuff up” as he pulled out his textbook.

Rudy continued to write $\frac{(3 x+y)}{2}=10$ on the board and asked, "Is that a quadratic?”

Colton had apparently found what he was looking for and said, “ $y$ equals $a x$ squared or something, that's the formula.” When Rudy wrote $4 x-5 x^{2}=y$, Colton claimed, "Yeah, that's it."

Ryan said, "It's got a square on it. No, it's not, no, it's not.”

Colton asked, "It isn't?”

Ryan said confidently, "I'm saying no.”

By this time many of the students were telling each other which equations they thought were and were not quadratics. Colton changed his answer saying, "No, it’s not."

Rudy said, “I haven't said anything besides asking questions. Why are you changing your answer?” 
Colton replied, "It has to be $y$ equals."

"It is $y$ equals," retorted Brady.

Cory explained, "You can switch it around."

Colton said, "Oh, so it's the same thing?”

Rudy wrote $x^{2}=y$.

"No, that's not it," claimed Colton.

Rudy crossed out the first three equations and drew a box around the number two in the exponent of both of the quadratic equations. "I knew it. I told you," Colton exclaimed.

Rudy asked, "What about this one?" as he wrote $4 x^{3}+2 x=-18 x^{2}+y$. He drew a box around both of the exponents and shook his head. Moving on he asked, "So, all the quadratics that we graphed and really broke it down, what is the graph of it called?”

Several students replied, "Parabola.”

Rudy agreed, "Parabola!” and asked, “What does it look like?”

Brady said, "U," and made a motion with his hands in the shape of a parabola.

Rudy explained, “Like a horseshoe. They can open what directions?”

Several students said, "Up and down.”

Rudy agreed, “Up or down.” And asked, “Sideways?”

Sidney said, “No.”

Rudy said "So back to our original question. What are roots or the zeros?” The students responded with silence as Rudy wrote $x^{2}+3 x-4=y$. He asked, "How can I solve for $x$ ?” Again, he was met with silence. “What if I do this?” he asked as he wrote 
$x^{2}+3 x-4=0$. "How can I solve for $x$ ?" he asked again, "How many ways are there?"

Melissa said, “Five.”

“Could this be one of them?” Rudy asked as he solved for $x$ by factoring. He wrote the coordinate points $(-4,0)$ and $(1,0)$ on the board as he said, "This is important, since our $y$ values are zero this is negative four and this one's one. What's important about these coordinates, or where do they fall on the parabola?” Rudy answered his own question saying, “The $x$-axis. How do you know? The $y$ value is zero. So it's the roots, the zeros where it crosses the?”

Liz said, “ $x$-axis.”

Rudy drew a set of $x$ and $y$-axes on the board with a parabola so that it had two $x$ intercepts and another blank set of axes before he asked, "Who can show me, or describe how there can just be one answer?” Rudy drew a parabola on the axes according to the student's response and did the same for no solution.

Rudy opened a new page on the interactive whiteboard and explained,

Now, I think I talked about this early on about using the degrees, the exponents, to figure out the number of roots of some of these. This is really the only idea we're going to be using from this section, and then we're going to be moving on to imaginary numbers.

He began to copy the following statement from his lesson plan onto the board as he said, “The largest degree in the equation represents the total number of zeros/roots.” He continued to write three examples on board $\left(x^{2}+6 x+9=0 ;-3 x^{5}-5 x^{2}=8 ; 4 x^{4}+\right.$ $15 x^{2}=x-6 x^{4}+1$ ) before he said, "These aren't meant to be tricky or hard or anything like that. Example number 1, what's the largest exponent or what's the largest degree?” Melissa said, “Two.” 
Rudy circled the two on $x^{2}$ and said, "Largest degree's two, so the total number of zeros is gonna be two. How about number 2? You're gonna wanna make sure to put it into standard form before identifying the largest degree. What's standard form again?” The students greeted his question with silence so he joked, "That's like the first or second day, right?”

Eventually Eli offered an answer and Rudy used it to elicit more information about standard form from the class. Rudy followed a pattern of questioning students and providing partial information similar to what he had done in their discussion about quadratics. In this discussion he arranged the second example in standard form before determining the degree and number of zeros. For the third example, Rudy asked only one student all of his questions in the process of rearranging the equation into standard form, determining the degree, and determining the number of zeros.

Rudy opened a new page on the interactive whiteboard and wrote "3.2 Imaginary \& Complex Numbers," and underlined it. He said, "Now, this is the section we're gonna be focusin' on for the next couple of days: imaginary and complex numbers.... First, we gotta figure out what a darn imaginary number is. A number that isn't real? It's make believe. It's fiction. What are some more?”

Colton offered, "In your head.”

Rudy warned, “This is something you're gonna want to put a box around," as he wrote $i=\sqrt{-1}$ and $i^{2}=-1$ and drew a box around both. He asked, "Who has seen an italicized, lowercase $i$ in math before?” When three or four students raised their hands he asked, “Where have you guys seen it before? Testing?” Without a response, he continued, So what this is, an italicized, lowercase $i$, it is equal to the square root of a 
negative number, the square root of negative one. $i$ squared is equal to negative one. It's that simple. Plain and simple, those two items.

Rudy wrote three examples $(\sqrt{-10} ; \sqrt{-28} ; 3 \sqrt{-12})$ on the board as he stated,

Everything we've been doing with square roots is going to be incorporated with this. These are some examples using imaginary numbers. We're gonna simplify. Expressions. In the past what have we done when we've seen a square root and then a negative inside of it? Have we been able to do anything with it? No, we just kind of stopped right? No solutions, no real solutions. Mama says negatives underneath the square root are the devil, just like negative exponents are the devil. First step is to get rid of the negative numbers in the square roots. How do you do that? You gotta take your i's out. Double meaning?

Rudy motioned like he was plucking his eyes out as he said, “Take your i’s out.”

Some of the students acknowledged his joke with a slight chuckle. He wrote $i \sqrt{10}$ under

the first example and said,

Remember that $i$ is equal to the square root of negative 1 . You'll get more in depth on what it actually is or how it's actually used, like word problems and all that once you get to Algebra two. Notice the difference. Take your $i$ out, the number's positive. Can you break 10 down, the square root of 10 down? Perfect squares. Four go into it? Evenly? Nine? No, so this is our answer. $i$ times the square root of 10. See it's not that different. What about [example] two? Negative underneath the root, what do we have to do first? Take your $i$ 's out. $i$ times the square root of 28. Is that our answer?

Kale said, "No.”

Rudy asked, “No, why not? Stacy, do any perfect squares go into 28?” Stacy did not reply so Rudy asked, "What are perfect squares?”

Stacy offered, "Where one number goes into it."

Rudy said, “Okay, so give me an example; the square root of what?”

Stacy started to say nine but cut herself off and said, "The square root of 9 is 3.”

Rudy asked, “Okay, any perfect squares go into the square root of 28?”

Stacy said, “No.” 
"What's below the square root of 9? What will give you a positive 2?” asked Rudy.

“Four,” Stacy replied.

Rudy continued, "The square root of 4 . Will the square root of 4 go into the square root of 28?” Stacy did not give a verbal response. Rudy wrote the steps for simplification as he said, "Square root of 4 times the square root of?"

Brady filled in the audible blank with, "Seven."

Rudy wrote the steps as he talked through the final steps of the example. He asked, “Brains hurting yet?”

Several students said, "Yes."

Rudy said, “That's a good thing. I told you guys every time you learn something new you get a new wrinkle in your brain?” Most students shook their heads. Rudy sounded surprised, "No, I hadn't told you that? You got another wrinkle.”

Rudy wrote the titles for the next sections on the board as he said them aloud. The next section involved complex numbers and addition and subtraction of complex numbers. The interactions over the addition example and subtraction example in this section were consistent with the interactions over the previous examples. The notes described above demonstrate the common interaction patterns that Rudy had with his fourth hour students as they were learning new material. For example, notice his infusion of subtle humor in his participation.

Homework. Then he said, “Homework. I'm gonna hand out two worksheets. We're gonna refer back to them for the next couple of days.”

The students started talking as Rudy handed each student a worksheet. He 
distributed both worksheets in the same manner, giving one to each individual student. Then, on the chalkboard on the left side of the room (where he wrote down all of the homework assignments), he drew two columns, one for each worksheet and wrote problem numbers in each column. When he finished writing he advised the class, "On the board is the homework.” Then he began writing on the interactive whiteboard again as he said, “There's a couple of them that are multiplying using $i$ 's. $i$ times $i$ is?”

Eli finished his statement, “i. Squared.”

“i squared,” Rudy confirmed and asked, “ $i$ squared is equal to what? If you go to the very beginning?” As the bell rang Rudy wrote -1 on the board and the students grabbed their things to leave class.

This was the common homework pattern for Rudy’s fourth hour class. He would state the homework and write it on the board. I will now describe the warm up, notes, and homework in fifth hour for comparison. In addition, I will describe some additional differences between the two classes.

\section{Fifth Hour}

As soon as most of the fourth hour students had made their way out the door, the fifth hour students began shuffling in. As the students took their seats I noticed that all of the girls sat on the right side of the classroom and the boys on the left. I learned from Rudy that they had chosen their own seats at the beginning of the year. Fourth hour had also chosen their own seats, but the genders were intermixed. Rudy explained that he had moved some of the students in fourth hour, but had not asked any of the students in fifth hour to change seats. In fifth hour the same warm up, note taking, and homework procedures are illustrated. This lesson also illustrates how Rudy interacts with fifth hour 
differently by telling an unrelated story at the beginning of class, but still covering more content by the end of class. One of the reasons he was able to cover more content was that he eliminated one of the examples finding the degree and number of zeros of a polynomial. Several instances also illustrate how fifth hour, particularly the student George, seeks to understand mathematical concepts, but Rudy avoids deep explanations.

Rudy's unrelated story. When the bell rang, Rudy was still busy typing the warm up into the interactive whiteboard software. A few minutes passed as the students continued to chat and Rudy finished typing the warm up. The girls on the right and a few of the boys on the left held conversations focused on social issues. George, Mike, Travis, and Ian, however, discussed the warm up exercise as Rudy finished writing it. Mike said, "I think we are underestimating this problem.” Then he asked, "How is three, right?” Eventually all four of them agreed that the answer was six.

At about the same time Rudy finished taking attendance and said, "Okay, let's get our warm ups out. We need to fire them synapses after being gone for break.”

"What's a synapses,” asked Mike.

Rudy clarified, "What's a synapse?”

“Didn't we just talk about this?” Matt asked.

George confirmed, "We did."

Rudy addressed the class, “What's a synapse?” After a couple of students made comments that were not decipherable on the recording, Rudy said, "Raise your hand if you have ever had accupuncture before.”

“I don't like accupuncture. I'm afraid of needles,” Mike said.

Rudy asked him, "Have you ever had it?” 
"I'm afraid of needles! I will never have accupuncture,” Mike clarified.

Rudy tried again, "Raise your hand if you have a family member or know someone who has ever had accupuncture.” Jess raised her hand and Rudy said, “Jess?”

“My Mom,” Jess confirmed.

Rudy asked her, "Did she tell you how it was?"

“No,” Jess said.

Rudy shook his head as he said, "I had accupuncture done once."

"If you move then it feels aweful,” Kayla interjected.

Rudy continued, “And it was horrible. I thought. I was like, I'm gonna walk in here and lay down and it's gonna be like a massage. I'll be on a beach somewhere I'll be calm.” Rudy shook his head, “Oh, it's horrible. What's the purpose, or what's going on with accupuncture?”

Mike explained, "They're hitting pressure points. Not that hurt you, that are good for you to hit, that calm you."

Rudy agreed,

There's a bunch of spots in your body where they are like pressure points, but just. Your bodies made up of electrodes and there's a bunch of energy constantly travelling through your body. There's a movie called phenomenon, has anyone seen it? It's from the nineties with John Trovolta. It's a really good movie. I highly recommend it. But it deals with telekinesis and moving things with your mind and so forth. But accupuncture they want to hit those spots throughout your body where your nervous system or where your electrodes are going through. And it's supposed to relieve you of pain or pressure and things like that. But oh, it's horrible. There's spots behind your knees where basically when they stick you with the needle it feels like a shock. But not good shock. Like you're getting electrocuted. And that's not relaxing at all.

All of the students were laughing by this time as Rudy brought them back to the point of the discussion, 
And synapses are parts in your brain. The more they're firing the more, the higher your thought process should be, make sure you're learning. So, firing synapses get you ready to learn. This is kind of a neat, cool little warm up to start the second semester off. If one fourth is one twelfth of how and if one fourth is one sixteenth of twice of how, find the product of how and why. Don't let how and why throw you off. Yes, words make this confusing. The only hint I'm gonna give you. Think of those two words as variables.

Rudy's initial interactions with his students in fourth and fifth hours, and his unrelated story, revealed some interesting differences between the classes. His interactions with fifth hour appeared more relaxed and personal.

Warm up. The students started working for a few seconds before Rudy continued,

So, if you start at the end, can you determine the product of how and why to start with? What's how times why? Are you able to come up with a number? Again, think of them as variables. Let's say how is $x$, why is $y$. What's $x$ times $y$ ? In order to figure out, or come up with a number, what do you have to solve for?

Some of the students continued to work and Rudy took a drink from a bottle of water as he walked around at the front of the room. He said, "I like seeing the thinking faces.”

George asked, "Is that juice like a bottle full of water?"

Rudy nodded and asked, "Have you tasted this water?”

"I live here,” George said, “So, I'm fine with it.”

Rudy explained, “The day I interviewed I almost didn't accept this job because the water tasted so bad and no one warned me.” All the students laughed as he continued, "I thought I was gonna drive back to college pregnant or something.”

“It's not even that bad,” George said defensively.

Kayla added, “The elementary school and the Chemistry room water doesn't taste that bad.” 
“I would rather lick a skunk than drink the water,” Rudy persisted.

All of the students were discussing how good or bad the water tasted by this time so Rudy tried to redirect the class saying, "Back to the warm up. Back to the warm up."

Rylee showed Sahara her calculator and asked, "Is this what you got?”

Rudy addressed the class, “How many equations are you going to set up before finding the product of how and why?” Two different students answered, “Two,” uncertainly. Rudy requested, "Raise your hand if you have an answer.” Based on the low response he said, “Keep working on it. I'll give you another minute or so.”

Several students were chatting with each other about the problem. Kayla said, "I feel like it's so simple, like you just set this, right?”

Amber asked Kayla, "What do you have?” The two girls discussed their solutions but most of the discussion could not be understood on the recording. Rudy checked several students' papers.

Rudy addressed the class,

There are a few ways you can go about doing this. You can use ratios or proportions, setting up equations, whichever you do you want to use the verbal statement and convert it into some kind of mathematical statement. If one fourth is represents what? Is represents what? Addition?

“Multiplication,” Jake responded.

Rudy wrote an equal sign on the board as he said, "One twelfth of is?”

“Multiplication,” Brynn said.

“Multiplication,” Rudy agreed, “How are we gonna solve for how?”

Mike asked, "Why would you solve for why?” The class laughed.

Rudy continued, “Multiply both sides by?” Without an audible response Rudy said, "You could divide by one twelfth. I don't really want to divide by fractions, you'd 
rather multiply by the?

Rylee said, “Reciproval.”

Rudy corrected, “Reciprocal. Or 12 . What's one fourth of 12 ? Or 12 divided by 4?” Rudy wrote three on the board before he said, "How about our second equation?” Rudy facilitated a similar discussion to complete the second equation, then said, “That was fun wasn't it? Alright, let's get to our notes. Fun time is over now.” Compared to fourth hour, the students in fifth hour appeared more engaged. Rudy let the conversation stray at times, for example the discussion about the water, which seemed to promote a relaxed learning environment for fifth hour.

Notes. Rudy started writing on the board as he said,

This unit is kind of unique. We're only going over a couple of sections. You're not going to have a test over this it's going to be more like a quiz or a quest. Going on a quest. Ben, you like quests don't you? Have you seen the new star wars movie?

Ben nodded and Rudy asked, "How many times?"

“Once, opening night,” Ben said.

Travis held up his hand showing five. Rudy asked, “Five times?” Travis nodded and George joked with him about how much he must have paid to see the movie five times.

Rudy returned to the lesson,

What's a root or a zero? Assuming you haven't done any math over Christmas break, think about first semester, quadratics. Ask yourself the question, say you're given a lineup of a bunch of equations. Are you able to determine yep this one's a quadratic, nope that one's not, this one yep, that one's not, these two are quadratic. How can you identify if an equation's a quadratic?

Without a response, Rudy asked, "What sticks out? Would this be a quadratic?”

He wrote $\frac{(3 x+y)}{4}=10$ on the board and received no response. He continued writing 
equations on the board $\left(10 x+4 y=0 ; 8^{x}+3=4 y ; 10 x^{2}=10 y ; x^{2}-10 x+3=y\right)$ as he asked, "That one? This one? That one? Would this be a quadratic?”

By the second or third equation in the list the students started to talk to each other about what they thought was a quadratic. After nobody seemed willing to share with the class, Rudy crossed out the first three and boxed the exponents on the last two equations. He said, "Looking for exponents. With quadratics think about all the things we've done with them... What's the graph of it called?”

Kayla said, "Parabola.”

"Parabola,” Rudy agreed, "What does it look like?”

Kayla motioned in the shape of a parabola. Rudy said, “An arc, opening up or down. Think about its key components or what did we look for when we break it down? What's the very max and very min called?” Ian said, "Vertex."

“Okay, the vertex," confirmed Rudy, "Say we are to solve.” He wrote $x^{2}+3 x-$ $4=y$ on board and said, "Solve for $x$." When he was greeted with silence, he wrote $x^{2}+$ $3 x-4=0$ instead and said, "Now solve for $x$. What's the difference? Instead of $y$ I replaced it with zero. Any light bulbs? Solving for $x$, how can you solve for $x . ”$

It dawned on Mike, “Oh, completing the square, rooting both sides, graphing, factoring."

"You got this," George encouraged.

"I got four of them," said Mike.

Travis asked, “Did you say quadratic equation?”

“That's what I was missing,” said Mike. 
Rudy continued, “Quadratic formula. Five different ways. What are you finding when you solve for $x$ ? And what do those numbers mean?

Rylee said, “ $x$-intercepts.”

“They are the $x$-intercepts,” Rudy agreed, "it's where it crosses the $x$-axis.” Rudy wrote the factored form on the board before he said, "So the zero product property, negative 4 and positive 1 . These numbers are where that what crosses the $x$-axis?”

“Parabola,” Mike answered.

Rudy did not hear him and asked, "One more time.”

“Parabola,” Mike said again.

“That could be an Arnold phrase too. The parabola,” Rudy said imitating the accent of Arnold Schwarzenegger. "Did you guys see the commercials over break, there was a lot of them. The one where he's like controlling things.” The students murmured their acknowledgement as Rudy continued, “Don't forget, these are coordinates. Your $y$ value is what?"

“Zero,” some students responded.

Rudy confirmed, “Zero. Why? Well you substituted zero in for $y$. Negative 4 comma 1." Rudy wrote $(-4,0)$ and $(1,0)$ on the board. "Can a quadratic have just one solution? Meaning it crosses the $x$-axis once?”

Ian said, "Yes."

“How so?” asked Rudy.

"Meaning the vertex is the $x$-intercept," Ian replied.

Rudy said, "If the vertex is on the $x$-axis. How about no solution?”

“If it doesn't cross the $x$-axis,” Ian continued. 
"If it doesn't cross the $x$-axis at all," Rudy confirmed. He wrote the following statement on the board as he said it, "The largest degree in the equation represents the number of total roots or zeroes.” Rudy wrote the examples $x^{2}+6 x+9=0$ and $3 x^{5}-5 x^{2}=8$ on the board. He only wrote two of the three examples he had used with fourth hour. When he was done copying the examples he said, "So, we're not gonna spend a whole lot of time on this section. So, the largest degree, that's going to give you the total number of zeroes. With number 1, what's the largest degree.”

Multiple students said, “Two.”

“Two,” Rudy agreed, “The largest exponent. That means the total number of zeros is two. We'll come back to number 1 . How about number 2?”

“Twelve?” Jake offered.

"You're gonna wanna make sure it's in standard form first,” Rudy said, "What's standard form mean? It's equal to 0 ? Exponents descending order. Is it equal to 0 ? No, it's equal to 8 . Subtract 8 over. Largest degree is?”

"Five," Rylee filled in.

Rudy agreed,

Five. That means the total number of zeroes is going to be five. So, coming back to number 1 . And you guys are going to go more in depth with this when you get to Algebra 2, but I want to point something out. The total number of zeros, meaning how many times will it cross the $x$-axis. The number of roots, zeros, it's where the parabola crosses the $x$-axis. So how many answers should there be? There should be two. Well, let's factor.

Rudy asked for student input, then wrote out the factored form on the board. "So, when we use the zero product property. Well, that's just one answer, meaning the vertex is at negative 3 comma 0 , right? So how can there be two total zeros?” 
George made a comment that could not be understood on the recording and Rudy replied, “I have you thinking now, George. I know that's your thinking face.” Rudy opened a blank page on the interactive whiteboard, wrote the title of the next section and said,

Complex and imaginary numbers. This is fun. Imaginary numbers, they're fake. Now, I'm not leaving you on a cliff hanger here. We'll come back to why or how that makes sense, the previous problem. Complex and imaginary numbers with expressions: this is what we are going to be going over in the next couple days. First we're gonna go over expressions, simplifying, reducing. Then, we'll get to equations and it'll probably be, it won't be till tomorrow. So, I lied to you, I am leaving you on a cliff hanger cause you're not gonna figure out until tomorrow. First, imaginary numbers.

Rudy wrote $i=\sqrt{-1}$ and $i^{2}=-1$ on the board and drew a rectangle around it when he said, "You're gonna want to put a box around this. These two are gonna guide you to solving and simplifying all the other problems. These two ideas will solve all your problems. It's like the Dalai Lama.”

"Where have I heard that? History?” asked Sahara.

Rudy joked, “The Dalai Lama? It's a Llama, and her name is Dolly.”

“That's not it," Sahara quipped.

“Do you know what a llama is?” asked Rudy.

"Yeah, that's not it," she insisted.

"It's like the Pope of Buddhism,” Amber explained.

“Oh, okay right,” said Sahara.

George's influence on fifth hour. Some of the differences in fourth hour and fifth hour may have been influence by George. George often asked questions to gain a deeper understanding of the mathematical material. Rudy wrote the next three examples 
on the board $(\sqrt{-10} ; \sqrt{-28} ; 3 \sqrt{-12})$. He said, "Yes we're gonna incorporate square roots. That's a good thing because we ended with square roots last semester. Now, what's wrong with these examples to start with?

“Negative,” Jake suggested.

Rudy clarified, “There's a negative inside the square root. What did mama say about negative exponents?”

“They're the devil,” Matt recalled.

“They're the devil, right?” said Rudy, “Well, guess what mama thinks about negatives under the roots? They're the devil also. Everything's the devil with mama. When you get a negative underneath the root, you have to take your i's out.” Rudy made a motion like he was plucking his eyes out. A few students chuckled. Rudy completed the first example by writing the simplified version $(i \sqrt{10})$.

Rudy explained the concept of an imaginary number more extensively in this class than with fourth hour. However, in the following dialogue it is also apparent that Rudy avoids a deep exploration of imaginary numbers. Rudy said,

Now, going back to what's in this box. Maybe you've already seen them. You're obviously going to be seeing them here in the future. Lower case italicized $i$, that's in math, not in english, that is an imaginary number. You're gonna do a lot more with them once you do get to Algebra Two. We're just going over the basics. Real numbers. What's a real number? Versus an imaginary number. George, give me an example of a real number.

“One,” George offered.

Rudy asked, "What's another example?”

“Two,” said Kayla.

“Jake, you better not say three,” Rudy warned. 
“Four,” said Jake. Then, he added, “negative.”

“What about Pi?” asked Rudy.

Mike chimed in, "I was going to say Pi."

“Is Pi a real number?” Rudy continued.

"I was going to say the first eighty some digits of Pi, but," Mike said.

Rudy asked, "Is the letter $e$ a real number?”

"Pi is a real number. I don't think $e$ is,” Mike claimed.

Rudy explained,

All the numbers that you guys have gone over or that you can think of, they're all real numbers. They have value, whether it's a fraction or a decimal. Imaginary numbers, again you're gonna get more involved with this next year, they're not real numbers. George, I know what you're thinking. It's hard to go further in depth without taking other class periods to explain what it actually is. That's for next year, and for another teacher to explain. I'm just kidding, I like it when you ask those questions. Alright, so, really all you need to know. The square root of negative one that's equal to $i$; $i$ squared is equal to a negative one. So, when you get a square root that has a negative number in it, the square root of negative 10, the first step, you gotta take your eyes out. You gotta get rid of the negative by taking an imaginary number out, it creates that to be positive. Now, back to the end of first semester. Can you break the square root of 10 down?

Ian said, "No."

"Why not?” Rudy asked.

"Because there are no other perfect squares that go into 10,” Ian explained.

Rudy continued by doing the next two examples on the board. He asked questions as he completed the simplifications but only gave students limited opportunities to answer out loud. When he was finished, Rudy opened a blank page on the interactive whiteboard and began writing a new heading and two examples $(i+6 i ; 4 \sqrt{-3}-\sqrt{-75})$. Rudy walked the students through the procedural process of simplifying the first of these 
expressions by making an analogy to combining like terms with the variable $x$. Then he had a student describe the process of simplifying the second expression. When he finished both examples he asked, "Does it make sense? Surprisingly, whether you want to admit it or not, I can tell by looking at your faces it does make sense.”

This excerpt illustrates Rudy's different participation with fifth hour than with fourth hour. He expanded on the topic of complex numbers by contrasting imaginary numbers with real numbers. However, he did not let the discussion continue. Instead, he returned to the procedural goal of simplifying expressions.

Greater content coverage in fifth hour. Rudy said, "Last three examples," as he wrote them on the board $\left((6 i)^{2} ; 2 i(4+7 i) ;(2-5 i)(3+\sqrt{-16})\right)$. These three examples were not covered in fourth hour. When he was finished Rudy passed out two worksheets that would be homework and he asked the students to complete the first example. Mike raised his hand and Rudy asked, "Do you have a question?”

“No, I have the answer," he replied.

Rudy finished passing out the worksheets and said, "Alright Mike, what is your [answer]."

"I have two answers actually, but I'm not sure,” Mike said.

"You have two answers?” Rudy said, surprised.

"I think it's negative 6 but if it's not that, it's negative 36."

“You're letting George get into your head?” Rudy asked.

Rudy started writing steps on the board as he said, "So, easy way, rewrite it twice. Six $i$ times $6 i$ that's what it means to be squared. So we have $6 i$ times $6 i$. Six times 6 , 36; $i$ times $i$, $i$ squared." Rudy flipped back two pages on the interactive whiteboard to the 
definitions he had drawn a box around earlier in the lesson and pointed to $i^{2}$. "Ben, what does $i$ squared equal?”

“One,” said Ben, “negative 1, sorry.”

Rudy agreed, " $i$ squared is equal to negative 1 so we have 36 times negative 1. Mike, the answer?”

“Negative 36,” Mike said, “I told you it wasn't 36, George.”

“That's still wrong,” George reminded him.

“That was my second answer though, so why are you making a big deal of it?” asked Mike.

“Oh, you two,” said Rudy. "Number 2. What do we want to do to the 2i?”

“Distribute,” suggested Amber.

“Distribute it,” Rudy agreed, “This gives you $8 i$ plus $14 i$ squared. Ben, what's $i$ squared?”

“Negative 1,” said Ben.

Rudy continued,

So, $8 i$ plus 14 times a negative 1 . Eight $i$ minus 14 . So this is when, we're going back to this, $a$ plus $b$ times $i$. Again, you're going to be using this concept in Algebra 2 with vectors and so forth. You want the number followed by the $i$. So right here, your answer, you need to switch them around. Your answer is negative 14 plus 8 times $i$.

Rudy paused and then asked, “Anyone feeling confident with 3? Yeah?” Nobody responded so Rudy asked, “Distribute first?” Again, he received no response, but several students appeared to be working on the example individually. "Your first step should be what? What should your first step be? Take the $i$ out.” Rudy wrote the step on the board. “And when you take the $i$ out, the square root of 16 is?” 
Sahara said, "Four."

Rudy continued,

Four, so the square root of negative 16 is $4 i$. Hey, if you can get rid of the roots, do so. It makes everything else a lot easier. You don't want to start multiplying, distributing and so forth with a negative number in the root still. We've done a bunch of these problems. Two times 3 is 6, 2 times $4 i$, plus $8 i$. Negative times a positive is a negative 15i. Negative. Four times 5 is 20 . $i$ times $i$ is $i$ squared. Can you combine any terms? The two middle terms that are i's 6 minus $7 i$ minus 20 times what, Ben?

“Negative 1,” Ben replied.

“Negative 1,” Rudy continued, “Negative 20 times negative 1 is? Positive 20. Six minus $7 i$ plus 20. Last step?”

“Combine like terms,” suggested Jake.

Rudy confirmed, "Combine like terms. You want the $i$ first or the number first?” “Number,” added Mike.

"Number first,” Rudy agreed, “Twenty six minus,” Rudy finished writing the final result $(26-7 i)$ and asked, “Questions?” No one asked a question.

Homework. Rudy continued, "Feel like you want to do some math problems now?” A few students made comments about going to lunch. As Rudy began writing the homework under the homework he had written on the board for fourth hour, he said, "You guys look eager to, maybe it's eager to go to lunch. Homework. The two worksheets, starting with imaginary. So the imaginary numbers 1 through 12 and then number 27 starred. Complex numbers 1 through 13 and 15. Number 14 is starred.” I learned later that "starred," meant the problem was extra credit. The students started gathering their things and in about 30 seconds the bell rang and the students left for lunch. 


\section{The Second Lesson}

The second day of formal observations at Valley View was Wednesday, January $6^{\text {th }}$. Wednesdays and Thursdays at Valley View were block schedule days. On Mondays, Tuesdays, and Fridays the students attended all eight of their classes in 45-minute sessions. On Wednesdays the students attended their first, third, fifth, and seventh hour classes in 90-minute sessions. On Thursdays the students attended their second, fourth, sixth, and eighth hour classes in 90-minute sessions. Thus, when I observed on Wednesday I saw fifth hour and I did not see fourth hour again until Thursday. However, I will describe both of these observations as the second lesson because they covered approximately the same content.

The descriptions of these observations illustrate some different ways Rudy provided students feedback on homework. Rudy approached homework feedback differently in each class hour and in multiple ways in fifth hour. They also continue to illustrate Rudy's use of notes as a primary class activity. In the note taking activity described in these classes, Rudy demonstrated how he mixed whole class interactions with interactions with individual students through the use of questioning. These lessons also illustrate Rudy's authority in the classroom, and his use of humor to lighten the authoritative nature of his interactions.

\section{Fifth Hour}

On Wednesday I watched the fifth-hour students walk into class as Rudy worked at his desk. The students chatted about their extra-curricular activities and other classes as they waited for class to start. About a minute after the bell rang for class to start, Rudy took attendance and turned on the projector for the interactive whiteboard. He asked the 
students to take out a worksheet they had completed before the winter break. The worksheet was a list of what Rudy called, "numbers with word riddles.” For example, the worksheet said $13=\mathrm{S}$ on the A F and the students were supposed to answer 13 stripes on the American flag. Rudy said he forgot to go over the worksheet the previous day and took the next several minutes to share the answer to each riddle on the worksheet. When he finished, the students chatted about which items they answered correctly while they waited for Rudy to begin the next part of the lesson.

One form of homework feedback. Rudy switched the projection to one of the worksheets he had given as homework the previous day and said, "I want to go over the homework.” He explained his plan for the day saying,

We have a couple of things that we're gonna do in terms of notes, then I want to get you all on the board. I wanna see some of your work, some of your answers. ... Let's go around the room. Number one. Megan, why don't you start us off.

The students appeared to know what he meant when he said, "Let's go around the room.”

After clarifying she was on the correct worksheet, Megan gave her answer for the first exercise on the homework, "I got $i$ square root of 49."

“Okay, and the square root of 49,” Rudy asked.

“Oh, my god," Megan exclaimed, "Seven.” Rudy wrote the answer on the board by the first exercise, and continued to write the answers students provided.

Rudy continued, “Two, Jess?”

"I got i square root of 10,” Jess offered.

“Three,” Rudy said.

"I got negative 36," said Veronica. 
"Four," said Rudy.

Olivia replied, “i square root 7.”

These students sat in the first row on the right side of the classroom and as Rudy continued, students in the next row shared their answers. It was clear they had done this before because each student knew when he or she was expected to give the answer. It was also implied that when Rudy did not correct the student, the answer he or she provided was correct. These aspects of Rudy's participation illustrate his role as the classroom authority for mathematical correctness as well as logistical direction.

"Five,” said Rudy.

“Six i root 31,” Replied Gabby

“Number 6," he continued.

Brynn said, "I got 35i squared, which would be negative 35."

Rudy nodded to Sahara and she said, "Well, this was the one that I didn't understand. Okay. I have this one, I have 7, 8, 11, and 12 circled. I still did them, but I just really don't want to say my outcome.”

“Which ones are you uncertain about?” Rudy asked.

She repeated, "7, 8, 11, and 12.”

“What did you get for 9?” Rudy asked.

"Um, negative 36," she said.

Rudy continued, "Rylee, seven, eight, or eleven?”

“I'll do 10,” Rylee offered, "negative 9i.”

Rudy wrote her answer on the board but starred the question. The class laughed. As this process continued it became apparent that the star indicated they would come 
back to the exercise later in the class, which generally meant the answer provided was incorrect.

Rudy addressed the first student in the next row, "Seven, eight, or eleven?” "I had root 7 times $i$ root 14,” Hudson said.

Rudy continued with the next two students for numbers eight and 11 . Then, he asked if anyone had answered number 12 and two students gave the same answer. He wrote, "7, 8, 10,11, 12," on the chalkboard and said, "We will come back to those five." He had the students switch to the other worksheet and continued the process where he had left off, asking, Kayla, the next student for the answer. She provided the correct answer, but the next student, Ben, did not. His exercise was $(4-7 i)-(5-3 i)$. Rudy explained, "So with these, I'm guessing the confusion probably is, um distributing. These aren't the same as, say, these down below here where the two binomials are mutliplying each other. Addition, subtraction. Now, what's gonna happen with this negative sign?” The response was inaudible, but Rudy said, "Yep, so you're gonna have 4 minus 7i minus 5 plus 3i.”

“Oh!” Jake exclaimed.

Rudy continued,

Then, you're gonna combine like terms. Answer is a negative 1 minus $4 i$. Number three is almost the same. What are you gonna do with the 2 and the negative 5 ? Distribute through and then combine. 16 plus 12i. Number four. I think this was an example in class wasn't it? Alright, number five, George.

Rudy continued the process through the rest of the worksheet, skipping the starred, extra-credit exercises and returning to the first student when everyone had answered a question. When they finished all of the exercises that had been assigned for homework the students began chatting about how well they performed and Rudy wrote, 
" $6,10,11,13,14,15$ " on the chalkboard below the numbers he had written from the first worksheet. Rudy rewrote most of these numbers spaced out on the chalkboards that covered three walls of his room and one on the interactive whiteboard.

Another form of homework feedback. When Rudy finished, he looked at Ian and said, “Pick one, who’s your partner?” Ian knew what was happening because he chose his partner immediately and looked back and forth between his paper and the numbers on the board to choose an exercise. Rudy instructed the class, "Please write the original problem down, and then your work.” Ian was still choosing an exercise, but Rudy asked, “Travis, who's your partner?” Rudy continued to ask the students on the left side of the room to choose their partners and to go stand by their exercise on the board. Each boy chose one of the girls for a partner and the pair went to the board and wrote their process for simplifying the exercise they chose. Sahara was left without a partner because one of the boys was absent. She worked on the only exercise that remained on the board, but Rudy told her she did not have to finish the exercise because, ironically, it was one of the exercises for which she had not wanted to share her answer earlier in class. As students finished writing their work on the board they returned to their seats. Rudy seemed to be checking some of the work on the board as students were finishing.

Rudy acting as authority with humor. When everyone finished Rudy started going over the exercises. He provided a brief explanation for each exercise as he pointed to the steps the students had written on the board. When the steps were incorrect, he erased what the students had written and wrote in the correct process. He did not ask students to contribute during this process with two exceptions. Almost every time he saw $i^{2}$ on the board he asked Ben, or simply looked at Ben, who said, "Negative 1." He also 
asked the class about perfect squares when he was simplifying the square root in one exercise.

After Rudy explained each exercise he asked, “Anyone have an answer for number 14?” Kayla and Mike raised their hands. He erased some of the other problems, then asked, “Kayla, what did you get for an answer?”

"Negative 223," she replied.

“Who else had? Mike, you said you had an answer?” Rudy asked.

Mike said, "Yeah but I'm pretty sure I am wrong."

“What'd you get?” Rudy persisted.

“Negative 191 plus 256i,” Mike said.

“I have 290,” said Olivia.

Rudy started the exercise, which was $(1+4 i)^{2}(1-4 i)^{2}$, by writing four sets of parentheses on the board and asking, "What's gonna go in here?” Mike and Kayla told Rudy what to write in the parentheses. Rudy worked through the distribution and simplification without further student input. When all the steps were complete, the answer was 289 .

Sahara exclaimed, "I got it! I was thinking I screwed up or something because 289 is really close to $290 . ”$

Rudy joked with Sahara, "So, it looks like there were no correct answers. It looks like no one got it right.” Smiling, Sahara persisted that she had gotten the answer correct and Rudy continued to act oblivious.

Kayla asked, "What if you had something that would be like, I don't know like 90i to the fourth power, if it wasn't $i$ to the second?” 
“Ninety $i$ to the fourth power?” Rudy confirmed. "Using the properties of exponents here you can break it down. You want to relate back to the $i$ squared so you can,” Rudy's voice trailed off. He wrote on the board as he said, “ $i$ squared times $i$ squared. You're gonna add the exponents, that's the same thing there.” He was pointing to $i^{2} \cdot i^{2}$ and $i^{4}$. "So, negative 1 times negative 1 which would be positive 1 . So 90 times 1 . Now if it's like i to the 10 th power." He wrote $i^{2} \cdot i^{2} \cdot i^{2} \cdot i^{2} \cdot i^{2}$ then said, "Negative 1 , negative 1 , negative 1 , negative 1 , negative 1 , which positive, positive, so that would be negative. Questions?” When nobody asked any questions Rudy said, “Back to this guy here,” referring to number 14 . He explained, “To make it a little easier you could rearrange it and multiply these two first then multiply these two," pointing to the conjugate pairs. He said, "You'd get the middle two terms to cancel out... So when the signs... are opposite they will cancel out. Just like our conjugates.” Jake frowned when Rudy said conjugates and the class laughed. Rudy replied, "You need to turn that frown upside down.”

Notes. Transitioning to the next part of class, Rudy said, “Alright, let's get our notes out. Students chatted as they got their notes out, opening their five-subject notebooks.

Mixing whole class and individual interactions through questioning. Rudy

opened a blank page on the interactive whiteboard and wrote rationalizing the denominator. He said, “Ian?”

In an Arnold Schwarzenegger accent, Ian said, "Rationalizing the denominator." “Were you practicing over break,” Rudy asked. “Ah, not really,” Ian replied. 
Rudy continued, “Alright, rationalizing the denominator. What does that consist of? What are we doing when we rationalize the denominator? Don't be scared, you can say it in a normal voice.” Amber raised her hand and Rudy nodded to her.

"When there's a root on the bottom," she said.

Rudy expanded on her answer, "When you simplify and reduce and there's still a root in the denominator. Getting that root out of the denominator, you're rationalizing it. Just how, or just like you can't have roots in the denominator, you don't want your answers to be represented using an $i$ in the denominator. The process of getting that $i$ out of the denominator, it's almost exactly the same as what we would do with the roots."

Rudy wrote two examples $\left(\frac{4}{5 i}\right.$ and $\left.\frac{10}{\sqrt{-5}}\right)$ on the board. He said, "Number one can't be reduced any further. Let me ask you guys, how, or what, what are we going to have to multiply by? How can we get rid of this $i$ in the denominator?” Amber, Ian, and Mike raised their hands. Rudy called on Ian.

Ian said, "You multiply the numerator and the denominator by negative $5 i$.

“No,” Rudy replied, “mmm, you could. It's gonna make a little more work for yourself.” He nodded to Mike.

"You just need $i, ”$ Mike said.

As Rudy started writing the process on the board he said, "All you have to do is multiply it by $i$. How is that going to get rid of the $i$ in the denominator? Ben?”

"It will be $i$ squared and then it's negative one,” Ben explained.

Rudy demonstrated the process of simplification and also discussed the equivalence the negative fractions $\frac{-4 i}{5},-\frac{4 i}{5}$, and $\frac{4 i}{-5}$. He clarified these are not equivalent 
to $\frac{-4 i}{-5}$. Then he continued to the next example saying, "Number two, well, there's no $i$ in the denominator. What do we do, just not do it?” Several students said yes, but Rudy said, "You should be disagreeing with that," and called on Ian.

"You need to take out the $i$ for square root of negative five.” Rudy demonstrated this and then explained the process of rationalizing the denominator for this example. He reminded the students to simplify the real number parts of the fraction at the end of the process. Only two students participated in this process because Rudy answered most of his own questions. As Rudy was completing the example, Travis, Mike, and George were having an intense discussion about how to simplify it. When Rudy was finished, Mike asked why he had not performed the simplification like in the first example. Rudy explained that would have only been partially simplified.

Mike said, “Okay, Okay, I didn't think of that. Okay, never mind. You could have said that from the beginning George.”

"I did,” George retorted and several others supported his claim. George asked Rudy about another way to simplify but Rudy explained that he did not want George and the other students getting into bad habits that would make it harder for them in their next mathematics class.

Rudy opened a new page on his interactive whiteboard and began writing as he said, “Last part with our expressions. Conjugates using $i$.” Rudy pointed to the $a+b i$ he had written on the board and continued, "and again not gonna be used for this year but next year you'll be using it. So I want you to get in the habit.” He wrote two examples on the board $\left(\frac{5}{2-5 i}\right.$ and $\left.\frac{9}{-3+\sqrt{-4}}\right)$. Then, he said, 
Really the same rules, the same problems you run into with conjugates using $i$ is the same exact thing as if you're dealing with roots. Can you rationalize the denominator when you multiply the top and bottom by $i$ ? No, because, yeah you're gonna get rid of this $i$ here, but you're gonna have $2 i$ still in the denominator. What would the conjugate be for number one? Jake what's the conjugate.

The bell rang for the students to take a lunch break, but Rudy said, "When Jake tells, stop, everyone, shh.” Everyone waited impatiently to go to lunch. "If you open your mouth you're getting nun-chucked,” Rudy said jokingly, "What's the conjugate gonna be? Conjugates gonna be a binomial, so you know there's two numbers.”

“Two plus 5i?” Jake said softly. Rudy put his hand to his ear as if he could not hear Jake. “Two plus 5i.”

Rudy strained his neck closer with his hand still to his ear and said, “I can't hear you.”

Jake seemed hesitant at this point, but the class encouraged him to say his answer louder so he tried one more time, “Two plus 5i.” Rudy nodded and motioned for everyone to leave class. The students hurried out the door, heading for lunch. They had no need to take their belongings because they would be back to finish the hour after they ate lunch.

When the students came back into class they carried over their conversations from lunch as they waited for class to start. After a few minutes, Rudy said, "Let's finish up our notes. What is the conjugate, Jake?”

“Two plus 5i,” he replied.

Rudy continued, “So, once we determine what our conjugate is, we're gonna multiply the top and bottom by 2 plus $5 i$. For those that forget what the conjugate is or how we determine what it is, Jake, enlighten us. How did you come to your answer?” 
“It's a binomial,” he said.

The class laughed and Rudy asked, "Similarities? differences? How did you get it?"

“Changed the sign,” Jake added.

"Yeah,” Rudy said, “everything is the same except?”

“The sign,” Jake completed Rudy’s sentence.

Rudy completed his own sentence, “The middle operation. Distribute, 10 plus $25 i$. What should happen to the two middle terms?”

“They should cancel out,” recalled Brynn.

Rudy continued to simplify the example completely before he answered a brief question and said, "See if you can do number two," after a short time he added, "Raise your hand if you think you got it.”

George raised his hand almost immediately and Rudy stood by George to look at his work. Rudy stuck out his hand and George gave his pencil to Rudy. Rudy erased something. George took his pencil back and started writing. Rudy pointed to something he was writing and George erased, but then kept writing. Rudy returned to the front of the room until Mike raised his hand. Rudy looked at Mike's answer but made no comment before switching back to looking at George's work. Rudy picked up the pencil and erased something, then George continued. Matt showed Mike his answer. Rudy went to the board and started drawing in lines, parentheses, and equal signs for each step. He had a template of signs and symbols on the board with blanks for number and letter when he finished. Rudy called on several students as he simplified the example. At the end he said, "Raise your hand if you got this correct. Pat yourselves on the back. Last one, and 
then I'll have you spend a little time on your homework.” Before he started the next example, Mike explained that he thought the answer was incorrect. Rudy spent several minutes discussing the result with Mike and George and the rest of the class became distracted in unrelated conversations. Mike was confused about the equivalent forms of negative fractions Rudy had discussed earlier in the class, but Rudy helped him work through his misunderstanding. Although Rudy intended to interact with the entire class throughout this episode, it demonstrates his use of individual interactions to engage the whole class. He questioned individuals and answered questions while attempting to maintain the attention of the whole class.

Combining authoritative action with motivating humor. Rudy searched for something in his desk drawer. When he found what he was looking for he wrote the final example on the board $\left(\frac{10-\sqrt{-100}}{-\sqrt{-24}}\right)$. Then, he said, “Alright, if someone gets this correct, or the first person to get it correct, you will get a thing of Blistex.” The class laughed as he held the Blistex he had found in his desk up for them to see.

“That's the medicated stuff too," George observed.

“It is not even opened, still sealed,” Rudy said.

"He did a good job of resealing it,” Sahara joked.

George asked, "But why do I want that?"

Rudy listed off the features saying, "Medicated lip balm. Lip protection, sunscreen, SPF 15.”

"Why don't you have the orange mango blast Blistex?” George asked, "So much better." Rudy pointed to the problem on the board, indicating everyone should start. “Just try it, who cares," said Rylee. 
Sahara claimed, "I'm doing it for my brain, not for the Blistex."

Someone asked, “Do you have a better prize?”

Rudy looked through his desk drawer again and eventually held up a bell in front of the class.

“Okay I'll do it for the bell,” someone conceded.

The students became quiet as they competed for the bell and Blistex. Rudy said, “Things just got real. Blistex or a bell.” After a minute Rudy said, "If you want to work with a partner that's fine.” Two students asked to work with George, but Jake told Matt he was already working with George. Rudy clarified, "You and your partner would have to share the Blistex.”

Most students were chatting as they worked with a partner. Mike was the first to offer an answer but he was incorrect. Rudy told the class they could have two chances. Mike was also the second to offer another answer before Kayla made her first attempt. Ian raised his hand. Rudy checked his paper and held out the bell and Blistex. Ian chose the bell. Rudy went to the board and completed the example, getting several students to participate in the process.

When he finished the example Rudy assigned homework. The bell rang, and the students left the class. In this last episode, Rudy was in control, directing the lesson. He used humor to motivate and encourage his students to follow his direction.

\section{Fourth Hour}

The next day, Thursday, I returned to Valley View to observe the fourth hour class. The students chatted as they waited for class to start. Some of them were discussing the homework assignment, but most of the conversations were socially related. Rudy 
worked at his desk through the bell, but soon he said, "Let's take a seat.” He took attendance, asking about a couple of students who were absent. Then, he asked students to move forward if there were empty seats in front of them. The students continued to chat as they moved around and Rudy prepared the interactive whiteboard for class.

Different homework feedback for fourth hour. The initial feedback Rudy provided for the students in fourth hour was similar to the feedback provided for the students in fifth hour. However, he did not provide answers for all of the homework assignment because he had covered less content in the previous class period with fourth hour than with fifth hour. He also did not have students demonstrate their work at the board in fourth hour.

When Rudy said, “Okay, homework,” the students stopped talking and he laid out the plan for the day, "We're gonna go over some of these homework questions. Then, we're gonna finish up complex, imaginary numbers in terms of expressions: taking your i's out, getting rid of the negative underneath the square roots. This is the imaginary numbers one.” Rudy pointed to the worksheet he had showing on the board. "You had 1 through 11, 12 was an extra credit one. Kyle, what did you get for 1 ?

“I got 7i," Kyle replied.

Rudy explained, "You take your $i$ out. You get $i$ square root of 49. Square root of 49 is?”

Several students said, "Seven

“Seven so 7i,” Rudy confirmed as he wrote the answer on the board, "Two was an in class example. Take your $i$ out. You cannot reduce. Square root of 10.” Again, Rudy wrote the answer on the board. "Three, Reese what'd you get for 3? 
“Negative 36i,” he replied.

"Reese, got negative 36i,” Rudy said, "Raise your hand if you concur with Reese. Raise your hand if you do not concur." Several students raised their hand to concur, but Cory seemed to be half raising his hand and asking Reese something. Rudy said, "Let's try this again. Raise your hand if you agree.” Cory laughed and most of the class raised their hands. Rudy continued, "Raise your hand if you do not agree.” Cory and a couple other students raised their hands. "What'd you get?” Rudy asked Melissa.

“I have like $1 i$ but I don't know how,” she said.

Rudy said, “Okay, first step take that $i$ out. Negative $3 i$ square root of 144 . The square root of 144 is gonna be?”

“Twelve,” Brady said.

“Twelve,” Rudy confirmed, “So negative $3 i$ times 12. Even though this one does not have an $i$ you can still multiply the numbers together. Negative 36i.” Rudy continued by working through the steps of exercise four, which he had done as an example in class, and five, to which a student gave the incorrect answer. Then, he said, "We'll come back to the other ones, the multiplying ones.” On Tuesday Rudy had mentioned early in class that $i^{2}=-1$ and then reminded the students of this relationship as the bell was ringing. Since he had not done any examples involving this equivalence, he completed examples later in the class hour and then ask the students to redo some of the homework exercises that had involved multiplication and $i^{2}$. Rudy opened the other worksheet on interactive whiteboard and said, "Complex numbers," to indicate he wanted the students to get out the other worksheet. Before asking for the answer to the first exercise he wrote it on the board $(7+3 i)+(2-5 i)$. He also wrote $(7+3 i)(2-5 i)$ and asked, "What's the 
difference between these two? Dalton?"

“One way you multiply, one way you add,” Dalton replied.

Rudy confirmed, “One's multiplication, one's addition. Everything else is the same. What do you do with this bottom one," referring to the multiplication version.

"Distribute," said Dalton. Rudy confirmed his reply and then worked the first exercise step-by-step before asking for the answer to the second exercise $(4-7 i)-$ $(5-3 i)$. He worked with a couple of students (not the next student in the row) to determine the correct result for this exercise and explaining that, "Everything in this parenthese is going to be multiplied by a negative.” When he moved on to the next exercise he returned to the row where he had left off. He worked with Devin to complete the third exercise because Devin's answer was incorrect. Rudy explained,

We'll do the rest here in a little bit. Your homework is gonna be a little different than what's up there. You're in a different spot than the other classes. It's still gonna be using these two worksheets. Are there any questions with the ones we went over, not the ones we didn't go over. I assume you probably have some questions over those. Alright, let's get our notes out.

This homework feedback process indicates a few differences between fourth and fifth hour feedback. Rudy did not have students demonstrate their work on the board in fourth hour. Most of the exercises he had fifth hour write on the board were not covered when students shared their answers in fourth hour. Rudy had not covered some of the examples that would have prepared the students for those homework exercises, but he had assigned them as homework nonetheless. Instead of checking them, he decided to assign them as homework again. Since they did not check the exercises in fourth hour, Rudy did not have students write their procedures on the board. He also pointed out that fourth hour was behind the other class. 
Notes. The students took out their five-subject notebooks and Rudy started writing notes on the board. Fifth hour had completed this first section of notes on Tuesday, but fourth hour had not seen examples involving $i^{2}$. He explained, "We were kind of rushed for time yesterday, two days ago. We didn't like get to multiplying using $i$. We did, or I showed one quick example.” Rudy wrote three examples on the board $\left((6 i)^{2} ; 2 i(4+7 i) ;(2-5 i)(3+\sqrt{-16})\right)$. These were same examples he completed with fifth hour during the previous lesson.

Mixing whole class and individual interactions through questioning. Rudy said, “Number one, first step. Just because we have an $i$ and imaginary number involved doesn't change our first step.”

Dalton raised his hand. When Rudy nodded to him, Dalton said, "Would you need to write it $6 i$ times $6 i$ ?”

Rudy confirmed what Dalton said, then nodded to Kate, who had her hand raised. “I guess I put 36i squared,” she said.

“Six times 6, $i$ times $i$," Rudy said as he wrote on the board, "Kate, you're on a roll.”

She continued, “ $i$ squared doesn't that mean it's a negative? So you make it, it means negative $1 . ”$

"Back at the very beginning of the notes for the section,” Rudy directed, "i equals what?”

“The square root,” said Eli.

“The square root of?” Rudy probed.

“A negative number,” he said. 
"Negative one or a negative number,” Rudy continued, “i squared equals?”

"Negative one," Eli completed the statement.

Rudy confirmed, "Negative one. Whenever you have an i squared you need to substitute or replace it with negative one. Thirty-six times negative one is negative 36. Reese, number two. How would you start that?”

“Distribute,” Reese replied.

Rudy performed the distribution silently on the board and began to simplify. Then, he said, "What do we know about i squared?” Nobody answered at first, so he asked, “What does that equal?”

"Negative 1," Zane offered.

Rudy finished simplifying, warning the students to put their answer in the form of $a+b i$. He shifted away from whole class interaction. He said,

I'll give you a minute and a half to see if you can do three. You can work on 'em with a partner check your answers with a partner. Raise your hand when you have an answer. The only hint I'll give you, you do not want to distribute first.

Rudy walked between the rows on the right side of the classroom and looked over the students' work. He pointed to something on Cory's paper. When Kate raised her hand, Rudy went to look at her paper. Kale raised his hand. Rudy pointed to something on Kate's paper and she started to change it. Reese and Dalton raised their hands, and Rudy went to check Reese and then Dalton's answers. Reese seemed to think he had the correct answer when Rudy left. Rudy used Dalton's pencil and wrote something on Dalton's paper. Rudy checked Kale's paper and marked something. Cory raised his hand and Rudy looked at his paper but said nothing as he went by on his way to the board. Cory held his hands up as if he were confused about the lack of response. Similar to his interaction with 
fifth hour, Rudy used gestures, and wrote directly on students’ papers as he interacted with them individually. Rudy asked fewer questions of individuals than he did during whole-class interactions.

At the board Rudy addressed the class, "Well, if your first step isn't to distribute, what is it?”

“Take your i's out,” said Brady.

"Yep,” Rudy agreed, “Remember, mama says they're the devil.” Rudy continued to ask students for elements in each step as he simplified the third example. When he was finished, he joked about wanting to speak like an auctioneer before opening a blank page on his interactive whiteboard. He wrote Rationalizing the denominator using $i$. He asked, “Anybody work on their Schwarzenegger voice over break?” when nobody offered to demonstrate he suggested, “Kyle, let's hear what you got.” Kyle gave his attempt at an Arnold Schwarzenegger impression and Rudy nodded approval. He wrote two examples on the board $\left(\frac{4}{5 i}\right.$ and $\left.\frac{10}{\sqrt{-5}}\right)$ and asked, "What do we do when we rationalize the denominator, or what's the process behind it?”

"You multiply the top and the bottom by the same number," Allison said.

“What, why do you rationalize the denominator?” Rudy asked. Allison's answer was not audible on the recording. Rudy said,

Dealing with our square roots, we simplify it, we reduce, all that good stuff. If your final answer has a square root in the denominator, you don't want that. You want to rationalize it. How? You multiply the top and bottom by the square root of whatever that number is. Everything is the same except you're dealing with i's.

Pointing to the first example, he continued,

We cannot reduce anymore, but yet we have an $i$ in the denominator. Just like negative numbers in the roots, negative exponents, mama doesn't like them. 
Mama doesn't like a whole lot. She wants to get rid of it. How? Rationalizing. What do we need to multiply the top and bottom by in order to eliminate an $i$ in the denominator? What could we multiply by? How could we get rid of an $i$ ?

Eventually David raised his hand and Rudy called on him. “Negative five,” he said. Rudy hesitated and David revised his answer to, "Negative 5i."

Rudy, still hesitant, said, "You could eventually get the correct answer but you're making a little more work for yourself. But you're really warm.”

“Multiply by zero,” guessed Brady.

“Multiply by zero, mmm, no bueno,” Rudy said shaking his head.

“That would get rid of it,” Brady countered.

Rudy called on Dalton, who had his hand raised, "Well, if you multiplied it by $5 i$ that would make, square it and make it negative and then just.”

“What squared?” Rudy interrupted

“The $i$,” Dalton clarified.

Rudy asked, "So, the $i$ squared would be?”

Dalton said, "Negative.”

Rudy appeared to be waiting for Dalton to finish, but eventually asked, “Zane, what's $i$ squared equal?

“Negative 1,” he replied.

Rudy addressed Dalton, “So, what does $i$ squared equal?”

“Negative 1,” he said.

Rudy continued, “So, what Dalton said, multiply the top and bottom by 5i, again, that would solve the problem, but you're making a little bit more work for yourself still. Kate?” 
Kate suggested, “i, just $i$. ”

"Let's see what happens," Rudy suggested as he began writing out the steps on the board. "The numerator you'll have 4i. Denominator you have $5 i$ squared. $i$ squared is?" "Negative one," said several students.

"We had 4i, 5 times a negative 1, which would be negative 5.” As Rudy wrote equivalent forms of the fraction $\left(\frac{-4 i}{5},-\frac{4 i}{5}\right.$, and $\frac{4 i}{-5}$.) on the board he said, "Don't forget about this, we discussed this last semester.” He also reminded them that the fraction $\frac{-4 i}{-5}$ is not equivalent to the other forms.

Rudy had them continue with the next example saying, "Alright, number two. See if you can do this by yourself. You can work it out with a partner, I'll give you a minute and a half. Your hint is you don't rationalize first.” Some of the students worked together, but most worked individually. Rudy checked students’ papers as they worked, including some students who raised their hands. Rudy communicated primarily non-verbally with the students, but made comments to a few students indicating that they were close to the correct answer. After a few minutes Rudy worked through the example at the board, asking students for contributions throughout the process. When he finished he asked, “Questions?” and said, "Rationalizing, it shouldn't be too tough. We've already done this before, now we're just including i."

Rudy opened a blank page on the interactive whiteboard and told the class, "There's one more concept I want you to get written down." He worked through the concept of complex conjugates with the students, asking them to recall what they had learned about using conjugates to rationalize during the previous semester. They did one 
example together as a class and then Rudy said, "Go take a break. Colton, why are you smiling? You're not having fun are you? Don't worry I won't tell anyone. I don't want any swirlies.” Almost every student left the room for a few minutes. Rudy drew a template of signs and symbols for each step of simpligying the expression in the second example while they were gone, just like he had done with fifth hour. When the students began returning to the room he said,

Once you get back, see if you can do number two. There's a template already kind of filled out for you. Follow the template to see if you can come up with a solution. The hint kind of is shown to you. Your first step is not to multiply by the conjugate."

Kate asked, "Can we talk about this?”

“Complete as much as you can. You can discuss with a neighbor,” Rudy replied.

"Once we're done with this we're gonna have a contest for the last example."

"Yeah, I'm not gonna waste my brain on this one," said Nick.

“Waste your brain?” Rudy questioned. The class laughed.

Nick continued, "I'm already yawning, I need to save that oxygen for later."

A discussion about yawning and the use of oxygen continued until Rudy said, “Alright, let's get back on track here.” Students continued to talk, but they seemed to be working together on the example. Rudy walked around keeping a couple of students on task and helping others who had raised their hands. In contrast to his typical approach most of these interactions involved verbal communications with students. After a few minutes Rudy stood at the board and said, "So, your first step, what do you want to do?"

“Take the i's out,” Colton suggest. "However you do that,” he added.

"You need to take the i's out," Rudy agreed.

Rudy talked as he demonstrated this step on the board, then he asked, "What is 123 
the conjugate?” Without a response, he asked again, “Liz, what would the conjugate be?” “Negative 3 minus 2i,” she replied.

Rudy showed the distribution in the numerator on the board, then said, "Stacy, you ready?” He was about to ask her to complete the multiplication in the denominator $((-3+2 i)(-3-2 i))$

"Yep," she said.

“Deep breath, negative 3 times negative 3,” he continued.

"Positive 9," she responded.

"Negative 3 times a negative 2i," he said.

She replied, "Um, positive 6i squar, no.”

“Positive 6?” he said.

"i,” she finished.

“Yep. Two $i$ times negative 3,” he continued.

"Negative 6i," she responded.

"Positive times a negative is?" he asked.

"Negative 4," she jumped ahead.

He confirmed, “Two times 2 is 4 , $i$ times $i$ is $i$ squared.” Rudy continued simplifying the example himself, asking Zane about $i^{2}$. At the end he said, "Raise your hand if you got it correct.” Allison, Kate, Liz, Kale, Kaylee, and Dalton raised their hands and Rudy said, "Give yourself a hug."

“Alright, you guys ready for the last one?” Rudy asked.

"Yes!” several students replied. 
Combining authoritative action with motivating humor. As Rudy started to look for something in his desk drawer he explained, "Then we're gonna go over some of the homework and you'll have the rest of the time to work on your homework. So, I have some good news for you.”

"No homework," Reese guessed.

“Haha, you’re a funny guy Reese,” Rudy said.

Rudy found what he was looking for in his desk and addressed the class with his good news,

Okay, so, I'm gonna give you a problem. You and a partner, I'll say up to groups of 3. No more than 3 , if it's more than 3 you're getting judo chopped and you're disqualified. The problem I'm gonna put up here, the first group to get it correct is gonna get their choice of some items that I have behind my back, which I'll show you in a second.

“Haha, what color pen do you want?” joked Nick.

Rudy gave a few more rules about the number of guesses each group could make and then decided to showcase the prizes, "So, the first one is, a pen. It says Valley View High School on it." The students sarcastically oohed and aahed. "The second one is a piece of double-mint gum,” Rudy declared.

"How do you split that with the people in your group?" asked Colton.

“The next one is, a broken rubber band,” Rudy said. The class laughed as Rudy said, "And, the grand prize is, Blistex.”

“Is it used?” asked a couple of students.

Rudy shook his head and listed the features of the Blistex,

Medicated lip balm. SPF 15 for those who don't do so well in the sun. Could be yours if the question is right. I want to be an auctioneer and a gameshow host. So, you guys ready? On your marks, get set, go. 
Students got quiet as most began to work. "Should I get the metronome going?” Rudy asked.

“Oh, my god,” said Eli.

“Actually, this is gonna stress me out” Melissa added.

Eli said, "Yeah, same here.”

Rudy started the metronome from his desk and Eli tapped his foot in rhythm with the metronome ticking. Several students started chatting as they began working together, or in some cases stopped working altogether. Kale raised his hand saying, "Why not? Why not?”

When Rudy came to Kale’s desk he asked, “Where's your answer?” before Kale showed him and he said, "Nope.” He addressed the class warning, "I'll give you four more minutes." Kale gave his second answer before anyone else made an attempt, but it was also incorrect. Rudy kept giving warnings as the time ran down. Callie and Liz gave an answer. Reese and Kyle made an attempt as well. David gave an answer, then Allison, and David gave a second answer, but all were incorrect. Eventually, Rudy said, “Alright, let's get back to our seats. We're gonna go over it.” He went through the entire simplification process, asking for some student input as he simplified. At the end he stated, “That was fun.” Then, Rudy assigned the homework and most of the students worked for the remaining seven minutes of class.

\section{The Third Lesson}

On Friday, January 8, I did not observe because Rudy was not teaching both of his classes. He left during fifth hour because he was coaching at a wrestling tournament. He did spend some time with fourth hour on Friday, and he went over homework 
problems with them. However, I returned on Monday to continue my observations.

Rudy's interactions in this third lesson illustrates several aspects of his participation with his students. In this lesson he used a mini quiz to assess his students. He also used a mixture of direct instruction through mathematical statements and questioning of students individually and as a whole class. Finally, in fifth hour Rudy interacted with a mathematical problem for which he did not have a prepared procedure. This helps illustrate how Rudy conceived of mathematics because the situation provided a more genuine problem-solving situation than most of his classroom encounters with mathematics.

\section{Fourth Hour}

When I arrived on Monday, the students were already working on an example problem. Rudy was at the board drawing a line down the middle. The students were working with assigned partners with the two members of each pair completing a different example. The two examples were very similar. Examples $a$ involved subtraction $(2 i \sqrt{32}-\sqrt{-72})$, while example $b$ involved multiplication $(2 i \sqrt{32} \cdot(-\sqrt{-72}))$. Many of the students were working with their partners, but also consulting with other students working on the same example. Rudy walked around the room checking on students' work in his typical non-verbal style. Melissa left her seat and marked on Sydney's paper in a manner that struck me as similar to Rudy.

Combining questioning and direct instruction. After the students had worked for several minutes, Rudy asked them to discuss with their partners the differences between the two examples. The students talked briefly before Rudy asked, "Are your first steps the same? What is the first step?” He continued to ask for the typical level of 
student participation while working the two examples simultaneously until he reached the point at which the examples diverged. He said, "Give your partner a high five if you got both of these parts correct.” Three pairs high fived before Rudy asked, "Is the next step going to be the same?” and the students said no. Rudy continued to simplify each expression separately, the addition expression followed by the multiplication expression. He asked for student input and highlighted the differences in the two examples. When both examples were simplified, Rudy said, "People that are $a$ 's raise your hand if you got $a$ correct. Keep your hands raised. People that are $b$ 's raise your hand if you got yours correct. If you and your partner got both of them correct you are allowed to high five yourself.” Not many pairs high fived.

Mini quiz. Rudy signaled what he would call a mini quiz by saying, "Clear your desks. Half sheet of paper.” Students cleared their desks and many shared pieces of paper. It was clear they knew what was going on. This mini-quiz was not part of Rudy's plans. As students took some time to clear their desks, Rudy said, "The longer I have to wait the harder the question is going to be. Gettin’ harder, gettin’ harder, gettin’ harder. We're on a level 4. Uh, level 5. Callie, you ready?”

"Yeah," she said as she put her pencil case on the floor.

$$
\text { Rudy wrote four exercises on the board: }(-3 i)^{2}, \frac{1}{\sqrt{-3}},(-3+i)(4+\sqrt{-9}) \text {, }
$$

and $\frac{3}{(2+3 i)}$. When Rudy finished writing he said, "Choose three of them.” Rudy sat down at his desk and the students worked on the quiz quietly. After a few of minutes Brady walked to the front of the room and put his quiz on a chair by the board. One-by-one the other students did the same. After about five students laid their quizzes on the chair, 
Rudy said, “Once you finish, open to your notes.” Three students were still working on the quiz when Rudy said, "I'll give you two more minutes." Before Rudy picked up the quizzes he asked, “Is anybody's mini-quiz out still?”

Combining questioning and direct instruction. Rudy set the quizzes on his desk and began writing the headings for the next section of notes. He wrote the examples $x^{2}+100=0$ and $4 x^{2}+78=6$ below the new headings. "Imaginary and complex numbers with equations," he said,

Everything we've been doing have been expressions. So, simplify, reduce, evaluate. Now, we're getting into equations, equal sign. We're solving. We spent a lot of time solving these type of equations. How would we solve? Number one, how would we solve for $x$ ?

"You would subtract 100 from both sides and then you square root," said Eli.

Rudy wrote on the board the steps that Eli had described. When he reached the point of taking the square root of negative 100 he said,

In the past this is where we would stop. But now we're level 86, what was Colton, 86? At least 86 math wizards, about i's and imaginary numbers and all that good stuff. Take an $i$ out. Now, when you do square root both sides, I know this is something that many of you missed half points on quizzes, tests, so forth.

Rudy pointed to $\sqrt{-100}$. "What did I leave out?" he asked. He wrote \pm in front of the $\sqrt{-100}$ and said, "Plus or minus, and that's important because there's two answers: $x$ equals plus or minus $i$ square root of 100 and what's the square root of 100? See if you can do two.”

Students worked on the second example individually. After a few minutes, Rudy asked a few different students to share their answers. Then, Rudy completed the example on the board and asked for the typical level of student participation. When he finished he wrote another example on the board $\left(2 x^{2}-2 x+7=5\right)$ and the students began working. 
After a few minutes Rudy asked the class, "So, how is this one different than the previous two? David?”

David said, "It has a $2 x . "$

“Okay, how does that effect what we can do or how we can solve?” asked Rudy. David started to explain how to factor, but Rudy stopped him. He explained, "You're on the right track. You're not gonna be able to factor this. Are you gonna be able to solve it like we did above? Are we able to solve it by square rooting both sides?” When nobody answered, Rudy continued, “There's an extra $x$. We have $x$ squared and $x$. When we have equations like this we can't root both sides. We can't solve it by rooting both sides. We'll get back to this tomorrow.” Rudy assigned homework and as the bell was ringing he said, “This appears to be a lot more homework than what it actually is.”

In this lesson Rudy combined direct instruction with questioning. The students participated in the lesson through their responses to the questions. However, Rudy provided the direction of the lesson and most of the information.

\section{Fifth Hour}

The fifth hour students chatted right through the bell, until Rudy said, "Alright.” Rudy reminded the students what they had done on Friday and then decided to go over the exercises from the textbook.

Combining questioning and direct instruction. Rudy showed one of the exercises that had two parts $(\sqrt{-5}+\sqrt{-80}$ and $\sqrt{-5} \cdot \sqrt{-80})$. He said, "You should notice both of them are the same, except one's addition and one's multiplication. Take your i's out first." He simplified both on the board simultaneously. "What should be your next step? Or what. You don't necessarily have to do this, but it will make the problem go 
easier.”

“Break 80 down,” said Mike.

“You can break 80 down,” Rudy agreed, “The square root of 16 times the square root of?”

"Five," Sahara filled in the blank.

Rudy wrote the same steps for both exercises and continued, "Square root of 5 times? And when I say you don't necessarily have to do this step, which one do you have to. One of them you have to do the step, the other one you don't necessarily have to.

\section{George?”}

"You have to do the addition,” George said.

Rudy asked, “Why so?”

“Because you can’t combine them without that,” replied George.

"Yeah, you can't add them together in this step. Both of them have an $i$, but the roots are not the same. Here they're both square root of 5. Do they have to be the same to multiply them? No.” Rudy finished writing the rest of the exercises on the board.

Rudy looked around the room at the students, apparently deciding how to pair students. He started pointing at two students at a time, based on proximity, and said, "Let's go, you two are partners. You two are partners," and he continued until all of the students had been assigned a partner. Then, he gave the directions,

Number 30 was another extra credit one that we did not go over. Designate one person to be $a$ and the other one to be $b$. I'll give you a few moments to figure both of them out. After you are done, I want you to compare answers with your partner. Similarities, differences all that good stuff.

The partners talked quietly about their work. After a couple minutes Rudy started checking on student work. After sufficient time to complete the exercises, Rudy told the 
class, "Raise your hand if you and your partners got the same answers.” Nobody raised their hands so he asked, "Raise your hand if you got different answers."

George seemed confused, "Well, if we each do a different one, we should all have different answers.”

“Okay, why?” probed Rudy.

“One's multiplication and one's subtraction,” George said.

“Okay, so what would be their similarities?” Rudy asked, “How would you go about solving it. For the most part, the steps are the same as you started. What's step one as you started?” Rudy wrote the steps of the two parts of the exercise on the board in a similar manner to what he did with the first exercise. He asked for student participation and worked each part simultaneously.

Mike had his hand raised as Rudy started to ask for questions at the end of the exercise. He nodded and Mike asked, "Can I have permission to text Ben, what's $i$ squared?” Rudy laughed but shook his head. Rudy asked the students if they had questions about any of the homework assignments. Rudy answered Matt's question by working the exercise on the board, having Matt tell him most of the steps. At the end he had Matt identify where he had made a mistake when doing the homework.

Rudy interacting with mathematics. “Any other questions?” Rudy asked. Kayla asked him about $i^{41}$. Rudy said, "Ironically, you asked a question about one similar to this."

"I get it but, Brynn asked me to ask," she said.

“Thanks,” said Veronica.

“And Veronica asked me to ask,” explained Brynn. 
“So, I intimidate the two of you?” Rudy asked.

"I guess,” Veronica said laughing.

“I guess,” agreed Kayla.

Rudy started writing on the board as he explained,

$i$ squared is equal to negative 1 . This is the idea that we're gonna be using for this. How many $i$ squared's are gonna be in $i$ to the 41st power? So, if. You said that there's $20 i$ squareds in $i$ to the 41st power. It doesn't go in evenly, we'll get to that. We know that $i$ squared is, so 20 times. Ahh, that's wrong.

Rudy stepped back and though for a minute. He wrote $\sqrt{x^{41}}$ on the board and asked, "Remember these? What do we want to do to these type of problem, square root problems?”

“Cross them out,” Kayla said.

“Alex, I can see the gears turning,” Rudy said.

Alex said, "Um, we want to get them to the closest even number."

“Closest even number," Rudy said as he wrote $\sqrt{x^{40}} \sqrt{x}$. "Okay, this will get you the square root of $x$ to the 41st power. Then?”

Alex continued, "Uh, you would divide by 2 I think. So, it would be 20.”

Rudy wrote as he said, " $x$ to the 20th power. Absolute value?”

"Um, no cause it went from even to even,” Alex explained.

Rudy said, "This is something similar to that as well. Getting it to the nearest even. Why? Because, this,” Rudy pointed to $i^{2}=-1$

If we look at, let's say, $i$ to the fourth. This ones a lot easier. $i$ squared times $i$ squared. Negative 1 times negative 1 would be positive 1 . What about $i$ to the sixth power? $i$ squared, $i$ squared, $i$ squared. Negative 1 , negative 1 , negative 1. And this is what we kind of went over last week I think when Kayla asked. How can we come up with a rule, or see a pattern? When $i$ has an even number, even exponent it's either gonna be positive one or negative one. 
George asked, "Has an even exponent?”

“Even,” Rudy confirmed, pointing to $i^{6}$.

"It will be negative one, even,” said George.

“Even,” Rudy said again, pointing to $i^{4}$.

"It will still be one," George said.

Rudy asked, "What if we have $i$ to the 8th power, will it be positive or negative?"

Several students said, "Positive."

"What about $i$ to the 24th power, positive or negative?” asked Rudy.

Several students said, "Positive.”

Rudy asked, "Parker? You gonna say positive cause everyone else is?

"Yeah,” Parker replied.

"How can we come up with some sort of rule instead of guessing there," asked

Rudy.

Mike offered, "I divide the exponent by 2 and then if the exponent is odd it's negative, if it's even, it's positive."

Rudy said,

Okay, so, divide the exponent by 2, if it's even it'll be positive. Divide the exponent by 2, if it's odd it'll be negative. Will that be true for all of them? This is the same idea as the absolute value. Even to an even, even to an odd.

Rudy pointed to Ian who said, "Well, I was going to say if it's a factor of 4 it's going to be positive. Like, the exponent I mean.”

“Okay, yep,” Rudy confirmed, “So using that idea, 40 divided by 2 you get. Is 20 even or odd? Last time I checked it was even. So this is gonna be negative 1 or positive 1 ?” 
Several students responded, "Positive.”

Rudy agreed, “Positive 1 times $i$. Anyone get $i$ ?” Several students raised their hands. “Any other questions?” Rudy asked. He answered one more question from Matt, working the exercise quickly on the board.

Because Rudy was forced into a genuine problem-solving situation with Kayla's question, his interaction with mathematics is unique. Rudy typically applied a defined procedure to a given exercise. In this case, because he did not have a predefined procedure prepared, he found a similar exercise and by solving that exercise he developed his solution process for the problem in question. This illustrates his conception of mathematics as an internally consistent system in which problem solving can be accomplished through analogical reasoning.

Mini quiz. “Let's clear our desks,” said Rudy. Some students seemed surprised but they cleared their desks and shared half pieces of paper, just like fourth hour. Rudy waited for students to clear everything off their desks then put up the problems he had written on the board for fourth hour. "Pick any 3," he said. The students worked silently and Rudy worked at his desk. After several minutes students started placing their quizzes on the chair under the board. "When you're done, take your notes out," Rudy said as he made sure everyone had turned in the quiz.

Combining questioning and direct instruction. Rudy started writing notes on

the board including the two examples $x^{2}+100=0$ and $4 x^{2}+78=6$. He said, Imaginary and complex numbers with equations. Everything up to this point has been expressions. So, we've been evaluating simplifying reducing. Now, since we have equations we'll be solving. Solve number one. Numero uno. I don't know how to say solve in Spanish. 
George said, “10.”

“It is not 10,” Rudy replied

"Yeah, sorry 10i," George tried again.

"It is not 10i," Rudy said, "But it is 10i."

“Thanks, thanks. So, am I right or not?” George asked.

Other students began to contribute guesses similar to 10i. Eventually Rudy said, "You guys don't want to play this? What do we do first?"

"Subtract the 10 over. Or no, sorry it's 100," said George.

“Then what do you want to do?” Rudy asked.

"Square root it," several students replied.

Rudy said, "Inverse.”

Sahara said something about taking the square root, but Rylee reminded her, "But you can't cause you have to take the $i$ out.”

“Oh right, right!” she said.

Rudy wrote $x=\sqrt{-100}$ but left space between the equal sign and the square root symbol and put a box there. “What goes there?” he asked.

“Is it zero?” Mike asked.

Rudy wrote $x=i \sqrt{-100}$ and included a box to the left of the $i$. He asked, "What goes there?” The students were talking to each other but did not offer any answers to Rudy. He wrote $x=10 i$ and still drew a box to the left of the 10. "What goes there?" he asked, "Parker, do you know?”

“Zero,” Mike guessed again. 
“It could not be a zero,” George said.

“Olivia?” Rudy asked.

"No,” she said.

Finally, Rudy wrote \pm in all three boxes.

“Oh,” the students said collectively.

"Remember plus or minus, plus or minus," Rudy said, "So positive $10 i$ is, an, is a correct answer. Negative $10 i$ is the rest of it.” Note the difference in the ways Rudy reminded the students to include both the positive and negative roots as the solutions to a quadratic equation in the two classes. In fourth hour, Rudy answered his own question, “What did I leave out?” almost immediately. In fifth hour he asked a similar question, but gave students more time to think about the question and contribute to the conversation before he provided the answer.

Students worked individually on example two initially. After a few minutes, Rudy solved the equation on the board in his typical fashion. At the end he said, give yourself a handshake if you got this right. Some students tried. Then, he asked, “Are you ready for the super, ultimate, crazy-difficult one?”

Kayla said, "We can skip it. I think I'll pass.”

Rudy reiterated, “Super, ultimate, crazy-difficult problem,” as he wrote $2 x^{2}-$ $2 x+7=5$ on the board. He asked, "How is three different from the previous two?"

“It’s a quadratic equation,” Ian suggested.

“Quadratic equation? The first two were still quadratics except this one is?”

“A trinomial,” Ian said.

“A trinomial,” Rudy confirmed, “What. Since it's a trinomial, can we solve it by 137 
square rooting both sides?”

Several students said, "No.”

“No,” he agreed, “That's not gonna be an option. What do we want to do, or what can we do?” Several students offered suggestions for the other ways to solve quadratics. Rudy suggested, “Take your graphing calculators out and graph it real quick.” A few students did, but most just waited for the bell, which rang in less than a minute.

\section{The Fourth Lesson}

On Tuesday I returned to Valley View for the final observation of the unit about imaginary and complex numbers.

This final lesson illustrates another approach Rudy took to providing homework feedback and how he graded the homework in one case. It also demonstrates his reliance on prior lessons to help establish the mathematical understandings in the current lesson. The mathematical content Rudy had taught in prior units is important in this lesson, just as it has been throughout the prior three lessons.

\section{Fourth Hour}

When I returned on Tuesday Rudy was finishing up some work at his desk. Rudy took attendance as the students chatted. Rudy began class by asking the students to take out their homework assignments.

Homework feedback and grading. After the students pulled out their assignments, Rudy stood up with his gradebook and said, "I'm going to come around and check. This is what I'm checking right now.” Rudy drew a set of brackets around the assignment he had written on the board Monday and said, "I am just checking that and equations. So, you should have some from the worksheet and then some from the book.” 
Rudy waited another 30 seconds to allow students to get the correct assignment out and then started looking at students' papers. He started with Kaylee on the left side of the classroom. "If you have 20 done, let me know," he said because 20 was extra-credit.

He proceeded to look at each student's paper between the first two rows on the left side of the classroom. He wrote something in his gradebook periodically, but not after each student. The students chatted quietly about unrelated topics as Rudy continued to check each student's homework. After he finished, Rudy said,

At the end of the week I'm gonna put grades into [the online grading system]. Probably about four or five assignments. Keep that homework out. Before I forget I'm gonna hand the mini-quizzes back and we'll go over these first, and then we'll go over the homework.

The students continued to talk quietly as Rudy handed each student his or her quiz. When he was finished he went to the interactive whiteboard and wrote out the process of simplification for the first exercise on the quiz. He asked for student input only a few times as he demonstrated each exercise from the quiz. When he had finished, he asked, “Questions on this?” Nobody responded, and he began the process of checking the homework by saying, “Kate, what did you get for 22?” Kate answered correctly and Rudy continued to ask students for the answers, but he did not go down each row like he had previously. Instead he called on students in what seemed like a random order. One student asked a question, wondering if they could simplify a solution more than what was given in the answer. Rudy addressed the question briefly and continued. He also worked the final exercise from the worksheet before asking for questions and continuing to the exercises from the textbook. With the textbook exercises he attempted to have the class say the answers in unison. It took them a few tries on the first exercise, but eventually they answered together. 
When they finished, Allison raised her hand and asked, “Can we do number 38?”

Rudy solved the equation and asked if there were any more questions and then declared, “Notes."

Using prior lessons to build mathematics as a system of procedures. As the students opened their five-subject notebooks Rudy showed the example they had not finished the previous class $\left(2 x^{2}-2 x+7=5\right)$ on the board. He said,

So, we ended with this one with the other class. All the homework questions besides number 20, you're really solving them the same way. You're getting the variable squared on one side, then the inverse means the square root of both sides. But with this one you can't do that. Why? Cause you have a variable squared and just a single variable. You're gonna have a trinomial. David helped us yesterday. What did we do first?

“Made it equal to zero,” David recalled.

Rudy did the work to get the quadratic equal to zero and said, "So, remember those five ways to solve quadratics? Square rooting both sides?” Four students filled in graphing calculator, factoring, quadratic formula, and completing the square. Rudy said, "We're down to four different ways because we can't do square rooting both sides. We talked about we're not able to factor. Could we help ourselves out by reducing this at all?” A student suggested dividing by 2 and Rudy performed the operation, explaining, "This would make it easier to see, okay, can I factor it out.... Punch this into your graphing calculator.” Rudy and his students used their graphing calculators and Rudy asked, "What's wrong with the picture, David?

"It's not going through the $x$-axis," he replied

Rudy asked,

Will it intersect the $x$-axis? No. So, does that mean it's no solution. In the past, or a couple of sections ago, it would be no solution. Why? Because it's not intersecting the $x$-axis. Um, we kind of talked about this when I introduced this 
chapter, or this unit. So, is our work done? Unfortunately, not. Why don't you, well, what was example one that we did? Was it $x$ squared plus 100 equals zero? Punch that into your graphing calculator. Graph that.

Everyone graphed the equation and Rudy helped them adjust the view so the graph was visible. Rudy asked, "Will it cross the $x$-axis? No.... Well, with our very first example that we did from yesterday, did we get an answer? Yeah, what did we do Nick?

“We just subtracted 100 over,” Nick explained.

“Then?” Rudy inquired

“Take the $i$ out,” Nick said.

“And the square root of 100 is?” asked Rudy.

Nick filled in, “Ten.”

Rudy explained, "So our answer was plus or minus 10i. Even though it didn't cross the $x$-axis, we still got two answers. Positive $10 i$, negative $10 i$. Going back to this example,” Rudy pointed to $2 x^{2}-2 x+7=5$.

Can you use your graphing calculator to figure out the solutions to this? No.... So we're down to. Well you guys just said we're not able to factor it, so we're down to two different methods, completing the square or quadratic formula. Who wants to show off their intelligence. Quadratic formula. Dalton? $x$ equals?

“a $x$ squared plus,” Dalton tried.

“Um, no,” said Rudy.

“ $a b$," he tried again.

“Negative $b$ plus or minus the square root of,” Rudy started him off “Negative 4 a c,” Dalton continued.

“ $b$ squared minus 4 a c over $2 a$,” Allison corrected.

Rudy had Callie give him the values of $a, b$, and $c$ and he substituted the values into the quadratic formula. Then, he completed the steps to compute the solutions until an 
$i$ would need to be indicated. He said, "There were a few problems, one of them I think was on a quiz or test or both, where you get to this point. We would stop there because what can we not have?”

"Negative," said several students.

“Negative square roots,” Rudy corrected, “Now, we know what to do. Mr. Level 86?” he asked, referring to Colton.

"Oh gees. Take the i's out," Colton replied in a questioning tone.

Rudy finished simplifying and said, “Those would be your 2 answers.” Then, he asked the students to work on $2 x^{2}-5 x=-7$, which was the extra credit exercise from their homework. The students started for about 1 minute before Rudy said, "Can you solve it by square rooting both sides? Since you cannot solve it by square rooting both sides, what are you gonna want to do to the equation? Once you do that, then what?” Only about half the students were working as Rudy checked on a couple of students’ papers. He stopped and said, "Most of you have done the first step correct. What do you want to do? Set it equal to zero.” He demonstrated this part of the process on the board then continued, "Cannot root both sides. If you punch this into your graphing calculator it's not gonna cross the $x$-axis. Can't use that method. Quadratic formula. What's your a?” Rudy used student responses to substitute values in the quadratic formula and said, "Raise your hand if you had this set up correctly.” When about a third of the class raised their hands he said, "Give yourself a handshake.” Rudy asked several students to help him with the process of computation and simplification. When they finished he said, "Raise your hand if you got this as your answer. Pat yourselves on the head and rub your stomach.” 
Rudy assigned the homework for the day, writing it on the chalkboard with the other assignments still listed there. He explained they would be grading the homework and taking a quiz the next time the class met. He said, "We still have seven minutes or so. I'm gonna take this time to go over some examples from this homework.... So, examples to go over?" A student requested an exercise, but Rudy said, "For the ones that are $i$ to some sort of power, don't worry about that." Note that he took a very different approach with this type of exercise with fourth hour than he had with fifth hour the previous day. Kate asked Rudy to do $(-4+6 i)(2-i)(3+7 i)$. Rudy completed the exercise, asking only one question of the students. He said he would do one more and Nick asked for $\frac{5+i}{3 i}$. The bell rang as Rudy was completing the exercise and the students left when he was finished.

\section{Fifth Hour}

As soon as fourth hour started leaving the classroom, the fifth hour students started entering the room. Soon, the bell rang and Rudy said, "Let's get our homework out please. The imaginary numbers worksheet and then the bookwork.”

Homework feedback and grading. Rudy said, "I'm gonna come around and check." He went around the classroom checking students' homework and marking in his gradebook in the same manner he did with fourth hour. "I am going to put grades in at the end of the week. By the end of the week you'll have four or five assignments," he explained. “Keep your homework out. Before I forget, like I about just did, we're gonna go over your mini-quizzes first." He handed the quizzes to the students and then demonstrated each exercise on the board. He requested very little participation, but at the end he asked, “Questions on these?” Nobody asked any questions so he said, “Okay, let's 
start with the imaginary numbers worksheet.” He asked the students in the row on the left side of the class to share their answers and then asked, “Any questions on these?” When nobody had questions he had the class give the answers to the textbook portion of the assignment in unison.

After they went through all of the exercises Rudy asked, “Questions?” Jess asked about one of the exercises and Rudy demonstrated the process of finding the solutions. They had a short conversation, then Rudy confirmed Matt's assumption about not answering in decimal form saying, "No! You know what mama thinks about them?”

“They're the devil,” Matt guessed.

“They are the devil. Keep them in root form.” Rudy said. "Let's turn to our notes.”

Using prior lessons to build mathematics as a system of procedures. Rudy

wrote $2 x^{2}-2 x+7=5$ on the board, which was the example they had ended with on Monday. He also wrote $x^{2}+4=0$ on the chalkboard along with the procedures for finding the solutions to the equation. Rudy clarified,

You don't have to write this down. So, with number 3, I think we discussed that we were not able to solve this quadratic by square rooting both sides. Why? Because it's a trinomial. So, we start with five ways, we can't use square rooting both sides, so we're down to four ways. What are we gonna want to set this equal to?

“Zero,” offered Mike. Rudy showed the process on the board and asked how to make the example a little simpler. Matt suggested dividing by 2, so Rudy wrote that process on the board as well. Rudy demonstrated how he would attempt to factor the quadratic, but in the end he said, "Does that work? No. So, we're down to three ways.” Three students listed graphing, quadratic formula, and completing the square.

Rudy directed their attention to the example on the chalkboard $\left(x^{2}+4=0\right)$ and 
said, “Let's say we start with this. We're able to square root both sides.” He talked through the steps he had written on the board. "Instead of solving this way, say you're one that likes to use that graphing calculator, right, that's one of the options that we still have. Put this into a graphing calculator.”

“It doesn't cross the $x$-axis,” Ian said.

“What? It doesn't cross the $x$-axis?” Rudy said sarcastically,

That's crazy. This goes back to what I was getting to when I introduced this unit to you guys. Your answer for $x$ is where the parabola crosses the $x$-axis. Does the parabola cross the $x$-axis with this? No. But yet we still have answers. Imaginary numbers. It's make believe, it's made up. Before George asks.

"I was gonna say, what are they?” George interrupted.

Rudy continued,

You will get into what's happening with that in Math III or Algebra 2. Let's come back to this one. So, we tried factoring, it did not work. That brings us down to three options. Put this into $y$ equals. Does it cross the $x$-axis? No, it does not. So you cannot use your graphing calculator to still solve for $x \ldots$... So, we're down to two options. What two are available?

Students listed the quadratic formula and completing the square and Rudy asked, "Who wants to show off their intelligence and recite the quadratic formula?"

" $b$ to the square root of $b$ " Mike began.

Rudy had him start again, “ $x$ equals, repeato por favor.”

He said, "I had the wrong variables. I think it's $a$. If I say the variables wrong here don't judge me.”

Rudy said, "I'll give you a template here.” He wrote the quadratic formula leaving blanks for $a, b$, and $c$. Kayla raised her hand and Rudy called on her.

"It's $b$ plus, minus in front of the squared. Uh, negative $b$," she corrected herself. "Um, I don't remember what's inside. I remember $a$ and $c$ are after that and I know $a$ is 
underneath.”

Ian raised his hand and said, "b squared,” when Rudy pointed to him.

Rudy asked the students to identify $a, b$, and $c$ in the equation they were trying to solve. A couple of students helped him identify the values and Rudy started completing the steps to calculate the solutions using the quadratic formula. When he reached the step in which $i$ should make an appearance he said, "This is the step where... if we use the quadratic formula we get to here and say no solution. Well, there actually is a solution, it's just not real.”

“So, there's no solution,” said George.

“What do we have to do?” Rudy continued, "We take the $i$ out.” He finished simplifying and said, “So, your two answers should be this. 1 plus $i$ square root of 3 all over 2, and 1 minus $i$ square root of 3 all over $2 . ”$

He opened a new page and said, “One last example. Number 20 on page 137. I want you to see if you and a neighbor can come up with an answer.” The students started chatting with their neighbors as they worked on the exercise. After less than a minute Rudy asked, "So, are we able to solve it by square rooting both sides? No. So, now we have four different methods. Maybe try to use your graphing calculator, maybe try to use factoring.” After another minute Rudy started checking students’ work. George asked Rudy who came up with the quadratic formula.

George wondered, “Did they just try it one day? Oh, look! This worked every single time.”

"Imagine being that guy to do it,” Rudy said, "That would be awesome.” “Would he be a millionaire?” Matt asked. 
Rudy continued checking students' papers and students started comparing their answers. Eventually, Rudy said, “Okay. most of you are getting to the, getting to the answer or getting close." He demonstrated the process of finding the solutions for the equation using the quadratic formula. He did not ask for any student input during the process. At the end he asked, "Any questions?”

A Historical Tangent. While Rudy was helping various students George had asked about the origins of the quadratic formula. Rudy addressed the class,

George asked who's the guy that came up with the quadratic formula. I don't know who he is. I should know more about math history. That would be kind of an interesting class. Just going over famous mathematicians. Can anyone think of any famous mathematicians?

Students listed a couple of mathematicians, then Rudy started talking about Leonardo da Vinci. He said da Vinci was his, “favorite person of all time.” He talked about da Vinci's work. He mentioned how remarkable it was that mathematicians had developed as much as they had without modern computational tools. He explained how da Vinci worked in many areas that are specialized fields of study in modern times. He also talked about the Fibonacci Sequence, Pascal's Triangle, and the Golden Ratio, which he used to include in a project in Geometry. At the end of the conversation he said, "So, if you ever get a chance look up da Vinci and some of his work. Man, I really wish we could do that project.” He spent about ten minutes on this discussion before he said, "Alright, tomorrow you have a quiz over the imaginary numbers, complex numbers, expressions, equations.” He also explained the homework and what he would be grading during their next class.

Rudy sat at his desk for a moment and then he said, “Amber, I feel like you're the type that's really intested in the illuminati.” She pointed at Kayla and Rudy asked, 147 
“Kayla, you are?” She nodded. Rudy told her a story about his trip to Europe and wanting to follow a man with a tattoo of an eye in a triangle. After a few more minutes the bell rang and Rudy said sarcastically, "I'll see you all tonight at the Wrestling meet."

\section{Rudy's Reflections}

I asked Rudy to reflect on his teaching, but I did not want his learning to be excessively influenced by this practice. Therefore, I was not very persistent in my pursuit of his reflections. I was also not forceful in prescribing how he should reflect. Rudy provided me with three reflections. He recorded two reflections on an audio recording device after the fourth lesson. Each recording was approximately 1.5 minutes. He also emailed me a reflection after he gave another quiz on the day following the fourth lesson. The email included a list of the five ways he taught students to solve quadratic equations and stated, "This is something that I didn't anticipate going over or stressing as much until after the first class.” The two audio-recorded reflections contained similar content.

In the first reflection, he described that he decided to focus more on connecting the use of imaginary numbers and "taking $i$ 's out" with the five methods used for solving quadratic equations. He had originally planned to talk about solving quadratic equations, but over the course of the unit decided to put more emphasis on the five methods for solving quadratic equations, which they had learned the previous semester. He also described adding a mini quiz because he was taking longer than he expected to finish the unit. In the second reflection he expanded on his description of the five methods for solving quadratic equations. He said that he had emphasized deciding which method to use to solve a quadratic. He explained that a trinomial could not be solved by, "square rooting both sides,” and imaginary answers could not be determined using a graphing 
calculator or by factoring.

In addition to the think aloud that Rudy labeled a reflection, these are the only reflections I have on record. It stands to reason that Rudy reflected on his own practice in ways that he did not record. However, the lack of recordings may indicate that he reflected minimally on his teaching practice.

\section{Follow-Up Interview}

After all of my observations, not all of which are included in this analysis, I conducted a follow-up interview with Rudy. The interview occurred on March 3, 2016 and lasted approximately 45 minutes. I provide a sample of this interview below.

\section{Rudy's Form of Authority}

I started with several questions I had developed during my observations and never asked. I had noticed Rudy's role as the authority figure was strong in some ways, yet accommodating in others. I wanted to know what his role was in some logistical arrangements so I asked, "Do your classes have seating charts that you assign them?”

Rudy replied that he allowed his classes to choose their seats at the beginning of the year to, "put more responsibility on them," with the warning that he, "can always rearrange them.” He explained that he had not rearranged students in fifth hour, but he had moved some of the students in fourth hour.

Then, I said, "There were a couple of times when, like, they worked in partners and stuff. Do you choose those partners too?”

He explained,

About the second or third week of class, after I have a good idea of their capabilities, I end up pairing them up with someone else. So, when I have them get with their partners they already know who they. I ended up having to switch 
some of them around. And I tried to switch it up the second semester so they have different partners. I don't think I did that for one of them. Fifth hour I actually ended up letting them choose who they wanted to work with.

\section{Rudy's Perception of My Impact as a Researcher}

I asked, "Would you say, in general, over the time that I observed, like your teaching, was it typical of your teaching in general?... And the students, were the students pretty typical?”

Rudy replied,

Yeah, students were pretty typical. I was wondering if they were gonna be acting different, almost closed, not opening up because you were in there, but it was pretty typical of them. Pretty typical of my teaching style. Now, we're getting into basically second semester of Math II is all geometry. So, really the same style but there is some different things that I'll do.... Um, but yeah, pretty typical.

\section{Rudy's Self-Described Learning}

I asked Rudy about his own learning saying, "Is there anything that you can think of that you would describe as learning that happened over the course of... when you were talking about imaginary and complex numbers...”

Rudy thought for a moment,

Um, for next year, talking with the Math II teacher and the upper level teacher, she said that they're struggling with like, factoring and using the quadratic formula. Um, I'm almost thinking about rearranging some stuff so that we do the factoring, quadratic equations at the end of the year, versus at that very beginning. I haven't looked to see if that will work. Some of the geometry stuff needs the, needs to know how to solve that in order to do some of the questions later on. But, that's one thing I'm gonna look into...

It is apparent that Rudy did not perceive an extensive amount of learning to have occurred over the course of my observations. Rudy’s learning, as I will describe in Chapter V, did not take the typical form of internalizing knowledge. Perhaps his perception that he learned little is related to a conception that learning involves 
internalized cognitive knowledge.

\section{Rudy’s Collegial Relationships}

I tried to alter my next question (Describe how your interactions with colleagues shaped your practices over the course of this unit?) to fit Rudy's situation. I asked him to expand his answer to include his teaching career to this point and not just the unit I observed. I also asked him to include how his mathematics teacher colleagues, other teachers, coaches, and coaching influenced his practice.

Rudy asked for the first part of his answer to be off the record. Afterward, he described his difficulties in collaboration with Jean and Julie and his reaction to their treatment of him. He described that he would rather talk with teachers from other high schools than Jean and Julie. Finally, he described his use of coaching philosophies in the mathematics classroom. He said,

Um, at first, it was one of the high school math teachers, she's been here a long time. The other one has been here a year longer than me. At first, it was I didn't want to say a whole lot because I was new at [teaching]. Just more, I was figuring some stuff out on my own. Then, it was I've been teaching for awhile now, I'll try to add my two-cents and help each other out, but they just kept shutting me down. So now, it's like back to I'm not saying anything but I'm just kind of doing my own thing. That part gets frustrating like if I do have questions, or would like some opinions or thoughts. I don't even want to go talk to them about it.

Instead of collaborating with Jean and Julie, Rudy described how he approached

mathematics teachers from other high schools. He explained,

I'll ask other math, high school teachers what their thoughts are on it [pacing with an integrated curriculum] even though they're not integrated. When we go to, each year we go to three different... conferences where a bunch of math teachers from surrounding schools get together and do professional development.

He described another area school and said,

Their teachers are pretty nice to work with. So, talking with them about, for instance, the quadratics unit cause I feel like that takes up so much of my time. 
How long should I be teaching this, versus let's move on and get to something else? It's still a work in progress because we haven't been teaching integrated that long.

Although Rudy did not describe specific collegial influences from other coaches

on his teaching, he did describe his use of coaching philosophies in his teaching.

I definitely use my coaching philosophies in the classroom and just try to be like a salesman basically for math. And that's one thing math teachers struggle with. I'm not saying be the kids' best friend but the kids have to like you, otherwise they're not gonna be totally buying in to the class. You get them bought into the class, then learning's gonna be taking place, I guess. It even takes benefits of, benefit of the doubt is treating them like young adults goes a long ways. Like the seating chart type thing. Wow, I get to choose where I sit as long as I'm not crazy disruptive or a nuissance, I'm not gonna be moved.

\section{Rudy's Learning From His Students}

I asked a follow-up question, to search for more information about his coaching colleagues, but he directed his answer toward his students. I asked, "In your coaching do you feel like you've been able to learn things from other coaches, like, more easily than your teaching learning comes from other teachers?”

Rudy replied,

Yeah. Um, I learn a lot from the kids also. Um, finding there's always a few kids that are more mature than the other ones. Like that fifth hour class, for instance. I learn so much from them. Just by being honest with them. There will be times where, hey guys this is the first year that I'm teaching this concept, help me out here. What deficits do you guys have? Do you understand this part? Where did you start understanding it? What parts of the lesson were you interested in? Just little things like that too. And that helps with developing that good relationship too with them. If they see me asking them genuine questions like I want their feedback, opinion, then they almost see that I'm human too.

“Do you do that on a regular basis?” I asked.

He responded,

I probably should do it more than what I do. When, a lot of times, say wrestling practice when we do conditioning and stuff, when we do sprints or I'll wrestle live with them, it gives me a good indicator too, to see how tired they should be.... If 
I'm crazy dog tired, then yeah, it's probably a good amount of sprints or whatever. It helps I guess, especially now with the Common Core Standards that have changed, it is being pushed to student led. I guess it's almost including them in the assessment type stuff when I'm asking them those questions. And I know that they're gonna be honest. They're not gonna tell me what I wanna hear.... What I grow from the most is when the kids are telling me because they're the ones that...

Rudy's voice was not audible on the recording at the end. I continued on the same topic, "You said when you coach, sometimes you run with them and that allows you to gauge. Are there other things besides, like you are talking about asking, are there other things that you use with your teaching to gauge?”

He responded,

Obviously like quizzes and tests. Every once in a while, and I'll do this with my [support] class... There is 10 of them in there and they're lower level.... I do ask that class kind of the same questions so I get both ends of the spectrum.... I'll do things like, we're reviewing for a test, okay, I'll break down the section kind of what we went over, covered, and I'll have them make a chart and I want you to rate yourselves 0 to 10,10 being the highest, 10 meaning you'll get a 100\%. Rate yourself in each section, say you're gonna take the test now, what do you think you're gonna get on each of these sections. And I'll take the average of each, all the ratings and I'll put it up on the [interactive whiteboard], so all the other students can see in section two the average of all the other kids is six and a half, they can see okay, I'm not the only one having troubles. And it helps me gauge what parts I don't have to spend as much time on and what parts I do need to emphasize more. Things like that.

"Okay, so that's something that you'll typically use for, as information to make adjustments in the following year?” I asked.

"Yep," he confirmed

I asked, "Do you ever use that to make adjustments, like...the next day redo stuff because of feedback that you get? Is it just the next year, or is it stuff that you deal with on the fly with the current class?”

He said, 
Um, some of it's on the fly, some of it will be used in the next units or chapters. For instance, solving quadratics, say they have trouble factoring. Well, we'll get into that solving for $x$ given a couple of angles, where they have to set up the equation, factor it, so I'll make sure to point that out, spend more time on it with the same class.... I guess, I don't know, to answer your question it's more for the future. I do keep it in mind I guess as we move forward throughout the year.

\section{Rudy's Use of Humor and Quirks}

I changed topics and said,

Every teacher's got their things, I don't know, things that students probably see as quirks or whatever. And actually sometimes those quirks are very helpful in their teaching.... You sometimes have like that little plastic frog or the eraser and set it on students' desks.... Can you explain that to me and what that does for you and your students, because it seems like an important thing, but I'm not sure I understand it.

The plastic frog I was referring to was specific to sixth hour, which is not part of

this analysis, but Rudy used this opportunity to talk about a variety of the quirks of his

teaching style. He said,

The classes that the kids get off task and, or if we do get off task and it's, "Okay let's get back to math.” They struggle with that getting back on track quickly. I don't do as much of, but it goes back to kind of what my teaching philosophy is, making them have fun, wanting them to be excited when they come in the classroom. Even though it's not maybe necessarily math that we're going over or discussing, getting them interested, being goofy or weird can go a long ways, I guess.

Rudy explained his practice of including a bonus question on each test that is not

mathematical. He explained how the students grew to appreciate the question, how it

helped him learn about his students, and how the critical thinking involved in the

questions could have some mathematical value. Explaining some other typical practices, he said,

I ended up with one student 6th hour where if she starts griping I put an eraser on her desk. I just think of that stuff on the fly I guess.... Sometimes a certain concept or rule we have to do. I'll call on a student, just that student every time.... The kids kind of see that as fun I guess. They almost want to be a part of it 
because if I'm not picking on them to answer the question. Well, why doesn't he want me to do this? They want to participate more. I'll overhear some students talk mostly bad, occasionally good about another teacher in the building or they just came from a class like I hate so and so.... I'll just be kidding around, man what do you guys say about me when I'm not around or when you leave my class and they'll say, "Nothing bad really." Except they'll list some goofy things that I'll do. They don't know it but I'll use that in the future as part of that goofy stuff, reference back to it.... And those bonus questions give me a good sense of specific interests for that person or group of people. Being a coach helps out with that because I see some of the students more and interact with them more outside of class. So, I know more about just their personal life outside of school. It helps me build stronger relationships with some of them. And I interact with them differently than the other teachers.

It is apparent that although Rudy often established these practices in the moment, not as premeditated actions, he was also purposeful in his use of humor to engage students. His response indicates his belief in the power of humor to motivate and build relationships.

\section{Concluding the Results}

In this chapter I have provided a full description of the data I collected in this study. The descriptions should provide a solid foundation for the coming chapters. In Chapter V, I will describe my analysis of the data presented here. I will use the CoP framework to delve into the topics of community, meaning, identity, and learning. These four aspects have helped me organize my analysis and understanding of Rudy’s teaching practice and his learning through practice. They helped me develop meaning from my participation with Rudy in his practice. 


\section{CHAPTER V \\ DISCUSSION}

I have shared a thorough description of my experience with Rudy in his classroom context. Now, I will describe my application of the CoP framework for my analysis of Rudy's communities of practice, negotiation of meaning, identity, and learning. I will begin this chapter with the analysis and description of Rudy's communities of practice. Then, I will describe the analysis of Rudy's negotiation of meaning and share how he experienced meaning in his communities. Third, I will use these first two descriptions to develop a picture of Rudy's identity as a teacher. Finally, I will take all three prior descriptions into account as I describe how Rudy learned through his practice.

\section{Communities of Practice}

As I analyze the communities of practice in which Rudy is a member, remember that I am answering the question: What are the characteristics of Rudy's communities of practice? In order to do so I must answer the subordinate question, how do you know that a particular community constitutes a community of practice? A community of practice is not merely a group; it has more specific characteristics. In particular, a community of practice gains coherence as a community through practice in three ways: mutual engagement, joint enterprise, and shared repertoire. These are the three characteristics I

will use to describe Rudy's communities of practice. In so doing, I will provide evidence that the community is one that is given coherence through practice. 
One additional note as I begin to discuss communities of practice. For the sake of brevity, I will typically use the term community in place of community of practice. If I use the term community in the more general sense of the term I will note that usage. In all other instances for the remainder of this discussion you may assume the term community refers to a community of practice. In addition, I use the terms mutual engagement and engagement, joint enterprise and enterprise, and shared repertoire and repertoire interchangeably. Furthermore, I may add other adjectives such as community enterprise or mathematical repertoire to emphasize particular aspects of these concepts. When I do this I hope to retain the defining aspects of these technical terms while accentuating particular characteristics of the concepts, including their flexibility.

\section{Classroom Communities}

Rudy's fourth and fifth hour Math II classes each constituted separate communities of practice. However, the similarities in the communities outweigh the differences as a result of Rudy's strong participation in both communities. Therefore, I will describe each dimension in general terms while providing information, as appropriate, about what differentiates the communities. In this description I will organize the picture of community by first detailing mutual engagement, then joint enterprise, and finally, shared repertoire as distinct dimensions of the community. However, these elements play interactive roles in defining the community so elements will overlap in my descriptions.

Mutual engagement. The operationalized definition of mutual engagement I used was: an overlapping or interaction of practices of two or more people. Note one element that is not actually implied in the definition is verbal communication. The overlapping or 
interacting practices may involve verbal communications such as discussion or feedback written on a quiz, but the interacting or overlapping practices could also be handing out a worksheet, gesturing, or students working on individual assignments in tandem. These overlapping practices contribute to the work of the community.

As I described in Chapter III, while I coded instances of mutual engagement I developed a set of sub-codes that helped produce meaning for me in my analysis of engagement. I found several types of engagement that characterized the engagement among community participants. Table 3 includes the codes I used to distinguish the types of engagement in communities. Each definition includes clarification of situations that were difficult to categorize. In some cases a single interaction was coded with multiple mutual engagement codes. For instance, the following excerpt from the first lesson in Rudy's fourth hour class was coded as teacher-class and as teacher-student interaction. This was teacher-student because the teacher was interacting with a specified individual, and also teacher-class because it was within a context that allowed for the engagement of all students. First, Rudy asked for anyone to participate, but then chose to engage with one student in particular. Note that this interaction allowed the rest of the class to continue participating because Rudy then asked the class to evaluate the result of the interaction.

After the students worked on the exercise individually, Rudy addressed the class. Rudy: So, how am I going to set this equation up? Anyone? Brady raised his hand. Rudy: Devin, thanks for volunteering. What's your second equation? Devin: I got one fourth equals one sixteenth times two times $y$. Rudy wrote the equation on the board. Rudy: Is he correct? 
Table 3

Mutual Engagement Codes

\begin{tabular}{|c|c|}
\hline Code & Definition \\
\hline Teacher-class & $\begin{array}{l}\text { Instance in which a teacher was attempting to communicate with the } \\
\text { entire class. This could include communication that was directed at } \\
\text { individual students, either by verbal specification or through } \\
\text { conversational context, but was conducted in the context of a whole class } \\
\text { interaction. }\end{array}$ \\
\hline Teacher-student & $\begin{array}{l}\text { Instance of an interaction or overlapping practice between an individual } \\
\text { students and a teacher in which the student was not just acting as a class } \\
\text { representative but as an individual. This could include instances in which } \\
\text { a teacher-class interaction was occurring but the teacher addressed the } \\
\text { particular student or was responding to the particular student involved in } \\
\text { the interaction. Additionally, these interactions could be non-verbal, such } \\
\text { as the passing of papers between a teacher and a student. Situations in } \\
\text { which a student was responding to a general question posed to the class } \\
\text { without being addressed by the teacher were not considered teacher- } \\
\text { student interactions because the student was not addressed and was acting } \\
\text { as a class representative. }\end{array}$ \\
\hline Individual work & Instance in which students were engaged in individual practices. \\
\hline Group work & $\begin{array}{l}\text { Instance in which students were engaged with one another toward a } \\
\text { purposeful end in a teacher sanctioned group setting. }\end{array}$ \\
\hline Student-student & $\begin{array}{l}\text { Instance in which students were engaged with one another toward some } \\
\text { purposeful end, either mathematical or otherwise, and the interaction was } \\
\text { not established through formal grouping. }\end{array}$ \\
\hline Minimal response & $\begin{array}{l}\text { Instance in which students were or a student was unresponsive to the } \\
\text { teacher's repeated attempts for teacher-student or teacher-class } \\
\text { engagement. }\end{array}$ \\
\hline Teacher-teacher & Instance in which a teacher was engaged with another teacher. \\
\hline Teacher-staff & $\begin{array}{l}\text { Instance in which a teacher engaged in practice with an administrator or } \\
\text { other non-teaching school personnel. }\end{array}$ \\
\hline
\end{tabular}

After I applied these codes to all of the data sources for Rudy, I further analyzed the use of the codes across sources in two ways. First, I looked simply at the prevalence 
of the codes to understand the principal ways in which Rudy engaged with his classes. Then, I looked for patterns in the instances referenced for each code. One of the ways I searched for patterns was describing the activities in which these types of engagement occurred. Another was using a cross-code analysis of how participation codes intersected with a given mutual engagement code.

Table 4 displays the total number of instances coded with each mutual engagement code for all sources, all class observations only, fourth hour observations only, and fifth hour observations only. The all sources category includes evidence of Rudy's engagement in all of his communities of practice, but classroom observations include only his engagement with his classroom communities. Note that the percent of mutual engagement codes ascribed to each type of code is relatively consistent regardless of source. The primary differences occur in teacher-teacher, teacher-staff, and studentstudent codes. The difference in teacher-teacher and teacher-staff codes are merely a reflection of the observations not including opportunities for those interactions, and I will explore those interactions in the section about Rudy’s professional communities. I will investigate the student-student code differences in the section about student-student engagement.

Rudy appears to be an agent in the vast majority of instances of mutual engagement in his classroom based on the count of instances of engagement coded as teacher-class or teacher-student interaction (84\% of all engagement codes in classroom observations). My experience in Rudy's classroom indicated this result before it was revealed in my coding scheme. In a typical day, Rudy spent the majority of his time at the front of the classroom engaging his classes in the process of learning mathematics. He 
Table 4

Instances of Mutual Engagement Codes for Rudy's Sources

\begin{tabular}{|c|c|c|c|c|c|c|c|c|}
\hline \multirow[b]{2}{*}{ Code } & \multicolumn{2}{|c|}{ All sources } & \multicolumn{2}{|c|}{$\begin{array}{c}\text { All } \\
\text { observations }\end{array}$} & \multicolumn{2}{|c|}{$\begin{array}{c}4^{\text {th }} \text { hour } \\
\text { observations }\end{array}$} & \multicolumn{2}{|c|}{$\begin{array}{c}5^{\text {th }} \text { hour } \\
\text { observations }\end{array}$} \\
\hline & \# & $\%$ & \# & $\%$ & \# & $\%$ & \# & $\%$ \\
\hline $\begin{array}{l}\text { Mutual } \\
\text { engagement }\end{array}$ & 521 & - & 462 & - & 230 & - & 232 & - \\
\hline Teacher-class & 220 & 42 & 197 & 43 & 103 & 45 & 94 & 41 \\
\hline Teacher-student & 197 & 38 & 190 & 41 & 98 & 43 & 92 & 40 \\
\hline Individual work & 23 & 4 & 23 & 5 & 11 & 5 & 12 & 5 \\
\hline Group work & 18 & 3 & 15 & 3 & 7 & 3 & 8 & 3 \\
\hline Student-student & 32 & 6 & 32 & 7 & 8 & 3 & 24 & 10 \\
\hline $\begin{array}{l}\text { Minimal } \\
\text { response }\end{array}$ & 5 & 1 & 5 & 1 & 3 & 1 & 2 & 1 \\
\hline Teacher-teacher & 20 & 4 & 0 & 0 & 0 & 0 & 0 & 0 \\
\hline Teacher-staff & 6 & 1 & 0 & 0 & 0 & 0 & 0 & 0 \\
\hline
\end{tabular}

moderated the checking of homework, presented new material (often while connecting to and reviewing prior learning), and followed times of individual or group work on an exercise with a presentation of the correct result. In each of these activities it was apparent that Rudy's engagement with the whole class often involved interactions with individual students. Thus, it is no surprise that teacher-class and teacher-student codes are almost equally prevalent. For example, when Rudy moderated the checking of homework assignments he used a variety of methods. One day he called on individual students to share their answers on an assignment. On the same day, but for the second portion of the 
assignment, he asked for a choral response from the class for each exercise. In both instances the interactions were intended for the entire class, but in the first case they also involved specific interactions with individual students.

Given the prevalence of teacher-class and teacher-student interactions, I will begin with these coded references as I explain the themes and patterns that emerged in the classroom engagement.

Teacher-class. I found patterns across the instances of teacher-class interactions in two different ways. First, I looked at the types of activities that involved these teacherclass interactions. Then, I looked at Rudy's styles of participation within the teacher-class interactions. These two forms of analysis help to explain what Rudy does with the class and how he interacts in those situations.

Activities. Based purely on observation and no further analysis I would have described Rudy’s primary activity as “notes.” This analysis confirms my experience because the majority of Rudy's teacher-class engagements involved his presentation of primarily new, but sometimes previously covered, mathematical content. This was the main event of classroom activity for three of the four days of observation, splitting time with an activity I will call "homework." Each time he introduced notes he used a phrase such as, "alright, notes," which was meant to imply the longer phrase he occasionally used, “Alright, let's get our notes out.” This type of activity could be separated into presenting content, working examples, and checking examples worked by students, but these additional subdivisions did not yield significant information in the analysis of mutual engagement. Notes involved various forms of participation to be described in the following section. 
He also addressed the class in activities that involved the evaluation of students' work, which, as I mentioned, I call homework. Rudy went over the answers to every homework assignment as a class, although not necessarily on the day the assignment was due. As I have mentioned, this often involved student participation and included teacherstudent interactions as well as teacher-class interactions. Despite most of this activity involving homework I also consider Rudy's demonstration of the solution processes involved on a quiz to be in this category.

Less prevalent forms of teacher-class engagement included logistical interactions, warm ups, and non-relevant activity. Intermittently, Rudy addressed the class for logistical purposes including assigning homework, explaining the plan for the unit, describing the content of a quiz, and assigning partners. On the first day of observations Rudy had students participate in a warm-up exercise that resulted in multiple instances of teacher-class interactions. This was the only day during these observations that Rudy used a warm-up activity, but the inclusion of a warm-up section in the students' five subject notebooks indicates the typical use of warm ups as a class activity. Some instances of teacher-class engagement consisted of non-mathematical and nonpedagogical activity. For example, Rudy started the fifth hour class after winter break with a statement about firing synapses. It was apparent that many students were not familiar with the term synapse, so he proceeded to explain, through a description of acupuncture, what a synapse was. A description of this story telling episode was included in Chapter IV at the beginning of the Fifth Hour section in The First Lesson.

Participation. In order to further analyze teacher-class engagement I separated the instances of teacher-class engagement according to how the interactions were coded in 
terms of Rudy's participation. Table 5 includes the definitions of the most used

\section{Table 5}

Participation Codes (Abbreviated)

\begin{tabular}{ll}
\hline \multicolumn{1}{c}{ Code } & \multicolumn{1}{c}{ Definition } \\
\hline Allaying fears & $\begin{array}{l}\text { Instance of the teacher trying to calm the students and mitigate fear or } \\
\text { anxiety, particularly in a mathematical situation. }\end{array}$ \\
Directing & $\begin{array}{l}\text { Instance of the teacher giving directions, managing behavior, or engaging } \\
\text { in other authoritative non-mathematical interaction. }\end{array}$ \\
Evaluating & $\begin{array}{l}\text { Instance of the teacher evaluating student work and responses for } \\
\text { instructional purposes. }\end{array}$ \\
$\begin{array}{l}\text { Facilitating } \\
\text { self-evaluation }\end{array}$ & $\begin{array}{l}\text { Instance of the teacher creating space for students to reflect on their own } \\
\text { work, check their solutions, or learn from their participation in the } \\
\text { community (especially in regards to mathematics). }\end{array}$ \\
Using humor & $\begin{array}{l}\text { Instance of the teacher using humor in an interaction. } \\
\text { Mathematical } \\
\text { telling }\end{array}$ \\
Questioning & $\begin{array}{l}\text { Instance of the teacher making a statement that is both mathematical and } \\
\text { instructional. }\end{array}$ \\
Instance of the teacher questioning students for instructional purposes. \\
Story telling & $\begin{array}{l}\text { Instance of the teacher sharing information in a narrative fashion not } \\
\text { intended as instructional. }\end{array}$ \\
Using a nickname & $\begin{array}{l}\text { Instance of the teacher using a student's last name or a nickname to } \\
\text { address the student instead of his or her first name. }\end{array}$ \\
Withdrawing & $\begin{array}{l}\text { Instance of the teacher purposefully disengaging from interactions for a } \\
\text { period of time. For instance, leaving the classroom or sitting behind a desk } \\
\text { may be indicative of withdrawing (note that this need not be construed } \\
\text { negatively). }\end{array}$ \\
\hline
\end{tabular}

participation codes for this section of analysis (for a full list of participation codes see Appendix F). Table 6 includes the number of instances of teacher-class engagement that are coded at each participation code. 
Table 6

Teacher-Class Engagement Instances Coded at Participation

\begin{tabular}{|c|c|c|c|c|c|c|c|c|}
\hline \multirow[b]{2}{*}{ Code } & \multicolumn{2}{|c|}{ All sources } & \multicolumn{2}{|c|}{ Observations } & \multicolumn{2}{|c|}{$4^{\text {th }}$ hour } & \multicolumn{2}{|c|}{$5^{\text {th }}$ hour } \\
\hline & \# & $\%$ & \# & $\%$ & \# & $\%$ & \# & $\%$ \\
\hline Participation & 277 & - & 252 & - & 128 & - & 124 & - \\
\hline Allaying fears & 7 & 3 & 6 & 2 & 4 & 3 & 2 & 2 \\
\hline Answering & 24 & 9 & 24 & 10 & 8 & 6 & 16 & 13 \\
\hline Directing & 97 & 35 & 93 & 37 & 46 & 36 & 47 & 38 \\
\hline Evaluating & 58 & 21 & 52 & 21 & 30 & 23 & 22 & 18 \\
\hline $\begin{array}{l}\text { Facilitating } \\
\text { peer-to-peer } \\
\text { engagement }\end{array}$ & 10 & 4 & 9 & 4 & 3 & 2 & 6 & 5 \\
\hline $\begin{array}{l}\text { Facilitating self- } \\
\text { evaluation }\end{array}$ & 72 & 26 & 71 & 28 & 32 & 25 & 39 & 31 \\
\hline Hinting & 15 & 5 & 15 & 6 & 9 & 7 & 6 & 5 \\
\hline Using humor & 77 & 28 & 74 & 29 & 25 & 20 & 49 & 40 \\
\hline $\begin{array}{l}\text { Coordinating } \\
\text { logistics }\end{array}$ & 18 & 6 & 18 & 7 & 11 & 9 & 7 & 6 \\
\hline $\begin{array}{l}\text { Mathematical } \\
\text { telling }\end{array}$ & 179 & 65 & 179 & 71 & 84 & 66 & 95 & 77 \\
\hline Motivating & 28 & 10 & 18 & 7 & 9 & 7 & 9 & 7 \\
\hline Questioning & 182 & 66 & 178 & 71 & 95 & 74 & 83 & 67 \\
\hline Story telling & 3 & 1 & 3 & 1 & 0 & 0 & 3 & 2 \\
\hline $\begin{array}{l}\text { Uncategorized } \\
\text { participating }\end{array}$ & 35 & 13 & 15 & 6 & 6 & 5 & 9 & 7 \\
\hline $\begin{array}{l}\text { Using a } \\
\text { nickname }\end{array}$ & 17 & 6 & 17 & 7 & 16 & 13 & 1 & 1 \\
\hline
\end{tabular}

As I share my analysis of the results presented in Table 6 I will do two different 
things. First, I will look at the general distribution of types of participation in all of Rudy's teacher-class engagements. Then, I will discuss some of the differences that arise in the way Rudy engages with fifth hour and fourth hour.

Note two seeming paradoxes represented in Table 6. First, the number of total instances coded as participation and coded as teacher-class engagement, exceeds the number of teacher-class engagement codes for any selection of sources. This simply attests to the multiple types of participation within a given instance of teacher-class interaction. Second, when the percentages for all the individual participation codes are combined, the total far exceeds 100 percent. This attests to multiple types of participation within the same teacher-class interaction. It was often the case that a given teacher action was coded as participation with multiple participation codes applied. These multiple codes were not counted multiple times in the total participation count because they referred to a single instance of participation although it was characteristic of multiple types of participation.

Note in Table 6 that Rudy's teacher-class interactions were often characterized as mathematical telling and questioning (each was $71 \%$ of the teacher-class interactions coded as participation). Even in instances when Rudy was using direct instruction he often did so through the medium of questioning. Rudy's pervasive use of questioning allowed him to continually engage his students in mathematics without letting go of the teacher-centered classroom. The following excerpt from the second lesson in fourth hour illustrates how Rudy integrated the use of questioning and mathematical telling in teacher-class interactions. Rudy had just given his fourth hour students some time to simplify the expression $\frac{10}{\sqrt{-5}}$ and was beginning to demonstrate the simplification process 
at the board.

Rudy: First step.

Kale: Take your i's out

Rudy: Take your i's out. 10 over $i$ square root of 5. Can you reduce, can you break the ten and the square root of 5 down at all? No, one's a whole number, one's underneath the root. Can this be your answer?

Several students: No.

Rudy: No, why not?

Jennie: inaudible

Rudy: You have a root in the denominator and?

Jennie: $i$

Rudy: you have an $i$. What did we do when we had an $i$ in the denominator?

Brady: Multiplied by $i$

Rudy: Multiplied the top and bottom by?

Brady: $i$

Rudy: Not the denominator, just by $i$. So that'll get rid of the $i$ in the denominator, will that get rid of the root 5 in the denominator?

Brady raised his hand. Eli shook his head.

Rudy: Eli says no, I agree.

Eli: It would be $i$ squared?

Rudy: How, say we just have

Eli: No, that doesn't make sense.

The work continued...

Rudy was also a consistent director of classroom activity (46\% of the teacherclass interactions coded as participation were also coded as directing) He often communicated his expectations to the class and helped organize the participation of the members of the classroom community through his explicit direction. He employed many other means to organize the participation of the class members, such as the procedures associated with taking notes, which I suspect were less explicit at the time of observation than at the beginning of the school year. I expect these means for organizing classroom activity were objects of Rudy's direction early in the year as he engaged with his students. The development of these reifications, such as the word notes referred to earlier, allowed Rudy to limit his direction and focus on mathematical telling and questioning as he engaged with his students. However, Rudy was still extensively engaged in the 
direction of classroom activity.

Rudy's engagement with his students was riddled with humor (29\% of the teacher-class interactions coded as participation were also coded as humor). He used humor almost as frequently as directing in his whole class interactions. He used humor as a way to engage students for better recollection of mathematical definitions, principles, and procedures. For example, he used the phrase "mama thinks they're the devil” to refer to negative numbers within a square root. This was intended to help students remember to simplify expressions or solutions including negative numbers within a square root by using $i$. He also used humor to keep students attentive and to connect with individual students in the whole class setting. I will discuss these uses further in the section Directing, evaluating, and using humor in Rudy’s Participation in Practice.

Rudy found multiple ways to facilitate self-evaluation during teacher-class interaction. The primary way that he provided students a means to self-evaluate was giving whole class examples. He would write an exercise on the board, allow students time to work the exercise individually, and then work the exercise himself on the board. As he worked the exercise on the board he would often use questioning, but would also use mathematical telling. I consider this process self-evaluation because it allowed students to engage in the work of the community by verifying their own solution processes.

Not surprisingly, Rudy used whole class communication as an opportunity to evaluate his students almost as often as allowing them to evaluate themselves. The coding of instances of evaluation may have even missed many cases in which Rudy evaluated his students because I could not infer the evaluation from the data. Two ways that Rudy 
evaluated his students were in the acceptance or rejection of answers, and by asking for a raise of hands or other class-wide indication of correctness. In the first case, Rudy's intentions were primarily evaluative of the mathematical correctness of individual contributions to whole class discussions. This occurred both during the checking of homework and during notes after students had worked examples individually or as the class worked them together. The second type of evaluation was representative of Rudy's evaluation of the class educationally. In these instances he was not personally determining mathematical correctness, but was, instead, determining the performance of the class on a given task or the readiness of the class for the next part of the lesson. He often used evaluative means that were also productive motivators. For example, he would ask students to shake their own hand, or high five a neighbor if they finished an exercise correctly. This disguised his evaluation, took the pressure off students to perform for the class, and still allowed him to perform an informal check of the students' understanding of the material.

The remainder of Rudy's participation in teacher-class interactions was divided among allaying fears, answering, facilitating peer-to-peer engagement, hinting, coordinating logistics, motivating, story telling, undefined participating, and using a nickname. Each of these forms of participation accounted for less than $15 \%$ of the references coded as participation and teacher-class engagement. A full discussion of these forms of participation can be found in the section describing how Rudy negotiated meaning in his classroom context.

The general nature of Rudy's teacher-class engagement was relatively consistent between fourth and fifth hour with a couple of exceptions. Most notably, Rudy engaged 
in more mathematical telling than questioning in fifth hour and the opposite in fourth hour. I could speculate a variety of reasons for this, but I claim that this pattern of participation is related to Rudy's conception that fifth hour was "the most talented class" he had ever taught. I am not claiming that Rudy was making a conscious decision to engage with the two classes differently in terms of questioning and telling, but some of the factors that contributed to Rudy's conception that fifth hour was a more talented class may have also contributed to this difference in engagement. For instance, fifth hour responded more consistently and correctly to Rudy’s questioning in teacher-class interactions. I found this by investigating all the instances that involved questioning in teacher-class interactions that were not teacher-student interactions. I did not include teacher-student interactions because in those instances Rudy called on students and I wanted to check on students' voluntary response to questioning. In fourth hour, students responded to the questioning in 55\% of the instances, but students responded in $63 \%$ of the instances in fifth hour. Rudy answered his own question in the remainder of the instances. Of the student responses, $78 \%$ were correct in fourth hour, but $92 \%$ were correct in fifth hour. This discrepancy likely contributed to Rudy's perception that fifth hour was a better class because they were attentive to his questioning and could answer his questions correctly. Because the primary purposes for his questioning were evaluation and motivating attentiveness, I hypothesize that he reduced his amount of questioning over the year with fifth hour because they consistently responded correctly and were attentive. This may have allowed him to increase efficiency in covering content, which was a means for Rudy to cope with the sometimes overwhelming demands of his communities, as you will see in the analysis of the joint enterprise. 
Rudy used humor twice as often in teacher-class interactions in fifth hour. I

attribute this discrepancy to a purposeful difference in the way Rudy engaged the two classes. In the post-interview I asked Rudy to describe some of the goofy things that he did with his classes. I also mentioned a particular type of engagement with a student in one of his other classes and asked whether he did that with all of his classes. He responded,

The ones where... The classes that the kids get off task, and, or if we do get off task and it's, "okay, let's get back to math" they struggle with that getting back on track quickly, I don't do as much of it. But it goes back to kind of what my teaching philosophy is, making them have fun, wanting them to be excited when they come in the classroom. Even though it's not maybe necessarily math that we're going over or discussing, getting them interested being goofy or weird can go a long ways I guess.

This statement attests to Rudy's purposeful use of humor, but also how he tones down that type of engagement with classes that struggle to retain a focus on mathematical activity. In another place in the same interview Rudy described fifth hour as "more mature.” Together, these descriptions could explain why Rudy uses humor more prevalently with fifth hour.

Teacher-student. Similar to my analysis of teacher-class engagement I found patterns across the instances of teacher-student interactions in two ways. First, I looked at the types of activities that involved these teacher-student interactions. Then, I looked at Rudy's styles of participation within the teacher-student interactions. These two forms of analysis help explain what Rudy does with the individual students and how he interacts in those situations.

Activities. Rudy's teacher-student engagement occurred in the same activities (primarily homework and notes) that his teacher-class engagement occurred. However, 
the distribution of teacher-student engagement within the notes activity was different than the distribution of teacher-class engagement. Many teacher-student interactions occurred during notes. Although the majority of the notes activity involved teacher-class interactions, a smaller percentage involved teacher-student interactions. In particular, teacher-student interactions often occurred when Rudy had students work on a problem individually or in groups. At times Rudy walked around the room and engaged with individual students, but I would not call his engagement during this activity typical. This type of engagement is described in more detail in the section Participation, which follows this section. After giving students time to work, Rudy always worked the problem on the board and teacher-student engagement was also common during this part of the notes activity. Teacher-student engagement also occurred as Rudy answered students' questions, and as he reviewed material that had previously been covered in the class.

During homework, teacher-student engagement often consisted of Rudy asking for an answer and the student providing his or her answer. However, it also included students providing more extended responses about their solution processes or Rudy answering students' questions.

Less prevalent forms of teacher-student engagement included logistical interactions, warm ups, and non-relevant activity. Rudy occasionally engaged with individual students for logistical purposes including distributing worksheets, clarifying homework or directions, and allowing students to leave class. The warm-up activity allowed Rudy to engage with individual students in a similar way to notes. Many instances of teacher-student engagement consisted of non-mathematical and nonpedagogical activity. 
Participation. In order to further analyze teacher-student engagement I separated the instances of teacher-student engagement according to Rudy's participation. Table 5 includes the definitions of the most used participation codes for this section of analysis (for a full list of participation codes see Appendix F). Table 7 includes the number of instances of teacher-student engagement that were coded with each participation code.

Again, note the instances coded as participation and teacher-student interaction outnumbered the identified instances of teacher-student interaction. This can be attributed to the use of multiple participation codes on a single instance of teacher-student engagement. Also, the percentages may sum to a value greater than 100 percent because multiple types of participation may have been attributed to a single instance of participation.

Rudy's participation during teacher-student interactions was predominantly questioning (51\% of instances coded as teacher-student and participation were also coded as questioning). The prevalence of this type of participation can be attributed to Rudy's practice of questioning as a means of direct instruction. He tended toward whole class instruction as the primary method of education, but utilized questioning heavily within that process. Of the 96 references coded questioning and teacher-student interaction, 94 were also coded teacher-class interaction. This would further indicate that Rudy's interactions with students that are not within the context of a whole class interaction do not involve questioning. However, I say this with some caution because Rudy's interactions with individuals were not always audible on the recordings. Therefore, some instances when Rudy was questioning individual students may not have been recorded in a manner that could have been coded as questioning. 
Table 7

Teacher-Student Engagement Instances Coded at Participation

\begin{tabular}{|c|c|c|c|c|c|c|c|c|}
\hline \multirow[b]{2}{*}{ Code } & \multicolumn{2}{|c|}{ All sources } & \multicolumn{2}{|c|}{ Observations } & \multicolumn{2}{|c|}{$4^{\text {th }}$ hour } & \multicolumn{2}{|c|}{$5^{\text {th }}$ hour } \\
\hline & \# & $\%$ & $\#$ & $\%$ & $\#$ & $\%$ & \# & $\%$ \\
\hline Participation & 198 & - & 189 & - & 99 & - & 90 & - \\
\hline Allaying fears & 4 & 2 & 3 & 2 & 2 & 2 & 1 & 1 \\
\hline Answering & 26 & 13 & 26 & 14 & 7 & 7 & 19 & 21 \\
\hline Directing & 33 & 17 & 33 & 17 & 20 & 20 & 13 & 14 \\
\hline Evaluating & 62 & 31 & 57 & 30 & 36 & 36 & 21 & 23 \\
\hline $\begin{array}{l}\text { Facilitating } \\
\text { peer-to-peer } \\
\text { engagement }\end{array}$ & 5 & 3 & 5 & 3 & 1 & 1 & 4 & 4 \\
\hline $\begin{array}{l}\text { Facilitating self- } \\
\text { evaluation }\end{array}$ & 66 & 33 & 66 & 35 & 29 & 29 & 37 & 41 \\
\hline Hinting & 7 & 4 & 7 & 4 & 3 & 3 & 4 & 4 \\
\hline Using humor & 38 & 19 & 36 & 19 & 14 & 14 & 22 & 24 \\
\hline $\begin{array}{l}\text { Coordinating } \\
\text { logistics }\end{array}$ & 2 & 1 & 2 & 1 & 1 & 1 & 1 & 1 \\
\hline $\begin{array}{l}\text { Mathematical } \\
\text { telling }\end{array}$ & 37 & 19 & 37 & 20 & 19 & 19 & 18 & 20 \\
\hline Motivating & 12 & 6 & 8 & 4 & 7 & 7 & 1 & 1 \\
\hline Questioning & 100 & 51 & 96 & 51 & 56 & 57 & 40 & 44 \\
\hline Story telling & 3 & 2 & 3 & 2 & 0 & 0 & 3 & 3 \\
\hline $\begin{array}{l}\text { Uncategorized } \\
\text { participating }\end{array}$ & 33 & 17 & 24 & 13 & 15 & 15 & 9 & 10 \\
\hline $\begin{array}{l}\text { Using a } \\
\text { nickname }\end{array}$ & 15 & 8 & 15 & 8 & 14 & 14 & 1 & 1 \\
\hline
\end{tabular}

The second most prevalent type of participation Rudy practiced in teacher-student 174 
interactions was facilitating self-evaluation (35\% of the instances coded as both participation and teacher-student were also coded as facilitating self-evaluation). In the majority of these cases Rudy did not communicate with the student to help him or her self-evaluate, but interacted with the individual student within a broader discussion aimed at students' self-evaluation. The broader discussions took one of two forms: the class was checking a homework assignment or the class was checking an in-class example that students worked out independently or in groups. In some cases Rudy was answering a student's question by reverting follow-up questions back to the student. In these cases Rudy was using the interaction to help the individual student self-evaluate, but this occurred less than a dozen times out of the 66 instances of facilitating self-evaluation.

The next most prevalent type of participation while Rudy was engaged in teacherstudent interactions was evaluation ( $30 \%$ of the instances coded as both participation and teacher-student were also coded as evaluation). Some of these instances of evaluation overlapped with the instances of facilitating self-evaluation described above. In particular, when the class was reviewing homework answers Rudy was generally evaluating the solution provided by a given student, which in turn provided a means for self-evaluation for all of the other students. Rudy sometimes evaluated student responses during questioning, but this was typically only apparent when the questioning regarded an exercise students had worked on independently first. Both of these cases would have also been coded teacher-class interactions. Another prevalent situation coded evaluation and teacher-student interaction involved Rudy checking individual student work in private interactions. These interactions did not often involve verbal communication. The following transcript excerpt from the second lesson in fifth hour is an illustrative example 
of these teacher-student interactions.

Rudy: See if you can do number 2. Raise your hand if you think you got it. A readable answer, Kayla.

George raised his hand immediately.

Kayla: What? (sarcastically)

The class laughed.

Rudy looked at George's answer. He stuck out his hand and George gave Rudy his pencil. Rudy erased something on George’s paper. George took back his pencil and started writing. Rudy pointed to something on the paper. George erased and continued to write. Rudy went to the front of the classroom. Mike raised his hand. Rudy proceeded to Mike's desk (he was seated next to George) and looked at his answer, but made no comment. Rudy switched back to looking at George's work. He picked up George's pencil and erased something. George continued to work. Matt, who was seated behind Mike, showed Mike his answer.

It is apparent from this interaction that the students in Rudy's classes are accustomed to this type of evaluative procedure. This was not the only occurrence and students never seemed taken aback by this type of non-verbal interaction. On the contrary, they seemed to understand what different forms of this participation implied. In cases like this, I interpret that no response from Rudy indicated that Mike had reached the correct answer. Matt illustrated this understanding when he showed his own answer to Mike, presumably to receive Mike’s evaluation.

When Rudy employed mathematical telling in teacher-student interactions, which occurred in $20 \%$ of these dually coded instances, he was generally engaged with the students in one of two situations. In some cases he was answering a question asked by a student. In other cases he was in the process of evaluating and correcting students' work. Just as often as Rudy used mathematical telling, he used humor in teacher-student interactions. The majority of these situations were also teacher-class interactions. The lack of private interactions involving humor could be attributed to a lack of evidence of specific private interactions, or to an attribute of Rudy’s engagement with the students. 
For example, it could be that Rudy engages in a more serious manner with students oneon-one. Or it may be that Rudy's intentions with the use of humor (i.e., as a way to engage students for better recollection of mathematical definitions, principles, and procedures, and as a way to keep students attentive) were more appropriately applied during whole class interactions.

Rudy’s directing during teacher-student interactions involved giving passes, giving directions, assigning partners, determining seating arrangements, allocating timing, and redirecting students. Note that Rudy did not spend a significant amount of his teacher-student interactions on behavior (neither did he focus on behavior interventions with the whole class). Rudy redirected two individuals in only one instance.

In almost all circumstances in which Rudy was answering students in teacherstudent interactions these interactions were in whole class settings and also coded as teacher-class interactions. As with humor, this raises the question of why Rudy did not interact with individuals by answering in situations other than those also coded as teacher-class. The answer could be simply that the interactions were not audible for transcription. However, the main reason is more likely that there was little time for teacher-student interaction outside of the whole class discussions.

The remaining forms of participation, allaying fears, facilitating peer-to-peer engagement, hinting, coordinating logistics, motivating, and using a nickname, each accounted for less than 15 percent of the participation codes in any selection of sources. As a result, I am not presenting a thorough analysis of these forms here, but in the section Rudy's Participation in Practice. In addition, undefined forms of participation accounted for around $15 \%$ but do not represent a cohesive category for analysis, so I discuss those 
codes in Rudy's Participation in Practice.

Rudy's teacher-student engagement was less consistent across the two classes than was his teacher-class engagement. Rudy's engagement with fourth hour consisted of less answering, slightly more directing, more evaluating, less facilitating self-evaluation, less using humor, and more questioning. The difference in answering could be attributable to the students' participation, because Rudy elicited student questions the same number of times in the two classes. It is possible that prior experiences regarding questions asked by students in fourth and fifth hour influenced the students in different ways toward less or more question asking respectively, but I have found no evidence to support that conclusion. The difference in directing is attributable to menial differences such as students entering and leaving class in the middle of an hour and requiring individual direction, an instance of redirection, and adjusting the alignment of desks in the classroom all occurring during fourth hour. Rudy engaged in more evaluating during fourth hour because he checked individuals' work more as they performed independent exercises, and he had to correct students' responses to his questioning more frequently. Note that the greater frequency of correcting students' responses may be partially attributable to Rudy's greater frequency of questioning in fourth hour. The greater occurrence of facilitating self-evaluation codes is attributable to Rudy interacting with specific students more in fifth hour during instances such as checking homework that allowed students to self-evaluate. Although this may have a significant meaning in terms of differences in engagement, I have not found evidence to support any reasoning that attributes this difference to more than differences in student engagement. Rudy's less pervasive use of humor in fourth hour is consistent with my prior interpretation of his use 
of humor in teacher-class interactions.

The difference in questioning was the most significant difference in Rudy’s teacher-student engagement between the two classes, except perhaps using humor. I do not mean statistically significant; I mean qualitatively significant in terms of the implications for results. I searched for various reasons that Rudy’s questioning practices might be more prevalent in teacher-student interactions in fourth hour than fifth hour, but the only evidence wielding explanation I have found is a conjecture based on the results from teacher-class engagement. I claimed Rudy’s teacher-class engagement was tilted toward questioning in fourth hour because of the lower percentage of responses and lower percentage of correct answers from students in fourth hour. Rudy felt the need to continue his use of questioning as a form of evaluation and a way to engage students in the learning process in fourth hour. I claim his use of questioning in teacher-student engagement is an extension of the same response to questioning in fourth hour. Because fewer students responded to Rudy’s general questioning in fourth hour he used more direct questioning of individual students to keep more students engaged in the learning process. My claim is supported, if only slightly, because all of the teacher-student questioning interactions, except two, were also teacher-class interactions in which Rudy called on particular students. This supports my claim because Rudy's response to the less effective nature of his teacher-class questioning in fourth hour was an alteration of the teacher-class questioning to also be teacher-student questioning.

Individual work. In keeping with my pattern of analysis I will describe the activities during which students engaged in individual work, and then I will describe how Rudy participated with the students during individual work time. The occurrences of 
individual work in Rudy's classes are few, so this analysis will be much shorter.

Activity. Despite 11 and 12 references coded as individual work for fourth and fifth hours respectively, these references represent only nine and eight distinct occurrences of individual work in the respective classes. In fourth hour six of the nine instances were exercises that followed an example in which Rudy demonstrated the procedure needed to solve the exercise. Four of the eight instances in fifth hour followed this same form. One instance in each hour involved students engaged in a warm up. Two instances in each hour involved students engaged in homework. The final instance in fifth hour involved students engaged in an initial attempt at solving a problem they had not been shown how to solve. It is telling of Rudy's practice that in four class hours that would span an entire week of classes, students engaged in independent work an average of only twice per session.

Participation. Table 8 presents the participation codes across instances of student engagement in individual work. Once again, pertinent definitions of the participation codes are provided in Table 5 (for a full list of participation codes see Appendix F).

Directing was Rudy’s most frequent form of participation during individual work time in fifth hour (46\% of instances) and the second most frequent form during fourth hour (58\% of instances.) His directing in these situations typically involved information about whether students could work together, how much time they had left, what they should do when they finished.

Evaluating was the most frequent type of participation during individual student work in fourth hour (63\%), but was almost non-existent during fifth hour (15\%). The difference can be attributed almost entirely to three separate instances of individual work 
that occurred in a single lesson in both classes. In the first instance of individual work,

Table 8

Individual Work Engagement Instances Coded at Participation

\begin{tabular}{|c|c|c|c|c|c|c|c|c|}
\hline \multirow[b]{2}{*}{ Code } & \multicolumn{2}{|c|}{ All sources } & \multicolumn{2}{|c|}{ Observations } & \multicolumn{2}{|c|}{$4^{\text {th }}$ hour } & \multicolumn{2}{|c|}{$5^{\text {th }}$ hour } \\
\hline & $\#$ & $\%$ & $\#$ & $\%$ & $\#$ & $\%$ & $\#$ & $\%$ \\
\hline Participation & 32 & - & 32 & - & 19 & - & 13 & - \\
\hline Allaying fears & 1 & 3 & 1 & 3 & 1 & 5 & 0 & 0 \\
\hline Answering & 0 & 0 & 0 & 0 & 0 & 0 & 0 & 0 \\
\hline Directing & 17 & 53 & 17 & 53 & 11 & 58 & 6 & 46 \\
\hline Evaluating & 14 & 44 & 14 & 44 & 12 & 63 & 2 & 15 \\
\hline $\begin{array}{l}\text { Facilitating } \\
\text { peer-to-peer } \\
\text { engagement }\end{array}$ & 3 & 9 & 3 & 9 & 2 & 11 & 1 & 8 \\
\hline $\begin{array}{l}\text { Facilitating self- } \\
\text { evaluation }\end{array}$ & 0 & 0 & 0 & 0 & 0 & 0 & 0 & 0 \\
\hline Hinting & 4 & 13 & 4 & 13 & 4 & 21 & 0 & 0 \\
\hline Using humor & 4 & 13 & 4 & 13 & 2 & 11 & 2 & 15 \\
\hline $\begin{array}{l}\text { Coordinating } \\
\text { logistics }\end{array}$ & 3 & 9 & 3 & 9 & 1 & 5 & 2 & 15 \\
\hline $\begin{array}{l}\text { Mathematical } \\
\text { telling }\end{array}$ & 0 & 0 & 0 & 0 & 0 & 0 & 0 & 0 \\
\hline Motivating & 2 & 6 & 2 & 6 & 1 & 5 & 1 & 8 \\
\hline Questioning & 4 & 13 & 4 & 13 & 1 & 5 & 3 & 23 \\
\hline Story telling & 1 & 3 & 1 & 3 & 0 & 0 & 1 & 8 \\
\hline $\begin{array}{l}\text { Uncategorized } \\
\text { participating }\end{array}$ & 8 & 25 & 8 & 25 & 5 & 26 & 3 & 23 \\
\hline $\begin{array}{l}\text { Using a } \\
\text { nickname }\end{array}$ & 0 & 0 & 0 & 0 & 0 & 0 & 0 & 0 \\
\hline
\end{tabular}


Rudy engaged with multiple students in fourth hour but fewer students in fifth hour. Even though I have less data to analyze, as compared to my analysis of teacher-class and teacher-student interactions, I hypothesize that this phenomenon is a product of the interaction of engagement and Rudy’s developing perception that fifth hour was more talented.

In the second instance, Rudy allowed students to work with partners in both hours, but fifth hour took advantage of the opportunity and fourth hour did not. This resulted in no evaluation in individual work codes for fifth hour because the evaluation occurred during group work. I also compared the two situations across evaluation, regardless of individual or group work, there were still more evaluation codes for fourth hour than fifth hour, but not by Rudy’s choice. Rudy gave the exercise as a competition, and because fourth hour took longer to come up with the correct answer the competition continued and Rudy evaluated more students.

In the third instance, Rudy gave the students homework but fifth hour did not have time to start the work, so no evaluation occurred. In fourth hour the class used the time because Rudy gave a strong suggestion to do so and walked around the room evaluating students. On another day fourth hour did not have time for the homework but fifth hour did have time. This could have balanced the instances of evaluation but fifth hour did not use the time to start the homework because Rudy sat down at his desk and had an unrelated conversation with one of the students. Overall, Rudy’s engagement in evaluation was not as strong in fifth hour, and this was likely a developing interaction between his engagement and his perception of fifth hour as more talented.

Aside from uncategorized forms of participation, note that Rudy's third most 
frequent form of participation during individual work in fourth hour was hinting. It was only used four times in four days. Rudy did not use hinting during individual student work in fifth hour. The difference is notable and could be attributed to Rudy's perception of the two classes in terms of talent, however, the difference in hinting is not as pronounced across all instances of hinting in the two classes.

The other form of participation employed in more than 15 percent of individual work instances in fifth hour was questioning, but it was used only three times in fifth hour and once in fourth hour. I could begin to surmise the influences on these differences, but the small amount of questioning during group work and a brief qualitative view of the instances lead me to believe that the small amount of questioning that occurred during group work may not represent a repeatable pattern across a larger sample of Rudy's interactions during student individual work time.

Group work. Group work was also a rare occurrence in Rudy's classes during my time of observation. Because of the limited occurrences, I will not provide a table that depicts the instances of group work coded as participation. Only five of the eight observations included instances of group work. This stands in contrast to Rudy's assertion in the initial interview that he used "a lot of group work.” Despite the lack of evidence, I will still evaluate the activity and participation surrounding the instances of group work.

Activity. On several occasions Rudy presented an example problem and then gave his students a similar problem with the option of working individually or with a partner. Students chose to work with partners in only three instances, one of which was a problem that involved a competition to be the first group with the correct answer. Students worked 
with partners more frequently when Rudy assigned the partners. He did this three times, and in all three instances both partners should have already completed the exercise on a homework assignment.

Participation. The first thing to notice is students seemed somewhat reluctant to participate in groups outside of those Rudy assigned. Rudy described in the initial interview that early in the year he assigned partners based on ability. Although he was not explicit about what he meant, my observations indicate that he pairs a higher achieving student with a lower achieving student. Based on the pairings I observed in fifth hour it also seemed he paired a female with a male. In the interview he explained that these partners would work together for the whole semester, whenever he told them to work with their partners. However, he used these pairings only once in fifth hour and he assigned partners based on proximity during another lesson in both classes. As I mentioned, students did not readily participate in groups without these assignments, whether spontaneous or lasting, even when Rudy suggested they could work with a partner. Also, note that it was not a foregone conclusion that students were allowed to work in pairs or groups on problems that Rudy asked them to complete. Rudy mentioned explicitly if they were allowed to work together. On one occasion a student asked if they could work in groups, which indicates that Rudy's statements were not just a formality but also a legitimate sanctioning of group work.

Rudy engaged most, out of all forms of participation, in directing, evaluating, and facilitating peer-to-peer engagement during group work. Facilitating peer-to-peer engagement was simply due to his sanctioning of group work. Directing and evaluating had similar patterns to those in individual work. He directed students by informing them 
on items such as they were allowed to work together, how much time they had left, and what they should do when they finished. He evaluated student work of individuals or groups by walking between the rows of desks and looking over students’ papers. His participation in this way was consistent with what I described in the section about teacher-student engagement.

Student-student. Students talked with each other in Rudy’s classes far more than might be assumed by the lack of group work and student-student engagement codes. I did not apply these codes to most interactions for two reasons. First, the verbal communications in most of the interactions could not be discerned from the recordings because multiple interactions were taking place or student voices could not be heard. Second, the interactions rarely involved a purposeful end toward which the engagement was aimed. This was a necessary requirement of the coding because mutual engagement does not involve all types of interaction, but only those addressing the community enterprise. In the following sections I analyze the few student-student interactions in the typical manner, but first I return to the issue of differences in the student-student engagement in fourth and fifth hours.

Table 4, at the beginning of the section Mutual engagement illustrates that fourth hour had far fewer student-student interactions than fifth hour (eight and 24 respectively). Student-student interaction was the only form of engagement that differed significantly from class to class. I claim that the difference may have developed in tandem with the joint enterprise in each community. The form of the enterprise in the two communities is related to student-student engagement in several ways. Individual students in fifth hour were more responsible for the products of the enterprise than the class as a whole. The 
opposite was true in fourth hour. The difference in responsibilities was the most dramatic in relation to developing procedural skills (see Table 10 in the section Negotiating for complete results). The only area in which fourth hour ascribed more responsibility to individual students was in completing tasks. In the area of completing tasks fifth hour put more emphasis on correct answers than did fourth hour. Across enterprises fifth hour put more emphasis on understanding and explanation than did fourth hour. Combining these ideas that individual students were more responsible than the class as a whole in fifth hour, and more responsible in particular for correct answers and understanding, it seems reasonable that students would require greater levels of student-student communication directly related to the community enterprise. Conversely, greater student-student engagement may have contributed to these differences in the enterprise.

Activity. These few student-student interactions took place in the context of most of the normal activities of the classroom. The majority occurred during notes (20 instances), but some also occurred during homework and even outside the prescribed class activities. During notes seven of 20 instances of student-student interactions occurred during individual or group work time. The other 13 instances during notes were within the context of teacher-student or teacher-class engagement. Many of those involved students expressing some sort of solidarity or offer of help. Six instances of student-student engagement occurred during homework. Three instances of studentstudent engagement occurred outside the prescribed work of class. For example, some students started working on the warm up together before class began. Only four instances of student-student engagement hinted at any sort of conflict among students, and three of those instances occurred between the same two students. I would not characterize their 
relationship as antagonistic, but they engaged in a definite intellectual rivalry. The rivalry tended toward friendly competition but escalated slightly in one class.

Participation. Student-student engagement was occasionally spurred by Rudy’s participation. He was often engaged in questioning a particular student when a classmate expressed solidarity or offered help as the student searched for an answer. In other cases Rudy was facilitating self-evaluation or evaluating students when the student-student engagement was elicited. For example, when Rudy finished demonstrating an example he had given the students to work out individually, students would occasionally share with one another about whether they were successful. I did not analyze the few instances of Rudy's participation around student-student interactions when his participation was unassociated with the interaction.

Minimal response. Rudy only had four references coded as minimal response. Two of the four instances occurred at the beginning of notes on the first day after winter break. In another instance Rudy asked his students to recall the quadratic formula, which they had learned the previous semester. In a final instance, Rudy asked the students to recall a process they had just learned. These do not significantly contribute to this description of Rudy's mutual engagement in class. However, the lack of instances of minimal response suggests that students were engaged in the class.

Joint enterprise. I used the following operationalized definition of joint enterprise: the communally negotiated goals and practices of a working group. I searched for evidence of the joint enterprise by means of three characteristics of the enterprise.

First, it is collectively negotiated among members of the community of practice. Second, it is indigenized. Third, it produces mutual accountability for the members of the 
community. The enterprise can be considered negotiated because members of the community determine and apply the enterprise in their collective engagement in practice. The enterprise is a constantly changing and evolving dimension of the community that influences, and is influenced by, the practices of members. The enterprise is indigenized because no outside influence fully determines the form of the enterprise. The community members themselves take external influences and indigenize the enterprise of the community in a localized setting. The enterprise produces accountability because all of the members have some responsibility to pursue the enterprise. The accountability may be felt among members, but the accountability is first and foremost to the enterprise itself. Each member's perceptions of obligation may be traced through expressed accountabilities to other individuals in the community, but the ultimate obligation is to pursue the enterprise that has been collectively determined among the accountable members of the community. Thus, a member may not precisely follow their obligations toward other individuals in the community, but pursue a combination of these obligations in an attempt to balance the demands. This is an accountability to the negotiated enterprise itself, as born out in the demands of mutual accountability to community members. I used these three characteristics of the joint enterprise, as operationalized in the definitions in Table 9, to code instances of the enterprise in action.

These three codes allowed me to identify critical instances in which the joint enterprise was being applied in the classroom community. After I coded all the sources with these three codes, I began to investigate the internal patterns in the coding. I discerned the enterprise of each class, how it was negotiated and indigenized, and how community members were held accountable to the enterprise. I will detail this analysis 
separately for each code (negotiating, indigenizing, and accountability) as I attempt to draw a comprehensive picture of the enterprise in each class.

Table 9

Joint Enterprise Codes

\begin{tabular}{cl}
\hline \multicolumn{1}{c}{ Code } & \multicolumn{1}{c}{ Definition } \\
\hline Negotiating & $\begin{array}{l}\text { Instance in which parties in the community are negotiating the joint } \\
\text { enterprise of the community through mutual engagement. }\end{array}$ \\
Indigenizing & $\begin{array}{l}\text { Instance in which parties in the community are responding to external } \\
\text { influences as they instantiate the joint enterprise within their practice. }\end{array}$ \\
Accountability & $\begin{array}{l}\text { Instance in which parties are holding each other accountable to pursue the } \\
\text { joint enterprise of the community, or feeling the pressure (perceived or } \\
\text { otherwise) of accountability to pursue the joint enterprise. }\end{array}$ \\
\hline
\end{tabular}

Negotiating. As I explored the instances coded as negotiating I found two elements in the instances worthy of analysis. First, each instance had a product that was deemed worthy of production. Second, each instance had a community member who was deemed responsible for the production. The products of these instances included a completed task (which might include an expectation for a correct answer), a mathematical explanation, a mathematical understanding, a procedural skill, a recollection of prior learning in mathematics, and non-mathematical products. Those responsible for these products varied among the teacher, the class, or a student. Table 10 displays the frequency of each of these products and responsible parties across all of the instances of negotiating found in the observations of Rudy’s classes.

The first observation I made from Table 10 is that most of the expected products in the classes were completed tasks and developed procedural skills. Together these 
Table 10

Instances of Negotiating Coded at Products and Responsible Parties

\begin{tabular}{lcccc}
\hline \multicolumn{1}{c}{ Product } & Class & Student & Teacher & Total \\
\hline Completion & 7 & 13 & 4 & 24 \\
Explanation & 2 & 3 & 1 & 6 \\
Understanding & 4 & 6 & 3 & 13 \\
Procedure & 14 & 13 & 15 & 42 \\
Recollection & 6 & 1 & 1 & 8 \\
$\begin{array}{l}\text { Non- } \\
\text { mathematical }\end{array}$ & 1 & 2 & 3 & 6 \\
\hline Total & 34 & 38 & 27 & 99 \\
\hline
\end{tabular}

accounted for two thirds of the products desired in these instances of negotiating the enterprise. It is clear that the community valued these products in terms of daily output. However, the enterprise was broader than the immediate outcomes of daily class activities. These instances of negotiation point to the ultimate outcome of getting through the class and being able to do mathematics. Together I claim these make up an enterprise I call “doing school.” A differentiation of the classes is revealing in this case. Table 11 includes the same data as Table 10, separated by class.

Notice a significant difference in the distribution of products for fifth hour. Fourth hour focuses on the doing school enterprise, but understanding took on a significantly more important role in the enterprise of fifth hour than it did for fourth hour. This indicates a slightly different emphasis in the fifth hour enterprise that has an increased focus on understanding. I call this enterprise “doing mathematics.” It would stand to 
Table 11

Instances of Negotiating Coded as Products and Responsible Parties

\begin{tabular}{|c|c|c|c|c|c|c|c|c|}
\hline \multirow[b]{2}{*}{ Product } & \multicolumn{2}{|c|}{ Class } & \multicolumn{2}{|c|}{ Student } & \multicolumn{2}{|c|}{ Teacher } & \multicolumn{2}{|c|}{ Total } \\
\hline & $4^{\text {th }}$ & $5^{\text {th }}$ & $4^{\text {th }}$ & $5^{\text {th }}$ & $4^{\text {th }}$ & $5^{\text {th }}$ & $4^{\text {th }}$ & $5^{\text {th }}$ \\
\hline Completion & 2 & 5 & 7 & 6 & 2 & 2 & 11 & 13 \\
\hline Explanation & 2 & 0 & 0 & 3 & 0 & 1 & 2 & 4 \\
\hline Understanding & 0 & 4 & 0 & 6 & 0 & 3 & 0 & 13 \\
\hline Procedure & 9 & 5 & 3 & 10 & 6 & 9 & 18 & 24 \\
\hline Recollection & 4 & 2 & 0 & 1 & 0 & 1 & 4 & 4 \\
\hline $\begin{array}{l}\text { Non- } \\
\text { mathematical }\end{array}$ & 1 & 0 & 2 & 0 & 2 & 1 & 5 & 1 \\
\hline Total & 18 & 16 & 12 & 26 & 10 & 17 & 40 & 59 \\
\hline
\end{tabular}

reason that Rudy's perception of fifth hour as the more talented class influenced his engagement with fifth hour and altered the form of the enterprise. However, I claim that the class altered the form of the enterprise. In particular, the participation of one student pushed the enterprise in a direction which Rudy was unprepared to move and, in many respects, unwilling to move. The following transcript excerpt from the first lesson in fifth hour illustrates my claim, and it is not the only instance of a similar nature. In this excerpt Rudy had just introduced the imaginary number $i$ and had students list off a variety of real numbers.

Rudy: Imaginary numbers, again you're gonna get more involved with this next year, they're not real numbers. George, I know what you're thinking. It's hard to go further in depth without taking other class periods to explain what it actually is. That's for next year, and for another teacher to explain. I'm just kidding, I like it when you ask those questions. Alright, so, really all you need to know: the square root of negative one, that's equal to $i$; $i$ squared is equal to a negative one. 
So when you get a square root that has a negative number in it, the square root of negative 10, the first step: you gotta take your i's out. (Rudy made a motion like he was plucking his eyes out)

Rudy’s anticipation of George’s question indicates how typical it was for George to ask a probing question about meaning. George wanted to understand more about what an imaginary number was, not just that it was the square root of negative one. In this instance George was not given the opportunity to speak for himself, but in other cases George confirmed that he was interested in asking precisely the questions that Rudy anticipated he wanted to ask. Also, note that George did not get an answer. Rudy claimed that he liked George to "ask those questions," but proceeded to avoid answering the question and claimed that all the students needed to know was the definition he provided. Notice that Rudy's next statement is a procedural statement. Rudy is implicitly making the claim that the reason the definition of $i$ was important was because it produced the procedure "taking the $i$ out."

I am not claiming that Rudy never answered George’s questions. Similarly, I am not claiming that Rudy did not alter his approach to the enterprise in fifth hour. However, I am claiming that the strongest influence toward understanding as a significant product of the enterprise was initiated by the student, George. I am also claiming that Rudy was resistant to George’s push for understanding in the majority of instances I observed. Rudy may have been resistant in part because of the conflictual relationship of this understanding enterprise with the enterprise of his mathematics teacher community, which I will show was content coverage. Rudy’s statement that, “It's hard to go further in depth without taking other class periods to explain what it actually is” gives credence to this notion that he perceives the understanding enterprise and the content coverage 
enterprise in conflict. In this case it seems that the mathematics teacher community at the school seems to have won the battle.

One case in which Rudy was not resistant was when George asked about the development of the quadratic formula. Rudy took the opportunity to talk about the history of mathematics. Unfortunately, he did not know who first derived the quadratic formula and he did not take the opportunity to derive the formula with the students. Instead, he talked about other historical figures and their contributions to mathematics. Although his discussion was not directly related to the original question, I interpret this instance as Rudy's attempt to validate George’s approach to the enterprise and understanding mathematics. It also illustrates that Rudy was unprepared to indulge George's attempts to alter the joint enterprise.

You may also observe from Table 11 that the proportion of all products the teacher was responsible for in each hour was similar. The teacher was responsible for $25 \%$ of the products in fourth hour and $29 \%$ of the products in fifth hour. However, the responsibilities were distributed differently between the class and individual students. Individual students in fourth hour were given more responsibility for the basic completion of tasks ( $64 \%$ of the completion tasks) and the class took a higher responsibility for developing procedures (50\%), recalling prior learning (100\%), and explaining (100\%). In fifth hour developing procedures and explaining were more the responsibility of individual students (56\% and $75 \%$, respectively) than the class as a whole. The other products were distributed approximately equally between students and the class. The difference in the distribution of responsibility between classes could be attributed to Rudy's perception of the talent level in the classes. It was Rudy who tended 
to assign the responsibility for the products and the likely reason for the differences in his engagement in this regard was his perception of talent.

One final observation from Table 11 is that Rudy was sometimes responsible for conveying or using procedural skills, but rarely any other products. This was consistent across both classes. Rudy was less responsible than the students or class for every product except procedures and non-mathematical products according to the aggregate figures in Table 10. The same result holds for all cases in Table 11 except explanations in fifth hour. The most pronounced distinction in responsibility was that for completing tasks, which was heavy on the side of students and the class.

When I included the evidence from sources other than observations I found a slightly different perspective regarding the negotiated enterprise. In particular, evidence from interviews suggests that some of Rudy's primary objectives were non-mathematical. His statements about his philosophy of mathematics education suggested that some of his primary goals were motivating students and making mathematics bearable. When asked about big picture objectives in the initial interview he mentioned that he wanted students "leaving math class with it still on their mind," and contemplating "change the world ideas.” He may have had essentially the same goals in mathematics class as he had as a wrestling coach: motivating students/wrestlers, making life in practice/class bearable, using hard work and dedication to develop these same qualities, creating dreamers willing to pursue their passions. Based on the rest of the analysis of the negotiated enterprise, this vision of Rudy's goals does not seem to bear itself out in its entirety in the classroom. However, as you will see in what I have yet to share, Rudy’s idea of motivation was not what I would traditionally imagine, but was consistent with his work 
in negotiating the enterprise. In addition, these goals may have been personal goals pursued in relation to the coaching or teaching communities and only coordinated with the pursuit of the classroom enterprise. Thus, it may be expected that these goals did not manifest themselves in the work of the classroom community. Now, I turn to indigenizing the enterprise.

Indigenizing. I did not find a significant amount of evidence of Rudy's classes indigenizing the enterprise. I only coded 24 instances in all my sources. In the observations that total dropped to seven instances. This lack of evidence could mean one of the following three things. It could mean that I overlooked many instances of indigenizing. I do not think this is the case because of the coding procedures I utilized. It could mean that few external forces were at play in the classroom communities during my time of observation. I do not think this is precisely the case because there are significant power structures at play in any school setting. More likely it is this third possibility. It could mean that most of the indigenizing of the enterprise occurred early in the school year, or even throughout the students' years of schooling and Rudy's years of teaching. At the time of observation, January of Rudy's seventh year in the district and the students' grade 10 year, the enterprise may have been thoroughly indigenized. The outside influence may have already been built into the local practices of the community so that local negotiations among members represented outside forces inherently. This does not imply that indigenization was not occurring, but that it was an underlying process not easily identifiable to an outside observer.

In all of the instances coded as indigenizing Rudy was the only force of indigenization. Rudy took external influences that dictated grading programs and 
procedures and adapted the policies for his purposes. For example, he told his students that he would not enter grades in the online reporting system for the first two weeks of the spring semester. Rudy also indigenized content scope and sequence policies and created a localized adaptation of those expectations. For example, he took sections from two different chapters in the textbook (Carter et al., 2012) and made them into the unit he taught during my observations. The students' role in this type of indigenization was indirect through their engagement with Rudy in class. Rudy may have used his experiences with the students to inform his indigenization decisions. Due to the lack of evidence regarding indigenization of the enterprise I will turn my attention to the accountability to the enterprise.

Accountability. As I explored the instances coded as accountability I categorized the instances in two ways. First, I separated the instances into those in which the teacher was the subject of accountability and those in which the students were the subjects of accountability. I also categorized the instances based on the community or group espousing the enterprise to which the subjects were accountable. I included accountability to the classroom enterprise, the mathematics teaching enterprise, the landscape of educators' enterprise, and the enterprise of the school's constellation of communities. I am not claiming that all of these are specific communities of practice, but constellations and landscapes are more complex systems of interacting communities (constellations and landscapes are each explained in the section Rudy's Boundary Encounters). The class, or specifically Rudy, felt some sense of accountability to the enterprises developed among these groups. The accountability to these communities, constellations, and landscapes may have, in some cases, influenced Rudy's engagement in his classes and the enterprise 
of the classroom community. Table 12 includes the number of instances of accountability to each community intersected with the subject of accountability.

Table 12

Accountability of Students and Teachers to Communities

\begin{tabular}{lcccc} 
Subject & Classroom & $\begin{array}{c}\text { Mathematics } \\
\text { teachers }\end{array}$ & Educators & School \\
\hline Students & 98 & 0 & 0 & 1 \\
Teacher & 39 & 4 & 14 & 10 \\
\hline
\end{tabular}

Note in the data that students were the subjects of accountability to the enterprise of the classroom community more often than Rudy. Rudy was the subject of accountability about two-thirds of the number of times his students were the subjects of accountability. Considering only classroom observations, Rudy was the subject of accountability one-third as often as his students.

Students were accountable in three ways in the class. First, they were accountable to the enterprise through their participation in the enterprise. By this I mean each student felt a sense of accountability through his or her own identification as a member of the classroom community. His or her pursuit of the joint enterprise represented a form of competence in the community that promoted a sense of identity as student. When he or she failed to pursue the enterprise, he or she compensated in a way that allowed him or her to continue to justify his or her role as a community member. For example, Rudy assigned fourth hour an exercise to complete during the second lesson and told them the next exercise would involve a competition. Nick compensated for his decision not to 
pursue the enterprise by completing the exercise, by stating, “I’m not gonna waste my brain on this one.” His claim was that his brainpower would be better employed in application to the next exercise involving the competition. One could argue that this was merely a flippant remark by a student who did not feel like doing another mathematics exercise. I would agree, but I also claim that the flippancy was a means of social temperance that allowed him to justify, to the community to whom he was accountable, his failure to pursue the enterprise.

This episode illustrates not only the student's accountability to the enterprise through his participation in the enterprise, but also his accountability to his classmates as community members. This is the second way students were accountable in the classroom community. The accountability among students in fourth hour was less pronounced than in fifth hour. The accountability in fifth hour often took the form of accountability for correct answers. For example, I mentioned previously that two students in fifth hour had developed a rivalry. The winner, for lack of a better term, of the competition in this class was typically determined by who had the correct answer. The following example from the first lesson in fifth hour illustrates their rivalry and accountability to answer correctly.

Rudy: Alright Mike, what is your [answer].

Mike: I have two answers actually, but I'm not sure.

Rudy: You have two answers?

Mike: I think it's negative 6 but if it's not that it's negative 36 .

Rudy: You're letting George get into your head.

Mike: No, I was thinking about it but then when he said it I, yeah. I think it's negative 6 but if it's not that then it's negative 36 .

After working through the problem.

Rudy: Mike, the answer?

Mike: Negative 36. I told you it wasn't 36 George.

George: That's still wrong.

Mike: That was my second answer, though, so why are you making a big deal of it? 
Rudy: Oh, you two.

George and Mike were not the only students interested in the correct answer. In the next excerpt, from the second lesson in fifth hour, Rudy was calling on students to provide their answers to homework exercises. Sahara responded, "Well, this was the one that I didn't understand. Okay. I have this one, I have 7, 8, 11, and 12 circled. I still did them, but I just really don't want to say my outcome.” Rudy did not press her to share her answer for that exercise and allowed her to share her answer for another exercise of her choosing. I claim that this student was feeling some accountability to her classmates for providing a correct answer. Even though she was making it clear in this statement that she did not fully understand the mathematical concept, and that her answer was most likely incorrect, she did not want to reveal the answer to her classmates. She felt more comfortable admitting that she did not understand one of the exercises and sharing a correct answer to a different problem than presenting an incorrect answer.

The third type of students' accountability to the enterprise came through Rudy’s engagement with students. The students’ accountability to Rudy took concrete form primarily in the practices of homework and assessments. The students were accountable for both completing and providing correct answers in both of these cases. However, the emphasis in homework was on completion. Correct answers and procedures were as much the responsibility of Rudy and the whole class as individual students. The answers and sometimes the procedures were often provided before the homework was graded, and in cases when the answers were provided after grading, Rudy based the grade on completion. In the case of assessments the expectation for correct answers was stronger. Rudy provided the correct answers after grading, and the grade was always based on 
correct answers and procedures.

Rudy's participation in these practices also requires analysis. He assigned homework every day that I observed. He also gave what he called a mini-quiz in the middle of the unit, and one quiz at the end of the unit. He adapted these practices for situation-specific needs, based on the negotiated participation of the community. When he adapted his lessons in order to spend more time reviewing how to solve quadratics, he added an unplanned mini-quiz. He also adapted his coverage of homework based on the different needs of his classes. He spent time going over homework with fourth hour on a day that he left for a wrestling meet during fifth hour. On the following class day he spent more time going over homework with fifth hour to compensate for the altered needs of the community. However, in adapting his participation he also demonstrated a tension across classes to cover approximately the same content in approximately the same amount of time. This was likely, at least in part, out of a sense of accountability to the enterprise of the school community that had decided to de-track their classes.

Rudy was accountable to a variety of enterprises for the communities in which he was a member, including the enterprises of his classes. The primary means by which he experienced accountability in the classroom settings was through questions asked by his students. In fourth hour the students' questions typically requested a procedural account of finding correct answers. This is consistent with the analysis of the negotiated enterprise. In fifth hour, however, George attempted to hold Rudy accountable to a different standard. George expected Rudy to help him understand in addition to applying correct procedures. In the discussion of the negotiated enterprise I described how Rudy anticipated George’s questions. This is indicative of a history of accountability for 
George's understanding that resulted in Rudy's accountability to the community enterprise, which had evolved to include understanding over the school year.

Determining the joint enterprise was the most difficult aspect of characterizing the classroom community. It involved the most interpretation of all three dimensions, and it is the aspect for which it is hardest to justify the label community of practice for a classroom community. One of the reasons it is difficult to label a classroom a community of practice is because the teacher does not seem to fit. In this dimension it sometimes appeared that Rudy was not engaged in the same enterprise as the students, suggesting he may have been interacting with students, but was accountable to another community. I claim that his action was at the boundaries of multiple communities and he acted as a broker among communities, but this did not make him less of a member of the classroom community. The evidence presented here attests to his membership in the classroom community. He is not just an outsider of the classroom community attempting to shape the community for the students. Now, I turn to the third dimension of the classroom communities of practice, shared repertoire.

Shared repertoire. I used the following operationalized definition of shared repertoire: the elements of co-constructed meaning, usefulness, and practice of a working group. As I explained in Chapter III, as I coded instances of shared repertoire I developed a set of sub-codes that helped me produce meaning in the analysis of the repertoire. I categorized the repertoire on two dimensions. First, I labeled elements of the shared repertoire according to content (classroom, mathematical, global, local). Second, I labeled elements of the shared repertoire according to stage of development in the community (emerging, established with discrepancies, established, and unnecessary). The 
second label is an over-simplification because individual members of the community may have differing access to the elements of the shared repertoire. Thus, making a global determination of the stage of development for the community neglects the place of individual learning in relation to the repertoire. However, in the classroom context, it serves as a reasonable approximation of the element's position in the community. Table 13 includes the definitions I used to distinguish the content and stage of development codes of the shared repertoire. I coded each element of the shared repertoire with both a content code and a stage code.

Table 14 includes the counts and percentages of all shared repertoire codes. The percentages were calculated in each sub-category (content and stage) not for the whole category of shared repertoire.

Table 13

Shared Repertoire Codes

Code Definition

Content

Classroom Non-mathematical element of the classroom shared repertoire including tools, artifacts, norms.

Mathematical Mathematical elements of the shared repertoire could include mathematical definitions, postulates, theorems, procedures, strategies, norms, sayings, notations, visuals, representations, and possible other mathematical elements. Answers to mathematical problems, when the problem and solution process are not discussed, or directions that involve minimal mathematical information are not considered elements of the repertoire.

Educational Educational elements are related to the educational sphere and shared by those involved in education (e.g., mathematics teachers, or the local community of educators). 


\begin{tabular}{|c|c|}
\hline Code & Definition \\
\hline Global & $\begin{array}{l}\text { Shared cultural experiences based on larger societal memberships } \\
\text { (e.g., movie references, pop-culture, social media) }\end{array}$ \\
\hline Local & Part of local or school culture \\
\hline \multicolumn{2}{|l|}{ Stage } \\
\hline Emerging & $\begin{array}{l}\text { Element of a shared repertoire that is being initially established by } \\
\text { one or more members of a given community participating in an } \\
\text { interaction. Mathematical elements of the shared repertoire that fit } \\
\text { this categorization must be part of the teacher's lesson objective for } \\
\text { the day. }\end{array}$ \\
\hline $\begin{array}{l}\text { Established } \\
\text { with } \\
\text { discrepancies }\end{array}$ & $\begin{array}{l}\text { Element of a shared repertoire that is partially established for } \\
\text { community members participating in a given interaction. Partial } \\
\text { establishment of a mathematical element is evidenced when both of } \\
\text { the following are true: (a) the element is no longer the expressed } \\
\text { objective of the given lesson for the teacher, (b) discrepancies in the } \\
\text { understandings of various community members were observed in the } \\
\text { interaction (implied discrepancies are not significant evidence; the } \\
\text { discrepancy must be observable). }\end{array}$ \\
\hline Established & $\begin{array}{l}\text { Element of a shared repertoire that is established for community } \\
\text { members participating in a given interaction. No discrepancies in } \\
\text { understandings were observed in the interaction and the element is } \\
\text { not the objective for the day. }\end{array}$ \\
\hline Unnecessary & $\begin{array}{l}\text { A possible element of the shared repertoire that the teacher dismisses } \\
\text { as unnecessary to establish in the community. }\end{array}$ \\
\hline
\end{tabular}

Note in Table 14 that the number of content codes does not match the number of stage codes. The mismatch is the result of some overlapping coding. For example, a continuous discussion of a mathematical topic would have been coded as a single mathematical element of the shared repertoire. However, aspects of this mathematical discussion may have been coded as emerging or established depending on the state of the class' use of the particular aspect.

From the counts in Table 14, note that classroom and mathematical elements of 
the repertoire were predominant. This should come as no surprise because I was observing a mathematics classroom. Also, notice that fifth hour had a higher percentage of classroom elements than mathematical and fourth hour had the opposite. However, the distribution of stage codes was consistent across classes. In order to better understand how the categories worked together, Table 15 presents the number of overlapping codes for each content code with each stage code.

\section{Table 14}

Elements Coded at Shared Repertoire for Rudy's Sources

\begin{tabular}{|c|c|c|c|c|c|c|c|c|}
\hline \multirow[b]{2}{*}{ Code } & \multicolumn{2}{|c|}{ All sources } & \multicolumn{2}{|c|}{$\begin{array}{c}\text { All } \\
\text { observations }\end{array}$} & \multicolumn{2}{|c|}{$\begin{array}{c}4^{\text {th }} \text { hour } \\
\text { observations }\end{array}$} & \multicolumn{2}{|c|}{$\begin{array}{c}5^{\text {th }} \text { hour } \\
\text { observations }\end{array}$} \\
\hline & \# & $\%$ & \# & $\%$ & \# & $\%$ & \# & $\%$ \\
\hline All shared repertoire & 749 & - & 534 & - & 247 & - & 287 & - \\
\hline Content & 341 & - & 239 & - & 110 & - & 129 & - \\
\hline Classroom & 112 & 33 & 99 & 41 & 44 & 40 & 55 & 43 \\
\hline Mathematical & 155 & 45 & 106 & 44 & 53 & 48 & 53 & 41 \\
\hline Educational & 28 & 8 & 0 & 0 & 0 & 0 & 0 & 0 \\
\hline Global & 15 & 4 & 15 & 6 & 4 & 4 & 11 & 9 \\
\hline Local & 31 & 9 & 19 & 8 & 9 & 8 & 10 & 8 \\
\hline Stage & 408 & - & 295 & - & 137 & - & 158 & - \\
\hline Emerging & 98 & 24 & 46 & 16 & 21 & 15 & 25 & 16 \\
\hline $\begin{array}{l}\text { Establish with } \\
\text { discrepancies }\end{array}$ & 51 & 13 & 46 & 16 & 23 & 17 & 23 & 15 \\
\hline Established & 239 & 59 & 196 & 66 & 91 & 66 & 105 & 66 \\
\hline Unnecessary & 20 & 5 & 7 & 2 & 2 & 1 & 5 & 3 \\
\hline
\end{tabular}


Table 15

Overlapping Content and Stage Codes for Shared Repertoire

\begin{tabular}{lcccc}
\hline \multicolumn{1}{c}{ Content } & Emerging & $\begin{array}{c}\text { Established with } \\
\text { discrepancies }\end{array}$ & Established & Unnecessary \\
\hline Classroom & 6 & 4 & 106 & 0 \\
Mathematical & 80 & 42 & 120 & 18 \\
Educational & 12 & 2 & 17 & 0 \\
Global & 3 & 2 & 10 & 5 \\
Local & 5 & 2 & 25 & 1 \\
\hline
\end{tabular}

Classroom elements tended to be well-established elements of the shared repertoire (91\% of the classroom elements were established). This is to be expected in January because the students had been in this class for five months. Many established elements of the classroom shared repertoire added efficiency to the practices of the community. For example, the notes activity I mentioned in the mutual engagement portion of the analysis was used as a typical means to organize classroom activity. When Rudy said "notes” students understood to take out their five subject notebooks, open to the section they had designated for this activity, and prepare to learn new mathematical content. The word symbolized much more than a general concept that transferred across classes. It symbolized a form of organization of information, a process of production for the community, and the beginning of what would be emerging elements of the shared repertoire. Similarly, when Rudy said, “clear your desks” it initiated a particular classroom practice of taking a mini-quiz. Students immediately tore out a sheet of paper, ripped it in half, often gave half to a neighbor, cleared everything from their desk except 
a pencil and the half sheet of paper, and waited for Rudy to write exercises on the board. They proceeded to work out the exercises and then place their half sheets of paper on a chair at the front of the room. None of this needed any explanation at this point in the year because it was an established part of the repertoire. The simple phrase, "clear your desks” indicated more than a single action.

I think it is very unlikely that Rudy started the year by introducing this phrase as the indicator for this activity. However, in the course of community engagement in practice, this phrase became more than Rudy intended. Not only did his students learn what Rudy was trying to teach them, but Rudy learned as this element of the class repertoire emerged.

Emerging elements of the classroom repertoire were elements Rudy used to help students recall mathematical content. For example, in fifth hour Rudy called on a student, Ben, the first time that he needed to use the equivalence of $i$ squared with negative one. The second time Rudy employed the same equivalence he called on Ben again. Rudy called on Ben nearly every time the equivalence was employed. Even in situations when Rudy probably would not have called on a student under normal circumstances he pointed to the $i^{2}$ that appeared on the board and Ben would fill in the blank as quickly as Rudy himself. Even on the day that Ben was absent he called Ben's name more than once. These elements of the shared repertoire (the equivalence of $i^{2}$ and -1 and Ben being the one to provide it) became so interconnected that on the day Ben was absent a student raised his hand and asked to text Ben and ask what $i^{2}$ was. One might suggest that this was a mathematical element, and I would agree that it was inseparably connected with the mathematical concept, but it was unique to this classroom. Rudy did not do the 
same thing, with the same concept in fourth hour. He did, however, use a similar tactic with other concepts and with his other classes. The evidence hints that when they were learning about complex conjugates the student whom he asked to provide the complex conjugate was the same student he asked repetitively to provide the conjugate when they were learning about rationalizing the denominator during the previous semester. These instances of emerging classroom elements connected with emerging mathematical elements may be few, but they were significant in Rudy's classroom nonetheless.

The mathematical elements of the shared repertoire were predominant over the other content in terms of references coded. This would be expected in a mathematics classroom. I also expected that the most prevalent stage code for mathematical elements would have been emerging, but the most prevalent code was established, followed closely by emerging. The reason for this can be explained in two ways. First, the instances that helped promote the emergence of a particular mathematical concept were coded over large swaths of time that may have included multiple examples or discussions of the same emerging topic. The other codes were not often applied over similarly expansive sections of observations because the established elements were not the focus of the lesson. Second, Rudy typically used several established elements of the mathematical shared repertoire to help develop one emerging element of the mathematical shared repertoire. Thus, I think established mathematics codes outnumbering emerging is somewhat misleading

In these overlapping codes, it is apparent that Rudy built connections among mathematical concepts that were established and concepts that were just emerging. This was likely a pervasive aspect of Rudy's practice, but the mathematical content covered 
during my observation period lent itself especially well to these connections. In the previous semester the class had learned about radical expressions and quadratic equations. The unit I observed involved expressions involving complex numbers and equations with complex solutions (particularly quadratics). These content areas are related in such a way that there was an analogue from a prior unit for every mathematical procedure employed in this unit, or the mathematical procedure in this unit was an extension of a prior procedure. Table 16 includes a list of the analogues for this unit.

Table 16

Procedural Analogues From Prior Units for Procedural Elements of the Emerging Mathematical Shared Repertoire

\begin{tabular}{|c|c|c|c|}
\hline Element & Example & Analogue & Example \\
\hline $\begin{array}{l}\text { Identifying the } \\
\text { number of } \\
\text { solutions for a } \\
\text { polynomial } \\
\text { equation }\end{array}$ & $\begin{array}{l}\text { The number of solutions for } \\
\text { the equation } \\
3 x^{4}-2 x^{2}=x^{5}-7 \\
\text { is five because the standard } \\
\text { form of the equation is } \\
x^{5}-3 x^{4}+2 x^{2}-7=0 \\
\text { and the degree of the } \\
\text { polynomial } \\
x^{5}-3 x^{4}+2 x^{2}-7 \\
\text { is five. }\end{array}$ & $\begin{array}{l}\text { Identifying the } \\
\text { degree of a } \\
\text { polynomial }\end{array}$ & $\begin{array}{l}\text { The degree of the } \\
\text { polynomial } \\
x^{5}-3 x^{4}+2 x^{2}-7 \\
\text { is five because the highest } \\
\text { degree of the terms in the } \\
\text { polynomial is five }\end{array}$ \\
\hline $\begin{array}{l}\text { Taking your } \\
\text { i’s out }\end{array}$ & $\begin{array}{c}\sqrt{-13} \\
\sqrt{-1 \cdot 13} \\
\sqrt{-1} \cdot \sqrt{13} \\
i \sqrt{13}\end{array}$ & $\begin{array}{l}\text { Extracting } \\
\text { perfect } \\
\text { squares }\end{array}$ & $\begin{array}{c}\sqrt{12} \\
\sqrt{4 \cdot 3} \\
\sqrt{4} \cdot \sqrt{3} \\
2 \sqrt{3}\end{array}$ \\
\hline
\end{tabular}




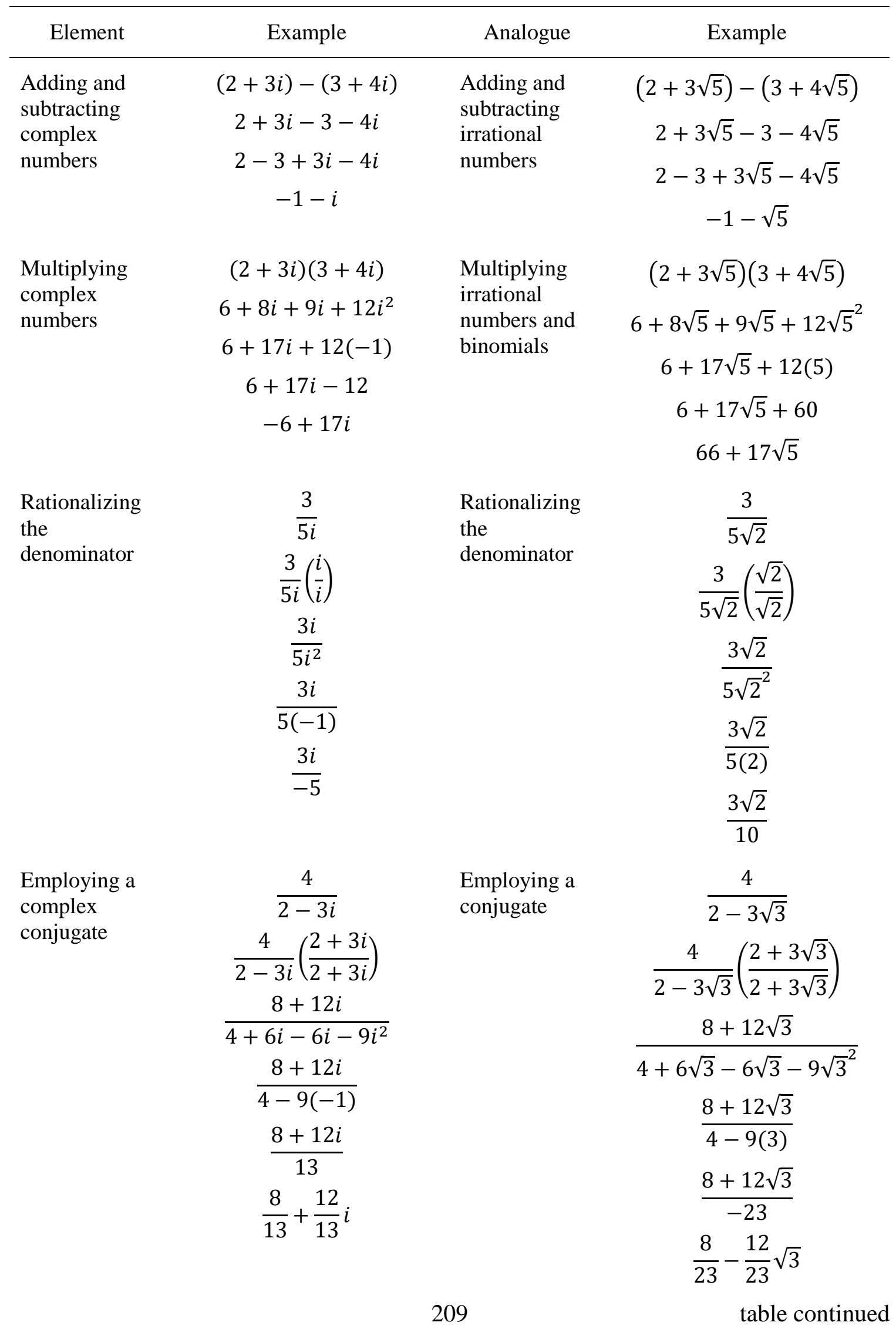




\begin{tabular}{lclc}
\hline \multicolumn{1}{c}{ Element } & Example & Analogue & Example \\
\hline Solving & $x^{2}+100=0$ & Solving & $x^{2}-100=0$ \\
quadratic & $x^{2}=-100$ & quadratic & $x^{2}=100$ \\
equations with & $x= \pm \sqrt{-100}$ & equations & $x= \pm \sqrt{100}$ \\
complex & $x= \pm 10 i$ & & $x= \pm 10$ \\
solutions & & & \\
\hline
\end{tabular}

The first column lists the primary mathematical procedures that were developed as elements of the mathematical shared repertoire during my observations. The analogue column includes a mathematical procedure that was already an established element of the shared repertoire during my observations. These elements in the analogue column were either a similar procedure that Rudy described as similar while teaching the mathematical element in the unit I observed, or he extended in the unit I observed. For example, identifying the number of solutions for a polynomial equation is a direct extension of the procedure for identifying the degree of a polynomial. However, the procedure Rudy called "taking your $i$ 's out” is analogous to the procedure of extracting perfect squares because each step in one procedure has a corresponding step in the other procedure, as can be seen in the examples in Table 16 (note that not all of the examples in the table were used in the classes I observed).

These analogous and extended procedures allowed Rudy to make connections between established elements of the mathematical repertoire and emerging elements of the mathematical repertoire. Because the enterprise was focused largely around the application of mathematical procedures, I surmise that the connections to prior learning may have been stronger in this unit than was typical. I also conjecture that this analogical reasoning was an element in how Rudy experiences mathematics. I will argue in a later 210 
section about mathematical reifications (Mathematical objects) that his meaning making in mathematics involved the development of mathematics as an internally coherent, logical system. These analogical procedures are one of the elements that established the internal coherence in Rudy's mathematical understandings.

The education elements of the shared repertoire were not part of the repertoire of the classroom community, so I will describe them further in relation with the mathematics teacher community in the section Mathematics teachers at Valley View High School. The other elements of the shared repertoire were not very prevalent. The only other category that was somewhat prevalent included established elements of the local shared repertoire. This included things like the school bell, the school's online grade reporting system, and the technology improvement plan. The majority of these elements, as would be expected, were established. Those elements that were emerging appeared in the teaching community and not the classroom community.

\section{Professional Communities}

Most researchers who have investigated teachers' learning in communities of practice have focused their analysis, and reasonably so, on the teachers' professional communities. Although I am focusing my analysis on classroom communities, I also want to provide a general picture of the professional communities for context and to better understand Rudy's identity as a teacher. The data sources that demonstrate Rudy's participation in these communities provided me far less information than the data collected for his classroom communities. Despite the abbreviated nature of this analysis, the results present some interesting implications for learning through practice. 
Mathematics teachers at Valley View High School. Rudy was in community with two other mathematics teachers at Valley View High School. These were the only three mathematics teachers at the school. I had one opportunity to observe Rudy as he engaged with the other two teachers, Jean and Julie. I described this interaction in the section Teacher Inservice in Chapter IV. Rudy also described his relationship with them at several points in his two interviews, and described their interaction with the middle school mathematics teachers on one occasion. Based on his description I would surmise that the middle school teachers constitute a separate community that intersects with the community of high school mathematics teachers in significant ways. However, the lack of data regarding the middle school community and its interactions with the high school community lead me to limit my speculations. Just as in the analysis of the classroom community, I will describe the mutual engagement, joint enterprise, and shared repertoire of these communities separately despite the integrated nature of these dimensions of community.

Mutual engagement. Rudy described a few types of mutual engagement in terms of the activities the teachers do together. He described historical activities involving decisions about curriculum, course scope and sequence, and course offerings. He also described and engaged in current discussions about course scope and sequence. Finally, he described collaboration such as sharing class activities and designing lessons together.

The historical activities of decision-making were not only a product of their community, but involved their collaboration with administrators. Rudy described his perspective in these decisions as conflicting with the other teachers and administrators. However, I think his engagement was not always conflictual; I believe he was in 
agreement on the decisions to use an integrated curriculum, and to institute what they call an essentials course. However, he did describe his opposition to the implementation plan promoted by the administration and Jean and Julie, and said it "went against everything I said, but no one really listened to me cause I'm just young and don't know what I'm talking about.” He had cautioned them against having each teacher be responsible for one section of each of the new courses. Rudy warned them that the workload would be "way too much.” He described his experience in that first year of implementation as "a waste.” I do not have evidence that anyone else thought it was a waste, but Rudy assured me that Jean and Julie started complaining after a couple of months.

During the follow-up interview Rudy described how his engagement with Jean and Julie changed over the course of time in the following way:

Um, at first, it was one of the high school math teachers, she's been here a long time. The other one has been here a year longer than me. At first, it was I didn't want to say a whole lot because I was new at it. Just more, I was figuring some stuff out on my own. Then, it was I've been teaching for a while now, I'll try to add my two-cents and help each other out, but they just kept shutting me down. So now, it's like back to I'm not saying anything but I'm just kind of doing my own thing. That part gets frustrating. Like, if I do have questions, or would like some opinions or thoughts, I don't even want to go talk to them about it.

The way Rudy engaged with the other teachers during the inservice meeting was consistent with this description of his current engagement. I did not observe conflict, but Rudy presented his questions and Jean and Julie presented answers. They did not offer suggestions, but told him what he needed to cover based on what they were or were not covering. This type of engagement could have been as much a product of Rudy's prior participation as Jean and Julie's, but it was clear that Rudy did not hold the same position as competent in the community.

Rudy described his collaboration, beyond scope and sequencing discussions, with 213 
Jean and Julie several times throughout the study. He described them as "hard to work with.” In the same episode I described above, when he was describing the implementation of their changes to an integrated curriculum, he explained that they wanted to collaborate more, but he claimed "that's something to do after we've established pacing guides, curriculum maps.” In the interview after my observations he described his collaboration in this way:

I think for me, I would like to collaborate more. I think that you can't collaborate enough. There's been so many changes and I'm young enough, I haven't been teaching long enough where I have things down to where I have enough free time to go around and collaborate. My first year I locked myself in my room. I worked through my preps, my lunches, I'd come in on Sundays, lesson plan, things like that. I didn't have time to collaborate. We taught three years and then, three or four years. The schedule's changed so much. We were on block, then we went to modified just for math and English in the mornings. So, the kids would come here for 40 minutes, 45 minutes whatever, and then they would flip flop with their english class for 45 minutes, but it was just for the morning classes. The afternoon classes were still block. And then we went to the modified block, we, we're on now where it's block classes Wednesday, Thursday; Monday, Tuesday, Fridays are traditional. Throw in the okay, we're going integrated, throw in the here's new textbooks, all that stuff. You're teaching every class. It was pretty stressful and it was hard to collaborate. Not to mention, we don't have a common prep.

Rudy clearly had significant challenges to overcome during his first seven years of teaching. The obstacles he saw to his collaboration were significant. However, in his seventh year as a teacher, in the third year implementing an integrated curriculum, and the second year on a consistent schedule, he continued to cite a lack of time and experience as reasons for not collaborating. I claim these reasons may have contributed to his avoidance of collaboration at one time, but the primary reason he was not collaborating at the time of my study was his marginal membership in the mathematics teachers’ community of practice. 
Joint enterprise. I found evidence for the joint enterprise of the mathematics teachers' community in the same places and stories I described in the mutual engagement analysis. In hindsight it would have been revealing to spend more time collecting data with Jean and Julie to better understand the community, but I did not know beforehand that Rudy would be a peripheral member. The evidence I have suggests that the joint enterprise of the community was limited. One might expect a community of mathematics teachers to have the mathematical education of students as their jointly negotiated enterprise with additional undergirding goals and practices. Although I think the community possessed a hint of this, the main enterprise, from my observations, was presenting the students an adequate set of mathematical topics to prepare them for standardized testing, graduation, and subsequent career paths. I will call this the content coverage enterprise. The only negotiation of goals and practices I observed among the teachers focused on scope and sequence. The only mutual accountability to the enterprise regarded covering particular topics in the appropriate course. The only indigenization of the enterprise involved the choice of topics from the textbook ascribed to a given course. All three of these attest to the content coverage enterprise.

Shared repertoire. The shared repertoire of the mathematics teachers' community consisted primarily of mathematics. This mathematics was significantly influenced by the textbooks being used at the time of observation. It is likely that they also had shared understandings of a variety of other things including the school system, the history of mathematics course offerings, pedagogical principles, and information about specific students. Unfortunately, the limited observation of the interactions of this community limit the evidence of the shared repertoire to mathematical concepts as presented in the 
textbooks used for their Math I, Math II, and Math III courses.

Mathematics teachers beyond Valley View High School. I did not purposely seek evidence of Rudy's relationships with teachers beyond the mathematics teachers at Valley View High School. However, his answer to one of the follow-up interview questions about how interactions with colleagues shaped his practice included a description of his interactions with teachers from other schools. He made these comments:

I'll ask other math, high school teachers what their thoughts are on it even though they're not integrated. When we go to, each year we go to three different... like conferences where a bunch of math teachers from surrounding schools get together and do professional development.

He described another area school and said,

Their teachers are pretty nice to work with. So talking with them about, for instance, the quadratics unit cause I feel like that takes up so much of my time. How long should I be teaching this, versus let's move on and get to something else? It's still a work in progress because we haven't been teaching integrated that long.

This is the entirety of the evidence I have for this community. As such, I cannot claim it to be a community of practice, but these other teachers at least represent an aspect of the landscape of practice. Rudy's engagement with them was a boundary encounter between communities of practice within the same landscape of practice. I include this description despite the lack of evidence about the interactions because it presents an interesting relationship within the landscape of practice. Even though these teachers may not have been a part of Rudy's community of practice, he saw them as a part of his landscape of practice. This allowed him to engage with these teachers in meaningful ways. Not only did he engage with them, but he claimed he would rather engage with them than with the teachers in his own community of practice. 
Coaches at Valley View High School. Recall that, outside of his meeting with the mathematics teachers, Rudy interacted exclusively with physical education teachers during the inservice day. These teachers were also coaches at the school and I claim this group comprised a separate community of practice at Valley View High School. The evidence from these interactions is not robust, but is enough to suggest that more than friendships existed among these coaches, and possibly others, at the school. I will briefly present the evidence of mutual engagement, joint enterprise, and shared repertoire for this coaching community of practice.

Mutual engagement. It is important to remember that mutual engagement is more than interactions among friends. Rudy’s conversations with his fellow coaches and his choice to sit at their table during the staff meeting and at lunch do not necessarily constitute mutual engagement. But looking a bit deeper, the conversation over lunch with Coach Roger and Coach Ryan was a small indication of the mutual engagement of Rudy and the coaches he was seated with. First, he mentioned that he coached baseball with Ryan. This relationship implies a stronger form of engagement than mere coexistence. In addition, Rudy informed Roger that he had used the bouldering wall with his wrestlers. There were two aspects of this conversation that could point to a sustained relationship of mutual engagement. First, Rudy informed him after the fact indicating an existing understanding about shared space and equipment. Second, after Rudy informed Ryan he used the wall, Ryan inquired about how he used the wall and how his athletes performed. This extended the conversation into an evaluation and sharing of practices that could contribute to the enterprise of the community. The conversation continued as Rudy told Ryan how he could access equipment typically under Rudy’s care. These extensions 
indicate that Rudy and Ryan were engaged over the joint enterprise of the community through a discussion of the shared repertoire that could be used to accomplish the enterprise.

Joint enterprise. The lunch conversation included evidence of a joint enterprise within the coaching community. The sharing of equipment and ideas about its use expressed the mutual engagement around the physical development of student athletes at Valley View High School. Furthermore, the way the coaches discussed the athletic development of student athletes indicated a negotiated enterprise of physical development integrated across sports. They described the desire of one student athlete to prepare for a spring sport while participating in a winter sport. Their description of the proper path to success in both sports indicated how the community of coaches was focused on a collective enterprise beyond the goals of a single sport. They also discussed the athletic prowess of one particular student athlete, his talents beyond a single sport, and the physical development that would be necessary for his success beyond Valley View High School. These conversations indicate that the coaching community may have been engaged in the enterprise of physical development for the student athletes at Valley View High School.

In his follow-up interview Rudy made the following comment:

With my wrestlers, yeah, do we want to go undefeated, is it about wins, losses. It's nice but it's not all about that. It's a lot about the life lessons that you can take out of just the sport in general. Between the discipline, the mental attitude, all that stuff.

This indicates that the enterprise, or at least Rudy's instantiation of it, may not be entirely about physical development. It may include a strong focus on aspects of character and mental development as well. 
Shared repertoire. The discussion described in the section about mutual engagement illustrates elements of a shared repertoire of the coaching community. Rudy and Ryan shared tools of the trade. They used common equipment and shared an understanding of how to appropriately apply the use of those tools for the development of student athletes. They also discussed a known group of student athletes and the physical characteristics and developed skills necessary for success in particular sports.

\section{Rudy's Boundary Encounters}

Now that I have described Rudy's communities of practice it is important to note that these communities do not operate in isolation. Communities of practice come in contact with one another at boundary encounters. The boundary encounters can be significant sources of learning for individuals in the communities and the communities themselves. Wenger (1998) has described interacting communities of practice in at least three different ways: constellations, landscapes, and multimembership. I will not take time here for a full analysis of these boundary encounters among Rudy's communities, but it is imperative that I mention them before I finish this discussion about communities of practice.

In Communities of Practice Wenger (1998) introduced the concept of a constellation of communities. In this construct a group, such as a school, may be viewed as too large and disconnected to constitute a single community of practice, but as the interacting constitution of a group of communities of practice. This view may be helpful in analyzing the interactions of the communities of practice in Rudy's environment. However, I lack sufficient evidence about the majority of these communities at Valley View High School to do justice to a description of the constellation of communities. 
Wenger (1998) has also described a landscape of practice. In this metaphor the interlocking communities of practice that make up a field of knowledgeability constitute a landscape. Each community has common elements because they are focused on the same domain, but each community has unique aspects that contribute to the diversity of the landscape. Consider Rudy's mathematics teacher community at Valley View and those mathematics teachers he met three times each year outside of Valley View. Rudy described how these communities of practice came together in a boundary connection among practices that contributed to the function of the individual communities. Rudy took back suggestions, comments, practices, questions, and tools he gained in these boundary encounters to implement in his practice in his local community.

Wenger (1998) described boundary encounters in more ways than constellations, landscapes, and multimembership, but the final description I would like to use for Rudy's community interactions is multimembership. Rudy was a community member in each of his classrooms, not just the ones I have written about. I have also shown that he was a member of the community of mathematics teachers at Valley View High School and the community of coaches at Valley View. I am going to adopt the assumption that Rudy was also a member of many other communities of practice that I have not observed. He was the head wrestling coach and presumably had a community of coaches who supported him. He was a baseball coach and presumably had a community of practice specific to that team. He was a person and likely had communities of practice outside of school for hobbies, family engagements, or other activities. All of these communities had an impact on Rudy as a member. Each one influenced his identity as a person and influenced his identity in the others. His identification as a coach impacted his practice as a teacher in 
the community of mathematics teachers. His identification as a teacher in the community of mathematics teachers impacted his practice as a teacher in the classroom community. His identity as a teacher in fourth hour had an impact on his practice as a teacher in fifth hour. As I mentioned, this is not the point at which I will include a full analysis of these boundary encounters. Instead, you will find a fuller description of the interacting forces of Rudy’s communities in the section Identity, and the section Learning.

\section{Negotiation of Meaning}

As I turn from community, it should never be excluded from this analysis.

Community is an interactive piece of every aspect of this theory. However, it is no longer the focus of my analysis as I attend to meaning as it was negotiated in Rudy's practice. Also, recall that practice is the underlying theme in community, meaning, identity, and learning. Practice gave coherence to Rudy's communities through mutual engagement, joint enterprise, and shared repertoire. Now I will describe how practice established meaning in Rudy's experiences through his participation in communities of practice and reifications that organized his experience into a concrete reality. It is the interplay of these two aspects of existence (participation and reification) that allowed Rudy to draw meaning from his experiences. I am seeking to address the following question as I describe meaning: How did Rudy negotiate meaning in practice?

\section{Rudy's Participation in Practice}

I purposefully chose to discuss participation first because I want to give participation precedence in a community that is often more concerned with reification. As educators, we give teachers a new textbook and tell them to work out the details. We develop a new set of standards and expect a drastic change in education as a result. I 
watch a teacher as he participates in community and then I put words into a dissertation. These words are supposed to be the most important product of three years of hard work, but they are no more important than what I watched. They are no more important than my interactions with Rudy or the hours I spent in participation through analysis. Do not misunderstand me, these words are important, but these words are an expression of participation. These words are a reification of Rudy's participation in his communities of practice, of my participation in his communities of practice, of my participation in an academic community of practice. Participation is not more important than reification, but participation is more important than I, at least, have tended to assume.

Recall that participation is simply living, doing, interacting, working together. As described by Wenger (1998), participation "describes the social experience of living in the world in terms of membership in social communities and active involvement in social enterprises." In Chapter III I described that as I began coding instances of participation I developed codes that characterized that participation. Because I used participation codes to assist with my analysis of mutual engagement, I included an abbreviated list of those codes in the mutual engagement section. A complete list of the participation codes and their operationalized definitions is included in Table 17.

I applied these codes to all the data sources to begin characterizing Rudy's participation in his communities of practice. These codes led me to one description of Rudy’s participation. Table 18 helps begin my description by providing the number of instances coded as each type of participation. It also includes the percentage of participation in each community coded at the given type of participation. 
Table 17

Participation Codes

\begin{tabular}{|c|c|}
\hline Code & Definition \\
\hline \multicolumn{2}{|l|}{$\begin{array}{l}\text { Participation in the } \\
\text { classroom community }\end{array}$} \\
\hline Allaying fears & $\begin{array}{l}\text { Instance of the teacher trying to calm the students and mitigate fear } \\
\text { or anxiety, particularly in a mathematical situation. }\end{array}$ \\
\hline Answering & $\begin{array}{l}\text { Instance of the teacher answering students for instructional } \\
\text { purposes. }\end{array}$ \\
\hline Directing & $\begin{array}{l}\text { Instance of the teacher giving directions, managing behavior, or } \\
\text { engaging in other authoritative non-mathematical interaction. }\end{array}$ \\
\hline Evaluating & $\begin{array}{l}\text { Instance of the teacher evaluating student work and responses for } \\
\text { instructional purposes. }\end{array}$ \\
\hline $\begin{array}{l}\text { Facilitating } \\
\text { peer-to-peer } \\
\text { engagement }\end{array}$ & $\begin{array}{l}\text { Instance in which teacher's participation encourages peers to engage } \\
\text { with one another in a process of evaluation, support, discussion. }\end{array}$ \\
\hline $\begin{array}{l}\text { Facilitating self- } \\
\text { evaluation }\end{array}$ & $\begin{array}{l}\text { Instance of the teacher creating space for students to reflect on their } \\
\text { own work, check their solutions, or learn from their participation in } \\
\text { the community (especially in regards to mathematics). }\end{array}$ \\
\hline Hinting & Instance of the teacher providing hints to help students. \\
\hline Using humor & Instance of the teacher using humor in an interaction. \\
\hline $\begin{array}{l}\text { Coordinating } \\
\text { logistics }\end{array}$ & $\begin{array}{l}\text { Instance of the teacher participating in classroom activity through } \\
\text { logistical arrangements and other non-interactive contributions to } \\
\text { community activity. }\end{array}$ \\
\hline $\begin{array}{l}\text { Mathematical } \\
\text { telling }\end{array}$ & $\begin{array}{l}\text { Instance of the teacher making a statement that is both mathematical } \\
\text { and instructional. }\end{array}$ \\
\hline Motivating & $\begin{array}{l}\text { Instance of the teacher attempting to motivate students. Or an } \\
\text { instance in which students are motivated by the teacher's actions } \\
\text { regardless of the teacher's intent. }\end{array}$ \\
\hline Questioning & $\begin{array}{l}\text { Instance of the teacher questioning students for instructional } \\
\text { purposes. }\end{array}$ \\
\hline Story telling & $\begin{array}{l}\text { Instance of the teacher sharing information in a narrative fashion not } \\
\text { intended as instructional. }\end{array}$ \\
\hline
\end{tabular}




\begin{tabular}{ll}
\hline \multicolumn{1}{c}{ Code } & \multicolumn{1}{c}{ Definition } \\
\hline $\begin{array}{l}\text { Uncategorized } \\
\text { participation }\end{array}$ & $\begin{array}{l}\text { Instance of the teacher's participation in the classroom activity that } \\
\text { does not fit a currently defined code. }\end{array}$ \\
$\begin{array}{l}\text { Using a } \\
\text { nickname }\end{array}$ & $\begin{array}{l}\text { Instance of the teacher using a student's last name or a nickname to } \\
\text { address the student instead of his or her first name. }\end{array}$ \\
$\begin{array}{l}\text { Withdrawing } \\
\text { Instance of the teacher purposefully disengaging from interactions } \\
\text { for a period of time. For instance, leaving the classroom or sitting } \\
\text { behind a desk may be indicative of withdrawing (note that this need } \\
\text { not be construed negatively). }\end{array}$ \\
$\begin{array}{l}\text { Participation in the } \\
\text { teaching community } \\
\begin{array}{l}\text { Developing } \\
\text { matructional }\end{array}\end{array}$ & $\begin{array}{l}\text { Instance of the teacher developing plans for instruction } \\
\text { Influencing } \\
\text { change }\end{array}$ \\
$\begin{array}{l}\text { Uncategorized } \\
\text { participation }\end{array}$ & $\begin{array}{l}\text { Instance of the teacher participating with colleagues in the process } \\
\text { of making large scale changes including curricular changes, class } \\
\text { sequence changes, or other large scale changes. }\end{array}$ \\
$\begin{array}{l}\text { Instance of the teacher's participation in the teaching community } \\
\text { that does not fit a currently defined code. }\end{array}$ \\
\hline
\end{tabular}

Table 18

Instances of Participation Codes for Rudy's Sources

\begin{tabular}{|c|c|c|c|c|c|c|c|c|}
\hline \multirow[b]{2}{*}{ Code } & \multicolumn{2}{|c|}{ All sources } & \multicolumn{2}{|c|}{$\begin{array}{c}\text { All } \\
\text { observations }\end{array}$} & \multicolumn{2}{|c|}{$\begin{array}{c}4^{\text {th }} \text { hour } \\
\text { observations }\end{array}$} & \multicolumn{2}{|c|}{$\begin{array}{c}5^{\text {th }} \text { hour } \\
\text { observations }\end{array}$} \\
\hline & $\#$ & $\%$ & \# & $\%$ & $\#$ & $\%$ & \# & $\%$ \\
\hline All participation & 805 & - & 701 & - & 337 & - & 364 & - \\
\hline $\begin{array}{l}\text { Participation in the } \\
\text { classroom community }\end{array}$ & 758 & - & 701 & - & 337 & - & 364 & - \\
\hline Allaying fears & 8 & 1 & 7 & 1 & 5 & 1 & 2 & 1 \\
\hline Answering & 19 & 3 & 19 & 3 & 6 & 2 & 13 & 4 \\
\hline Directing & 95 & 13 & 91 & 13 & 44 & 13 & 47 & 13 \\
\hline
\end{tabular}




\begin{tabular}{|c|c|c|c|c|c|c|c|c|}
\hline \multirow[b]{2}{*}{ Code } & \multicolumn{2}{|c|}{ All sources } & \multicolumn{2}{|c|}{$\begin{array}{c}\text { All } \\
\text { observations }\end{array}$} & \multicolumn{2}{|c|}{$\begin{array}{c}4^{\text {th }} \text { hour } \\
\text { observations }\end{array}$} & \multicolumn{2}{|c|}{$\begin{array}{c}5^{\text {th }} \text { hour } \\
\text { observations }\end{array}$} \\
\hline & $\#$ & $\%$ & $\#$ & $\%$ & $\#$ & $\%$ & \# & $\%$ \\
\hline Evaluating & 70 & 9 & 56 & 8 & 33 & 10 & 23 & 6 \\
\hline $\begin{array}{l}\text { Facilitating } \\
\text { peer-to-peer } \\
\text { engagement }\end{array}$ & 6 & 1 & 5 & 1 & 7 & 2 & 5 & 1 \\
\hline $\begin{array}{l}\text { Facilitating self- } \\
\text { evaluation }\end{array}$ & 35 & 5 & 30 & 4 & 13 & 4 & 17 & 5 \\
\hline Hinting & 16 & 2 & 16 & 2 & 10 & 3 & 6 & 2 \\
\hline Using humor & 75 & 10 & 73 & 10 & 26 & 8 & 47 & 13 \\
\hline $\begin{array}{l}\text { Coordinating } \\
\text { logistics }\end{array}$ & 30 & 4 & 30 & 4 & 15 & 4 & 15 & 4 \\
\hline $\begin{array}{l}\text { Mathematical } \\
\text { telling }\end{array}$ & 171 & 23 & 171 & 24 & 78 & 23 & 93 & 26 \\
\hline Motivating & 25 & 3 & 17 & 2 & 9 & 3 & 8 & 2 \\
\hline Questioning & 145 & 19 & 141 & 20 & 71 & 21 & 70 & 19 \\
\hline Story telling & 4 & 1 & 4 & 1 & 0 & 0 & 4 & 1 \\
\hline $\begin{array}{l}\text { Uncategorized } \\
\text { participation }\end{array}$ & 41 & 5 & 23 & 3 & 11 & 3 & 12 & 3 \\
\hline $\begin{array}{l}\text { Using a } \\
\text { nickname }\end{array}$ & 14 & 2 & 14 & 2 & 13 & 4 & 1 & 0 \\
\hline Withdrawing & 4 & 1 & 4 & 1 & 0 & 0 & 4 & 1 \\
\hline $\begin{array}{l}\text { Participation in the } \\
\text { teaching community }\end{array}$ & 47 & - & 0 & - & 0 & - & 0 & - \\
\hline $\begin{array}{l}\text { Developing } \\
\text { instructional } \\
\text { materials }\end{array}$ & 20 & 43 & 0 & 0 & 0 & 0 & 0 & 0 \\
\hline $\begin{array}{l}\text { Influencing } \\
\text { change }\end{array}$ & 6 & 13 & 0 & 0 & 0 & 0 & 0 & 0 \\
\hline
\end{tabular}




\begin{tabular}{|c|c|c|c|c|c|c|c|c|c|}
\hline \multirow[b]{2}{*}{ Code } & & \multicolumn{2}{|c|}{ All sources } & \multicolumn{2}{|c|}{$\begin{array}{c}\text { All } \\
\text { observations }\end{array}$} & \multicolumn{2}{|c|}{$\begin{array}{c}4^{\text {th }} \text { hour } \\
\text { observations }\end{array}$} & \multicolumn{2}{|c|}{$\begin{array}{c}5^{\text {th }} \text { hour } \\
\text { observations }\end{array}$} \\
\hline & & \# & $\%$ & \# & $\%$ & $\#$ & $\%$ & \# & $\%$ \\
\hline & $\begin{array}{l}\text { Uncategorized } \\
\text { participation }\end{array}$ & 21 & 45 & 0 & 0 & 0 & 0 & 0 & 0 \\
\hline
\end{tabular}

Mathematical telling and questioning. Rudy's most prominent forms of participation were mathematical telling and questioning (24\% and $20 \%$ of the classroom participation codes respectively.) Much of Rudy’s time in class was spent in front of his class participating in prescribed activities (i.e., notes, warm ups, homework). When Rudy participated in any of these activities his participation typically took the form of mathematical telling or questioning.

Table 19

Mathematical Telling and Questioning in Mutual Engagement as Percent of Instances Coded as Participation

\begin{tabular}{lcccc}
\hline & \multicolumn{2}{c}{ Fourth hour } & \multicolumn{2}{c}{ Fifth hour } \\
\cline { 2 - 5 } $\begin{array}{c}\text { Mutual } \\
\text { Engagement }\end{array}$ & $\begin{array}{c}\text { Mathematical } \\
\text { telling }\end{array}$ & Questioning & $\begin{array}{c}\text { Mathematical } \\
\text { telling }\end{array}$ & Questioning \\
\hline Teacher-class & 66 & 74 & 77 & 67 \\
Teacher-student & 19 & 57 & 20 & 44 \\
Individual work & 0 & 5 & 0 & 23 \\
Group work & 0 & 1 & 0 & 0 \\
Student-student & 0 & 3 & 0 & 7 \\
Minimal response & 0 & 3 & 2 & 2 \\
\hline
\end{tabular}


Table 19 shows the percentage of mutual engagement instances (Teacher-class, teacher-student, and others) also coded as participation that were coded as mathematical telling or questioning. In other words, I found the number of instances dually coded as any form of participation and one form of mutual engagement for each class, then I found the percent of those instances coded at mathematical telling and the percent for questioning. Note that these figures are the same as those presented in the mutual engagement section, but organized for comparison across types of engagement. In the section Teacher-class I discussed the discrepancy in Rudy's use of mathematical telling and questioning during teacher-class engagement in the two class hours. I found that the difference was likely attributable to some of the same forces that contributed to Rudy's perception of fifth hour as a more talented class.

Table 20

Mutual Engagement Codes as Percentage of all Instances Coded at Mathematical Telling and Questioning

\begin{tabular}{lcccc} 
& \multicolumn{2}{c}{ Fourth hour } & \multicolumn{2}{c}{ Fifth hour } \\
\cline { 2 - 5 } Mutual & $\begin{array}{c}\text { Mathematical } \\
\text { telling }\end{array}$ & Questioning & $\begin{array}{c}\text { Mathematical } \\
\text { telling }\end{array}$ & Questioning \\
\hline Teacher-class & 82 & 60 & 83 & 61 \\
Teacher-student & 18 & 35 & 16 & 30 \\
Individual work & 0 & $<1$ & 0 & 2 \\
Group work & 0 & $<1$ & 0 & 0 \\
Student-student & 0 & 2 & 0 & 5 \\
Minimal response & 0 & 2 & $<2$ & 2 \\
\hline
\end{tabular}


To determine the percentages in Table 20 I found the percentage of all instances of mathematical telling coded at a particular type of mutual engagement. Consider the numbers in the cell at the intersection of fourth hour mathematical telling and teacherclass engagement. In both Table 19 and Table 20 I used the number of instances coded as both mathematical telling and teacher-class engagement in fourth hour. In Table 19 the 66 is that number as a percent of all instances of teacher-class engagement coded as any form of participation. In Table 20 the 82 represents that same number as a percent of all instances of mathematical telling in fourth hour.

Table 20 shows over $80 \%$ of Rudy's mathematical telling involved teacher-class engagement and nearly all of the remainder was teacher-student engagement in both class hours. The mutual engagement was slightly more distributed for Rudy's questioning, but still occurred primarily during teacher-class engagement.

Participation helped me describe the ways in which Rudy developed meaning in his classroom existence. Rudy participated in two primary ways, mathematical telling and questioning, both of which helped convey mathematical content, including mathematical procedures. Questioning had the added benefit of allowing him to evaluate the progress of individual students toward the correct application of procedures, and evaluate the progress of the class as a whole along the same trajectory. These forms of participation match well with my prior analysis of the enterprise of the classroom community and the enterprise of the mathematics teachers. The classroom community sought to complete tasks and develop procedural skills, and similarly the teachers' community sought to cover appropriate course content. Both of Rudy's most prominent forms of participation helped him find meaning in pursuit of these enterprises and the evaluation of his progress 
in those pursuits.

Directing, evaluating, and using humor. As evidenced in Table 18, Rudy also directed classroom activities (13\% of the instances coded as participation), used the occasional dose of humor (10\% of the instances), particularly in fifth hour, and provided evaluation (8\%), particularly in fourth hour. In all types of mutual engagement (see Table 21, which includes calculations consistent with Table 19), Rudy used humor more during

Table 21

Directing, Evaluating, and Using Humor in Mutual Engagement as Percent of Instances Coded at Participation

\begin{tabular}{lcccccc}
\hline & \multicolumn{3}{c}{ Fourth hour } & & \multicolumn{3}{c}{ Fifth hour } \\
\cline { 2 - 7 } $\begin{array}{l}\text { Mutual } \\
\text { Engagement }\end{array}$ & Directing & Evaluating & $\begin{array}{c}\text { Using } \\
\text { humor }\end{array}$ & Directing & Evaluating & $\begin{array}{c}\text { Using } \\
\text { humor }\end{array}$ \\
\hline $\begin{array}{l}\text { Teacher-class } \\
\text { Teacher- }\end{array}$ & 36 & 23 & 20 & 38 & 18 & 40 \\
student & 20 & 36 & 14 & 14 & 23 & 24 \\
$\begin{array}{l}\text { Individual } \\
\text { work }\end{array}$ & 58 & 63 & 11 & 46 & 15 & 15 \\
$\begin{array}{l}\text { Group work } \\
\begin{array}{l}\text { Student- } \\
\text { student }\end{array}\end{array}$ & 62 & 62 & 8 & 56 & 33 & 22 \\
$\begin{array}{l}\text { Minimal } \\
\text { response }\end{array}$ & 29 & 57 & 14 & 16 & 11 & 11 \\
\hline
\end{tabular}

fifth hour than in fourth hour. I have already discussed this, attributing his reluctance to use humor in fourth hour to his perception of fifth hour as more talented and more mature. In the interview after the observations he talked about being goofy less in classes 
that had a hard time getting back to mathematics. Table 22 also demonstrates Rudy's greater focus on evaluation in fourth hour. Once again, I think this is because of Rudy's perception of fifth hour as a more talented class. This perception gave him confidence that the students in fifth hour were consistently making progress at developing procedural skills and recalling mathematical concepts, which alleviated his need to check on their progress.

Table 22

Mutual Engagement Codes as Percentage of all Instances Coded at Directing, Evaluating and Using Humor

\begin{tabular}{lcccccc}
\hline & \multicolumn{3}{c}{ Fourth hour } & & \multicolumn{3}{c}{ Fifth hour } \\
\cline { 2 - 7 } $\begin{array}{l}\text { Mutual } \\
\text { Engagement }\end{array}$ & Directing & Evaluating & $\begin{array}{c}\text { Using } \\
\text { humor }\end{array}$ & Directing & Evaluating & $\begin{array}{c}\text { Using } \\
\text { humor }\end{array}$ \\
\hline $\begin{array}{l}\text { Teacher-class } \\
\text { Teacher- }\end{array}$ & 71 & 37 & 71 & 72 & 60 & 60 \\
$\begin{array}{l}\text { student } \\
\begin{array}{l}\text { Individual } \\
\text { work }\end{array}\end{array}$ & 16 & 37 & 20 & 15 & 35 & 29 \\
$\begin{array}{l}\text { Group work } \\
\begin{array}{l}\text { Student- } \\
\text { student }\end{array}\end{array}$ & 4 & 14 & 5 & 4 & 3 & 6 \\
$\begin{array}{l}\text { Minimal } \\
\text { response }\end{array}$ & 1 & 10 & 3 & 8 & 2 & 2 \\
\hline
\end{tabular}

Table 22 (which includes calculations consistent with Table 20) demonstrates that Rudy did most of his directing in teacher-class interactions. He spent much less time directing individual students. This attests to his desire for efficiency in the classroom. In 
fifth hour, Rudy did more of his evaluating in teacher-class interactions. This was related to his perception of fifth hour because he felt less need to evaluate the progress of individual students.

Evaluating was an aspect of Rudy’s participation that helped him establish meaning in two ways. First, as I mentioned previously, evaluating helped Rudy determine the progress of his community toward accomplishing the goals of the community enterprise, both his classroom community enterprise and the enterprise of the mathematics teachers' community. Second, evaluating allowed Rudy to fulfill an aspect of his perceived identity as a teacher. He saw teacher as authority, but Rudy's variety of authority was not dictatorial, rude, or condescending but he expected to be respected and he expected to direct classroom activity. The type of evaluation that allowed him to have a sense of competence in this role was his evaluation of students' correctness. In this evaluation he maintained his position of authority on what is mathematically correct. In the following excerpt from the first lesson in fourth hour Rudy demonstrated both aspects of meaning making in evaluation.

Rudy: Raise your hand if you think you have an answer. Liz and Brady raised their hands immediately. Rudy went over and looked as Liz's paper. Without commenting he proceeded to look at Brady's paper. At this point Callie raised her hand and Rudy moved on to check Callie's work, again, without commenting on what Brady had done.

Asking students to raise their hands allowed Rudy to gauge the class' progress and checking on individual students allowed him to determine correctness and communicate his evaluation to the students. I think that Rudy not giving any response to students indicated they were correct, just as I explained in the case I presented in the analysis of evaluation in the section Teacher-student. 
Directing helped Rudy organize students’ classroom experience and his own. This provided a sense of competence in identity for Rudy as a teacher based on two aspects of what being a teacher meant to Rudy. Rudy identified with teacher as authority and teacher as motivator. I will discuss these two aspects of Rudy's identity as a teacher further in the section Identity. Rudy's frequent use of directing helped him fulfill his identity as authority and maintain a sense of competence in his teaching identity. Rudy's style of motivating was not about getting students emotionally excited, or providing students with direct applications of mathematics to their immediate lives, but providing an environment that was safe for students and relationships that made them want to return to class. Directing allowed Rudy to create a safe and predictable environment where students were comfortable because they knew what to expect each day when they entered Rudy’s classroom.

Humor served Rudy in multiple ways as he established meaning in his experience. His use of humor was true to his identity as it transcended contexts of particular communities of practice. When he brought humor into the classroom it allowed him to fulfill his identity. In my earlier discussion of humor in teacher-class interactions I described three purposes: (a) to engage students for consistent recall of mathematical concepts, (b) to keep students attentive, and (c) to connect with students relationally. The first purpose allowed Rudy to pursue the enterprise of the community and find meaning in that pursuit. The second and third purposes allow him to fulfill his role as motivator in the classroom.

Because I did not describe these purposes well when I introduced them in teacherclass interactions, I will describe how humor fulfilled these purposes for Rudy in his 
participation before I move on to discuss additional forms of participation. In terms of using humor to engage students for consistent recall of mathematical concepts, I have already described his use of the phrase, “mama thinks they're the devil” to describe negatives within a square root. He used the same phrase to refer to negative exponents, radicals in a denominator, an $i$ in a denominator, and likely any other element of mathematical notation that is considered to not be in simplified form. I have also shared his use of the phrase, "take your i's out," in a transcript excerpt although it was not the focus of the excerpt. He used this phrase, along with an eye-plucking motion, to help students remember what to do with the negative within a square root. I have not mentioned his use of an Arnold Schwarzenegger accent when rationalizing the denominator, or his reference to the equivalences $i=\sqrt{-1}$ and $i^{2}=-1$ as the Dalai Lama of imaginary numbers. All of these instances are examples where Rudy was using humor to help students develop consistent recall of mathematical content.

Humor helped Rudy keep students attentive by breaking the monotony that can occur during note taking in mathematics classes. His mathematical use I just described accomplished this same purpose, but he often threw in humor that was not mathematically helpful. These comments were the kind of dry humor many have come to expect from mathematics teachers. Probably a few of his students did not realize some of these comments were intended as humor and many of the others did not think they were very humorous, despite his intentions. He made comments like, "This should get you back into the rhythm of doing some fun math. You guys were probably getting to the point where you were having withdrawals," or "Who remembers what a root is? Something that a tree has, right?” He drew smiley faces, or surprised faces around his 
answers sometimes when he circled them. He told students, "give yourself a hug" or, "shake your hand" if they answered a question correctly during independent work. These little asides helped keep students attentive. However, he described in his follow-up interviews that he was also careful not to take these uses of humor too far with classes that were more prone to off-task behaviors.

The third reason Rudy used humor was to connect with his students. He occasionally told stories that helped students see different aspects of his identity. These stories were always humorous, but notice in Table 18 that he only told stories in fifth hour, just as he used humor more often in fifth hour. The use of stories and humor interacted with Rudy's personal relationships with his students in a reciprocal relationship. The use of humor and stories impudent use of humor.

Story telling, using a nickname, allaying fears, and motivating. As long as I have mentioned Rudy's story telling I would like to continue that discussion. I will also analyze Rudy's participation through using a nickname and motivating because they are somewhat related in the ways they helped Rudy establish meaning. Rudy participated in story telling only in fifth hour. But here he told an average of one story per day. These stories were not related to course content except in one case Rudy could argue that the story was somewhat related. In telling this story (This is a stretch of the term story.) he began from a student's question about who developed the quadratic formula and expanded the discussion to an extensive series of stories about Leonardo da Vinci and other famous mathematicians. The discussion culminated in a conversation about the Illuminati and Rudy's trip to Europe. These story-telling instances helped Rudy develop meaning in his experience by fulfilling his teaching identity as motivator. These stories 
helped students connect with Rudy in a more personal manner and feel safe in his classroom.

Using a student's nickname assisted in Rudy’s meaning making in the same way. When Rudy used a student's nickname it indicated a particular form of relationship with that student. The nickname was often a last name, and some of the students he called by a nickname were athletes. Using these students' nicknames showed that he knew who the students were beyond the walls of his classroom and the name in his gradebook. It is curious that he used nicknames much more frequently in fourth hour than fifth hour. In many other ways, his relationship was more relaxed and personal with fifth hour. The distribution of athletes could be the primary factor in this distinction but I did not track student characteristics, so I only have evidence of a few student athletes and cannot determine the distribution across classes.

Rudy’s participation in the classroom context occasionally involved a process of allaying fears. This represented a small portion of his participation in both classes, but was slightly more prevalent in fourth hour. He helped allay fears for the class as well as individual students. All except one of the instances involved attempts to relieve students' concerns over being incorrect. These instances allowed Rudy to fulfill his identity as motivator and gain a sense of competence in this aspect of his identity as teacher.

Motivating has proven to be the most surprising aspect of participation to me. The motivating code emerged from the initial interview. When asked about his teaching philosophy Rudy said, “One of my biggest teaching philosophies is being a good salesman. Not everyone likes coming to math...If you can make it fun, interesting, then I want them to want to come to math class, or not dread coming to math class.” Statements 
like these indicate Rudy's conception that the identity of a teacher involves being a motivator. Unfortunately, as I coded instances of motivation through Rudy's class observations I did not find significant evidence that he was practicing this role. In the interview after the observations he maintained his identity as motivator in statements like, “you get them bought into the class, then learning’s gonna be taking place.” It was not until I began analyzing Rudy more closely that I realized his definition of motivator was different than my own. His motivating involved knowing students well, making them feel safe, creating an environment in which humor softened (Peterson \& Williams, 2008) the mathematical experience. Peterson and Williams' (2008) study of a student teacher and his cooperating teacher revealed a practice of "softening the feel" (p. 475) of the classroom by using activities and manipulatives as a break, to make mathematics fun, and to connect with the students. These aims are consistent with those of Rudy's form of motivating. It is difficult to analyze the few instances I coded as motivating, because they have turned out to be somewhat anomalous. I could redefine this code, but I think that leaving things as they are helps illustrate the intersecting perspectives at play in this analysis. It appeared from my vantage point that Rudy had failed to fulfill his identity as a motivator in his classroom practice. However, an understanding of his perspective revealed a continuity in his practice that I may have overlooked without trying to find the consistency in Rudy's identity and his role in the classroom community.

Answering, facilitating peer-to-peer engagement, facilitating self-evaluation, hinting, coordinating logistics, undefined forms of participation, and withdrawing. Each of these remaining categories of classroom participation accounted for 5 percent or less of the total instances of participation in observations. Rudy's answering typically 
involved providing a yes or no response, or a reproduction of a procedure. On two occasions, both in fifth hour, his answering involved an explanation of why a particular strategy was or was not used. In both of the cases the student's question elicited this type of responses, and their questions were likely, in part, a result of the negotiated enterprise. Rudy's answering allowed him to find meaning in fulfilling the enterprise of developing procedural skill.

Rudy attempted to facilitate peer-to-peer engagement between once and twice per class hour. He typically did this by assigning an exercise and then suggesting, "you can work it out with a partner.” In a few instances students did work together, but many students ended up completing exercises individually. In two cases he assigned partners based on proximity, but this assignment was followed by little engagement among partners in both cases (one in each class). In one other instance he required students to choose a partner and put an exercise on the board. Rudy expressed that he used a lot of group work in the initial interview. Although my impression from my observations was that he did not follow this intention in practice, I can see from the analysis that he attempted to follow through on his intentions, but his desire to make his classroom a safe place for students meant that his attempts fell short. He allowed his students to choose whether to work with a partner in most cases so that his classroom would remain a safe place where students were comfortable with what was asked of them. More often than not, students decided to work alone. Rudy was attempting to fulfill his role as motivator as he facilitated peer-to-peer engagement, but his intention to facilitate group work was rooted in his attempts to identify as a competent teacher according to current education trends. I will discuss this tension between current trends and Rudy's practice rooted in his 
personal history in the identity section The local and the Global.

Out of the 13 instances in which Rudy facilitated self-evaluation in fourth hour, eight followed exercises students had worked on individually or in groups in class. The remainder were self-evaluations on homework assignments that generally involved only checking the answers but included Rudy demonstrating the procedures if requested. Out of the 17 instances in which Rudy facilitated self-evaluation in fifth hour, six followed exercises students had worked on individually or in groups in class. The remainder can be described in the same way as the remainder in fourth hour. In the first interview Rudy explained,

I like doing multiple examples of different problems or concepts that we're going over so kids can refer back to their notes, back to their homework, putting more responsibility on them. Versus me being a crutch, asking me questions, "Am I doing this right?" Well, look at your notes we just did an example that's basically the same thing, it's just different numbers, different variables.

This indicates Rudy's desire to have students self-evaluate instead of doing all of the evaluation himself. His participation did not demonstrate the particular illustration he used to make his point, but he did have students self-evaluate several times each class hour. This may be another aspect of his practice rooted in his identification as a teacher applying modern educational principles.

Rudy used hinting slightly more with fourth hour than with fifth hour (Table 18), but he only used explicit hinting, as opposed to leading questions or another less obvious form of hinting, about twice per class hour. He generally applied his hints to exercises students were working individually, and in about half of the cases he gave the hint as soon as he gave the exercise. Hinting helped Rudy fulfill his role as motivator by softening the classroom experience. 
Rudy participated by coordinating logistics in each class hour equally. He took attendance, worked the interactive whiteboard and projector, wrote homework and other non-instructional information on the board, erased the board. These activities were participation in the classroom community because they were necessary for the continuation of the community in the space provided. They assisted Rudy in establishing meaning in his environment by meeting the demands of intersecting communities (attendance) and building efficient workflow for the classroom community.

Rudy's undefined forms of participation included primarily his collecting and distributing items, checking individual homework, and helping individual students make corrections on their work. When he distributed, including blank worksheets, he handed a single sheet to each student individually. He checked homework by walking between rows and glancing over papers to assign marks in his gradebook. This was not the only way he assigned grades. I already described his practice correcting students’ work through nonverbal interactions. Checking homework was another way to meet the demands of his intersecting communities of practice, and his correcting of student work has already been explained in the evaluating form of participation.

Rudy's participation through withdrawing is sort of anti-participation and it was very infrequent. In most cases Rudy went to the hallway for about a minute during his lesson. I suspect these were interactions about wrestling because he was the head coach. If that is the case, then these were times that Rudy had to negotiate the conflicting demands of overlapping communities of practice.

Participation in other communities. The majority of Rudy's participation occurred in his classroom communities, and the data I collected is even more skewed in 
this direction. However, as I have described in the communities of practice section, Rudy participated in at least two other communities of practice. In particular, he participated in the mathematics teachers' community. My analysis of Rudy's participation in other communities focuses particularly on how he participated as a teacher in the mathematics teaching community at Valley View High School. However, these instances of participation also point to his connection to the broader landscape of practice.

I coded two particular forms of participation in teaching communities and all other types of participation I coded as undefined. The first form of participation I will describe is Rudy's participation in the development of instructional materials. I coded 20 instances in which Rudy was developing instructional materials, or was referring to developing instructional materials. I found three themes running through these 20 instances. First, in the initial interview Rudy explained, "My first year I locked myself in my room. I worked through my preps, my lunches, I'd come in on Sundays, lesson plan, things like that. I didn't have time to collaborate.” Rudy’s view of his early development of instructional materials included a theme of being overwhelmed in the process. This theme is also found when he described the first year Valley View implemented an integrated curriculum.

To me, I think that year was kind of a waste because I know myself, I was not a good teacher because I was just trying to plan for the class period before that day. It was hard to go in depth and differentiate and things like that.

These instances of Rudy's participation in overwhelming situations likely played a significant role in his identity development in his early years of teaching. He had to find ways to establish his competence as a teacher without spending every waking moment devoted to his teaching practice. Rudy had other aspects of his identity and other 
communities of practice to which he needed to contribute, but he also needed to be competent in his role as a teacher. I claim that he found a means to efficiency in planning that satisfied his various membership roles in communities of practice. I will discuss this further in the third theme.

Second, Rudy mentioned that he did not have time to collaborate. This lack of collaboration and difficulty relating with colleagues also came up more than once as he described his participation in developing instructional materials. Referring to the first year with an integrated curriculum Rudy said, “It was pretty stressful and it was hard to collaborate. Not to mention, we don't have a common prep.” This theme matches well with the overwhelmed theme I just described. Both are, at least by Rudy’s report, constructs of too little time and too much to do. Here it is worth noting that Rudy holds out hope that the situation will improve. He expects to collaborate in the future when he has things figured out for himself.

Third, Rudy’s planning was focused on mathematical content. The evidence I have suggests that Rudy did not concern himself with the other elements typically associated with lesson planning and instructional development. His lesson plans contained only the mathematical content with no reference to pedagogical principles or actions. If I stretch a little bit I could consider his statement on a lesson plan "go over homework," to be pedagogical or the term warm up or the inclusion of objectives. However, none of these actually prescribed a methodological approach to Rudy’s teaching. The reflections he gave me were also focused on mathematical content, the order in which he planned to cover it, the topics he would leave out, the examples he would use, the assessment he would apply, or how he had adapted what he chose to cover 
as he taught the content. However, Rudy may have cognitively planned pedagogy without making his plans explicit. I claim that Rudy's tendency to plan only content was a product of two things. First, the community enterprise was to cover mathematical content. If that is the enterprise the important elements for his reified plans involved primarily, or exclusively, mathematical content. Second, this was a way that he coped with early identity work in the face of time constraints. He found efficiency in planning by focusing solely on mathematical content and leaving methodological application to his moment-by-moment participation in the classroom.

The second form of participation I coded for was influencing change. I coded this only six times but these six instances were significant in Rudy's identity development. All of the instances surround a couple of changes involving the mathematics curriculum, courses, and scope and sequence at Valley View High School. It would appear that there may have been many aspects of these major changes in which Rudy was involved and agreed with the other individuals influencing the decision. However, the powerful theme in these instances is Rudy's marginalizing experiences. He explained that, "no one really listened to me cause I'm just young and don't know what I'm talking about.” Notice two things about this statement. First, this was a marginalizing statement because Rudy perceived that his community members took aim at his competence. He received the message that he was too inexperienced and did not have the level of expertise to speak wisely into the negotiated enterprise of the community. Second, instances like this shaped Rudy's identity at the time of observation and shaped his participation. Notice that he switched to present tense for the second half of his statement. He was making an observation about the past occurrence, but he was tellingly making a statement about his 
present identity. Instances of Rudy's participation in similar marginalizing situations placed him in a marginalized role in his community and in my observations he participated, or more accurately did not participate, accordingly.

The remaining participation was coded as undefined and a determination of any themes of participation in most of these instances still escapes me. However, there is a subset of these codes that I can describe. Some of the codes demonstrate Rudy's participation with his coaching community. Rudy's participation in these cases carried a much more positive feel. In fact, I claim that Rudy's participation in the coaching community allowed him to retreat to an identity of competence and subsequently extend this identity of competence back into his classroom communities of practice. This retreat is an idea presented by Fenton-O'Creevy et al. (2015) and I will delve into this more in the section Identity. For now, note Rudy's participation with the coaches on the inservice day as the participation of a full member in the community. Although his participation involved only an informal chat, sitting at the same table in a meeting, and a discussion over lunch I have described in the communities of practice section how these interactions made a case for Rudy's membership. Rudy's participation with this community helped him ascribe meaning because he was able to contribute to the enterprise of the community. At lunch he did not just hear from the coaches about student athletes, he contributed to the discussion in a way that demonstrated his shared understanding about physical and athletic development of student athletes. He made his mark on the negotiation of the enterprise of physical development and shared the ways in which he was contributing to the enterprise by the use of shared tools. Rudy demonstrated his competence in the community and his participation confirmed his competence and his 
productivity in the enterprise. Now that I have ended on a more positive note, I will turn to reification.

\section{Reification and Reifications of Rudy's Experience}

I use both reification and reifications in this heading because it emphasizes that reification is both a process and a product. Reification is the process of giving form to experience and it is those concrete forms as products. Despite my choice of title my description in this section is focused primarily on the products and in the section The Interplay of Reification and Participation for Meaning I describe the process of reification. Here, I focus on reifications as the objects of concrete experience. They are the objects that help organize participation in community.

In Table 23 I have included the operationalized definitions of the reifications I found in my analysis of Rudy's practice. Reifications, recall, are elements that bring meanings to experiences. Wenger (1998) described them as projections of "our meanings into the world.” Therefore, it can be difficult to recognize the entirety of reifications of the community even as a member of the community. That is to say, I may have missed some of the reifications that do not come in physical form. Furthermore, as I analyze Rudy’s projected meanings in these reifications it may be difficult for me to provide an accurate picture of meaning for Rudy. Instead, I will see these reifications in my own eyes as projections of my meaning. But I may not "recognize [myself] in those projections,” and “attribute to [my] meanings an independent existence” (Wenger, 1998, p. 58).

Although my own meanings are inevitably projected into this analysis, I attempted to see Rudy's meanings. Table 24 includes a count of all the reifications coded 
in Rudy's sources and for each code the percent of the number of instances of the code reification. Table 24 will help as I continue this conversation in a positive direction, beginning to understand how Rudy projects meaning in the reifications of his experience.

Table 23

Reification Codes

\begin{tabular}{|c|c|}
\hline Code & Definition \\
\hline CCSS-M & $\begin{array}{l}\text { Reference to the Common Core State Standards for Mathematics } \\
\text { (NGA Center \& CCSSO, 2010) }\end{array}$ \\
\hline Course & $\begin{array}{l}\text { Reference to a particular course (not the general subject, not a } \\
\text { particular class, not an hour in the school day) }\end{array}$ \\
\hline $\begin{array}{l}\text { Five-subject } \\
\text { notebook }\end{array}$ & $\begin{array}{l}\text { Reference to or use of a five-subject notebook as the specifically } \\
\text { defined tool in Rudy's classes }\end{array}$ \\
\hline Homework & $\begin{array}{l}\text { Reference to homework, assignment of homework, grading of } \\
\text { homework, checking of homework, collecting of homework, or other } \\
\text { engagement in the system of homework }\end{array}$ \\
\hline Lesson objective & Reference to an objective, goal, or focus of a given lesson \\
\hline Lesson plan & Reference to a lesson plan or the planning of a lesson \\
\hline Mathematical Object & $\begin{array}{l}\text { Reference to a mathematical concept, procedure, or topic that takes on } \\
\text { a form of existence that helps organize classroom experiences for the } \\
\text { teacher and students (These were only coded at the first use of the } \\
\text { object in a particular episode of activity (within one conversation, } \\
\text { example problem, or other episode)) }\end{array}$ \\
\hline Notes & Reference to notes, taking of notes, use of notes \\
\hline Quiz & $\begin{array}{l}\text { Reference to, grading of, completing of, or developing of a short, but } \\
\text { formal evaluation }\end{array}$ \\
\hline $\begin{array}{l}\text { Schoolwide } \\
\text { reification }\end{array}$ & $\begin{array}{l}\text { Any reification that is standard in the school, beyond the classroom } \\
\text { context and is non-mathematical }\end{array}$ \\
\hline Social norm & Reference to, use of, or establishment of a classroom social norm \\
\hline Technology & An element of technology that is part of participation \\
\hline
\end{tabular}




\begin{tabular}{ll}
\hline \multicolumn{1}{c}{ Code } & \multicolumn{1}{c}{ Definition } \\
\hline Test & $\begin{array}{l}\text { Reference to, completing of, grading of, or developing of a classroom } \\
\text { assessment referred to as a test }\end{array}$ \\
Textbook & Reference to or use of the textbook for a course (Carter et al., 2012) \\
$\begin{array}{l}\text { Uncategorized } \\
\text { Reification }\end{array}$ & $\begin{array}{l}\text { Reference to a reification that is not described by one of the current } \\
\text { codes }\end{array}$ \\
Warm up & $\begin{array}{l}\text { Reference to, completion of, development of a warm up as defined by } \\
\text { the participant using the term }\end{array}$ \\
\hline
\end{tabular}

Mathematical objects. Table 24 demonstrates that mathematical objects dominated Rudy’s community reifications. This does not necessarily imply that mathematical objects were the most significant reifications for Rudy's experience of meaning, but the prevalence of mathematical reifications indicates they play an important role in the classroom community. I will focus on two ways that these mathematical reifications are important in Rudy’s practice. First, I will explore how these reifications helped organize the experience of Rudy's communities of practice. This included his classroom community and his mathematics teacher community. Second, I will explore the meanings Rudy projected into these mathematical objects as reifications of his own experience.

Table 24

Instances of Reification Codes for Rudy's Sources

\begin{tabular}{|c|c|c|c|c|c|c|c|c|}
\hline \multirow[b]{2}{*}{ Code } & \multicolumn{2}{|c|}{ All sources } & \multicolumn{2}{|c|}{ All observations } & \multicolumn{2}{|c|}{$\begin{array}{c}4^{\text {th }} \text { hour } \\
\text { observations }\end{array}$} & \multicolumn{2}{|c|}{$\begin{array}{c}5^{\text {th }} \text { hour } \\
\text { observations }\end{array}$} \\
\hline & \# & $\%$ & \# & $\%$ & \# & $\%$ & \# & $\%$ \\
\hline Reification & 534 & - & 352 & - & 159 & - & 193 & - \\
\hline
\end{tabular}




\begin{tabular}{|c|c|c|c|c|c|c|c|c|}
\hline \multirow[b]{2}{*}{ Code } & \multicolumn{2}{|c|}{ All sources } & \multicolumn{2}{|c|}{ All observations } & \multicolumn{2}{|c|}{$\begin{array}{c}4^{\text {th }} \text { hour } \\
\text { observations }\end{array}$} & \multicolumn{2}{|c|}{$\begin{array}{c}5^{\text {th }} \text { hour } \\
\text { observations }\end{array}$} \\
\hline & \# & $\%$ & $\#$ & $\%$ & $\#$ & $\%$ & $\#$ & $\%$ \\
\hline CCSS-M & 7 & 1 & 0 & 0 & 0 & 0 & 0 & 0 \\
\hline Course & 17 & 3 & 7 & 2 & 1 & 1 & 6 & 3 \\
\hline $\begin{array}{l}\text { Five-subject } \\
\text { notebook }\end{array}$ & 4 & 1 & 4 & 1 & 3 & 2 & 1 & 1 \\
\hline Homework & 53 & 10 & 35 & 10 & 15 & 9 & 20 & 10 \\
\hline $\begin{array}{l}\text { Lesson } \\
\text { objective }\end{array}$ & 3 & 1 & 0 & 0 & 0 & 0 & 0 & 0 \\
\hline Lesson plan & 13 & 2 & 2 & 1 & 0 & 0 & 2 & 1 \\
\hline $\begin{array}{l}\text { Mathematical } \\
\text { Object }\end{array}$ & 232 & 43 & 187 & 53 & 92 & 58 & 95 & 49 \\
\hline Social norm & 11 & 2 & 11 & 3 & 4 & 3 & 7 & 4 \\
\hline Notes & 36 & 7 & 24 & 7 & 13 & 8 & 11 & 6 \\
\hline Quiz & 18 & 3 & 12 & 3 & 4 & 3 & 8 & 4 \\
\hline $\begin{array}{l}\text { Schoolwide } \\
\text { reification }\end{array}$ & 26 & 5 & 18 & 5 & 7 & 4 & 11 & 6 \\
\hline Technology & 8 & 1 & 6 & 2 & 3 & 2 & 3 & 2 \\
\hline Test & 7 & 1 & 3 & 1 & 0 & 0 & 3 & 2 \\
\hline Textbook & 32 & 6 & 4 & 1 & 1 & 1 & 3 & 2 \\
\hline $\begin{array}{l}\text { Uncategorized } \\
\text { Reification }\end{array}$ & 55 & 10 & 31 & 9 & 13 & 8 & 18 & 9 \\
\hline Warm up & 10 & 2 & 6 & 2 & 2 & 1 & 4 & 2 \\
\hline
\end{tabular}

Organizing experience. Reifications provided focus points around which Rudy organized his experiences. I observed one unit of instruction about imaginary and complex numbers in Rudy’s classes. The mathematics itself, through Rudy's 
interpretation and application, provided a means of organization for the classroom community of practice. I found that Rudy organized his experience in the classroom community with at least four fundamental constructs: (a) $i=\sqrt{-1}$ and $i^{2}=-1$, (b) expression, (c) equation, and (d) quadratic. At first, I was not sure that these had any more agency in organizing experience than as elements of Rudy's lesson plan, presented in a particular order, and with a few conceptual connections. However, I found evidence for the organization of experience around these ideas.

First, the definition of $i$ provided by Rudy helped determine the form of the enterprise, the productivity of the community, and the participation of community members. The enterprises of the classroom communities (doing school and doing mathematics) included the production of procedural skills, and the completion of tasks in fourth hour and fifth hour added mathematical understanding. When this new concept of an imaginary number came into the space of the community enterprise it required a particular instantiation of the enterprise. The production of procedural skills became organized around a skill that had been unnecessary. I would describe their prior experience with negative numbers inside a square root as short-circuiting the procedure necessary for the completion of a task. In order to maintain their fulfillment of the enterprise they gave a short-circuited definition to the completion of the task. They called the remainder of the exercise an impossibility. This conception is illustrated in Rudy's remarks as the class solved the equation $x^{2}+100=0$ in the third lesson in fourth hour. After subtracting 100 on both sides of the equation and taking the square root of both sides he said, "It would be no solution. In the past this is where we would stop." However, in the defining of $i$ they redefined the terms of the enterprise so that task 
completion and the production of procedural skill for the completion of that task took on a new meaning. They no longer had to stop at an impossibility, they could complete the impossible. For fifth hour, this caused a more problematic situation. Fifth hour's enterprise involved understanding, but understanding an impossibility is no easy task. The enterprise itself, it would seem became an impossibility. During the third lesson in fifth hour, while solving their second quadratic equation with complex roots, Rudy remarked, "If we use the quadratic formula we get to here and say no solution. Well, there actually is a solution, it's just not real.” George replied, “So, there's no solution.” Rudy proceeded to finish the problem using the definition of $i$ but leaving an understanding of the impossible out of the process.

These alterations in the enterprise created perturbations in the productivity of the community. For fifth hour the enterprise was held up as Rudy refused to pursue an understanding of the impossibility. This dereliction of the enterprise to impossibility forced the community to abandon the understanding enterprise for the unit and pursue productivity in procedural skill. In three instances George pursued an understanding of the definition of $i$ and in all three cases he was rebuffed. For both hours the production of procedural skill was the primary enterprise. Various procedural skills became involved throughout the unit but the unifying element was the definition of $i$. It became the defining force of productivity. Note the pervasive nature of $i$ in the unit as the defining characteristic of productivity in Rudy's comments about their final homework assignment,

Not all of them you will get an imaginary number. You will not get a negative root with all of them. Some of them may be whole numbers. So, don't just automatically assume that you have to take i's out and so forth. 
As the defining force in productivity the definition of $i$ elicited participation of community members that shaped community engagement. For example, I have discussed how Rudy repeatedly called on one student for the equivalence of $i$ squared. This was a participation established through the reification and producing a particular organization of activity in the fifth hour community of practice. Rudy also referred to the definition as the Dalai Lama. Students got the picture that this was the concept that would determine production for the unit and they organized their participation around the idea and its application in "taking the i's out."

The second mathematical entity that helped organize community activity was the expression. The expression helped organize community experience by defining the bounds of certain procedural skills and the products obtainable in the application of those skills to expressions. When Rudy switched topics from expressions to equations during the third lesson in fourth hour he expressed this bounding of productivity in the enterprise with the statement, "Everything we've been doing have been expressions. So, simplify, reduce, evaluate. Now, we're getting into equations.” He expressed in the community the specific forms of productivity that expressions had bound them to, and explained that the expansion to exercises involving equations would also expand the bounds of productivity. Of course, the students may not have explicitly grasped the implications of using expressions, but they experienced the bounds on their productivity introduced by expressions.

That brings me to the third mathematical entity that helped organize community activity. The equation produced organization for the community in much the same way as the expression. Rudy's introduction of the equation expanded the bounds of productivity 
to new realms. Furthermore, it implied a new set of procedural skills that became both the product and process of the enterprise. Many of these procedural skills were merely extensions of prior learning, but they became productive of the enterprise in new ways as complex numbers were integrated as viable solutions for equations. The equation also opened the community to the world of quadratics.

Quadratics were the final form of mathematics that helped organize community experiences that I will describe. The quadratic influenced community engagement in two ways: (a) it simultaneously expanded and bounded the joint enterprise and (b) it implied a history of learning that was brought to bear in shaping community participation. The quadratic expanded and bounded the joint enterprise in similar ways to the other three mathematical entities. For example, the quadratic implied, for the community, the expansion of procedural skills to include five methods Rudy encouraged the community to use for solving quadratics. At the same time, it defined the limits of production at the solution of quadratic, and not higher degree, polynomials. The expansion of the enterprise implied a history of learning that came into play as the members pursued the expanded enterprise. The history was unique to each community and it influenced Rudy's participation in community. One illustration of this influence was when Rudy altered his approach to include a full account of the history of learning in the interest of future productivity. His original lesson plans did not include an extensive review of the five methods (taking the square root of both sides, factoring, using a graphing calculator, using the quadratic formula, completing the square) the community employed to solve quadratics, or the application of appropriate methods for certain quadratics. Rudy's reflections described his alteration to focus more on these methods and their application 
to appropriate circumstances.

I anthropomorphized the mathematical entities in this section to emphasize the active nature of these reifications in productive ways in the community. However, I must also concede that the reifications are only given active participation in the community through the activity of members. These reifications act on the enterprise, the productivity, the participation of members, only through the practice of community members.

I must also mention, if only briefly, the role of mathematical reifications in organizing the mathematics teachers' community. I did not find the same four elements to be of particular importance in the organization of the teaching community. From my limited observations it would seem as if the mathematical entities were the only organizing reifications for the teachers’ engagement in community. The scope and sequence for courses at Valley View High School was the entirety of the content of the teachers' interactions. So, it is clear that the mathematical content played a role in organizing their participation. However, this content was mediated through the curricular resources available. Thus, participation was far more than a product of mathematical reifications. It was a product of pedagogical reifications, the reification of values and beliefs about mathematics, about who should learn, about what they should learn, and when they should learn it. Although these reifications were not made explicit and only the mathematics was recognizable in participation, the mathematics was the concretized form of the participation of a community of authors imposing itself in the local community. Then, the participation of the local community was a negotiation and reinterpretation of these reifications in the immediate context. 
Projected meanings. Mathematical entities represent Rudy’s projected meanings into the community. The mathematical entities were projections of Rudy's identity as a teacher of mathematics but also as a learner of mathematics. I have already shown that Rudy identified with a landscape of practice that extended beyond the teachers at Valley View High School. His practice in his local community was heavily influenced by the curricular resources at his disposal. These resources in conjunction with the Common Core State Standards for Mathematics (NGA Center \& CCSSO, 2010) provided an authoritative voice on the value of particular mathematical topics. Thus, when Rudy applied a mathematical element to classroom practice he instantiated a value statement from a broader landscape. In so doing, Rudy ascribed meaning to this reification as a productive means to competence in his community of practice and knowledgeability in the broader landscape. Rudy found meaning in these reifications as projections of his identity as a member of the landscape of practice for mathematics teachers. If he were assigning mathematical content independently I contend that it would have far less importance for him. This was evidenced in his meeting with the other mathematics teachers, and his connection with mathematics teachers from other schools. He found meaning in adhering to the values of the discipline for the development of productive students so much that he was willing to meet in collaboration with those who have marginalized him in his community of practice.

I found evidence of Rudy's projection of meaning as a learner of mathematics in an episode of instruction that was atypical for Rudy. During the third lesson in fifth hour Kayla asked Rudy to demonstrate an exercise from a homework assignment on the board. The exercise asked students to simplify $i^{41}$. Recall that Rudy's typical approach to 
teaching was to share by means of mathematical telling, with the occasional questioning, the procedures necessary to complete a task. In this case, the procedure relies on a pattern of four possible results for the natural number powers of $i: i^{0}=1, i^{1}=i, i^{2}=-1, i^{3}=$ $-i$. These four values repeat in the same order as the exponent increases. This pattern allows for the application of several different procedures to determine the simplified value of a power of $i$. For example, dividing the exponent by four and applying the remainder as the exponent will yield one of the four values described previously. I would have expected Rudy to apply this procedure or a similar procedure for the exercise. However, the following transcript excerpt from recounts the episode:

Rudy: $i$ squared is equal to negative 1 . This is the idea that we're gonna be using for this. How many $i$ squareds are gonna be in $i$ to the 41st power? So, if. You said that there's $20 i$ squareds in $i$ to the 41st power. It doesn't go in evenly, we'll get to that. We know that $i$ squared is. so 20 times. Ahh, that's wrong. (wrote $\sqrt{x^{41}}$ ) Remember these? What do we want to do to these type of problem, square root problems?

Kayla: Cross them out

Rudy: Alex, I can see the gears turning.

Alex: Um, we want to get them to the closest even number.

Rudy: Closest even number. (wrote $\sqrt{x^{40}} \sqrt{x}$ ) Okay, this will get you the square root of $x$ to the 41st power. Then?

Alex: Uh, you would divide by 2 I think. So, it would be 20 .

Rudy: $x$ to the 20th power. Absolute value?

Alex: Um, no cause it went from even to even.

Rudy: This is something similar to that as well. Getting it to the nearest even. Why? Because, this (pointing to $i^{2}=-1$ ). If we look at let's say $i$ to the fourth. This ones a lot easier. $i$ squared times $i$ squared. Negative 1 times negative 1 would be positive 1 . What about $i$ to the sixth power? $i$ squared, $i$ squared, $i$ squared. Negative 1 , negative 1 , negative 1 . And this is what, we kind of went over last week I think when Kayla asked. How can we come up with a rule, or see a pattern? When $i$ has an even number, even exponent (shut the door) it's either gonna be positive one or negative one.

George: Has an even exponent? (said something unclear)

Rudy: Even, (pointing to $i^{6}$ )

George: It will be negative one, even

Rudy: Even, (pointing to $i^{4}$ )

George: It will still be one. 
Rudy: What if we have $i$ to the 8th power, will it be positive or negative?

Several students: Positive

Rudy: What about $i$ to the 24th power, positive or negative?

Several students: Positive

Rudy: Parker? You gonna say positive cause everyone else is?

Parker: Yeah.

Rudy: How can we come up with some sort of rule instead of guessing there. Mike: I divide the exponent by 2 and then if the exponent is odd it's negative, if it's even, it's positive.

Rudy: Okay, so. Divide the exponent by 2, if it's even it'll be positive. Divide the exponent by 2, if it's odd it'll be negative. Will that be true for all of them? This is the same idea as the absolute value. Even to an even, even to an odd.

Ian: Well, I was going to say if it's a factor of 4 it's going to be positive. Like, the exponent I mean.

Rudy: Okay, yep. So using that idea, 40 divided by 2 you get? Is 20 even or odd? Last time I checked it was even. So this is gonna be negative 1 or positive 1 ?

Several students: positive

Rudy: Positive 1 times $i$. Anyone get i?

This episode demonstrates Rudy's sense-making as a learner of mathematics. In

this one case note that he was not prepared to present the procedure as a preconstructed product for students to apply. As a result, the episode showcased Rudy's mathematical activity as sense-making. Note that his sense-making here was not as much about a conceptual understanding of the concept as the logic of mathematics as an internally coherent system. I say this because he relied more on analogical reasoning (to a type of exercise that was familiar to the community) than deductive reasoning to develop his procedure. Thus, Rudy's experiences of mathematics are meaningful when he establishes mathematical reifications as elements in the coherent, logical system of mathematics he has developed for his mathematical and teaching practice.

Now, I further claim that Rudy projected his experience of mathematical learning as sense-making into the mathematical reifications he employed as a teacher. Rudy demonstrated this projection when he was teaching about simplifying expressions involving $i$ during the first lesson in fifth hour. As he wrote two examples on the board he 255 
said, "Hopefully, a lot of this stuff is easy. And it should be because I know that you remember all of the properties and steps from breaking roots down and rationalizing the denominator and so forth cause you guys have a good teacher, right?” His statement that the new concepts being easy was related to analogical reasoning to established elements of the shared repertoire or prior reifications. After completing the two examples Rudy said, "Does it make sense? Surprisingly, whether you want to admit it or not, I can tell by looking at your faces, it does make sense.” In this case the sense-making was about the procedural analogy to prior learning and the internal consistency of the mathematical system. He did not help students reason about why the procedures worked, why they were beneficial, or how they could be applied to real-life situations. Thus, I claim that Rudy was projecting his experience of mathematics as sense making into the mathematical reification of these procedures and assuming that his form of sense making was the way in which his students were experiencing these reifications.

Homework, notes, quiz, test, and warm up. Despite the prevalence of mathematical entities coded as reifications, they were not as much more significant than other reifications in the community as the numbers might make them seem. Another set of important reifications included homework, notes, quizzes, tests, and warm ups. All of these elements represent multiple sorts of reifications. First, they are reified as concepts beyond the classroom community. I assume all of these elements played a role for students in other classroom communities. However, the ideas took on specific meaning in Rudy's classroom. They took on meaning as implicating a particular type of participation for the students and Rudy. They also took on meaning as the concrete product of these implied processes, and the concrete product was not unified across all participants but 
took on form for each note taker or homework doer, including Rudy. Finally, they took on meaning as the concrete product became the source of further participation in the community. Although I am not including five-subject notebooks as a specific reification for analysis here, I will be referring to it in the course of the analysis of notes, homework, and warm up. I will not include any further analysis of the five-subject notebook reification because the code was rarely used and the reification provided meaning primarily as an organizer of the notes, homework, and warm up reifications. In the next section I will explain how each of the reifications in these three forms provided a means of organization for Rudy's classroom communities. Note, that I found no significant differences in these reifications across the class hours, so I will discuss the two as integrated.

Organizing experience. First, I will discuss homework, notes, quizzes, tests, and warm ups as ideas that bore out a particular process in Rudy's classes. The class hour would generally begin in one of two ways: the process implied in a warm up or the process implied in homework. If the class began with a warm up, the students understood the form of participation required was independent work, recorded in a particular section of their five-subject notebooks, followed by attending to Rudy's explanation. This only occurred in one case during my observations, but Rudy's reference to the warm up and the students' response implied a shared understanding about the procedural implications of the activity. If the class began with homework, Rudy had several implicated procedures that required further clarification for the students to determine their participation. Rudy would provide additional information about what form the homework procedure would take for that day. For example, when he said, “I’m gonna come around 
and check...” this implied that students should have the assignment on their desk and they could chat quietly as they awaited the completion of the process. When he said, "Let’s go around the room" it implied that students should be prepared to share their answers to the exercises aloud as Rudy called on them. It also implied that students should be checking their own answers and writing down all the correct answers. Rudy did not explain this each time he instantiated this process, but he reminded them as they prepared for a quiz they should have already written down all of the correct answers to the homework exercises.

After the homework or warm-up procedures were completed Rudy would indicate the notes activity by saying, "alright, notes" or a similar phrase. The phrase instituted a procedure that involved students turning to a particular section in their five-subject notebooks, listening to Rudy, answering questions, recording whatever Rudy wrote on the board, working on exercises individually or in pairs, and checking their work on those exercises against Rudy’s subsequent completion of the same exercises. Notes organized classroom activity around half of the time I spent observing Rudy and homework organized the majority of the other half of the time.

Two quizzes helped define classroom activity during my observations. These were distinct but related reifications and represented similar procedures. The first quiz was called a mini-quiz in Rudy's classes and it was his version of a pop-quiz, at least it was a pop-quiz in the instance I observed. Rudy called upon the procedure of the miniquiz with the phrase, “clear your desks.” The implied meaning here was that they were taking a mini-quiz and all the standard procedures of this process were called into play in this one phrase. Students immediately tore out a sheet of paper, ripped it in half, often 
gave half to a neighbor, cleared everything from their desk onto the floor except a pencil and the half sheet of paper, and waited for Rudy to write exercises on the board. They proceeded to complete the exercises and then place their half sheets of paper on a chair at the front of the room. A quiz implied a similar procedure, with a few differences. First, the students were aware of the quiz in advance. Second, the quiz was provided on copy paper Rudy distributed to the students. The rest of the procedure was essentially identical to that of the mini-quiz. I did not observe a test for this study so I will not make any comment on the procedures, but I think it is safe to assume that there was an associated procedure not far from that associated with the quiz.

At the end of class, the homework activity implied a different procedure. Every day I observed Rudy the homework procedure was invoked at the end of class. In this case Rudy's use of a phrase involving the word homework indicated that he would write an assignment in a predefined location on the chalkboard and students would copy the assignment. Furthermore, students were expected to do the homework in a particular section of their five-subject notebooks and return with the exercises completed the next class hour. On occasion Rudy would inform the students that they should begin the homework in class. Because this part of the procedure varied, Rudy was explicit in his direction.

Homework, notes, quizzes, tests, and warm ups also helped organize experiences as concrete products of the procedures I just described. All of these processes resulted in some written, concrete product for each of the students in Rudy's classes, and a somewhat different concrete product for Rudy. For example, warm ups, notes, and some forms of homework resulted in a lasting record saved electronically from the interactive 
whiteboard for Rudy. Essentially the same things were recorded in specified sections of students' five-subject notebooks. Some forms of homework also resulted in grades recorded in Rudy's gradebook, and assignments recorded on the chalkboard or in Rudy's lesson plans. Quizzes and tests resulted in a concrete object that was presented to students, the students' concrete records that were provided back to Rudy, Rudy's concrete record of grading provided back to the students, and Rudy's concrete record of grading in his gradebook. All of these concrete products of participation acted as organizers of experience by holding a record of participation.

These products organized further participation in the community. For example, Rudy described how notes and homework might impact participation when, in his interview, he explained,

I like doing multiple examples of different problems or concepts that we're going over so kids can refer back to their notes, back to their homework, putting more responsibility on them. Versus me being a crutch, asking me questions, "Am I doing this right?" Well, look at your notes we just did an example that's basically the same thing, it's just different numbers different variables.

The mini-quiz organized subsequent activity when Rudy demonstrated the procedures for task completion after passing back the quizzes. During the first lesson in fourth hour Rudy was asking students to recall how to identify a quadratic and one of the students said, "I'm gonna look this stuff up.” He proceeded to look back in his notes to find how to identify a quadratic.

Projected meanings. Rudy derived meaning from homework, notes, quizzes, tests, and warm ups through their organization of classroom activity, but also through his projection of meanings onto these processes, products, and further participations. In terms of processes Rudy projected meaning in two ways. First, the processes provided an 
efficiency to the classroom activity that helped him experience competence in his identity as a teacher in the aspect of authority or organizer of classroom activity. Second, the processes provided a predictability in the environment that helped Rudy experience competence in his identity as motivator or softener of classroom activity.

The products that resulted from the homework, notes, quiz, test, and warm-up processes may also be viewed as projections of Rudy's meaning. They represented the productive enterprise of the community. Rudy's enterprise as a teacher was dependent on the productivity of students in the enterprise of the classroom and these various products were concrete representations of the students' productivity.

Finally, the products were projections of meaning as influencers of participations. For example, the statement shared in the previous section from Rudy's interview illustrates how continued participation with these reifications fulfilled Rudy's perceived role in the classroom. These productions helped Rudy instantiate patterns of participation that fulfilled his teaching identity.

Social norm, schoolwide, technology, undefined. The third set of reifications I will discuss includes the remainder of the reifications for the classroom community. I will take each code in turn and briefly describe the form of the reification. Then I will discuss how the reifications ascribe meaning through organization and projection.

Social norms are a reality in any classroom. When I was coding for social norms I did not just code any process that could be considered a generalized social norm. Instead I coded norms somewhat unique to the classroom community, or those common among many communities but instantiated in Rudy's classroom purposefully. For example, Rudy used hand raising in particular ways in his classroom. General questioning in a whole 
class setting did not always require students to raise their hands, but many times the students did raise their hands in these whole class questioning sessions. When students were working individually it was implied that they could raise their hand for assistance, but Rudy also asked students on occasion to raise their hands when they had an answer. These social norms provided organization to classroom participation that increased efficiency and production. This allowed Rudy to fulfill his identity as authority. These norms also represented a projection of Rudy's organization and efficiency he found necessary to develop competence in his role as teacher, as determined by overwhelming early career experiences.

The schoolwide reifications relevant to the classroom community included the bell to begin and end class hours, the online grading and grade reporting system, and lunch. The first two of these helped organize activity throughout the school day in the classroom and throughout the school. The grading system helped organize Rudy's participation in the teaching community. It was also a projection of meaning for Rudy because it included a representation of his competence as a teacher in terms of student achievement. However, Rudy also recognized the limitations of his impact on grades. When he explained that fifth hour was the most talented class he had ever taught, he justified his claim with the grade distribution.

I coded two technology reifications relevant to the classroom community: the interactive whiteboard and projector, and graphing calculators. Both of these items help organize classroom experience, but I do not have good evidence for the ways Rudy projected meaning in these reifications.

Two reifications relevant to the classroom community developed in the undefined 
category. First, the goofy things Rudy used to soften the classroom atmosphere helped organize classroom experience as a bearable form of participation. Rudy projected meaning in these reifications in two ways. He fulfilled his role as motivator. He also projected his broader identity in relation to humor into his classroom practice. The second reification coded as undefined was the use of partners. Rudy assigned partners for students and this helped him organize student participation fulfilling his role as authority and his picture of his teaching in line with his conception of modern methods.

Textbook, CCSS-M, lesson plan, lesson objective, course, schoolwide. The final set of reifications I will discuss includes the reifications Rudy brought to bear on his participation in his teaching community at Valley View High School. You may notice that schoolwide reification coding category appeared in the prior set of reifications as well. I separated the reifications into those relevant to the classroom community and those relevant to the teaching community, and will discuss those relevant to the teaching community in this section. This discussion will take the same form as the last section, in which I described a reification, described the organization it provided the community, and explained the reification as a projection of meaning for Rudy.

Rudy used the course textbook (Carter et al., 2012) for lesson planning, assigning homework, and as a guide in the teaching community decisions about scope and sequence. The textbook helped organize Rudy's planning of the enterprise, which involved content coverage. The textbook seemed to essentially define the appropriate coverage for all three teachers in the community. In their meeting on the inservice day the textbook was the main reference for what they needed to cover and how they would distribute it among classes. When textbooks overlapped in content they had to decide, by 
other means, in which course they would cover the content or if they would cover it in both. The textbook was a projection of meaning for Rudy because he defined his production in the community according to coverage of the textbook content.

Rudy mentioned the Common Core State Standards for Mathematics (CCSS-M) (NGA Center \& CCSSO, 2010) infrequently. He included a few standards at the top of his lesson plans. He also mentioned the influence of the CCSS-M in the school's decision to pursue an integrated curriculum. The CCSS-M provided a means of organizing Rudy's activity in lesson planning. It also became a projection of Rudy's meaning into his community because it provided a means of evaluating his productivity in the enterprise of content coverage. However, I did not find evidence of Rudy attending to the CCSS-M extensively in any of his activity.

Rudy used lesson plans to guide his classroom participation very loosely. He used lesson plans to organize his practice in the community of mathematics teachers by defining content coverage. Within each lesson he applied lesson objectives, but they seemed to be secondary to his participation. He did not mention objectives in class, they were merely included at the top of his lesson plans as a memory of prior planning. They helped organize his content coverage and determine his progress in pursuit of the enterprise of content coverage, but perhaps in a more historical manner. His lesson plan and objective reifications took prior years' reifications and allowed him to play them out as participation in the classroom community, while largely bypassing the planning process in the teaching community.

The course I observed Rudy teach was Math II. This course helped organize Rudy's participation in the mathematics teacher community by defining the content 
coverage necessary so he could pursue the enterprise of the community.

Schoolwide reifications that were relevant to the teaching community were the schedule, the integrated curriculum, the pacing guides, and collaboration time on Wednesday afternoons. The schedule and integrated curriculum helped organize Rudy's activity at the time of observation, but more importantly the transitions in these reifications significantly organized his participation in the community. The difficulty of a constantly changing schedule contributed to the overwhelming situations that produced the efficiency argument for Rudy's planning practices at the time of observation. The transition to an integrated curriculum created the tensions in Rudy's relations with his community members and his ultimate marginalization in the community. Rudy's experiences around both of these reifications projected a sense of incompetence that contributed to negative elements of his identity formation with which he has had to cope.

Note that as I described reifications and the meanings they established for Rudy I necessarily discussed participation. These two interwoven elements play into experiences in complex ways. To finish this description of participation and reification I will discuss this interplay in Rudy’s experience.

\section{The Interplay of Reification and Participation for Meaning}

Rudy's experiences in his communities of practice are not unique in the sense that similar intersecting forces are at work in the practices of teachers across a variety of global positions. However, his experiences are profoundly unique in the sense that he is the only one who will build them all together into a coherent identity and history of learning. In terms of reification and participation, these experiences represent and are a product of the interplay of the participation of community members and the reifications at 
play in the community.

The nature of this concept of the duality of reification and participation leads me to present this section of analysis slightly differently. I am not going to share aggregate data and the patterns of interplay found across codes of participation from reification and reification from participation. I think this simplifies the intricacies of the relationship. Instead, I will present a description of the interplay around the notes reification. I have already described the notes procedure and the notes reification, but here I will explain the interwoven nature of Rudy’s experience and the ways in which he experienced meaning in reification and participation cooperatively. Simultaneously I hope to weave in the contributions of a mathematical object as reification to the participations and reifications in the notes activity.

The reifications and participations of Rudy's community at the time of observation cannot be entirely separated from his history of learning in other communities of practice and the historical context of Valley View High School and the Math II course in which my observations took place. Although I know little about these elements, I will include what I do know. I have demonstrated that Rudy had a history in mathematics that has allowed him to reify the definition of $i$. Furthermore, this concept was reified in two more significant ways: in the textbook for Math II (Carter et al., 2012), and in the lesson plans Rudy printed out from prior years. These reifications came together as constructive forces on Rudy's experience as he participated in the pedagogical process of lesson planning. For example, the treatment of imaginary numbers in the textbook occurred in two separate chapters. Rudy’s prior lesson plans had included the concepts from these separate chapters in one unit. The conflicting relations of reifications 
came together in Rudy's participation with the result of a set of lessons that looked very similar to his prior plans and included homework assignments from both chapters in the textbook. Another reification, notes, influenced Rudy's lesson planning. This concept had been a reified element of school experience for decades, but Rudy gave it a special existence in his classroom. It held such an implicit place in his planning that he did not even write it on the plan. It was assumed that the examples and mathematical concepts he recorded were part of notes.

When Rudy took his plans into the classroom he set them on the shelf in front of the interactive whiteboard and began class. As he addressed the class he did not refer to his lesson plan and after his introductory preamble he simply stated, "Notes.” The reification initiated a participatory prescription for all the members in the community. Almost every student in the class took out a five-subject notebook, and turned to a section the student had labeled notes. The participation was not synchronous but it was nearly uniform. As Rudy looked down at his lesson plan, the one that did not label what he was about to write as notes, he wrote the definition of $i$ on the board. He drew a box around it and told his students to do the same. Drawing the box was not prescribed in his lesson plan, but it was a reification of the notes process. It denoted the importance of the concept. As if that was not enough, Rudy referred to the definition as the Dalai Lama of complex numbers. He explained that it would solve all the students' problems. Note that this was another reification denoting the same importance as the previous reification. Neither of the reifications were planned elements of Rudy's participation, but these reifications grew out of the participation.

As Rudy wrote the definition on the board he produced a reification of his 
participation in the classroom community and the students mimicked his participation by creating reifications of their own in those five-subject notebooks opened to the notes section. Not every student wrote the definition at first, but once he drew the box they all wrote. Some still did not draw the box. Each reification took the form of the participation of the community member producing the notes. Each participation took the form of the identity of the community member participating.

As Rudy went through the examples he called on a student, Ben, to give him the value of $i$ squared. Ben looked in his notes and turned his reification into his statement, "Negative one.” When Rudy came upon the need for the definition again he called on Ben, again. Ben did not need to look in his notes this time; instead he declared the value, "Negative one.” With just a couple more examples and the same participation a reification was born. Ben's participation was tied with the value of $i$ squared for the members of this community. In these examples a mathematical reification was developing for the students in this community in addition to, and in conjunction with a reification of Ben's participation regarding the mathematical reification. Rudy's mathematical reification was changing; it became connected to this participation for this community.

I hope this description helps illuminate the interlacing of reifications and participations in Rudy's classroom communities. In this explanation I have demonstrated how Rudy and his students weave together the duality of reification and participation through various principles of interaction, including: the conflicting and complementary work of multiple reifications; the way reification plays out in participation, not as direct production, but as a negotiation of the concrete form; the way participation yields 
reifications for the community that capture a piece, but not the entirety of participation; the way reifications influence participation differently across members of a community; the way participation develops into reifications differently for different members of the community; the way participations and reifications converge and diverge so that they meet only in moments and alter one another's existence over time; the way identity plays into the participation and reifications of a community of practice.

\section{Identity}

Now, I do not depart from meaning nor do I depart from community. Instead, as I focus on identity I will keep practice in mind by analyzing identity in terms of meaning and community. I will demonstrate how Rudy's membership in communities of practice and his trajectories in those communities constituted his identity. I will also describe the continuity of identity demonstrated in Rudy's negotiation of meaning. I will further explore membership as constitutive of identity by investigating teaching as multimembership. Finally, I will describe the interplay of Rudy's community memberships with the landscape of practice. In this section I am trying to address the question: What characterized Rudy's identity in practice?

\section{Community Memberships and Learning Trajectories}

In the production of identity, community plays a central role. The two elements of community I will use to describe Rudy's identity in this section are community membership and learning trajectory. The general concept of membership is basic enough, but for my purposes community membership goes deeper than, "Rudy was a member of the fourth hour classroom community." Membership entails a position in the community, a participation in the joint enterprise, typical forms of engagement with community 
members, and a relation to the shared repertoire. Membership also implies a trajectory within the community. This trajectory determines the path to eventual membership, or non-membership. Wenger (1998) called this a learning trajectory because learning here is a process of developing belonging.

Rudy's membership in the classroom community. I have already argued for the classroom as a community of practice. Now, I will continue my argument that Rudy is a member of that community. Some might argue that Rudy is not a member, but some type of broker or boundary worker who is a member in a community of professionals and a perpetual outsider of the classroom community. However, I contend that his engagement is too real, his pursuit of the enterprise too connected with that of the students, and his taste of the shared repertoire too deep to be a perpetual outsider.

Real engagement. Rudy's participation in the classroom communities of practice demonstrates an engagement too real for a community outsider. Recall that Rudy engaged with students in teacher-class interactions, and teacher-student interactions. He also helped orchestrate individual work, group work, and allowed for student-student interactions. Rudy's engagement with students was not one sided. The instances of minimal response from students were so small that an analysis was hardly necessary.

Rudy participated with his students in teacher-class engagement during activities labeled as notes, homework, warm ups, logistical coordination, and non-relevant discussions. His participation in these activities was characterized by mathematical telling and questioning, but he also spent significant energy directing, using humor, and facilitating self-evaluation and evaluating. Although his most prevalent engagement seems a bit impersonal because he was engaged with the entire class at once, he used 
questioning effectively to maintain an individual engagement in the process.

Rudy's questioning practices produced nearly as much engagement in teacherstudent interaction as teacher-class interaction. Rudy’s teacher-student engagement occurred across the same activities in the classroom community as teacher-class engagement, but the distribution of participation was different. Rudy engaged students most in questioning during teacher-student interactions. He also facilitated selfevaluation, evaluated students, employed mathematical telling, used humor, directed activity, and answered students.

Connected pursuit. Rudy engaged his students in pursuing a joint enterprise. Rudy's role in pursuing the enterprise was different, but his participation was connected with his students around the same pursuit. Recall from the section about the joint enterprise of the classroom communities that there were some differences in the enterprises of the two classes. In both cases Rudy joined with the class in pursuit of a collectively negotiated enterprises I called doing school and doing mathematics.

In the doing school enterprise the main objective was the production of procedural skills and the completion of tasks. This form of the enterprise was particularly applicable in fourth hour. Rudy participated in this pursuit primarily in the development of procedural skills. Rudy was rarely the party responsible for completing tasks, explaining, recalling prior learning, or developing understanding.

In fifth hour the doing school enterprise was not as palpable. The enterprise focused heavily on procedural development and evenly on understanding and completion of tasks. I called this enterprise doing mathematics. Rudy participated in this enterprise by pursuing the development of procedural skills. However, he was also held accountable 
for understanding, explaining, and recalling prior learning more in fifth hour than fourth hour. In both classes Rudy participated in the development of procedural skill primarily through the notes activity using mathematical telling and questioning. His participation in homework through evaluating, facilitating self-evaluation, and answering also contributed to the pursuit of the enterprise by developing procedural skills.

Taste of the repertoire. Rudy was thoroughly invested in the community through his participation in the shared repertoire. There is no evidence that he was left out of the shared understandings of the community in any way. He was fully invested from classroom elements, to mathematical tools and understandings. In many cases he was the source of the developing shared repertoire.

Authority and motivator. Rudy's engagement with his students in the pursuit of the joint enterprise through the application of the shared repertoire suggests his role is that of an insider in the classroom communities of practice. However, you may notice in his engagement, some differences in his role of participation than that of his students. Furthermore, his pursuit of the enterprise is limited to particular elements. However, a typical community of practice is not homogenous. The strange thing about this community is the synonymous role held by the students more than the anomalous role held by the teacher. Rudy's nonconforming role does not preclude him from full membership, but some clarifying details of his membership may be helpful in providing a more complete description. He was the teacher in the community. This implies an identity in the community for Rudy that also transcends the community and places him in a professional community. I have claimed previously that Rudy sees his identity as a teacher as authority and as motivator. This is born out not only in his perception but in his 
practice.

One aspect of Rudy's identity as a teacher in the classroom community is an authority. As I wrote in the section about mutual engagement, Rudy’s variety of authority is not dictatorial, rude, or condescending but he expects to be respected and he expects to direct classroom activity. This was evidenced in his engagement as he spent most of his time in teacher-class interactions as the center of activity for the class. This was evidenced in his participation because he spent most of his time using mathematical telling, questioning, and directing. He used a lot of mathematical telling, but softened this with questioning. In his interviews he made several remarks about building good relationships with his students. At one point he explained the benefits of treating students as responsible and gave the example of allowing them to choose their seating arrangement at the beginning of the school year. It was this mutual respect built into Rudy's definition of authority that combined well with his role as motivator.

Rudy also saw the role of a teacher as a motivator in the classroom. When I wrote about Rudy's participation I claimed that his style of motivating was not about getting students emotionally excited, or providing students with direct applications of mathematics to their immediate lives, but providing an environment that was safe for students and relationships that made them want to return to class. This definition of motivating was born out in Rudy's participation in the community. He employed reifications effectively to organize classroom activity and create a comforting, for some, predictability to students' classroom experiences. He furthered this predictability in his participation directing classroom activity. He used humor extensively in his participation as well as hinting and story telling. These forms of engagement aligned with what 
Peterson and Williams (2008) termed softening the classroom experience. They claimed that this was a typical cultural practice of teaching in U. S. classrooms.

Rudy's roles as authority and motivator combined in his engagement in the classroom community of practice. Neither aspect of his identity could appropriately be separated from the other. In Rudy they worked in tandem. Rudy engaged with his class in a show of mutual respect and unimposing, quiet authority.

Strophoid. Every member of a community has a learning trajectory in the community. Wenger (1998) described a variety of trajectories: inbound trajectories that take a member from peripheral participation to full participation in the community, outbound trajectories that usher members out of a community of practice in generational reconstitution, insider trajectories that allow full members to continue a learning process of adaptation within the community, peripheral trajectories that keep members out of full participation in the community in a marginalized position, and boundary trajectories that keep members interacting at the intersections of multiple communities without gaining full membership in any one community. I recount all of these trajectories to say that I do not find one that adequately describes Rudy's trajectory in the classroom community. The most closely resembling Rudy's trajectory would be an insider trajectory. Rudy was a fully invested member participating in the process of learning and change within the community. However, I do not feel as if this adequately describes the extent of his learning. I would also describe the trajectories of the students as insider trajectories for my time of observation, but this does not fully describe the extent of their learning.

I conjecture that at the beginning of the school year the students' and the teacher's trajectories looked more like inbound trajectories as they learned a common language and 
developed reifications that would guide their classroom participation. At the point I observed they were fully invested in the repertoire and enterprise of the community and engaged with one another in its pursuit. However, they were still learning an everchanging repertoire of mathematical concepts and procedures to attain the ever-changing target of the joint enterprise. By the end of the year they were probably projecting out of the community to the summer and the next year in school and the next course in mathematics. I will call this trajectory a "strophoid trajectory.” The word strophoid means a belt with a twist (O'Connor \& Robertson, 1997) and is used as the common term for a particular type of curve in geometry. To differentiate the role of the teacher in the community I will call Rudy’s a leading strophoid trajectory. Figure 1 shows a depiction of Rudy's community of practice as a convergence of learning trajectories. Rudy's leading strophoid is pictured as the solid strophoid and the students' trajectories are dashed.

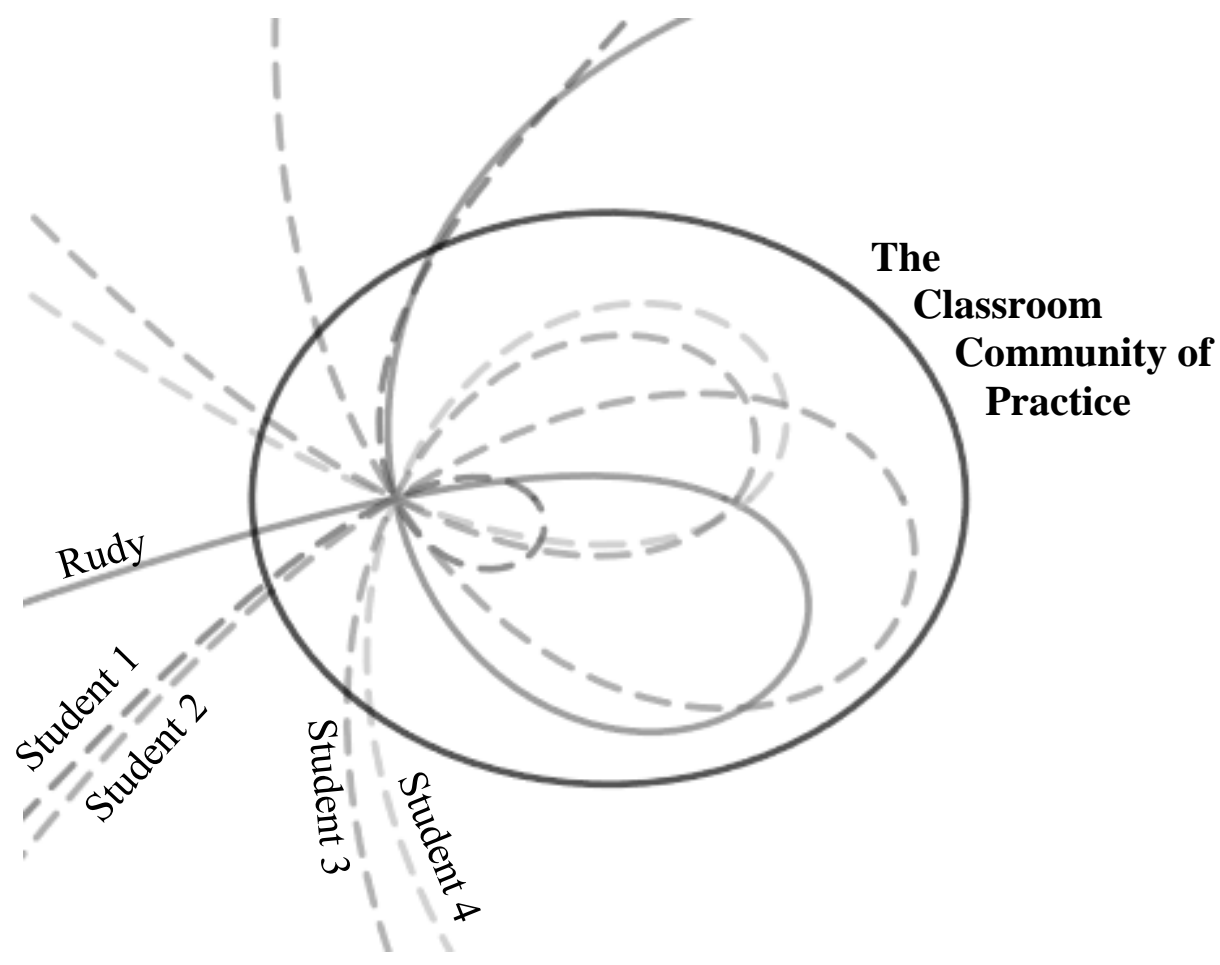


Figure 1. Converging strophoid learning trajectories in the classroom community of practice. The ellipse represents the emerging classroom community from the converging and diverging strophoid trajectories. Rudy's leading strophoid is pictured as a solid curve and the students' curves are dashed. The image was prepared using desmos.com/calculator.

The classroom community is unique because it does not have traditional generational discontinuities in the sense that new members enter the community and old ones exit. Everyone in this community of practice began to establish their membership simultaneously in conjunction with the establishment of the class. I am not claiming that this establishment automatically instituted a community of practice. It is possible that the community really evolved over the course of the school year, admitting new members as time wore on or even omitting members as the case may be. I do not mean by the addition or removal of students in the class, I mean that some members of the class may have been excluded from the community despite being a formal member of the class. I did not see evidence that this would have been the case for Rudy's two classes so I will make the assumption that the community commenced at the beginning of the school year and evolved in the intervening months. At the conclusion of the year I assume that many members exit the community, but in some ways the community may live on. The strophoid trajectories represent the typical end of year exit I hypothesize. However, the community may live on as some students are together in the same hour of mathematics the following school year. Those students are likely to retain many of the aspects of their former community and evolve based on the inclusion of a new set of members. Rudy will also retain a sense of the community in the following year. Although he may be the only 
remaining member, he will bring many aspects of the former community into his development of a new community. His strophoid trajectory will repeat upon itself with adjustments for a new set of members. In a small school like Valley View it is possible that many of Rudy’s students from Math II will be placed with him for Math III. This may provide generational turnover in a more traditional sense than is found in other classrooms and alter the strophoid trajectory to include a repeated loop.

Rudy's membership in the mathematics teacher community. Rudy is a member of the mathematics teachers' community at Valley View High School, but I am not certain that he wants to be. I have spent a significant portion of earlier sections describing aspects of Rudy's position in the teaching community, but here I will present the case for Rudy's position as a marginalized member on a peripheral trajectory in the mathematics teaching community of practice. As I did with Rudy's membership in the classroom community, I will describe evidence of Rudy's membership in engagement, enterprise, and repertoire. This will lead to a discussion of his position as a marginalized peripheral member and his peripheral trajectory.

Marginalizing engagement. Rudy's engagement in the community with the other mathematics teachers was characterized by marginalization. Note that I do not have extensive evidence about the relations in this community. I have evidence from one meeting and self-report data from Rudy. He described their historical interactions as conflictual. He described the teachers as hard to work with. And in the meeting I observed the engagement was minimal. The topics were addressed quickly and succinctly and Rudy did not offer opinions, he asked questions and recorded the answers.

The historical narrative about Rudy and his fellow mathematics teachers centered 
on the decision making processes about migrating to an integrated curriculum, choosing new textbooks, changing course offerings, and implementing the new curriculum. Rudy did not express an opposition to the decisions to implement an integrated curriculum, use a particular set of textbooks, or add a mathematics essentials course. However, he was opposed to the implementation plan for the integrated curriculum. This conflict dominated his narrative about these decisions and transferring to a new curriculum. Thus, the theme in Rudy's discussion was his marginalizing experiences. He explained that, "no one really listened to me cause I'm just young and don't know what I'm talking about.” I have claimed before that this statement demonstrates two things. First, this was a marginalizing statement because Rudy perceived that other community members took aim at his competence. He heard that he was too inexperienced and did not have the level of expertise to speak wisely into the negotiated enterprise of the community. Second, instances like this shaped Rudy's present identity and participation. Notice that Rudy switched to present tense for the second half of his statement. He was making an observation about the past occurrence, but he was also making a statement about his present identity. Instances of Rudy's participation in this and likely other marginalizing situations placed him in a peripheral role in his community and in my observations he participated, or more accurately did not participate, accordingly.

Rudy may have played a significant role in establishing his peripheral membership. In his interview after observations he said, "My first year I locked myself in my room. I worked through my preps, my lunches, I'd come in on Sundays, lesson plan, things like that. I didn't have time to collaborate.” He clearly isolated himself early in his career. Furthermore, when he was overwhelmed again at the implementation of an 
integrated curriculum it is likely that he isolated himself again. This isolation may have strained relations with the community because the other teachers intended to collaborate. Rudy explained he agreed with, "their [the other mathematics teachers] idea, we need to collaborate more.” But he added, "But that's something to do after we've established pacing guides, curriculum maps.” Rudy may have ignored the other teachers’ attempts at building a strong community because he was overwhelmed and because they marginalized him in the decision making process.

Disjointed pursuit. In my description of the joint enterprise I identified the main enterprise as content coverage. The teachers were concerned with presenting the students an adequate set of mathematical topics to prepare students for standardized testing, graduation, and subsequent career paths. The only negotiation of goals and practices among the teachers focused on scope and sequence. The only mutual accountability to the enterprise regarded covering particular topics in the appropriate course. The only indigenization of the enterprise involved the choice of topics from the textbook ascribed to a given course.

It is worth noting that my view of the enterprise was not only limited because I observed only one interaction among colleagues, it is also tainted because of the strained relations between Rudy and his coworkers. I say this taints my view because I may have gotten a different perspective on the joint enterprise pursued by Jean and Julie if had talked with them. However, my hypothesis is the joint enterprise was the same for Jean and Julie, but the engagement between the two may have been stronger. Rudy explained in the interview that Jean's and Julie's perspectives on what it means to cover a topic was different than his. Rudy claimed that Jean and Julie felt that presenting the material was 
adequate to meet the demands of teaching, even if the students had not mastered the material, based on his definition of mastery. His statement suggests further consistency in the joint enterprise.

It is clear that even if this enterprise was jointly held by all community members, it was pursued disjointedly by Rudy. He engaged with Jean and Julie minimally so that his pursuit of the enterprise was primarily in isolation. This suggests that he was a member of the community but not with the same form of membership as Jean and Julie. His participation was peripheral.

Minimal repertoire. My observation of the shared understandings, tools, and processes of the community was minimal. This does not necessarily imply that what the community shared was minimal, but it could. They certainly possessed many shared understandings about mathematics, the curricular resources available to them, and the courses at Valley View. However, a lack of evidence of any shared understandings unique to their community is evidence that the repertoire was minimal.

Beginner and efficient. I have already suggested that Rudy's position in the community is peripheral. I have also suggested that this position is the result of historical interactions of isolation on the part of Rudy and marginalization on the part of Jean and Julie. In order to cope with peripheral membership, I claim that Rudy held onto his identity as beginner. I claimed before that in his seventh year as a teacher, in the third year implementing an integrated curriculum, and the second year on a consistent schedule, Rudy continued to cite a lack of time and experience as reasons he was not collaborating. He explained that down the road five or ten years he might have time to collaborate. I claim that he was protecting his identity by using the beginner identity as 
cover. He covered himself with this identity as beginner because it justified his peripheral membership in the teaching community. Although he clung to this early career identity, he appeared to have an inner tension. He mocked the other teachers and administration for ignoring his wisdom about implementing the integrated curriculum because, in his opinion, they used the excuse that he was young and inexperienced. He clearly did not feel that he was actually a beginning teacher, but he covered his identity with beginner because it justified his position in the community.

His identity in the teaching community had taken on another form through his early career experiences of being overwhelmed. Recall that he cited a lack of time as a justification for not collaborating. This lack of time was a theme in his descriptions of his early career experiences, including the switch to an integrated curriculum. In response to the lack of time I claim that he had taken on efficiency as a primary role in pursuing the enterprise of the mathematics teaching community. The evidence for this can be found in his focus on content coverage in the enterprise of the community, his focus on content and not pedagogy in his lesson plans, his lack of reifying new plans for the current year and adapting lesson plans in classroom practice, and the consistent, predictability of his participation in organizing classroom activity. These elements allowed him a form of efficiency that freed him to be productive in the pursuit of the enterprises of various communities of practice and find competence in each. Note that this aspect of identity combined with his covering his identity with beginner because the two dimensions developed in tandem. It was as a beginner that he found the need to develop efficient systems that would allow his productivity in multiple communities. As he had clung to his beginner identity he had carried the efficiency in participation with it. 
Peripheral. Much like his membership, it appears that Rudy's trajectory was peripheral. He remained in the periphery for seven years in the district and his engagement with the community did not indicate a shifting position. However, in his retreat to an identity of beginner he may have been holding out hope for an inbound trajectory. He expressed plans to collaborate in the future. He held onto his early career identity as a means to justify his peripheral position and retain hope of a better position in the future community.

Rudy's position as coach. I have argued that Rudy was a member of the coaching community at Valley View and the coaching community was a community of practice. Rudy was both the head wrestling coach and a baseball coach. His interactions with the other coaches in the school indicated that he was, at the very least, a member of their social group. Despite a small amount of evidence, I will proceed to present it in the same manner as the prior two communities: engagement, enterprise, repertoire, position, trajectory.

More than social engagement. I have written previously that engagement is not just social interaction so I need to make a case that Rudy's interactions with coaches go beyond friendship. In my first description of this community I claimed that Rudy's lunchtime conversation with coaches Roger and Ryan attested to a deeper engagement around an enterprise. The conversation included that Ryan and Rudy were both baseball coaches, Roger and Rudy talked about shared equipment and space, and continued the conversation into a common enterprise in students' physical development. I did not observe Rudy's engagement with coaches in a way that would allow me to characterize typical patterns of engagement. 
Pursuit of character. The lunch conversation suggested an enterprise of physical development for the student athletes at Valley View High School. The coaches discussed the athletic development of student athletes including the proper path to success in multiple sports. The discussion indicated the coaches were focused on a collective enterprise more than a single goal in their own sporting area. Rudy's interview also indicated that his goals in coaching wrestling were about life lessons and that the enterprise of the coaching community may have been as much about character development as physical development.

Shared equipment. The discussion described in the section about mutual engagement illustrates elements of a shared repertoire of the coaching community. Rudy and Ryan shared tools of the trade. They used common equipment and shared an understanding of how to appropriately apply the use of those tools for the development of student athletes. They also discussed a known group of student athletes and the physical characteristics and developed skills necessary for success in particular sports.

Authority and motivator. Based on my scant evidence I claim that Rudy was a full member of the coaching community. He engaged with many other members of the community over a joint enterprise in mutually beneficial relationships through the use of a shared repertoire of tools and ideas. One of the ways Rudy engaged in this community was by coaching wrestling. In his descriptions of his wrestling coaching he provided a similar picture of his goals for his wrestlers as his goals for his students. This indicates that he was likely to see himself in a similar role of authority and motivator as coach. I also claim that his similar role as authority and motivator in teaching and coaching stems partially from his early career struggles in the teaching community of practice. He may 
have retreated (Fenton-O'Creevy et al., 2015) to his identity as coach, which was an identity of competence for him, in the face of a perceived lack of competence in the teaching community. His retreat to his coaching identity may have strengthened the boundary interactions across his classroom communities of practice and coaching community of practice over the boundary interactions across his classroom communities and teaching community. This could have caused a greater alignment of his teaching practices with his coaching practices than may have been the case had he experienced acceptance in the mathematics teaching community and an identity of competence in teaching.

Insider. I do not have evidence of Rudy's current trajectory as a coach, but I think it is relatively safe to suspect an insider trajectory. I have provided evidence that he is an insider in the coaching community. Therefore, it is reasonable to presume that his trajectory is some form of an insider trajectory.

\section{Experiencing Meaning}

Identity cannot be entirely summed up in memberships. Another aspect of identity is a person's experience of meaning. I have discussed at length how Rudy experienced meaning through participation and reification in his practice. In this section I will describe Rudy's experience of meaning in participation and reification as a picture of his identity in practice. If my description of Rudy's identity in membership is accurate this description should have present high degree of consistency between his identity as described in membership and his identity as described in meaning.

Patterns of participation. In the section on participation I demonstrated that mathematical telling and questioning characterized Rudy’s classroom participation. I 
claimed that these aspects of participation allowed Rudy to find meaning in the pursuit of the joint enterprise of the classroom communities, doing school and doing mathematics, and of the mathematics teacher community, covering content. In pursuit of these enterprises Rudy established his identity as a productive participant in these communities. These aspects of participation may have also allowed Rudy to fulfill his role in the classroom as authority and motivator because he was in control of the majority of classroom activity through teacher-class interaction, but softened the lecture with effective questioning.

Rudy also used directing, evaluating, and humor in his classroom participation. I argued that his roles in directing, evaluating, and using humor during classroom activity produced meaning for Rudy as a fulfillment of his perceived roles in the classroom as authority and motivator. Together, these aspects of participation were integrated in Rudy's activity as authority and motivator in the classroom. They also assisted in his pursuit of the classroom enterprise and in some respects the teaching community enterprise.

Rudy's application of story telling, using nicknames, allaying fears and motivating helped Rudy find meaning in identification as motivator. In other places I have argued that Rudy's roles as motivator and authority were well integrated and his participation in these aspects of identity was unified. In coding these three forms of participation and then grouping them together in my description it would appear as if Rudy acted out his role as motivator, at times, in isolation of his role as authority. However, I argue that my participation in analysis has created an artificial separation of participation because story telling, using nicknames, allaying fears, and motivating 
occurred within contexts of participations that fulfilled Rudy’s role as authority.

The remaining forms of participation also helped Rudy in pursuing the enterprise of his communities through his identification as authority and motivator. However, they each represented a rather small proportion of Rudy's activity so I will not take the space here to rehash my earlier evaluation of their contributions to Rudy's experiences of meaning. This does not mean I think they are unimportant aspects of Rudy’s participation or his experience of meaning or the constitution of his identity. I am simply leaving the analysis in its current location because a summary here is unnecessary for such short forms of analysis.

Turning to Rudy’s participation in the teaching community, recall that Rudy participated in the mathematics teacher community in two different ways. I described three themes in Rudy's participation developing instructional materials. The first theme was being overwhelmed, particularly in early career experiences. This theme corroborated my analysis of Rudy’s developing identity in the teaching community as a self-isolated, marginalized, and peripheral member in the community. I also found a theme of low collaboration and difficulty in collegial relationships. Perhaps I could better summarize this theme as disengagement, which fits with my analysis of minimal engagement in the teaching community and a peripheral form of membership. The third theme was Rudy focused on content. This placed his planning in line with the enterprise of the community so that his practice was in accordance with the pursuit of the negotiated enterprise.

Another form of participation in the teaching community was influencing change. I described the results of this participation as marginalizing. I also claimed that these 
instances of participation were instrumental in developing Rudy's present identity as peripheral and his coping mechanism of identifying as a beginner.

I did not mention in the participation section that Rudy's non-participation in the community of teachers is evidence related to his participation as well. Rudy did not engage consistently with his colleagues and the ways he engaged with them in their single meeting was minimalistic. His non-participation in the community is just as much a consistent picture of his identity as a peripheral member of the community as any of the evidence from his participation.

Rudy's participation in the coaching community demonstrated his contribution to the joint enterprise. He fulfilled his role as a member and demonstrated his competence in the community through communications with two other coaches over lunch.

In all of these forms of participation and non-participation, the picture of Rudy's identity is highly consistent with what I described from his community membership. Rudy participated as a fully invested authority and motivator in his classroom communities, a peripheral content coverer in his mathematics teaching community, and a full member in his coaching community.

Reified experience. The second way that Rudy experienced meaning was in reifications. I found a consistency here as well with his identification in membership. In my previous analysis of reification I showed that mathematical entities represented a significant portion of reifications in Rudy's experiences. I described how four particular mathematical objects served to organize experiences in Rudy's classroom by shaping the enterprise, productivity, and participation in his classes. Note that the form of consistency with community is demonstrated in that these elements influenced the form of the 
community and the community influenced the form of these organizing reifications. These were not merely separate entities in which I could identify consistency, but the entities interacted in forming one another so that consistencies and inconsistencies were inherent. However, I argued that Rudy projected meaning into these reifications in specific ways that I now claim are consistent with his identification in the classroom community. I described his application of mathematical entities in the community as influenced by his identification with the mathematics teaching community and a broader landscape of practice. The application of particular mathematical reifications in the classroom community allowed him to pursue the content coverage enterprise of the teaching community.

I also argued that he projected his meanings as a mathematics learner in mathematical reifications. He projected his own meanings into the classroom experience of his students that allowed a greater degree of consistency in his relation to mathematics and his pursuit of the community enterprise. What I mean by this is that his identity as a mathematics learner was an identity of sense making. For him, sense making involved building connections among sets of procedural skills that demonstrate the internal consistency of the mathematical system. His pursuit of the classroom enterprise as developing procedural skill allowed him to project his identity as mathematics learner onto his students as sense-making mathematics learners because they could potentially approach the procedural consistency in the mathematical system.

The other forms of reification that proved most influential in Rudy's experience of meaning were homework, notes, quizzes, tests, and warm ups. These reifications helped organize Rudy's pedagogical practices and fulfill his identity as authority and 
motivator. The procedural forms of these reifications contributed to his ability to execute pedagogical practices efficiently and productively in pursuit of the enterprises of doing school and doing mathematics. The product forms of the reifications also demonstrated the productivity of the community in these pursuits. Thus, Rudy's production of meaning in these reifications was in pursuit of the enterprise of the classroom community and was consistent with his identity in membership.

Another set of reifications that was productive of meaning in Rudy's experiences included social norms, and schoolwide reifications. The norms and rules in Rudy's classroom allowed him to maintain his role as authority and motivator, particularly in the aspect of authority. They also served as a projection of Rudy's organization and efficiency. Schoolwide reifications like grades were a projection of meaning as an indicator of Rudy's progress and that of his class in pursuit of the enterprise.

Rudy also applied reifications in his teaching community. His use of the course textbook (Carter et al., 2012) helped him organize his participation in the pursuit of the joint enterprise. He projected meaning in the textbook as it defined his production in the community according to content coverage. The CCSS-M (NGA Center \& CCSSO, 2010) were another means of defining his production. Rudy’ lesson plans and objectives gave him a means to pursue the enterprise and an efficiency in the pedagogical process.

In Rudy's development and use of reifications in the classroom community and in the mathematics teacher community there was a consistency in his identification as a member of those two communities. Rudy applied reifications as an authority and motivator to the enterprises of doing school, doing mathematics, and covering content. He used reifications to increase efficiency in pedagogical practices to pursue the 
enterprises.

\section{Multimembership}

In my prior description of membership as identity I described Rudy’s memberships in particular communities of practice. However, these memberships were not isolated aspects of Rudy's identity. Rudy brought each of the identities into his participation at all points in life. He emphasized certain identities in certain communities but these identities coexisted in the person of Rudy. In this section on identity as multimembership I will discuss the interrelations of Rudy's memberships.

Recall that I labeled Rudy an authority and motivator in his classroom communities. He identified as a teacher through his role as authority and his role as motivator in the classroom. He was a benevolent authority who maintained control while softening the classroom experiences of his students as motivator. Simultaneously, Rudy identified as beginner and efficient in the community of mathematics teachers. This identification attested to his covering identity as a continuing beginner who prized efficiency in practice. Because both of these identities related directly to Rudy’s pedagogical practices it is not difficult to see the interrelated aspects of most elements of these identities. The authority aspect of Rudy’s identity and the efficiency aspect of Rudy’s identity integrated well together. As authority, Rudy had control over classroom activity that allowed him to employ whatever means of efficiency necessary for accomplishing the enterprise. It also allowed him ease in planning that created efficiency at another level. Rudy’s role as authority made planning more efficient because he could focus on mathematical content and play out his participation through a consistent set of standard practices applied on a daily basis. This same set of consistent practices that 
allowed him to be efficient in planning supported his role as motivator in providing a predictable classroom atmosphere for students. He found an efficient means of being motivator in applying these predictable practices he could work out in practice and infusing his practices with humor and stories that helped soften the classroom experience.

I claim that the beginner aspect of Rudy's identity did not play a strong role in the classroom. As much as possible, Rudy left that aspect out of his identity as he engaged with his students. Instead, that aspect of his identity was manifested merely as a cover in the community of mathematics teachers. He used it as a protection against feelings of incompetence established through marginalization in that community.

Because of his beginner cover I claim that Rudy identified more as teacher in relation to his students and the classroom community than in relation to his colleagues. His primary identification with what it meant for him to teach was not found in his identity as beginner, nor in his identity as efficient but in his authority and motivator identity. Furthermore, I claim that this identity of authority and motivator had a stronger connection with his identity in the coaching community.

Rudy identified as a coach and as a teacher. The congruence of his identity as authority and motivator in both of these communities contributed to my hypothesis that his early career experiences built connections among teaching and coaching that influenced his identity as a teacher and created a stronger affinity in his teaching identity with his coaching identity than with his identity in the mathematics teachers' community. I have already described multiple times the self-isolation and community marginalization of Rudy's experiences in the mathematics teaching community. It stands to reason then, that Rudy would not have created strong bonds between his role in the teaching 
community and his classroom identity. Instead, his early experiences in coaching and teaching played strongly together in shaping his practices in both communities. Thus, he built an identity as authority and motivator in both. Because Rudy was on an inbound trajectory in the coaching community he integrated his identity in this community so that his position as authority and motivator was pervasive across his experiences of teaching, coaching, and within the coaching community. Instead of integrating this identity in similar ways with his identity in the mathematics teacher community he found ways to create a coexistence of the efficiency identity with authority and motivator and cover his peripheral identity with beginner.

\section{The Local and the Global}

Rudy not only identified with his local communities of practice, but he also associated himself with broader groups and categorizations. For example, Rudy identified as a mathematics teacher in the local community but also in the landscape of practice more broadly defined. He attended his meetings with teachers from other local schools and engaged with other mathematics teachers across boundaries. Rudy attempted to align himself with the practices of other communities through these boundary encounters to attempt to build knowledgeability in the landscape and transfer competence to his local community.

In another sense Rudy identified with an even broader category of modern teacher. This is my own term but what I mean by modern teacher is one who ascribes to current practices, which define a cultural conception of good teaching. Rudy's relationship to this idea of modern teaching can be viewed in a couple of different interview transcript excerpts. The first was when he was describing how he learns from 
his students in the follow-up interview. He explained that sometimes he asks them questions about how well they are understanding and what they need help with. He said, "It helps I guess, especially now with the common core standards that have changed, it is being pushed to student led. I guess it's almost including them in the assessment type stuff when I'm asking them those questions.” Rudy was referring to the practices espoused by this group I am calling modern teachers. In this statement he tried to align his practices with those of the modern teacher. He also implicated this modern teacher when he described his high school mathematics teacher in the initial interview.

The reason I'm a math teacher today is because I had an awesome math teacher in high school. If he were teaching now, he would be a horrible math teacher because it was so traditional, old school. Homework, you went over homework, you took notes, and you worked on the homework. And that was just everyday. It was clockwork. We never really got into groups. We didn't do projects.

This quote strikes me as one of the most interesting statements in this entire study. The implication is that the modern teacher is so different from the teacher of 12 to 16 years ago that an awesome teacher then would be a horrible teacher today. I do not want to claim that teaching practices should not adapt with the cultural changes over time, but this is a drastic statement.

Another fascinating element in this statement is Rudy claimed his teacher would be a horrible teacher at the time of observation because of the methods he used. When I read Rudy's description of what class was like I get a picture of Rudy's class in my mind. Note the juxtaposition of Rudy's historical roots and his attempt to align himself with the modern teacher playing out into his identity as beginner and efficient and also authority and motivator. Let me explain more of what I mean.

Rudy's history of learning in the realm of mathematics teaching extends back at 
least to his experiences in his high school mathematics classes. Rudy explained that his high school mathematics teacher was influential enough in his life that he directed Rudy's career path to teaching. The influence of this teacher's practices on Rudy's practices is likely significant. Rudy’s predictable patterns of using homework, notes, warm ups, and assessments are evidence of this influence. Rudy's identity as authority allowed the traditional role to be played out in his experience. I suspect that his identity as a teacher developed in these roles, in part, as a result of his overwhelming early career experiences. In order to increase necessary efficiency and because of an identity of isolation Rudy may have employed the practices established in his historical roots as a student. In addition, he practiced what I will call vicarious participation by viewing his class from his students' perspective. His own participation as a student may have strongly influenced this practice and resulted in Rudy's development of historically based practices.

In his practices at the time of observation, Rudy made somewhat significant alterations to traditional practices in order to align himself with the modern teacher. Rudy used questioning significantly. I claim that one of the reasons he used questioning was because it allowed him to approximate engagement with individual students and align himself, just a little bit, with the student-centered practices of the modern teacher. Rudy varied the process of homework evaluation. I claim that part of this variation was to align himself, just a little bit, with alternate evaluation practices of the modern teacher that emphasize self- and peer-evaluation. Rudy included the statement, "you can work with a partner” a couple of times per class hour. I claim that part of this facilitation of group work was to align himself, just a little bit, with practices of the modern teacher that 
emphasize collaboration. Rudy also claimed he used projects and group work more than what I was able to observe in my short time in his class. He alluded to projects that he had used in the past in one of his teaching episodes and described the integrated approach as including projects that incorporate a variety of content. I cannot verify that Rudy actually employed these practices, but I think that his overall practices align a little more closely with those of the modern teacher than the picture he gave me in my observation period.

These ways Rudy aligned himself with the practices of the modern teacher allowed him to hang onto the comfortable and consistent practices he had established as authority and motivator while fulfilling this broader alignment of his identity. They also allowed him to fulfill his role as efficient because he could maintain the practices he had established as routine and use the plans he had developed in the past.

\section{Learning}

I have been building a picture of practice, of communities, of meaning, of an identity. I have been building learning. My analysis of learning is not, in its essence, a separate question from those we have already answered. Learning is practice. Learning is community. Learning is meaning. Learning is identity. Learning is teaching. In this final section of this chapter I will continue to describe Rudy and his practice by taking a new perspective on my analyses of communities of practice, negotiation of meaning, and identity to illuminate learning. I explore learning through the lens of shifting memberships in communities in the section learning as belonging. I examine learning through the lens of making meaning in the section learning as experience. I analyze learning through the lens of transforming identity in the section learning as becoming. I 
investigate learning through the lens of changing practice in the section learning as doing. The question I would like to address in this section is: In what ways did Rudy learn through practice?

\section{Learning as Belonging}

In the original formulation of the theory of situated learning, in which the concept of a community of practice was born, the central tenet of learning was legitimate peripheral participation. The idea here was that learning occurred as a part of changing participation in changing practices. An individual entered a community on the periphery and not as a full member. This individual was allowed to engage in the practices of the community in a legitimate but limited manner at the periphery. As this individual became competent in their menial tasks they would take on more productive means of engagement in the practices of the community. Over time they would proceed along an inbound trajectory through legitimate peripheral participation into full membership in the community with access to the shared repertoire that would allow them to engage in the pursuit of the community enterprise. In this process the practices of the individual would adapt to suit the community, but the practices of the community would also adapt to accommodate the new member. This was positioned as the ideal of natural, social learning.

Legitimate peripheral participation in communities of practice, resulting in an inbound trajectory may be the ideal of learning, but it is not the only way that learning occurs. Wenger (1998), as I have mentioned, discussed a variety of trajectories that are possible in communities of practice. Each trajectory implies its own sort of learning. Recall, I posited a different sort of trajectory that may be at play in Rudy's classroom 
communities. Before I get to a complete discussion of this idea of learning as trajectory in communities, I will describe learning as it occurred for Rudy in mutual engagement, joint enterprise, and shared repertoire. Then, I will describe what I think is the most pertinent view of learning in community in a further discussion of trajectory.

Mutual engagement. When I began to look for learning in Rudy's mutual engagement I searched for three things. First, I looked for changes in the form of mutual engagement over the course of my observations. Second, I looked for adaptations in Rudy's engagement across communities that would point to a history of learning in engagement. Third, I looked for evidence of historical changes in Rudy's engagement in the teaching community. On the first account I searched in vain to find adequate evidence of a legitimate change in mutual engagement during my four days of observation. That does not imply that Rudy engaged with his students in the same way from day to day, but only that noticeable alterations that implied a sustained form of engagement were not observed. It also does not imply that learning did not occur in mutual engagement for Rudy, but only that it did not manifest itself in noticeably altered forms of engagement.

Evidence of historical changes in Rudy's engagement in the community were more abundant. Rudy's engagement with fifth hour differed from his engagement with fourth hour in several significant ways. The differences implied a history of learning in the communities as the members of the community negotiated forms of engagement.

Rudy's engagement with fourth and fifth hours was consistent in terms of the percentage of teacher-student, teacher-class, individual student, and group work engagement. The only minor difference in the two classes was a slightly lower percentage of teacher-class and teacher-student interactions in fifth hour than in fourth hour. This 
may have been related to a higher percentage of student-student engagement in fifth hour, but the student-student engagement did not seem to be related to Rudy's engagement in the community in a way that would imply Rudy altered his engagement.

Several ways that Rudy engaged differently with his fourth and fifth hour classes suggest that his conception of fifth hour as a more talented class was at play. Here, it is important to remember that this conception and his engagement existed in a reciprocating relationship. His conception that fifth hour was more talented developed, in part, as a result of his engagement, and his engagement with the classes evolved as a result of his developing conception. Thus, he was learning from his engagement, but the learning was the evolution of his engagement. One of the differences in engagement that attests to Rudy's history of learning was when Rudy engaged in teacher-class interactions he employed more mathematical telling than questioning in fifth hour and the opposite in fourth hour. I claimed in the section Mutual engagement in Classroom Communities that this pattern of participation was related to fifth hour's higher rate of answering Rudy's questioning and their higher percentage of correct answers. I will not recount my entire argument here, but the learning that I claim occurred involved an evolution of engagement with students in fifth hour as he reduced his amount of questioning in favor of efficiency based on the positive results of evaluation through questioning over time.

Another source of evidence for the evolution of Rudy's engagement in the two communities over time was his greater use of evaluation and questioning in teacherstudent interactions with fourth hour. One of the reasons Rudy engaged in more evaluating during fourth hour was because he checked individuals' work more as they performed independent exercises. The history of learning implied here is similar to what I 
found previously because Rudy’s engagement over time evolved to include more evaluating in order to address less correct answering in fourth hour. The higher level of questioning in fourth hour teacher-student engagement was also related to Rudy's use of questioning in teacher-class interactions. In the mutual engagement section about teacherstudent interactions I explained Rudy adapted his engagement to use more teacherstudent questioning because fourth hour was less responsive to group questioning.

A third source of evidence for Rudy's evolving engagement was evaluation during individual work time. Evaluating was the most frequent type of participation during individual student work in fourth hour, but was almost non-existent during fifth hour. In the section on engagement in individual work I explained the difference can be attributed almost entirely to differences in a single lesson. In three separate instances Rudy utilized individual work time. In two of those three instances the greater number of instances of evaluation in fourth hour may be attributed to the interaction of Rudy's engagement and his perception of fifth hour as more talented.

The first three evidences of Rudy's evolving engagement involved questioning and evaluating, but Rudy's use of humor is also a source of evidence for evolving engagement. Rudy used humor twice as often in teacher-class interactions in fifth hour than in fourth hour and nearly twice as often in teacher-student interactions. He rarely used humor in other forms of engagement. I could cite similar results in story telling, Rudy's comments about how much humor he used in classes indicated that his engagement differed in these classes purposefully. This suggests an adaptation of participation in one or both classes over the course of the year based on the results of the engagement, which indicated to Rudy that the class could, or could not, get "back on 
track quickly.”

Rudy's engagement in the teaching community adapted over his tenure at Valley

View. The strongest evidence of the changes is Rudy's direct statement about his history of learning in engagement.

Um, at first, it was one of the high school math teachers, she's been here a long time. The other one has been here a year longer than me. At first, it was I didn't want to say a whole lot because I was new at it. Just more I was figuring some stuff out on my own. Then, it was I've been teaching for awhile now, I'll try to add my two-cents and help each other out, but they just kept shutting me down. So now, it's like back to I'm not saying anything but I'm just kind of doing my own thing. That part gets frustrating like if I do have questions, or would like some opinions or thoughts. I don't even want to go talk to them about it.

If I can take Rudy at his word, then his engagement adapted over time based on the corresponding engagement of Jean and Julie. I do not have any additional evidence to suggest this is an accurate description of his engagement, but the evidence about his engagement at the time of observation is consistent with his description of his final state.

Joint enterprise. I also found evidence of Rudy's learning in an evolving joint enterprise in his classroom communities. The evolving enterprise took the form of learning for Rudy in three ways. First, Rudy demonstrated learning in his adaptions of forms of accountability for his students. Second, accountability to the enterprise also produced learning as Rudy adapted to differing forms of accountability in fourth and fifth hours. Third, Rudy learned in the negotiations over the enterprises as evidenced in the differentiated enterprises of the two classes.

In the section Accountability in Joint enterprise in Classroom Communities I described Rudy's practices in keeping students accountable through homework and assessments. He adapted his homework and assessment practices for situation-specific needs, based on the negotiated participation of the community. When he adapted his 
lessons in order to spend more time reviewing how to solve quadratics he also added a mini-quiz that he had not planned to include. He also adapted his coverage of homework based on the different needs of his classes. For example, he spent time going over homework with fourth hour on a day that he left for a wrestling meet during fifth hour, and on the following class day he spent more time going over homework with fifth hour to compensate for his perception of different needs of the communities. These adaptations in the forms of accountability were learning for Rudy.

In the section Negotiating in Joint enterprise in Classroom Communities I discussed how individual students had more responsibility for pursuing the enterprise in fifth hour than fourth hour. I claimed the difference in the distribution of responsibility between classes could be attributed to Rudy's perception of the talent level in the classes. Furthermore, the distribution of responsibility for the enterprise implies a history of learning that the distribution evolved together with the enterprise, and with Rudy's perception of talent in the classes. As students demonstrated competence in the enterprise consistently over time (e.g., through their correct answers to questions in mutual engagement) Rudy ascribed more responsibility to the individual students of the class. This attests to Rudy's learning in negotiated accountability to a joint enterprise.

Rudy's most significant learning in relation to the enterprise may have come through the course of the year in relation to the negotiated enterprise of fifth hour. I have previously described how understanding took on a more important role in the enterprise of fifth hour than it did for fourth hour. Although this is related to Rudy's perception of fifth hour as more talented, the perception was more the result of the enterprise than the enterprise the result of the perception. Still, I claim these two developed in concert, as 
interacting elements always do. I described in more detail in the section about negotiating the joint enterprise of the classroom community, how the evidence implies the enterprise developed. In this development, Rudy learned. He aligned himself with the enterprise in small ways, but primarily he came to anticipate the ways George would hold him accountable to understanding and Rudy prepared to renegotiate the enterprise toward procedural skill whenever it came into conflict with his role as efficient and the pursuit of the content coverage enterprise.

Shared repertoire. Learning in the shared repertoire may be the type of learning closest to the internalization that many typically associate with the term learning. The cognitive elements of learning are certainly at play in a tangible way in the shared repertoire, but remember that learning, in the CoP perspective, is primarily a social process of establishing community. Thus, learning in the shared repertoire was not merely about getting a concept into Rudy's mind. Learning here was about establishing an idea, a process, a tool as useful in the community for production in the enterprise.

With this view in mind the first way that learning took shape in the shared repertoire was in emerging mathematical elements. A traditional view would suggest that this was not learning for Rudy because he already had these mathematical ideas internalized and he was trying to establish them in the minds of his students. However, as he assisted in establishing the elements of the shared repertoire in the community, the process spurred learning for Rudy as well. These elements never took on quite the same form and meanings in Rudy's classroom communities as in his mind. So Rudy associated particular meanings in the community with the elements of the shared repertoire. Let me provide a few examples of what I mean. 
In fifth hour I have described how the emerging value of $i$ squared became directly and intimately associated with a student, Ben's, participation in consistently providing the value. Rudy's participation influenced the development of this element of the shared repertoire in a particular way within this community of practice so Rudy was learning how to apply this particular understanding within this particular community context. His participation in fourth hour did not imply the same form of this element of the shared repertoire, Rudy learned it differently in that community. However, I still submit that he learned it in the fourth hour community. The value of $i$ squared did not come with an extra piece of participation that helped me identify the learning in fifth hour, but Rudy learned what I call the "trappings of use" in fourth hour just like he did in fifth hour. If he did not, he may have tried to apply the added association from fifth hour in fourth hour. This was not the only instance of this type of learning where Rudy's participation influenced the trappings of use for an element of the shared repertoire. For example, Rudy had students use an Arnold Schwarzenegger accent when they referred to rationalizing the denominator.

These trappings of use for elements of the shared repertoire associated with particular communities were primarily the result of Rudy's own participation, but trappings of use also developed in student participation. For example, one student in what must have been a discussion about a difficult problem referred to a level of accomplishment in a gaming world. The reference was established prior to my observations and it was clear that Rudy did not fully understand the context of the remarks. However, he brought the trappings of use associated with a difficult exercise back into play more than once during my observations, associating them with the use of $i$. 
In the first instance, Rudy was solving a quadratic with complex solutions using the quadratic formula during the third lesson in fourth hour. He said, "In the past this is where we would stop. But now we're level 86, what was it, 86 ? At least 86 math wizards, about i's and imaginary numbers and all that good stuff.” During the fourth lesson in fourth hour on a similar problem the following exchange occurred,

Rudy: We would stop there because what can we not have?

Several students: negative

Rudy: Negative square roots. Now, we know what to do. Mr. Level 86. Craig: Oh gees. Take the i's out.

Yet another form of the trappings of use elicited learning for Rudy. However, this form produced learning more often in the shared repertoire of mathematics teachers and in most cases was more appropriately viewed as learning as experience in the classroom community. As Rudy introduced elements of the mathematical shared repertoire he would experience, through engagement, particular forms of participation from his students. At times he would associate a particular participation with a particular element of the shared repertoire and a particular student. For example, after constantly reviewing the value of $i$ squared with Ben, Rudy expected him to give the correct value every time. With other students, Rudy might have expected a particular misconception. Sometimes these elements became part of the shared repertoire of the classroom community, as in the case of Ben's participation, but more often they remained elements of Rudy's participation in the community. Another way he experienced student participation was across the community. For example, when many students in the class performed poorly on a particular task Rudy took note to inform future participation. This would occasionally become part of the trappings of use in the classroom shared repertoire as in the following transcript excerpt in which Rudy described a typical mistake (not including 
both positive and negative solutions) when solving quadratics using square roots:

Rudy: Take an $i$ out. Now, when you do square root both sides, I know this is something that many of you missed half points on quizzes, tests, so forth. (pointing to $x=\sqrt{-100}$ ) What did I leave out, didn't do?

Generalized trappings of use like this could be further generalized in the shared repertoire of the mathematics teachers' community. I did not have the opportunity to observe such an occurrence because of the lack of data and engagement in that community.

Emerging elements of the shared repertoire presented the best evidence for learning in the shared repertoire and because the vast majority of emerging elements were mathematical it is difficult to demonstrate the learning in the shared repertoire in other domains. However, there is evidence of a history of learning in the classroom elements of the shared repertoire. Let me describe the case of a mini-quiz for example. If Rudy had, on the second day of class, said, "Clear your desks.” The students in his classes would have taken everything off their desks, but they would not have torn a sheet of paper in half, they would not have shared it with a friend, they would not have kept out a pencil, they would not have mentally prepared themselves to complete a mathematical exercise for the purposes of evaluation. What happened between that time and my time of observation when all of those things would have taken place was learning. One might suggest that it was only learning for the students, but, in much the same way as with mathematical elements, I claim it was learning for Rudy as well. I speculate that Rudy did not spend the first day he gave a mini-quiz explaining to his students they should follow all of those procedures every time that he said, "clear your desks.” His adaptation of the phrase and the institution of the mini-quiz was a process of learning over the 
course of the year. As students became aware of the procedures he eliminated more aspects of his directions. As student demonstrated their participation he adjusted his to theirs. For example, during the third lesson in fourth hour he initiated the quiz and then he said, “The longer I have to wait the harder the question is going to be. Gettin’ harder, gettin’ harder, gettin' harder. We're on a level 4. Uh, level 5. Callie, you ready?” Additional procedures required in a given community became associated with the initiation process. Rudy learned how to initiate the process in the environment, the students on whom the class would be waiting, the time associated with completing the quiz, and any number of other trappings of use for the particular community.

Trajectories. The final, and pinnacle, view of learning through the lens of community is the learning trajectory. This type of trajectory refers to an individual's membership trajectory as learning. I have described various possible trajectories as inbound, outbound, insider, boundary, and peripheral. I also suggested that additional learning trajectories in a classroom community might be strophoid and leading strophoid for the teacher. I am not suggesting that all students would follow this strophoid learning trajectory, but I think it is the trajectory that traditional teachers have striven for. It is essentially an inbound trajectory followed at the end of the year by an outbound trajectory. I do not have the longitudinal data to support the reality of this type of trajectory for the students or for Rudy. What I have in the histories of learning I have been describing is evidence that Rudy's trajectory was more than an insider trajectory; it was more like an inbound trajectory or this strophoid trajectory that led and followed the learning of the students. Rudy's trajectory led in the sense that he initiated much of the shared repertoire, forms of engagement, and community enterprise. However, it followed 
because Rudy adapted and evolved with the community.

I have slightly more evidence of a learning trajectory in the community of mathematics teachers. I have described in the identity section about membership and trajectories that his trajectory was peripheral. The evidence from Rudy's discussion suggests that he attempted to develop an inbound trajectory and was directed onto a peripheral trajectory through marginalization. That trajectory implied for Rudy a lack of engagement in the community that resulted in stifled learning. This lack of learning is evidenced in a limited shared repertoire with the teachers, a continued lack of engagement, and an isolated pursuit of an enterprise that may or may not have resembled that of the rest of his community.

\section{Learning as Experience}

Now, I alter my perspective slightly to meaning and view learning as experience through the means of participation and reification. Participation and reification allowed Rudy to instill meaning in his experiences. Without meaning his experiences would have been nothing. As he experienced meaning in participation and reification he learned. The main analogy to view experience as learning is participation and reification as forms of remembering and forgetting. Remembering and forgetting here are not cognitive processes, but community processes. Reification provides a form of memory for the community in concrete productions of participation. It also provides a means of forgetting as it concretizes certain elements of experience and ignores others as forgetting. Participation serves as memory for the community as members bring to bear in any participation a history of participation in the community and a reinterpretation of the reifications they apply. Participation serves as forgetting for the community as new 
participations take the community in new directions and replace former ways of experiencing.

Experimental participation. Participation and reification served as forms of memory for Rudy in many ways. I will not share every form of memory in this section but I will try to describe the primary ways in which participation served Rudy as a form of learning in his classroom communities. Rudy described one type of learning in participation in his initial interview. He said,

A lot of it comes from the coaching standpoint, motivating the kids. And that's hard because each kid's motivated differently. You have to figure out what, what really gets, eats at them. You can't be too hard on some of them, they'll break so to speak. Some of them you have to be harder on. They can take that and use it positively.

In this description Rudy was explaining a sort of learning in participation that allowed him to understand students in terms of their participation in the community and his participation engaging with them. I will call this form of participative learning "experimental participation.” As he participated with students he came to understand, in their participation, what motivated them and how he could participate in a way that propelled them to learn. This was a process of learning in participation where the participation of the students served as memory for Rudy. In one sense it was memory as experimentation because their participation reminded him of what to, or not to do the next time to obtain the desired response. In another sense it was a memory because the students' current participation served as a source of the history of participation. Allow me to provide a couple of examples of how this idea played out for Rudy in his classes.

Here is a short example first from the second lesson in fourth hour.

Rudy: I always thought it would be cool to be an auctioneer. Kate: What do you mean? 
Rudy: Raise your hand if you've ever been to an auction.

Every student raised his or her hand.

Rudy: The guys who talk really fast, you can't understand them, and they mix words.

Reese: Can you do it?

Rudy: No, but I wish I could. I think I would talk like that more often than not. I just got Dalton to smile. Wouldn't that be fun, you're just talking with your buddies. (attempting an auction chant) Hey what are you doing tonight? Oh, I'm not doing anything I'll be free around 8 o'clock.

In this excerpt Rudy was participating in the classroom activity and saw Dalton smile.

This form of Dalton's participation served as a memory for Rudy. The smile indicated a history of not smiling and a rare form of participation. Rudy decided to mark the occasion as a triumph.

In the next example I compare two forms of participation. The following transcript excerpt is from the second lesson in fourth hour and the class was working on an exercise rationalizing the denominator in an expression with a denominator that was a complex number including both a nonzero real and nonzero imaginary part. They determined the complex conjugate and were ready to use it to multiply by a form of one. Rudy asked Stacy to multiply $(-3+2 i)(-3-2 i)$.

Rudy: Stacy, you ready?

Stacy: Yep

Rudy: Deep breath, negative 3 times negative 3

Stacy: Positive 9

Rudy: Negative 3 times a negative $2 i$

Stacy: Um, positive $6 i$ squar..no

Rudy: positive 6 ?

Stacy: $i$

Rudy: Yep. $2 i$ times negative 3

Stacy: Negative $6 i$

Rudy: Positive times a negative is

Stacy: Negative, 4

Rudy: 2 times 2 is $4, i$ times $i$ is $i$ squared.

The next transcript excerpt is from the first lesson in fourth hour and Rudy was reviewing 
prior learning about quadratic equations to help introduce the concept of an imaginary number.

Rudy: Alright Ryan, you're being tested here.

Ryan: Tested? Alright guys, help me out.

Colton leaned to say something to Cory and Brady seemed to assure Ryan he would help him answer Rudy's questions. Ryan looked back at the camera, or possibly another student as Rudy wrote the equation $2 x-4=y$ on the chalkboard.

Rudy: Is that a quadratic?

Ryan: No.

Rudy wrote $18^{x}-4 y=0$

Rudy: Is that a quadratic?

Colton: No.

Ryan: No, I guess no. I thought it was.

Colton: I'm gonna look this stuff up.

Colton pulled out his textbook.

Rudy continued to write $\frac{(3 x+y)}{2}=10$ on the board.

Rudy: Is that a quadratic?

These two excerpts illustrate the differences in Rudy's participation with different students based on a history of participation. He had learned that Stacy benefitted, in Rudy's opinion, from a particular form of participation from Rudy in order to ensure positive results in her future participation in the community. Jeff required, or at least allowed for, a different form of participation and motivation on Rudy's part. It is unfortunate that I have to present only in text because the fullness of these participations does not come through. I was not a member of the community for long, but in these interactions I saw a history of participation in Rudy's classroom and a history of participation that extended even farther into these students' pasts. Their voice, their gestures, their inflections, their glances at friends implied so much more than what I can convey here. Their participation was more than words and Rudy experienced that participation as a form of memory and held his own participation in check in relation to 
that memory.

Reificative participation. Another way participation served as learning involved the development of reifications through participation. I call this "reificative participation.” As Rudy participated in aspects of the classroom community, his participation developed into reified forms that served as memory for the community. A memory of participation that included certain aspects of the participation and excluded others. Let me provide two examples again. The first is a short example from the fourth lesson in fifth hour.

Rudy worked at his desk and took attendance in his attendance book. Rudy: If you have, Ben's still gone, huh?

Mike: Yeah

Matt: He's avoiding this.

Rudy: If he's gone tomorrow...

In this instance Rudy took attendance in class and turned it into a reification by marking it in his attendance book. His prior markings, as reifications, served as memory that this was not the first day Ben was absent. Notice that the marking reified Ben’s absence but it did not reify any of the other parts of Rudy’s participation with the other students surrounding the absence.

Another example is the written notes Rudy transcribed in class. Rudy’s participation in the notes process generally developed not one, but many forms of reifications in student notes. These reifications served as forms of memory for the community. As Rudy participated he wrote certain things on his interactive whiteboard. These elements became a reified form of notes Rudy could return to in future days. They included aspects of his participation in the form of writing and excluded aspects of his participation that were not written. However, the written reification served to conjure up 
Rudy's participation in a way that allowed him to remember certain aspects that were not directly reified. The notes also may have allowed him to remember certain aspects of his participation that did not exist. For example, when he looked back at his notes from fourth hour he may have remembered teaching a concept and using a particular phrase when in fact he used the phrase in fifth hour.

Vicarious participation. A third form of learning as experience is what I will call "vicarious participation.” In this type of participation, Rudy engaged with the class hypothetically as a student. In his initial interview Rudy described this practice in the following way:

Trying to put myself in the kids' shoes is a lot of it too. If I were sitting there listening to me, am I bored, am I listening, am I understanding. Things like that. Trying to pick up, trying to catch questions, mistakes before they happen so that if a kid asks a question I can read their mind. Oh yeah, I know what you did there, you did this. Oh yeah, okay, I understand that. Things like that.

What made this process a powerful form of learning in experience is when Rudy combined it with his participation as a teacher with his students. Notice that in the first part of the statement Rudy used the pronoun I. In determining if a student in his class was bored, listening, or understanding he could generally participate vicariously as an extension of his own experience as a student and have a reasonable picture of the student's experience. However, when he switched the conversation to anticipating mistakes, catching questions, and reading his students’ minds so that he could "understand that" he switched to talking about the students. I claim that in order to learn in vicarious participation Rudy had to use his legitimate participation as a teacher to put himself in the students' shoes. This vicarious participation that relied on his participation as a teacher and his imaginative participation as a student was a significant source of 
learning for Rudy. His participation as a teacher took a significant role in two ways.

First, Rudy's participation as a teacher was important for vicarious participation through experimental participation. When experimental participation was combined with vicarious participation it became a powerful force for developing participation. Take the second example of experimental participation. Rudy may have learned through experimental participation alone that Stacy, in his view, was sensitive to certain forms of participation and he may have learned to avoid engaging with her in those ways. However, that may have led him to not engage with her in a whole class setting at all. Vicarious participation allowed him to place himself in her shoes and understand what was difficult about certain types of participation and develop an adequate participation that would mitigate those negative aspects of whole class participation.

Second, Rudy's participation as a teacher was important for vicarious participation through learning the trappings of use in the shared repertoire. When Rudy participated as a teacher he learned the trappings of use associated with various mathematical concepts in his classroom communities. Some of those trappings were particular ways of thinking about a topic that may have been positive or negative. Some of those trappings were typical and atypical ways that certain students approached mathematics or problem solving. As Rudy learned the trappings of use associated with particular mathematical concepts it gave him a little bit of advantage in teaching. For example, Rudy understood the trappings of use associated with solving quadratics using square roots: students often forget that the solutions are both the positive and negative square root, not only the principal root. He applied this by reminding students that they often forget it and telling them to remember. However, that probably did not help most of 
his students the next time they did a similar exercise. When Rudy combined his learning of the trappings of use with vicarious participation it gave him a strong advantage in teaching. For example, Rudy understood the trappings of use associated with simplifying radicals: students often forget that they should not leave a negative number within a square root. However, he did not just tell students to remember this principle. By putting himself in the students' shoes he understood that he needed to apply some reasoning to the situation because it really did not make sense to students that leaving a negative within a square root is an unacceptable form. Therefore, he applied the reasoning that "mama thinks they're the devil.” Although this was ridiculous reasoning it served the purpose of improving students' application of this principle in simplifying radicals.

You should note that Rudy did not tell me that he combined his experimental participation and vicarious participation in the way I described, nor did he tell me he combined his learning about the trappings of use and vicarious participation in the way I described. I learned these things through vicarious participation combined with my observations of Rudy's experimental participation and learning of the trappings of use.

\section{Learning as Becoming}

In this section I will explore how Rudy learned in terms of identity and through identity work. Significant work was involved in Rudy's becoming. I have demonstrated some of the work, but I will try to make more of it explicit here. One of the ways to view learning as becoming is through engagement. Engagement sets people on a trajectory that takes them into or out of communities, defining their identities through membership. Another way to view learning as becoming is through alignment. Alignment extends people's membership to broader groups beyond communities of practice to which they 
belong. A third way to view learning as becoming is through imagination. Imagination takes people's learning into the realm of imagined others where they put themselves in another's position and take on new roles in their own communities as a result.

Engagement. Engagement involves legitimate participation in a community of practice. Rudy participated in at least three different communities of practice. His engagement in these communities created a trajectory of learning that helped him become a particular person as he engaged in these communities. His trajectory in the classroom communities may have looked like a strophoid. He travelled his way into the community on an inbound trajectory leading just ahead of his students and creating an engaged community of practice with a rich shared repertoire employed for the pursuit of an enterprise of doing school or doing mathematics. Because my data is limited in scope I cannot say much more about the trajectory of becoming in the classroom communities of practice.

In the mathematics teachers' community Rudy's trajectory of becoming started inward and was startled by his forms of engagement in the community. He stifled his becoming by isolating himself in his early career engagement in practice. However, in his perspective this was a necessary element of practice that allowed him to cope with the strains on his competence from the demands of multiple communities of practice. I claim that a significant contributor to his being overwhelmed in his early career experiences was the multimembership with which he had to cope. Not only were the demands of the communities in terms of time and enterprise pursuit stresses, but he was also stressed by multiple forms of becoming that he had to reconcile in one identity. When he taught multiple hours of the same course he was relieved of extra planning, and relieved of some 
level of extra identity work because the two communities would be similar in enterprise and repertoire. When he found a way to reconcile and almost entirely integrate his identity in coaching and his identity in the classroom community, Rudy was able to relieve a major tension in his identity work.

Rudy’s learning in his early career had significant implications for his identity at the time of observation because his learning was identity work. As he sought to learn within his various communities of practice in the ways I have already described in learning as belonging and learning as becoming, Rudy was simultaneously establishing his identity. He was becoming a particular type of teacher. When his identity work was stifled in his teaching community through his own isolation and marginalization by his peers, he retreated to an identity of competence in his coaching community. His learning in the mathematics community of practice was not ended, but it took him in a different direction. He learned to cope with the demands of the community peripherally. At the time of the study he pursued the community enterprise of content coverage through minimal engagement in the community. He talked about engagement through collaboration as a possible future, but gave me no reason to believe it would become a reality. Productive collaboration would mean that Rudy would be accepted as a legitimate member of the community with an inbound trajectory. Without engagement Rudy will continue to have minimal learning in this community.

In the community of coaches, he found an identity of competence with an inbound trajectory. Because he found himself on a peripheral trajectory in the teaching community he made connections between his coaching community and classroom community that might have otherwise been made between the teaching community and classroom 
community. Rudy found the way to cope with the demands of the communities was to integrate his identities into authority and motivator in both communities. He did not integrate this identity in the same ways in the teaching community because his learning there was stifled. Instead, he developed a covering identity as beginner and identity of efficiency that allowed him to cope with the demands of the enterprise despite the lack of integration of his identities across communities.

The learning that was Rudy's identity work showed up in his identity as authority and motivator during the time of observation. His roles as coach and teacher morphed into an integrated identity that allowed him to cope with the demands of both communities in a consistent and efficient manner. Another contributing factor to this learning to integrate identities was the small school atmosphere. Rudy was the coach and teacher of many of the same students. He discussed the importance of relationships with students on multiple instances. His identity as motivator attests to his desire to connect with students and pursue engaging relationships not just for the pursuit of mathematical understanding or wrestling prowess, but for the building of character and critical thinking. These relationships across communities may have contributed to Rudy's tendency to integrate identities across communities as well. He could improve competence in reaching the goals of the enterprise if he could pursue a similar enterprise in a similar manner in multiple contexts.

Alignment. Another way to view learning as becoming is through alignment. In alignment Rudy took the demands, values, ideals, expectations of groups he intended to please and aligned himself with them. Rudy aligned himself in several ways. First, he aligned his practice with the demands of the school. He upheld school rules and policies, 
abided by school scheduling, adhered to school assigned curriculum, and in these ways made himself a Valley View High School teacher. At times he had difficulty with this alignment and sought to change the policies and procedures that would alter his practice. For instance, he balked at the demands imposed on him when the school switched to an integrated mathematics curriculum. However, when he was ignored he learned a new system and aligned himself with the changing demands of the school to maintain an identity as a Valley View High School teacher.

Rudy also aligned himself with the demands of the Common Core State Standards for Mathematics (NGA Center \& CCSSO, 2010). His lesson plans always had CCSS-M standards written at the top, which aligned with his lesson objectives. He also mentioned the goals of the CCSS-M multiple times in his interview. He was attempting to align himself with the project-oriented approach, the student-centered approach, and the integrated approach in the CCSS-M. He suggested that the CCSS-M were the main reason that they decided to use an integrated approach. He said that the CCSS-M did not require it, but the integrated approach helped them reach the goals in the CCSS-M.

Rudy also tried to align himself with the broader landscape of practice. He described interactions with other mathematics teachers he met at conferences. His experiences allowed him to gain an understanding of what other mathematics teachers and programs were doing so that he could align his practices.

Imagination. The final way to view learning as becoming is in imagination. With imagination Rudy pictured himself in the roles of others. He saw himself as a member of a broad category that gave him some sense of belonging beyond what he could engage with. Rudy used imagination to see himself as a modern teacher. I discussed Rudy’s 
integration of the modern teacher paradigm and his historical roots in the section The Local and the Global in Identity. I did not find any evidence of Rudy's engagement with other teachers at Valley View High School that would have contributed to his identity as a modern teacher. Instead he had to project himself into the imagined position of a modern teacher: a teacher he probably learned about in college, or in some professional development sessions, or when he was getting his master's degree in administration. Rudy’s imagination work translated into minor alterations in practice I described in the earlier section to allow him to become a modern teacher and maintain the more traditional identity he had toiled so hard to develop in his classroom and coaching communities.

\section{Learning as Doing}

In learning as doing I will wrap up both the analysis of learning and this discussion chapter. Learning as doing implies a changing practice. Rudy’s participation in community and his negotiation of meaning in experience and his transformations of identity in practice attest to Rudy’s learning as doing. Because I have interpreted the aspects of learning in community, meaning, and identity through the lens of practice, it is appropriate that in this section I bring together these various perspectives of learning into learning in practice as doing.

I viewed community as established in practice through engagement of members in practices that pursue a joint enterprise with the assistance of a shared repertoire of understandings and tools. This view bears out practice as the source of coherence for the community. Thus, this view of learning as belonging also bears out learning as doing because Rudy’s engagement with students and colleagues in practice resulted in ever 
evolving forms of engagement that, when they were not observable in my short period of data collection, attested to a history of learning in engagement. Learning as doing also became observable in the adaptations of the joint enterprise because Rudy's practice adapted in form and function for the differing enterprises of the classroom communities. Learning as doing was illustrated in the emerging shared repertoire as Rudy's practice was ever more informed by the trappings of use of the elements he shared with the community through his teaching practice.

I viewed the negotiation of meaning as worked out in practice through the development of reifications and their applications on participation in communities. Rudy’s learning as experience demonstrated learning as doing in experimental participation because Rudy altered practice in purposeful adaptation to students' engagement in the classroom community. Rudy's learning as experience illustrated learning as doing in reificative participation because Rudy developed reifications of practice for use in practice through participation in practice. Rudy's learning as experience illustrated learning as doing in vicarious participation because Rudy participated in imaginative practice for the purpose of developing a practice more efficient in production toward the joint enterprise.

I have viewed identity as developed in practice and constitutive of practice through membership in communities of practice, trajectories of learning, and modes of experiencing meaning. Rudy’s learning as becoming represented learning as doing in engagement because Rudy’s identity in practice was formed in engagement with communities through practice and informed the practice of engagement in those communities. Rudy's learning as becoming demonstrated learning as doing in alignment 
because Rudy aligned his practices with broader communities through a process of adapting practice to fit community enterprises and the goals of broader social institutions. Rudy's learning as becoming illustrated learning as doing in imagination because Rudy imagined his practice in relation to a global construct that informed his practice as he engaged with local communities in a process of reconciling local and global schemas.

Learning as doing is learning as becoming, is learning as experiencing, and is learning as belonging. Rudy's learning in practice was significant. It was a source of identity, a source of engagement and productivity, a source of meaning, and it was a source of change in his professional practice. Rudy's teaching cannot be separated from his learning in practice. That learning defined who Rudy was and continues to define who he will become as a teacher. It defined his professional practice and his productivity.

In this final chapter I will summarize what I have demonstrated in Chapter V. I will also discuss the limitations of my study and the implications for practice and future research. I hope to provide some ways forward for the mathematics education community. 


\section{CHAPTER VI \\ CONCLUSIONS AND IMPLICATIONS}

In Chapter IV and Chapter V I provided a picture of Rudy’s practice. At this stage, I hope that Rudy's teaching practice is more than an intangible and disembodied concept. I have shared this reification of my participation with Rudy in his practice and I hope it has allowed for an imaginative participation with me in this study. It is from this space of imagined experience built out of this writing I would like to build my final production of meaning. If I have something to contribute to the community of mathematics educators, it cannot be an isolated piece of information for others to internalize and hope to apply. It must be an aspect of participation with me. It must emerge out of imagined experience with Rudy in practice. With this in mind, I will weave my way back through what I have presented to find the threads of meaning that can be productive elements of a continuing conversation in the field of mathematics education.

\section{Addressing My Questions}

My discussion has taken the form of the CoP framework I used for analysis. I began with community, travelled into meaning, explored identity, and ended with learning. The theme that held the system together in unity was practice. Each element was given coherence in Rudy’s practice as a teacher. I will start again at the beginning and recount how I have addressed my questions. 


\section{Characterizing Community}

I began with communities of practice. Recall my objective to address the question: What are the characteristics of Rudy's communities of practice? Recall practice provides cohesion to the community through mutual engagement, joint enterprise, and shared repertoire.

Rudy's classroom practice was a participation in overlapping communities of practice. His minimal engagement in the mathematics teacher community at Valley View High School implied a small influence on his classroom practice that may have been overshadowed by his engagement in the coaching community. The most influential community relations on his teaching practice were those in his own classroom. Rudy's engagement with his students revealed an identity as authority and motivator in classroom practice. As I have described in the section Rudy’s Participation in Practice, this is an identity consistent with what Peterson and Williams (2008) claimed is a typical cultural practice of teaching in the United States. Rudy engaged his classes primarily in teacher-class and teacher-student interactions that allowed him to control the class in a benevolent form of authority. His use of humor, predictable routines, and lecture through questioning softened the classroom experience for his students in similar ways to those found by Peterson and Williams. This form of engagement allowed Rudy to fulfill his identity as motivator.

Rudy’s participation in each class was relatively consistent, but each hour produced a community with unique traits. The joint enterprise of the two class communities provided the most striking difference between classes. Rudy struggled to negotiate the doing mathematics enterprise in fifth hour toward a doing school enterprise, 
like he had established in fourth hour, in order to reconcile with the content coverage enterprise Rudy was beholden to in the community of mathematics educators. However, fifth hour held Rudy accountable to the doing mathematics enterprise by consistently asking questions focused on understanding mathematics. Rudy retained a strong focus on developing procedural skills not by ignoring understanding, but by shifting the focus of understanding toward mathematics as an internally consistent logical system of procedures that could be understood through analogical reasoning. In fourth hour the enterprise evolved as doing school, in which Rudy and his students held a cooperative responsibility to develop procedural skills in mathematics and students were responsible for the less-emphasized task completion.

The shared repertoire of Rudy's classroom communities was an ever-evolving system of mathematical procedures and ideas. These items that were the means of production for the enterprise of task completion were established through the enterprise of developing procedural skills, with the aid of classroom tools of practice. The predictable but adaptable procedures of notes, homework, quizzes, and warm ups were applied consistently in the productive work of the classroom enterprises. With the aid of this shared classroom repertoire Rudy worked out the engagement of the community in the enterprises of doing school and doing mathematics.

Through his pursuit of the classroom enterprises Rudy was productive in the community of mathematics teachers, despite minimal interactions with his colleagues. Rudy isolated himself in early career attempts to retain competence, and was subsequently marginalized to a peripheral role in the mathematics teacher community that allowed him only minimal engagement and participation in a limited shared 
repertoire.

Because of Rudy’s peripheral position in the mathematics teaching community, his role in his classroom communities has been impacted just as strongly by his position in the coaching community. Rudy engaged fully in the enterprise of the coaching community through shared understandings of the tools of the trade. Rudy developed an integrated position as authority and motivator in coaching that also influenced his role in teaching.

\section{Characterizing Meaning}

Rudy’s participation in community gave rise to meaning in his experience. Recall my second research question: How did Rudy negotiate meaning in practice? Also recall that meaning is negotiated in practice through the duality of participation and reification.

Rudy’s participation in the classroom community produced meaning for Rudy. It helped him define and fulfill his identity as beginner and efficient and also authority and motivator through the pursuit of the enterprises of doing mathematics, doing school, and content coverage. Rudy’s participation consisted most extensively of mathematical telling and questioning. These practices allowed him to experience an identity of competence as efficient and authority. His efficiency made him productive in content coverage. The differences in participation in fourth and fifth hours allowed him to be productive toward doing school in fourth hour and doing mathematics in fifth hour. Because he was more efficient in the production of procedural skills in fifth hour, he could focus more on understanding. A higher rate of mathematical telling allowed for greater efficiency in fifth hour, and although Rudy did not pursue understanding strongly, the efficiency allowed the class space to produce more understanding. Rudy also participated in 
directing and evaluating, which both produced meaning in his role as authority. He used humor, story telling, nicknames, allaying fears, and motivating to produce meaning as motivator.

Rudy's participation in the mathematics teaching community involved the development of instructional materials and influencing change. His development of instructional materials was characterized in three ways. First, it was characterized by a sense of being overwhelmed in his early career experiences. This may have led to his role as beginner and efficient, which allowed him to find competence in his efficiency at producing instructional materials. Second, his development of instructional materials was characterized by a lack of collaboration. This was a source of discontinuity for Rudy, but he coped with a covering identity of beginner and an appeal to the necessity of efficiency in his pursuit of the enterprise of content coverage. Third, his development of instructional materials was characterized by a focus on content. This fulfilled his role as efficient in pursuing the content coverage enterprise.

Rudy's participation by influencing change was characterized by his resulting marginalization through a denigration of competence and relegation to a peripheral membership. Instances that produced this marginalization may not have been prevalent, but they appeared to be powerful. They were emotional experiences for Rudy and may have produced a retreat to an identity of competence in his coaching community.

Rudy's reifications in his classroom community helped him organize his classroom experience for meaning. Mathematical objects organized his pursuit of the enterprise of content coverage in the teaching community and procedural skills in his classroom communities. Homework, notes, quizzes, tests, and warm ups organized 
Rudy's classroom experiences into efficient participation through his role as authority. Rudy also projected his meanings onto these reifications in the classroom. The mathematical objects were a projection of Rudy's identity as a member of the broader landscape of practice who was doing the work of initiating students into a position of mathematical knowledgeability. Mathematical objects were also a projection of Rudy's understandings as a learner of mathematics. He viewed mathematics as a procedural sense making activity and his production of mathematical reifications in the classroom community allowed him to project this form of learning onto his students. Notes, homework, quizzes, tests, and warm ups were a projection of Rudy's identity as efficient authority, and in some ways his identity as motivator.

Rudy's reifications in the teaching community (the textbook (Carter et al., 2012), CCSS-M (NGA Center \& CCSSO, 2010), lesson plans, lesson objectives, and courses) were organizers of Rudy's experience that produced consistency with his efficiency and pursuit of content coverage. Rudy projected meaning onto these reifications as representations of his competence as efficient content coverer in the community of mathematics teachers.

\section{Characterizing Identity}

Rudy's participation in his communities of practice produced and reflected his identity. Recall my desire to address the question: What characterized Rudy's identity in practice? Also, recall that identity can be described by membership and trajectory in communities, by experiencing meaning, by multimembership, and by the relations of the local and global.

Rudy engaged fully in the pursuit of the enterprise of his classroom communities 
with the tools of an extensive shared repertoire. In this community he was a full member with a significant role as authority and motivator. His identity as authority and motivator played out in his engagement with students and his pursuit of the doing school and doing mathematics enterprises. His trajectory in the community may have had a strophoid shape and he led students on a similar trajectory.

Rudy engaged minimally as a peripheral member in the community of mathematics teachers. He participated in an isolated pursuit of the content coverage enterprise with minimal access to the elements of the shared repertoire that were unique to the community. His marginalizing experiences led to an identity of beginner and efficient. In this identity he coped with the overwhelming demands of his job through efficiency and with a peripheral membership through a covering identity of beginner. His marginalization produced a peripheral trajectory in the community, but his identification as beginner allowed Rudy to hold out hope for an inbound trajectory.

Rudy engaged fully in the coaching community as an authority and motivator on an insider trajectory. His pursuit of the enterprise of physical and character development was well aligned with his identity as authority and motivator. He built competence in the community in pursuit of the enterprise and carried the competence into the classroom community by integrating his identity in these communities.

Rudy's experience of meaning through participation and reification consistently demonstrated his identity as beginner and efficient and also authority and motivator. He found meaning in his participation because his participation established and fulfilled his multidimensional identity in the classroom. Although his identity as beginner was primarily relegated to his participation in the community of mathematics teachers, he 
found competence in the other three aspects of his identity in the classroom community. Rudy projected meaning onto reifications in the classroom as he viewed his own identity as efficient, authority, and motivator in them, as if in a mirror.

Rudy's identity as beginner and efficient and also authority and motivator attested to a history of learning in multimembership that required difficult and emotional work to integrate his identities in multiple communities. I surmised from Rudy's account that overwhelming situations in his early career led to self-isolation and subsequent marginalization by the members of his mathematics teaching community. I claimed that in the short term he retreated to an identity of competence in his coaching community that led to an integration of identities in his classroom and coaching communities. Rudy's retreat to this identity of competence in the coaching community, under the stresses of multimembership, is consistent with the findings of Fenton-O'Creevy et al. (2015). Rudy needed this retreat as a safe haven to maintain a sense of competence in the short term. I have claimed that over his full career, he coped with his marginalized and overwhelmed role in the teaching community by developing an identity of efficiency and retaining an identity of beginner to cover his peripheral membership.

Rudy's identity was not singularly rooted in his local communities of practice. Just as Walshaw (2004) found that teaching identity for a preservice teacher "developed in response to other identities” (p. 80), Rudy coordinated multiple social influences on his identity to establish his position as a teacher. Rudy identified with a landscape of practice of mathematics teachers. He participated in boundary interactions with other mathematics teachers outside of Valley View, and developed knowledgeability through communications about the enterprise of content coverage. He also aligned himself with 
the methods of his modern teacher prototype through imagination. The modern teacher came in conflict with his historical roots in teaching. To mediate this conflict, Rudy integrated aspects of modern teaching in ways consistent with his roots and localized identity so that he retained a sense of competence in all respects.

\section{Characterizing Learning}

As Rudy engaged in community, experiencing meaning, and defining his identity he learned. Recall my culminating question: In what ways did Rudy learn through practice? Also, recall that I viewed learning as belonging, experiencing, becoming, and in all of these learning as doing.

Learning as belonging for Rudy was a process of evolving engagement in a joint enterprise of adaptation with a shared repertoire developing the trappings of use on a strophoid trajectory. Rudy's differential engagement with his classroom communities pointed to a history of learning to engage productively with each community. He more efficiently engaged with fifth hour in the development of procedural skills so that he could attend to aspects of understanding. He engaged in facilitation and evaluation more with fourth hour to help him keep them accountable for the community enterprise.

Rudy demonstrated learning through his adaptations in the forms of accountability for his students. He altered the forms of homework on a daily basis and adjusted his decisions to include or exclude assessments over the course of the unit. Rudy's accountability to this enterprise also produced learning as he adapted to differing forms of accountability from fourth and fifth hours. He adjusted his practices to align with the different forms of accountability from each hour because of the differences in the negotiated enterprise. Rudy learned in the negotiations over the enterprises as evidenced 
in the differentiated enterprises of the two classes in doing school and doing mathematics. However, I claimed that Rudy missed an opportunity for extended professional growth in fifth hour. He stifled the community's pursuit of understanding instead of leveraging it toward more reform-oriented practices.

In relation to the shared repertoire of the community, Rudy learned primarily through establishing the trappings of use for elements in each community. Rudy himself instituted the majority of the elements of the shared repertoire. Through this process he learned the trappings of use of each element in the context of the differing classroom communities. He learned the participations of the community members that surrounded the development of the element as productive in a given community. He learned the misunderstandings and ways of thinking about elements of the developing shared repertoire that influenced the productivity of those elements.

These trappings of use are reminiscent of the construct of Pedagogical Content Knowledge described by Shulman (1986) and subsequently by many additional researchers, including Ball et al. (2008). However, the formulation of teachers' knowledge as more than cognitive, and situated within community adds at least two aspects to Pedagogical Content Knowledge. First, this view of teacher knowledge emphasizes that Rudy learned the trappings of use for mathematical elements of the shared repertoire within specific communities. Some of the elements generalized across classes, but many were unique to a specific classroom community and in some cases individual students. Second, the trappings of use emphasize the role of teacher participation in the development of this specialized knowledge. These trappings of use were, more often than not, elements that could not have been learned without Rudy's 
participation in the practice of teaching. Thus, research on PCK needs to be supplemented with further research from a social theory of learning. Although the dimensions of learning for teaching that are emphasized in studies like this may not be adequately incorporated into a theory of PCK, the juxtaposition of ideas from both an internalization view of learning and a social view of learning may be beneficial for developing teachers.

Rudy's learning through engagement, through participation in the enterprise, and about the trappings of use attest to a history of learning in which Rudy proceeded along an inbound trajectory and into an insider trajectory during the school year. Because I hypothesize an outbound trajectory near the end of the year I have suggested his learning trajectory was a strophoid.

In the community of mathematics teachers, I found Rudy on a peripheral trajectory of learning. Rudy described a history of learning in the community in which he pushed for mutual engagement but was rebuffed and retreated to a peripheral position of minimal engagement. His minimal engagement implied the limited opportunity for learning that was apparent in his isolated pursuit of the enterprise and the lack of shared repertoire among the members of the community. However, his lack of learning in the mathematics teachers' community, which resulted in a low perception of competence, allowed for his extended learning in the coaching community. His participation in the coaching community produced learning that integrated his identities in the coaching and classroom communities and rescued him from his marginalized role in the mathematics teacher community.

When I viewed Rudy's learning as experience I uncovered the learning processes 
of experimental participation, reificative participation, and vicarious participation. In experimental participation, Rudy applied his participatory experiences to new situations by viewing students' participation as a form of memory implying their prior participations. He adapted his forms of participation to suit his students because each new participation produced an evolving history of participations with the student. In reificative participation, Rudy produced reifications from participation as a form of memory for the community. These reifications were learning that retained not only a particular form of the prior participation, but influenced the form of future participations. In vicarious participation, Rudy engaged in the imaginative work of participating as a student in his own class. In this way Rudy adapted his forms of participation to meet the perceived needs of his students. By combining vicarious participation with experimental participation or with the trappings of use of the shared repertoire Rudy created a significant source of learning for the improvement of his practice. This idea is similar to what McDuffie (2004) found in her semester-long study of two student teachers, that reflection was most productive when focused on long-term growth. She focused on longterm growth as a recognition of patterns for teaching, which corresponds to one form of the trappings of use for the shared repertoire. The idea of vicarious participation adds a dimension to reflection for long-term growth. I will discuss the implications of this added dimension for growth in the section Implications and the section Future Research.

When I viewed Rudy's learning as becoming I found that he learned by engaging in classroom community, aligning with school and mathematics teaching communities, and imagining the role of the modern teacher. I found a historical account of Rudy's learning from his engagement with his communities of practice. This account attests to a 
difficult and emotional processes of identity transformation early in Rudy's career. According to Clandinin et al.'s (2015) work on early career teaching, this is to be expected. They found that identity formation was a complex and difficult process for early career teachers. Through this difficult process, Rudy came to cover his identity with beginner while maintaining efficiency and establishing an identity of authority and motivator. In order to align himself with school practices and policies he had to work out his disagreements with school colleagues and his identity as a Valley View High School teacher. In aligning himself with the CCSS-M (NGA Center \& CCSSO, 2010) and the landscape of practice for mathematics teachers, Rudy reconciled his forms of practice with those promoted by these extra-community forces. Rudy used imagination as a source of learning by placing himself in the role of the modern teacher. He adjusted his practice in minor ways that allowed him to maintain his identity and stay connected to his roots in traditional practices, while satisfying his imaginative role of a modern teacher.

In learning as doing Rudy adapted his practice to create a more productive enterprise, more meaningful participation, and a more consistent identity. Rudy learned significantly through practice. He learned in the space of my observations, but his practice also suggested a history of learning that implied a personal, experiential, social, and productive learning in practice.

\section{My Place in the Landscape of Practice}

This study allows me to connect with the mathematics education literature and extend understanding in the field in several ways. However, my purpose was to investigate teacher learning in the classroom context. Therefore, I will highlight the ways in which my study adds to the field in the area of teachers' learning through practice. In 
order to describe the role my study takes in this space I will return to my description from Chapter II.

\section{Teachers' Learning in Practice}

In Chapter II I discussed the relevant conclusions from several studies focused specifically on teachers’ learning in practice. I separated the studies into five different emphases based on the stimulus for learning (the first and second sets) and the products of learning (the third, fourth, and fifth sets). The first set of studies defined the stimulus for learning as professional communities. The second set of studies defined the stimulus for learning as reflection. The remaining studies either did not define the stimulus for learning specifically, defined it variably within the study, or were primarily concerned with the products as opposed to the stimulus of the learning. Thus, the third set of studies defined the product of learning as knowledge internalization. The fourth set of studies defined the product of learning as identity transformation. The fifth set of studies defined the product of learning as general change. In order to keep the focus of my discussion on learning in practice I would like to return to these studies and elaborate on the place of my findings in this landscape.

Professional communities. Graven (2004) critiqued the CoP framework suggesting that confidence be added as a missing component of the framework, in addition to practice, meaning, community, and identity. She argued that Wenger (1998) ignored confidence in the process of learning and as a product of learning. My findings support her conclusion that confidence deserves increased attention in the CoP framework. However, I argue that Wenger (1998) addressed confidence indirectly in the concept of competence, which is integrated in the dimensions of practice, meaning, 
community, and identity. In my findings I was able to address confidence through the concept of competence, implying that it may not warrant addition as another dimension of the framework.

I found Rudy's self-concept of competence and his perception of how others viewed his level of competence were important aspects of his participation in community and his resultant learning. For example, Rudy perceived that his fellow mathematics teachers viewed him as less competent. Graven presented this perception of others’ views as an aspect of confidence. For Rudy, this resulted in his isolation and lack of learning in the professional community. Thus, what Graven termed confidence played a role in how Rudy learned in relation to his colleagues. However, I described this in terms of Rudy's self-perception of his competence. Although the concept of confidence adds a degree of clarity to the analysis of learning, I am not convinced that it is a necessary dimension to accord the same level of prominence as practice, meaning, community, and identity.

Reflection. McDuffie (2004) described several types of reflection that produced growth for the preservice teachers in her study. She described immediate and delayed reflection-in-action, short and long-term reflection-on-action, and deliberate practice. Although I did not seek to observe reflection-in-action in my study, I saw the other three forms of reflection. McDuffie described short-term reflection-on-action as, "reflection about a recent lesson or experience after the episode,” (p. 42) and long-term reflectionon-action as, "reflecting over time about a pattern emerging from teaching and learning experiences” (p. 42). Rudy's short- and long-term reflections-on-action were provided to me explicitly in only a few cases. However, I inferred both short- and long-term reflections in Rudy's experimental participation and in his development of the trappings 
of use of the shared repertoire. Rudy described a process of developing an ability to anticipate mistakes and understand student thinking. I described this as the development of the trappings of use of the shared repertoire and could also characterize this as longterm reflection-on-action. McDuffie argued that this long-term reflection was more powerful for growth than short-term reflection, and my findings do not counter such an argument.

I also found Rudy engaged in deliberate practice, which McDuffie described as using, "existing knowledge, theories, and reasoning about teaching and learning to design plans for particular students’ learning.” I found one way Rudy accomplished this deliberate planning was through what I have called vicarious participation (Rudy's imagined participation in his class as a student). Thus, I have illuminated a particular type of deliberate planning McDuffie did not explicitly address. Furthermore, I claim that the combination of this vicarious participation with the trappings of use and experimental participation may produce significant learning for teachers. To use McDuffie's terms, the combination of deliberate planning with short- and long-term reflection may produce significant learning for teachers.

Knowledge. Margolinas et al. (2005) found that the two teachers in their study benefitted from outside interventions, which helped elicit learning. In one case Margolinas et al. claimed that the teacher's learning relied on the opportunity to share his reflections with a researcher. They claimed that without interactions with the researchers the teacher would not have reflected, and thus learned, to the same extent. Margolinas et al. also claimed that the other teacher only learned as a result of interaction with the researcher. My findings corroborate the difficulty of learning without outside influences 
because Rudy missed an opportunity for significant learning in fifth hour. However, I would not make my statement as strong as that of Margolinas et al. because Rudy learned a great deal without my intervention.

Identity. Two studies about identity presented significant connections with my findings about Rudy's learning. Goos (2005) found that the identity formation for the beginning teachers in her study could not be explained solely in terms of external influences. Instead, the teachers were active in the interpretation of environmental factors that influenced their identity. Similarly, Rudy did not merely appropriate his environmental influences into an identity for teaching. For example, he did not succumb to the marginalization of his mathematics teacher community and accept a peripheral role. Instead, he re-interpreted the marginalization by holding onto an identity of beginner with the hope of becoming a full member in the future. Thus, Goos' findings for beginning teachers may also apply to experienced teachers like Rudy.

Walshaw (2004) found that the varying influences on identity formation for preservice teachers interacted in complex ways in the development of teaching identity. Specifically, in many cases the influence of the teacher preparation program and the clinical experiences of the preservice teachers were in opposition. The preservice teachers reconciled the opposing experiences in different ways, but Walshaw claimed that the resulting identities were never in strict alignment with any single external influence. My description of Rudy's integration of varying influences on his identity extends Walshaw's findings to the identity of a practicing teacher. For example, Rudy integrated aspects of a traditional approach to teaching, which was partially influenced by his experiences as a high school student, with aspects of a modern approach to teaching. Rudy did not fully 
reflect either teaching style, but incorporated aspects of each into his identity in order to maintain a sense of competence in relation to varying communities of practice in the landscape of practice of mathematics teaching.

Because of the complex influence of experiences in constituting teaching identity, Walshaw suggested, "a rethinking of the notion of the pre-service teacher who has teaching experience towards conceptualizing the pre-service teacher as constituted through experience” (p. 80). I agree with Walshaw on this point, but I believe that we should extend this same principle to practicing teachers and to experiences beyond the act of teaching. Rudy did not simply possess teaching experiences. Rudy's identity as a teacher was derived through experiences with his students, experiences as a student of mathematics, experiences with his mathematics colleagues, experiences with his coaching colleagues, and a myriad of other experiences. He was a product of those variable experiences. This is an important restructuring of thinking about teachers because, as Walshaw points out, "teaching experience then becomes much more than an issue of content knowledge and technical skills; it is, above all, a source of (micro)political engagement” (p. 80). Thus, teaching experiences in teacher preparation are increasingly important for teachers' identity formation. In teaching practice, experience may be viewed as important not only as a means to develop the knowledge and skills of competence, but as a means to develop community relations that demonstrate competence as a contributing member of a community. For Rudy, his experience did not lead directly to a position of competence in the teaching community because it was not merely about his acumen as a classroom teacher. Instead, his competence was also a product of political acumen and experience in relation to other 
members of the community.

Change. Two studies about change provide important connections to this study. Boylan (2010) described a veteran secondary mathematics teacher's change through the process of a "teacher led, teacher-educator-supported professional development project" (p. 383). This teacher, who described himself as “an old cynic” (p. 386), experienced legitimate change through purposeful interactions with colleagues. His statement suggests that he would not have experienced change without the professional development program that instituted these purposeful interactions. I suggest that Rudy, who experienced some learning in relative isolation, would also benefit from more legitimate and purposeful interactions with his colleagues. Rudy, who did not appear opposed to change, would likely experience more significant growth if he had opportunities to work with his colleagues toward change. Unfortunately, Rudy avoided collaboration for a variety of reasons. This illustrates the importance of helping teachers develop communities conducive to collaboration so that change may occur.

Chapman and Heater (2010) described an iterative, four-stage process of change for a teacher who self-initiated a change in teaching style to a reform-based approach. The four stages were experiencing cognitive and emotional tension, attending to the tension, problematizing the tension, and resolving the tension. If I assume that these are necessary stages in the process of change it provides insights into where Rudy stalled in this process in his work with fifth hour. It is clear that he experienced the first stage of cognitive and emotional tension in his participation with fifth hour. He claimed that the deeper level questions fifth hour was asking were important, but he did not take the time to address those questions to the students' satisfaction. Despite the tension, he did not 
seem to attend to this tension. In order to reach legitimate change in response to the enterprise of his fifth hour class he would need a source to help him attend to and problematize the tension. However, Rudy recognized the tension between the traditional approach to teaching he saw when he attended high school and a more modern approach to teaching. He appeared to have problematized this tension and was doing the work of resolving the tension. He was resolving the tension by using aspects of both teaching styles in his classes. Thus, Rudy's case, again, attests to the potential of collegial relationships or other interventions to elicit more significant teaching change.

\section{Limitations and Validity}

Many limitations and issues of validity are the results of reasonable decisions to allow some limitation in favor of another benefit. The first limitation I will discuss is the decision to collect data from only one teacher. One might suggest that this limits our understanding of teacher learning through practice. I clearly have no grounds for generalization, and furthermore, I have no means of comparison to evaluate the important and unimportant aspects of my findings in relation to another teacher. This was a decision based on the benefits afforded by the study of one teacher over a study of multiple teachers. I have already explained why I chose case study as a methodology, but allow me to extend two additional reasons why I chose only one teacher. The first reason was for the depth of analysis. In order to adequately address the depth of understanding required by the CoP framework I limited my scope to one teacher. I attempted to include two student teachers in the analysis, but found that extending my analysis would either sell short the analysis of all of the teachers, or extend the writing beyond a reasonable scope. The second reason I chose to analyze only one teacher was to avoid the 
comparison of two cases, which tends to accentuate differences. This can lead to an evaluation of the teachers, which was not my aim. It can also lead to an emphasis on findings that contrast the two teachers, which may not be the most important elements about learning through practice. The comparison of more than two teachers tends to accentuate similarities to the neglect of the individuality of the teachers under comparison.

A related limitation was the length of the study. I observed Rudy for only four lessons, one of which was twice as long as a normal class hour. The first reason for this was that a longer period of time would have resulted in an extended set of data that may have compromised the depth of analysis feasible for the study. The second reason I chose this time frame, in opposition to the same number of days spread over a longer period of time, was because this allowed me to see sustained engagements on a day-to-day basis.

A third related limitation was the inclusion of only two classes. The reason I chose to include only two classes was for the sake of appropriate comparison. I wanted to see Rudy's participation in two communities, but these two communities allowed me to limit some of the variables contributing to community differences. For example, the differences cannot be related to student age or to course content.

In terms of validity, a primary concern to address is objectivity. The first answer to concerns about objectivity can be found in my paradigm statement in Chapter III. I have not attempted to be objective because these attempts mask a subjectivity that is inherent in analysis. As soon as I pointed my video camera in a particular direction I introduced a subjectivity that I could not erase. Instead of attempting to be objective, I have attempted to make my perspectives clear. The inherent subjectivity in analysis is 
illustrated in how often I found myself reflecting on my own teaching as I observed Rudy's. Wenger (1998) explained, "In reification we project ourselves onto the world, and not having to recognize ourselves in those projections, we attribute to our meanings an independent existence.” This is likely what would have happened if I had been striving for objectivity. I may have fooled myself, and perhaps my readers, into believing that my meanings existed independently in Rudy’s story. Instead, I hope that I have recognized how my meanings have been projected into Rudy’s story.

Despite my rejection of objectivity, a few elements of validity remain to be demonstrated for internal validity within a subjective standpoint. First, my coding schemes were checked against the coding of another party. The purpose was not to suggest that this made my codes any more valid as identifiers of objective reality. The process ensured an internal validity of consistency in how I applied my meanings to observable data. It also ensured that my meanings were adequately conveyed in my definitions so that readers could interpret my projected meanings.

Another form of validity that must be addressed is the skeptical view many take of self-reported data. I employed reflections and interviews in this study that provided significant information for analysis. I claim that self-reported data was not only acceptable, but also necessary for this study. I was interested in Rudy's learning and that learning was a personal experience. His perspectives were necessary. I was interested in Rudy's identity and his perspective was significant in forming his identity. What others thought of Rudy was also important, but his own conception of his identity was central. One illustration is in Rudy's identity as motivator. I would not have identified this aspect of his identity from an outside perspective because my understanding of motivating was 
significantly different than Rudy's. It was important that he identified that aspect of his identity so that I could investigate his meanings and present his identity. However, I tried to make explicit when his perspective on a historical situation was the only perspective I received. It does not make the conclusions invalid because what I was analyzing were his participations, his engagement, his learning, his identity transformations from those experiences. In that case, his view, his reality was the most important perspective. It was from his perspective that he learned.

\section{Implications}

I argued from the outset that teachers' learning in practice is significant. I have demonstrated through this study how learning in and from practice was significant for Rudy. In Rudy’s story I have shown significant learning without outside influence directed at teacher development. However, it has also become apparent that the learning was not necessarily easy, and it was not necessarily toward the development of the most effective teaching practices. So, let me expound on how these findings might be beneficial for the practicing world of education.

\section{Lesson One}

The first lesson I have learned from Rudy is that developing engaged and productive communities of practice is important for teachers. In Rudy's case I demonstrated both the negative aspects of marginalization and the power of engagement for learning. Rudy self-isolated and became marginalized in his community of mathematics teachers, and this stifled his learning in that community. This made me wonder what might have been. It is possible that both Rudy and his colleagues would have been better teachers if he had found a way to engage in the community. 
Furthermore, the difficult and emotional work of identity reconciliation may have been smoother if Rudy had developed an inbound trajectory toward an identity of competence. However, Rudy's case also demonstrated the power of engagement in professional community for positive learning. Rudy's membership in the coaching community was a safe haven for his identity and a positive force for his teaching practice.

This idea that professional communities of practice can have a strong impact on teachers' learning has several possible implications for professional development and teacher induction programs. Although these are conjectures based on Rudy's learning, I will make two suggestions, one for improving professional development and the other for improving induction programs.

First, induction programs should focus on establishing an inbound trajectory for new teachers. This means an induction program needs to enlist all members of the community of practice as part of the induction process. The entire community should show their support for a new teacher and welcome him or her into the teaching community, recognizing the new teacher's developing forms of competence in the community. This also means the program needs to encourage the new teacher not to isolate himself or herself even though it may seem necessary to the new teacher. Rudy felt it was necessary to isolate himself during his first year as a form of time management, but then he lacked the support of his community of practice. The community should engage the new teacher in collaboration that involves time-saving measures for the new teacher. At times the collaboration of professional communities produces extra tasks for teachers. It may be helpful for communities to avoid requiring early career teachers to perform some of the extra tasks and focus on collaboration with 
the new teacher that decreases the extent of his or her workload.

Second, professional development organizers should recognize the possible positive influence of less obvious communities on teachers' practices through boundary encounters. Recall that Fenton-O'Creevy et al., (2015) found that participation at the boundaries of communities can be difficult but it can also be beneficial. Rudy's teaching was impacted by his participation in the coaching community. Thus, professional development could focus on developing communities of practice that arise organically in the school environment rather than developing communities based on formal departmental structures. I think these departmental communities can be important, but we may also find productive growth when we allow professional communities to develop naturally and then foster learning at the boundaries of multiple communities.

\section{Lesson Two}

The second lesson I learned from Rudy is that reflective learning can be coupled with projective learning for productive learning in practice. In the history of learning I cited research that suggests reflection is a significant source of learning for teachers (McDuffie, 2004; Scherer \& Steinbring, 2006; Ticha \& Hospesova, 2006). The learning I cited in experimental participation and developing the trappings of use for the shared repertoire are consistent with these results. However, I suggested that the most significant source of positive growth for Rudy was in combining the projective learning of vicarious participation with these forms of reflective learning. Thus, I would suggest a reflective practice that takes into account both reflection on students’ participation and projection into future participations. Adding this dimension of vicarious participation to McDuffie’s (2004) reflections focused on long-term growth may enhance the reflection process. 
This implies a form of professional development that may be productive for teachers and could involve very little intervention. First, teachers could be asked to make explicit their reflections on their practice in the forms of experimental participation and the trappings of use of the mathematical shared repertoire. Then, the teachers could be asked to engage in vicarious participation that would account for these reflections. Asking teachers to document the reflections and projections would allow the teachers to see their own changes in practice over time. This would result in the kind of long-term reflection on patterns of teaching described by McDuffie (2004) with the added dimension of vicarious participation.

\section{Lesson Three}

The third lesson I learned from Rudy is that educators could leverage opportunities in practice for learning. Rudy was faced with a significant opportunity for learning as he participated in fifth hour throughout the school year. He had a class of students pleading to understand mathematics. He learned in that situation and adapted his practice for the community. However, he did not recognize the tremendous potential for professional growth in that community. Furthermore, I suspect that he will not transfer the learning in that community of practice to any new community unless the students in another class have a similar drive for understanding. We need to help teachers recognize the opportunities for professional growth and capitalize on those experiences.

Unfortunately, this study does not provide insight into the ways that educators can support teachers to recognize their opportunities for professional growth. Although research about teacher noticing (e.g., Sherin, Jacobs, \& Phillips, 2011) may help in this regard, there is a significant difference between the type of opportunities typically 
associated with noticing and the type of opportunity Rudy had with fifth hour. Teacher noticing often focuses on moments of opportunity. Rudy's participation in fifth hour was a broader opportunity for growth that was associated with an enterprise that was developing over time, not a momentary opportunity for change. One possible reconciliation of these ideas would be to develop a record of noticing over time. This could illuminate a pattern of participation in a class and result in changing practices and learning.

\section{Lesson Four}

The fourth lesson I learned from Rudy is that identity work in teaching is significant, difficult, and emotional, especially in the early years. This is not a new concept. For example, Clandinin et al. (2015) found that early career identity formation was a complex and difficult process for teachers. In addition, Fenton-O'Creevy et al. (2015) found that living at the boundaries of communities can be emotional experiences even for an experienced teacher who changes environments. This identity work is important and educators cannot, and should not, remove the struggle or the emotion entirely, but need to find ways to support teachers in this struggle.

One way that educators can support students who are becoming teachers is by beginning the struggle of identity transformation more significantly during teacher preparation programs. The existing structure of our teacher preparation programs leaves the major work of identity transformation to the first years of professional practice. If teacher preparation programs can begin the identity transformation more significantly while preservice teachers are still in preparation, then the students may have stronger support networks, alternate identities of competence to which they could retreat, and 
opportunities to develop a sense of competence in the midst of the transition. All of this could occur before they are the sole party responsible for the mathematical education of their students. I think that this identity transformation can begin more significantly by providing preservice teachers more opportunities for legitimate participation with teachers in their teaching practices and professional communities. Student teaching experiences can be beneficial in this regard, but the short timespan for these experiences and the lack of legitimacy accorded to student teachers by practicing teachers stifle the learning opportunities in student teaching. Perhaps extended timeframes and opportunities for preservice teachers to participate in parts of the professional practice of teaching in legitimate ways without taking on the entire role of a teacher would allow preservice teachers to gradually experience their changing role from student to teacher.

\section{Lesson Five}

The final lesson I learned from Rudy is, perhaps, the simplest and maybe the most difficult to apply. Educators need to acknowledge the importance of practice for developing knowledgeability and competence in the field of mathematics education. Rudy developed a form of competence in his mathematics teaching community, albeit limited, and a form of competence in his classroom community through practice. It is important to recognize that Rudy's marginalization as less competent in the mathematics teacher community was directly related to his level of experience. This implies that the teachers, at least Rudy, perceived practice as producing competence for members of their community. Educators and researchers need to recognize the role of community-based competence developed through practice because it is impacting teachers' development in both positive and negative ways. 


\section{Future Research}

Allow me to suggest some ways forward. First, I will share some methodological suggestions based on the strengths and weaknesses of this study. Second, based on the implications, I will make a few suggestions for productive lines of future research.

\section{Methodological Implications}

I have taken a somewhat unique approach to researching teachers' communities of practice by focusing on the classroom community instead of the professional community. I think this risk has yielded positive results because the classroom communities were shown to be important dimensions in Rudy’s learning. However, I also found that the professional communities were important. Thus, researchers who take a view of teaching as multimembership may be especially productive. This implies data collection that accounts for these multiple communities. In order to adequately address the professional communities, a researcher would need to include more observations of professional interactions as a minimum addition. The description of these communities could also benefit from interviews with other community members.

Although I found my data adequate for describing Rudy’s classroom communities, adding student interviews, student performance data, Rudy’s reflections on grading, and examples of student work would have provided additional information about those communities. Future research about classroom communities of practice would benefit from including these additional data sources, particularly the teacher's reflections on grading. Furthermore, researchers could put a stronger emphasis on teachers' think alouds and reflections. I was attempting to avoid influencing Rudy’s learning, so I did not provide significant direction about his think alouds and reflections, and I was also not 
persistent in eliciting those forms of data. Researchers who are less worried about a natural learning experience may find it beneficial to be more assertive in attaining those forms of data.

I found that it was beneficial to collect the data, particularly the observations, in a concentrated period of time. This allowed for a pointed analysis of the community with sufficient context for the analysis of each day's activity. However, significant benefits could also be gained by spreading observations over the course of a year or longer. In this case, I would suggest observing several days at a time. For example, I could observe one week at the start of the school year, one week in the middle of the school year, and one week at the end of the school year. This would increase the context of the observations and provide data on the teacher's changes over time. However, I would not reduce the consecutive days of observation to fewer than three because one day out of the context of surrounding days could be misleading.

In terms of analysis I would suggest that researchers not use the entire coding scheme I developed in this study. Most of the codes emerged in the process of analysis, and applying them in a different community of practice could provide a less than accurate picture of that community. However, the structure of my analytical process could be followed, including the development of new coding schemes. I will briefly outline what I mean.

My coding scheme emerged in the first stage of my analysis. I started with the broad categories of communities of practice and negotiation of meaning. Each of these categories had a set of codes that were taken directly from the CoP framework. When I coded a data source looking for evidence of communities of practice I searched for 
evidence of mutual engagement, evidence of a joint enterprise, and evidence of a shared repertoire. I would suggest that other researchers use the same concepts in order to align with the CoP framework. However, the types of mutual engagement I coded as evidence of mutual engagement may not apply to other communities, so I would suggest that researchers develop their own emergent subcodes for mutual engagement. For joint enterprise I used concepts that were derived from the CoP framework, so other researchers may also find negotiating the enterprise, indigenizing the enterprise, and accountability to the enterprise to be useful subcodes for the joint enterprise. In the shared repertoire, I found my subcategories of content and stage to be useful and I think they could apply to almost any community of practice. Furthermore, the stage codes could be useful, but other researchers may want to apply the stage of the element to individuals more than the community. The content of the shared repertoire codes should emerge in any study. When I coded for the negotiation of meaning I looked for evidence of reification and participation. These codes could be used in any study because these are concepts integral to the CoP framework. However, the subcodes for each category should emerge because the participations and reifications are unique to a community.

In addition to these elements of my coding scheme that may be applied to other studies, the process of coding could also be followed (see the data analysis section stage one for a more complete description of the remainder of the process). Beyond the coding, my iterative stages of analysis through the elements of the CoP framework could be useful for other researchers. 


\section{Continuing Studies}

A wide variety of studies could be conducted to build on this case study. Let me share just a few ideas. Researchers could study the application of reflective practice that combines reflective and projective participations. They might apply the idea that vicarious participation could be coupled with reflections on the trappings of use in the shared repertoire and the experimental participation of teachers in their community. I hypothesize changes in practice that are not only significant, but positively impact student learning.

Another study that is implied in the implications would be directed at assisting teachers to leverage their learning in practice. I am not suggesting that researchers take ideas to teachers and help them apply them in practice. I am suggesting that researchers take the learning opportunities that a teacher encounters in practice, help them recognize those opportunities, and leverage them for professional growth. Researchers need to learn to teach teachers to learn by teaching. I suggest that a productive line of research in this regard is teacher noticing. However, in order to be most productive, noticing would need to include a broader stance of recognizing class circumstances, like the enterprise established in Rudy’s fifth hour, that provide ripe environments for professional growth.

A third study implied would investigate the identity work involved in the transition to teaching. I do not have a specific form to suggest for this study because I know that many such studies already exist. They seem to have had minimal impact on how teacher preparation programs proceed at the end of teacher training programs and in the transition to teaching as a career. What the community needs here is not another study. The need is for educators, administrators, and teachers to do the hard work of 
applying what is known to a difficult situation for the betterment of the profession.

I could continue a list of studies that would further investigate learning in practice in ways that my own research has neglected. I could propose a very similar study to my own with observations spread across a year. I could propose a longitudinal study of the early years of learning in teaching. I could propose a study that employs this social framework of learning and a cognitive framework as juxtaposition in the same learning to leverage multiple perspectives on learning in practice. But what I would most like to propose is a continued conversation of how educators might apply these understandings about learning in practice in classrooms, in professional development, in education systems, and in communities of practice whomever they might include and whatever the enterprise.

\section{Not the End}

As I come to the end of my writing, I hope that I have succeeded in creating a new beginning. I know that my conclusions and implications create new beginnings for me because I will continue to research teacher learning through a $\mathrm{CoP}$ framework focused on the classroom community as a source of learning. However, I hope that I have created new beginnings for others to research in a similar way. I hope that the role students play in a teachers learning will be an important element of future research. I hope that professional development efforts, teacher induction programs, and teacher

preparation programs will benefit from the picture of natural learning that comes out of this and subsequent studies. If even a few teacher educators are encouraged to examine their own practice and help teachers leverage their own teaching experiences for professional growth, then I will consider this study successful. 


\section{REFERENCES}

Adler, J., Ball, D., Krainer, K., Lin, F.-L., \& Novotna, J. (2005). Reflections on an emerging field: Researching mathematics teacher education. Educational Studies in Mathematics, 60(3), 359-381.

Agyei, D. D., \& Voogt, J. (2012). Developing technological pedagogical content knowledge in pre-service mathematics teachers through collaborative design. Australasian Journal of Educational Technology, 28(4), 547-564.

Artigue, M., Haspekian, M., \& Corblin-Lenfant, A. (2014). Introduction to the theory of didactical situations (TDS). In A. Bikner-Ahsbahs \& S. Prediger (Eds.), Networking of theories as a research practice in mathematics education (pp. 4765). New York, NY: Springer.

Ball, D. L., Thames, M. H., \& Phelps, G. (2008). Content knowledge for teaching: What makes it special? Journal of Teacher Education, 59(5), 389-407.

Biniaminov, I., \& Glasman, N. S. (1983). School determinants of student achievement in secondary education. American Educational Research Journal, 20(2), 251.

Blackmore, C. (Ed.) (2010). Social learning systems and communities of practice. London, UK: Springer.

Boaler, J. (1998). A tale of two schools: Alternative teaching approaches and situated learning. In A. Watson (Ed.), Situated cognition and the learning of mathematics (pp. 83-92). Oxford, England: University of Oxford Department of Educational Studies.

Borko, H. (2004). Professional development and teacher learning: Mapping the terrain. Educational Researcher, 33(8), 3-15.

Boston, M. D. (2013). Connecting changes in secondary mathematics teachers' knowledge to their experiences in a professional development workshop. Journal of Mathematics Teacher Education, 16(1), 7-31.

Bourdieu, P. (1977). Outline of a theory of practice (Vol. 16). New York, NY: Cambridge University Press.

Boylan, M. (2010). "It's getting me thinking and I'm an old cynic": Exploring the relational dynamics of mathematics teacher change. Journal of Mathematics Teacher Education, 13(5), 383-395. 
Boyle, B., Lamprianou, I., \& Boyle, T. (2005). A longitudinal study of teacher change: What makes professional development effective? Report of the second year of the study. School Effectiveness and School Improvement, 16(1), 1-27.

Bright, G. W., \& Prokosch, N. E. (1995). Middle school mathematics teachers learning to teach with calculators and computers: Part II: Teacher change. School Science \& Mathematics, 95(7), 338-344.

Brodie, K., \& Shalem, Y. (2011). Accountability conversations: Mathematics teachers' learning through challenge and solidarity. Journal of Mathematics Teacher Education, 14(6), 419-439.

Brousseau, G. (1997). Theory of didactical situations in mathematics: Didactique des mathématiques, 1970-1990 (N. Balacheff, M. Cooper, R. Sutherland, \& V. Warfield Eds. \& Trans). Boston, MA: Kluwer Academic Publishers.

Brown, C. A., Stein, M. K., \& Forman, E. A. (1996). Assisting teachers and students to reform the mathematics classroom. Educational Studies in Mathematics, 31(1/2), 63-93.

Brown, L., \& Coles, A. (2010). Mathematics teacher and mathematics teacher educator change-Insight through theoretical perspectives. Journal of Mathematics Teacher Education, 13(5), 375-382. doi:10.1007/s10857-010-9159-3

Carter, J. A., Cuevas, G., Day, R., Malloy, C., Holliday, B., Luchin, B. M., . . Zike, D. (Eds.). (2012). Integrated math 2: McGraw Hill Education.

Chapman, O. (1999). Inservice teacher development in mathematical problem solving. Journal of Mathematics Teacher Education, 2(2), 121-142. doi:10.1023/A:1009948231298

Chapman, O., \& Heater, B. (2010). Understanding change through a high school mathematics teacher's journey to inquiry-based teaching. Journal of Mathematics Teacher Education, 13(6), 445-458.

Chazan, D., Ben-Chaim, D., Gormas, J., (with Schnepp, M., Lehman, M., Bethell, S. C., \& Neurither, S.). (1998). Shared teaching assignments in the service of mathematics reform: Situated professional development. Teaching and Teacher Education, 14(7), 687-702. doi:10.1016/S0742-051X(98)00022-5

Clandinin, D. J., \& Connelly, F. M. (1986). Rhythms in teaching: The narrative study of teachers' personal practical knowledge of classrooms. Teaching and Teacher Education, 2(4), 377-387.

Clandinin, D. J., Long, J., Schaefer, L., Downey, C. A., Steeves, P., Pinnegar, E., Robblee, S. M., \& Wnuk, S. (2015). Early career teacher attrition: intentions of teachers beginning. Teaching Education, 26(1), 1-16. doi: 
Clements, M. A., Bishop, A. J., Keitel, C., Kilpatrick, J., \& Leung, F. K. S. (Eds.). (2013). Third international handbook of mathematics education. New York, NY: Springer.

Connelly, F. M., Clandinin, D. J., \& He, M. F. (1997). Teachers' personal practical knowledge on the professional knowledge landscape. Teaching and Teacher Education, 13(7), 665-674. doi:10.1016/S0742-051X(97)00014-0

Diorio, J. A. (1982). Knowledge, autonomy, and the practice of teaching. Curriculum Inquiry, 12(3), 257.

Doerr, H. M., \& English, L. D. (2006). Middle grade teachers' learning through students' engagement with modeling tasks. Journal of Mathematics Teacher Education, 9(1), 5-32.

Drake, C., Spillane, J. P., \& Hufferd-Ackles, K. (2001). Storied identities: Teacher learning and subject-matter context. Journal of Curriculum Studies, 33(1), 1-23. doi:10.1080/002202701750039228

Edwards, T. G., \& Hensien, S. M. (1999). Changing instructional practice through action research. Journal of Mathematics Teacher Education, 2(2), 187-206.

Elbaz, F. (1981). The teacher's 'practical knowledge': Report of a case study. Curriculum Inquiry, 11(1), 43.

Elbaz, F. (1983). Teacher thinking : A study of practical knowledge. New York, NY: Nichols Publishing Company.

Erlwanger, S. H. (1973). Benny's conception of rules and answers in IPI mathematics. Journal of Children's Mathematical Behavior, 1(2), 7-26.

Fennema, E., Carpenter, T. P., Franke, M. L., Levi, L., Jacobs, V. R., \& Empson, S. B. (1996). A longitudinal study of learning to use children's thinking in mathematics instruction. Journal for Research in Mathematics Education, 27(4), 403.

Fenton-O'Creevy, M., Dimitriadis, Y., \& Scobie, G. (2015). Failure and resilience at boundaries: The emotional process of identity work. In E. Wenger, M. FentonO'Creevy, S. Hutchinson, C. Kubiak, \& B. Wenger-Trayner (Eds.), Learning in landscapes of practice : Boundaries, identity, and knowledgeability in practicebased learning (pp. 33-42). New York, NY: Routledge.

Franke, M. L., Carpenter, T., Fennema, E., Ansell, E., \& Behrend, J. (1998). Understanding teachers' self-sustaining, generative change in the context of professional development. Teaching and Teacher Education, 14(1), 67-80. doi:10.1016/S0742-051X(97)00061-9 
Gersten, R. M., \& Kelly, B. (1992). Coaching secondary special education teachers in implementation of an innovative videodisc mathematics curriculum.

Remedial and Special Education, 13(4), 40-51.

doi:10.1177/074193259201300411

Glesne, C., \& Peshkin, A. (1992). Becoming qualitative researchers: An introduction. White Plains, NY: Longman.

Goldsmith, L. T., Doerr, H. M., \& Lewis, C. C. (2014). Mathematics teachers' learning: A conceptual framework and synthesis of research. Journal of Mathematics Teacher Education, 17(1), 5-36.

Goos, M. (2005). A sociocultural analysis of the development of pre-service and beginning teachers' pedagogical identities as users of technology. Journal of Mathematics Teacher Education, 8(1), 35-59.

Goos, M., \& Geiger, V. (2010). Theoretical perspectives on mathematics teacher change. Journal of Mathematics Teacher Education, 13(6), 499-507.

Grant, S. G., Peterson, P. L., \& Shojgreen-Downer, A. (1996). Learning to teach mathematics in the context of systemic reform. American Educational Research Journal, 33(2), 509-541.

Graven, M. (2004). Investigating mathematics teacher learning within an in-service community of practice: The centrality of confidence. Educational Studies in Mathematics, 57(2), 177-211.

Guerrero, S. (2010). Technological pedagogical content knowledge in the mathematics classroom. Journal of Digital Learning in Teacher Education, 26(4), 132-139.

Handal, B., Campbell, C., Cavanagh, M., Petocz, P., \& Kelly, N. (2013). Technological pedagogical content knowledge of secondary mathematics teachers.

Contemporary Issues in Technology and Teacher Education (CITE Journal), 13(1), 22-40.

Hara, N. (2009). Communities of practice: Fostering peer-to-peer learning and informal knowledge sharing in the work place: Springer.

Herring, D. H., \& Lave, J. (2001). History in person: Enduring struggles, contentious practice, intimate identities. Santa Fe, N.M.: School of American Research Press Oxford.

Hiebert, J., Morris, A. K., \& Glass, B. (2003). Learning to learn to teach: An 'experiment' model for teaching and teacher preparation in mathematics. Journal of Mathematics Teacher Education, 6(3), 201-222. doi:10.1023/A:1025162108648 
Hill, H. C., Ball, D. L., \& Schilling, S. G. (2008). Unpacking pedagogical content knowledge: Conceptualizing and measuring teachers' topic-specific knowledge of students. Journal for Research in Mathematics Education, 39(4), 372-400.

Hill, H. C., Dean, C., \& Goffney, I. M. (2007). Assessing elemental and structural validity: Data from teachers, non-teachers, and mathematicians. Measurement: Interdisciplinary Research and Perspectives, 5(2-3), 81-92. doi:10.1080/15366360701486999

Hodgen, J., \& Askew, M. (2007). Emotion, identity and teacher learning: Becoming a primary mathematics teacher. Oxford Review of Education, 33(4), 469-487.

Horn, I. S. (2005). Learning on the Job: A situated account of teacher learning in high school mathematics departments. Cognition and Instruction, 23(2), 207-236.

Hughes, J., Jewson, N., \& Unwin, L. (2007). Communities of practice: Critical perspectives. New York, NY: Routledge.

Jaberg, P., Lubinski, C., \& Yazujian, T. (2002). One teacher's journey to change her mathematics teaching. Mathematics Teacher Education and Development, 4, 314.

Jaworski, B. (1998). Mathematics teacher research: Process, practice and the development of teaching. Journal of Mathematics Teacher Education, 1(1), 3-31.

Kazemi, E., \& Franke, M. L. (2004). Teacher learning in mathematics: Using student work to promote collective inquiry. Journal of Mathematics Teacher Education, 7(3), 203-235.

Kilic, H. (2011). Preservice secondary mathematics teachers' knowledge of students. Turkish Online Journal of Qualitative Inquiry, 2(2), 17-35.

Koh, J. H. L., Chai, C. S., \& Tsai, C.-C. (2014). Demographic factors, TPACK constructs, and teachers' perceptions of constructivist-oriented TPACK. Educational Technology \& Society, 17(1), 185-196.

Lave, J. (1988). Cognition in practice: Mind, mathematics, and culture in everyday life. New York, NY: Cambridge University Press.

Lave, J. (1996). Teaching, as learning, in practice. Mind, Culture, and Activity, 3(3), 149164. doi:10.1207/s15327884mca0303_2

Lave, J., \& Chaiklin, S. (1993). Understanding practice: Perspectives on activity and context. New York, NY: Cambridge University Press.

Lave, J., \& Wenger, E. (1991). Situated learning: Legitimate peripheral participation. Cambridge, UK: Cambridge University Press. 
Leinhardt, G., \& Greeno, J. G. (1986). The cognitive skill of teaching. Journal of Educational Psychology, 78(2), 75-95.

Leinhardt, G., \& Smith, D. A. (1985). Expertise in mathematics instruction: Subject matter knowledge. Journal of Educational Psychology, 77(3), 247-271. doi:10.1037/0022-0663.77.3.247

Liljedahl, P. (2010). Noticing rapid and profound mathematics teacher change. Journal of Mathematics Teacher Education, 13(5), 411-423.

Little, J. W. (1982). Norms of collegiality and experimentation: Workplace conditions of school success. American Educational Research Journal, 19(3), 325-340.

Lloyd, G. M. (2005). Beliefs about the teacher's role in the mathematics classroom: One student teacher's explorations in fiction and in practice. Journal of Mathematics Teacher Education, 8(6), 441-467.

Loewenberg Ball, D., \& Ruhama, E. (Eds.). (2009). The professional education and development of teachers of mathematics. United States of America: Springer.

Margolinas, C., Coulange, L., \& Bessot, A. (2005). What can the teacher learn in the classroom? Educational Studies in Mathematics, 59(1/3), 205-234.

McDuffie, A. R. (2004). Mathematics teaching as a deliberate practice: An investigation of elementary pre-service teachers' reflective thinking during student teaching. Journal of Mathematics Teacher Education, 7(1), 33-61.

Merriam, S. B. (1998). Qualitative research and case study applications in education. San Francisco, CA: Jossey-Bass Publishers.

Miles, M. B., Huberman, A. M., \& Saldaña, J. (2014). Qualitative data analysis: A methods sourcebook (3 ed.). Los Angeles, CA: SAGE Publications, Inc.

Mishra, P., \& Koehler, M. J. (2006). Technological pedagogical content knowledge: A framework for teacher knowledge. Teachers College Record, 108(6), 1017-1054.

National Governors Association Center for Best Practices \& Council of Chief State School Officers. (2010). Common core state standards for mathematics. Retrieved from http://www.corestandards.org.

Niess, M. L. (2013). Central component descriptors for levels of technological pedagogical content knowledge. Journal of Educational Computing Research, 48(2), 173-198.

O'Connor, J. J., \& Robertson, E. F. (1997). Right Strophoid. Retrieved from http://www.history.mcs.st-andrews.ac.uk/Curves/Right.html 
O'Hanlon, W. A. (2012). Characterizing the pedagogical content knowledge of preservice secondary mathematics teachers (Doctoral dissertation). Retrieved from http://search.proquest.com.libproxy.lib.ilstu.edu/docview/910320490

Park, J. (2013). Is the derivative a function? If so, how do students talk about it? International Journal of Mathematical Education in Science \& Technology, 44(5), 624-640. doi:10.1080/0020739X.2013.795248

Park, J. (2015). Is the derivative a function? If so, how do we teach it? Educational Studies in Mathematics, 89(2), 233-250. doi:10.1007/s10649-015-9601-7

Peterson, B. E., \& Williams, S. R. (2008). Learning mathematics for teaching in the student teaching experience: Two contrasting cases. Journal of Mathematics Teacher Education, 11(6), 459-478.

Peterson, P. L., Carpenter, T., \& Fennema, E. (1989). Teachers' knowledge of students' knowledge in mathematics problem-solving-correlational and case analyses. Journal of Educational Psychology, 81(4), 558-569.

Pinto, M., \& Moreira, V. (1998). School practices with the mathematical notion of tangent line. In A. Watson \& P. Winbourne (Eds.), New directions for situated cognition in mathematics education (pp. 261-286). New York, NY: Springer.

Polly, D. (2011). Examining how the enactment of TPACK varies across grade levels in mathematics. Journal of Computers in Mathematics \& Science Teaching, 30(1), $37-59$.

Remillard, J. T. (2000). Can curriculum materials support teachers' learning? Two fourthgrade teachers' use of a new mathematics text. The Elementary School Journal, 100(4), 331-350. doi:10.1086/499645

Remillard, K. S. (2014). Identifying discursive entry points in paired-novice discourse as a first step in penetrating the paradox of learning mathematical proof. Journal of Mathematical Behavior, 34, 99-113. doi:10.1016/j.jmathb.2014.02.002

Ross, J. A., \& Bruce, C. D. (2007). Teacher self-assessment: A mechanism for facilitating professional growth. Teaching and Teacher Education, 23, 146-159. doi:10.1016/j.tate.2006.04.035

Rowley, J. C. R., \& Leckie, N. (1977). A further look at the determinants of educational achievement. Canadian Journal of Sociology, 2(4), 339-353.

Scherer, P., \& Steinbring, H. (2006). Noticing children's learning processes - teachers jointly reflect on their own classroom interaction for improving mathematics teaching. Journal of Mathematics Teacher Education, 9(2), 157-185. 
Schifter, D. (1998). Learning mathematics for teaching: From a teachers' seminar to the classroom. Journal of Mathematics Teacher Education, 1(1), 55-87.

Lester, F. K. (Ed.) (2007). Second handbook of research on mathematics teaching and learning (Vol. 1). Charlotte, NC: Information Age Publishing.

Senger, E. S. (1998). Reflective reform in mathematics: The recursive nature of teacher change. Educational Studies in Mathematics, 37(3), 199-221.

Sfard, A. (2008). Thinking as communicating: Human development, the growth of discourses, and mathematizing. New York, NY, US: Cambridge University Press.

Sfard, A. (2009). Moving between discourses: From learning-as-acquisition to learningas-participation. AIP Conference Proceedings, 1179(1), 55-58. doi:10.1063/1.3266753

Sherin, M. G. (2002). When teaching becomes learning. Cognition and Instruction, 20(2), $119-150$.

Sherin, M. G., \& Han, S. Y. (2004). Teacher learning in the context of a video club. Teaching and Teacher Education, 20, 163-183. doi:10.1016/j.tate.2003.08.001

Sherin, M. G., Jacobs, V. R., \& Phillips, R. A. (Eds.). (2011). Mathematics teacher noticing: Seeing through teachers' eyes. New York: Routledge.

Shulman, L. S. (1986). Those who understand: Knowledge growth in teaching. Educational Researcher, 15(2), 4-14.

Shulman, L. S. (1987). Knowledge and teaching: Foundations of the new reform. Harvard Educational Review, 57, 1-22.

Smith, L. M. (1978). An evolving logic of participant observation, educational ethnography and other case studies. In L. Shulman (Ed.), Review of Research in Education. Itasca, IL: Peacock.

Sowder, J. T. (2007). The mathematical education and development of teachers. In F. K. Lester (Ed.), Second handbook of research on mathematics teaching and learning (Vol. 1). Charlotte, NC: Information Age Publishing.

Ticha, M., \& Hospesova, A. (2006). Qualified pedagogical reflection as a way to improve mathematics education. Journal of Mathematics Teacher Education, 9(2), 129156.

Vithal, R. (2003). Teachers and `street children': On becoming a teacher of mathematics. Journal of Mathematics Teacher Education, 6(2), 165-183. 
Vygotsky, L. S. (1999). Thinking and speech (N. Minick, Trans.). In R. W. Rieber \& A. S. Carton (Eds.), The collected works of L.S. Vygotsky: Vol 1 (pp. 39-285). New York, NY: Plenum Press. (Original work published 1934)

Walshaw, M. (2004). Pre-service mathematics teaching in the context of schools: An exploration into the constitution of identity. Journal of Mathematics Teacher Education, 7(1), 63-86.

Warfield, J., Wood, T., \& Lehman, J. D. (2005). Autonomy, beliefs and the learning of elementary mathematics teachers. Teaching and Teacher Education, 21, 439-456. doi:10.1016/j.tate.2005.01.011

Watson, A. (Ed.) (1998). Situated cognition and the learning of mathematics. Oxford, England: University of Oxford Department of Educational Studies.

Watson, A., \& Winbourne, P. (Eds.). (2008). New directions for situated cognition in mathematics education (Vol. 45). New York, NY: Springer.

Wenger, E. (1998). Communities of practice: Learning, meaning, and identity. Cambridge, UK: Cambridge University Press.

Wenger, E. (2010). Communities of practice and social learning systems: The career of a concept. In C. Blackmore (Ed.), Social learning systems and communities of practice (pp. 179-198). London, UK: Springer.

Wenger, E., Fenton-O'Creevy, M., Hutchinson, S., Kubiak, C., \& Wenger-Trayner, B. (Eds.). (2015). Learning in landscapes of practice: Boundaries, identity, and knowledgeability in practice-based learning. New York, NY: Routledge.

Wenger, E., McDermott, R. A., \& Snyder, W. (2002). Cultivating communities of practice : A guide to managing knowledge. Boston, MA: Harvard Business School Press.

Wenger-Trayner, E., \& Wenger-Trayner, B. (2015). Learning in a landscape of practice: A framework. In E. Wenger, M. Fenton-O'Creevy, S. Hutchinson, C. Kubiak, \& B. Wenger-Trayner (Eds.), Learning in landscapes of practice: Boundaries, identity, and knowledgeability in practice-based learning (pp. 13-29). New York, NY: Routledge.

Wessman-Enzinger, N. M. (2015). Developing \& describing the use \& learning of conceptual models for integer addition and subtraction of grade 5 students (Doctoral dissertation). Retrieved from http://ir.library.illinoisstate.edu.libproxy.lib.ilstu.edu/etd/441.

Wilson, S. M., \& Berne, J. (1999). Teacher learning and the acquisition of professional knowledge: An examination of research on contemporary professional development. Review of Research in Education, 24, 173-209. 
Yin, R. K. (2003). Case study research: Design and methods. Thousand Oaks, CA: Sage Publications.

Yonemura, M. (1982). Teacher conversations: A potential source of their own professional growth. Curriculum Inquiry, 12(3), 239-256. 


\section{APPENDIX A}

\section{PRINCIPAL EMAIL}

\section{Dear Principal XXXX,}

My name is Ted Rupnow and I am working on my $\mathrm{PhD}$ in mathematics education at $\mathrm{A}$ University. I taught high school mathematics for five years and became interested in the ways we learn as teachers. I believe that teachers learn a tremendous amount through the act of teaching, and I hope to better understand this learning through my dissertation research. I hope that a better understanding of how teachers learn in practice will help us leverage clinical and student teaching experiences for more meaningful growth. We may also develop more effective professional development experiences that build on teachers' classroom practice.

I am searching for two secondary mathematics teachers who would be willing to participate in my dissertation study and who will be teaching a course for the first time in their careers. The study would involve each of the two teachers for approximately three weeks. They will be asked to participate in two interviews, allow me to act as a volunteer in their classroom for one week, have two class periods (if available) observed and videotaped for two weeks, and share their lesson planning and reflection processes. I am willing to offer time compensation for these teachers as well as a small monetary stipend.

If your school might be interested in participating in this study please let me know by replying to this email. I would like to get in touch with the teachers myself so that they do not feel any administrative pressure to participate.

Thank you,

Ted Rupnow 


\section{APPENDIX B}

\section{TEACHER EMAIL}

Dear Mr. Reuttiger,

My name is Ted Rupnow and I am working on my $\mathrm{PhD}$ in mathematics education at $\mathrm{A}$ University. For my dissertation I am researching secondary mathematics teacher learning. I am searching for two secondary mathematics teachers who would be willing to participate in my study. You are a preferred candidate if you are teaching a course for the first time and teach two periods of that course. Mr. Principal has informed me that Valley View is implementing an integrated math curriculum for the first time. If you are one of the teachers implementing this new program I would be interested in working with you.

The study would involve you for approximately three weeks. You will be asked to participate in interviews, allow me to act as a volunteer in your classroom for one week, have two periods of the course you are teaching for the first time observed and videotaped for two weeks, and share your lesson planning and reflection processes. I am willing to offer time compensation and a small monetary stipend for your participation. I am also willing to provide you with additional resources for your continued learning at the end of the study. However, this is not a professional development experience. I am interested in your learning as it naturally occurs in your practice.

If you are interested in participating in this study please reply to this email so that we can find a time for me to share more information about the study with you.

Thank you,

Ted Rupnow 


\section{APPENDIX C \\ LESSON PLANNING THINK-ALOUD PROTOCOL \\ Lesson Think-Aloud Protocol}

As you plan your lessons please record your thought processes. You may videotape yourself thinking aloud, audio-record yourself thinking aloud, or type your thoughts into your lesson plans. The main focus is how you are learning through this process. I understand that you may plan for an entire week of lessons or more at one time. Simply record your think-alouds whenever you are planning for the lessons being studied. If you plan ahead of time and later return to make adjustments to your plan, please record both planning sessions.

Please be sure to discuss any of the following items that may come into play as you plan your lesson:

- reflection on past experiences you bring to bear on your current lesson

- mathematical understandings you apply and struggles you encounter

- resources you consult as you plan including curriculum documents, textbooks, standards, websites, colleagues, etc.

- instructional practices that you utilize, ones that may be challenged, or practices with which you may be experimenting

- Pay particular attention to anything you would define as learning or professional growth. In those instances, please expound on the influences that spurred the learning or growth. 


\section{APPENDIX D \\ REFLECTION PROTOCOL}

After each class period you teach please respond to the following prompt in a format that you find most convenient. Feel free to type, write, or record an audio file of your reflections. Please share your reflections with Ted Rupnow via google drive (XXXX@XXX) at the end of each day.

\section{Prompt:}

- Describe how you adjusted your teaching practices and your engagement with students during this class period.

- What did you learn in this class period?

- How might you adjust your future lessons (e.g., your practices, your participation in the learning process, your engagement with students, the content presented)? 


\section{APPENDIX E \\ INTERVIEW PROTOCOLS \\ Initial interview protocol}

1. How long have you been a teacher?

2. What courses have you taught?

3. Have you taught at other schools in the past?

4. Tell me how you became a mathematics teacher.

5. Please describe your teaching practices, the ways you engage with students, how you approach mathematical content.

6. Please describe some of the influences that shaped your teaching practices, how you engage with students, how you approach mathematical content.

7. How do you think about mathematics as a subject area?

8. Describe how your relationships with colleagues impact your teaching.

9. Describe how your relationships with your students impact your teaching.

10. What do you consider the most important general objectives when you teach?

11. What are the most important concrete objects in your teaching?

\section{Post-observation interview protocol}

1. Describe your learning over the course of this unit of instruction.

2. Tell me about the sources of that learning.

3. Describe how your interactions with colleagues shaped your practice over the course of the unit.

4. Describe how your interactions with students shaped your practice of the course of the unit. 
5. How has your engagement with your students, your relationships with your students (particular or general), or your participation in the learning process of your students changed over the course of the unit?

6. What concrete objects or ideas for teaching have come out of this unit that you will continue to utilize in the future?

7. How has your students' participation and engagement changed over the course of the unit? 
APPENDIX F

\section{CODE DEFINITIONS}


Table F-1

\section{Mutual Engagement Codes}

\begin{tabular}{cl}
\hline \multicolumn{1}{c}{ Code } & \multicolumn{1}{c}{ Definition } \\
\hline Teacher-class & $\begin{array}{l}\text { Instance in which a teacher was attempting to communicate } \\
\text { with the entire class. This could include communication that } \\
\text { was directed at individual students, either by verbal } \\
\text { specification or through conversational context, but was } \\
\text { conducted in the context of a whole class interaction. }\end{array}$
\end{tabular}

N 


\begin{tabular}{|c|c|c|}
\hline Code & Definition & Example of code application \\
\hline Teacher-student & $\begin{array}{l}\text { Instance of an interaction or overlapping practice between an } \\
\text { individual students and a teacher in which the student was } \\
\text { not just acting as a class representative but as an individual. } \\
\text { This could include instances in which a teacher-class } \\
\text { interaction was occurring but the teacher addressed the } \\
\text { particular student or was responding to the particular student } \\
\text { involved in the interaction. Additionally, these interactions } \\
\text { could be non-verbal, such as the passing of papers between a } \\
\text { teacher and a student. Situations in which a student was } \\
\text { responding to a general question posed to the class without } \\
\text { being addressed by the teacher were not considered teacher- } \\
\text { student interactions because the student was not addressed } \\
\text { and was acting as a class representative. }\end{array}$ & $\begin{array}{l}\text { From the first lesson, fourth hour: } \\
\text { Rudy: Devin, thanks for volunteering. What's your } \\
\text { second equation? } \\
\text { Devin: I got one fourth equals one sixteenth times two } \\
\text { times } y \text {. } \\
\text { OR } \\
\text { From the first lesson, fourth hour: } \\
\text { Liz and Brady raised their hands. Rudy went over and } \\
\text { looked as Liz's paper. Without commenting, Rudy } \\
\text { proceeded to check Brady's work. Callie raised her hand. } \\
\text { Without commenting on Brady's work, Rudy proceeded } \\
\text { to check Callie's work and without commenting } \\
\text { proceeded to check two more students who had not raised } \\
\text { their hands. }\end{array}$ \\
\hline Individual work & $\begin{array}{l}\text { Instance in which students were engaged in individual } \\
\text { practices. }\end{array}$ & $\begin{array}{l}\text { From the first lesson, fourth hour: } \\
\text { Most of the students seemed to be working on the warm } \\
\text { up during this break in whole class discussion. }\end{array}$ \\
\hline Group work & $\begin{array}{l}\text { Instance in which students were engaged with one another } \\
\text { toward a purposeful end in a teacher sanctioned group } \\
\text { setting. }\end{array}$ & $\begin{array}{l}\text { From the third lesson, fifth hour: } \\
\text { Students chatted as they started, but then quieted down as } \\
\text { they began to work. Partners talked quietly about their } \\
\text { work. After a minute and a half Rudy started checking on } \\
\text { student work and students started talking more, mostly } \\
\text { about their work. }\end{array}$ \\
\hline
\end{tabular}

table continued 


\begin{tabular}{|c|c|c|}
\hline Code & Definition & Example of code application \\
\hline \multirow[t]{6}{*}{ Student-student } & \multirow{6}{*}{$\begin{array}{l}\text { Instance in which students were engaged with one another } \\
\text { toward some purposeful end, either mathematical or } \\
\text { otherwise, and the interaction was not established through } \\
\text { formal grouping. }\end{array}$} & From the first lesson, fifth hour: \\
\hline & & $\begin{array}{l}\text { Mike: Oh, completing the square, rooting both sides, } \\
\text { graphing, factoring, }\end{array}$ \\
\hline & & George: You got this. \\
\hline & & Mike: I got four of them. \\
\hline & & Travis: Did you say quadratic equation? \\
\hline & & Mike: That's what I was missing. \\
\hline \multirow{7}{*}{$\begin{array}{l}\text { Minimal } \\
\text { response }\end{array}$} & \multirow{7}{*}{$\begin{array}{l}\text { Instance in which students were or a student was } \\
\text { unresponsive to the teacher's repeated attempts for teacher- } \\
\text { student or teacher-class engagement. }\end{array}$} & From the first lesson, fourth hour: \\
\hline & & $\begin{array}{l}\text { Rudy: So, back to our original question. What are roots or } \\
\text { the zeros? }\end{array}$ \\
\hline & & In the silence Rudy wrote $x^{2}+3 x-4=y$ \\
\hline & & Rudy: How can I solve for $x$ ? \\
\hline & & Silence \\
\hline & & $\begin{array}{l}\text { Rudy: What if I do this? (wrote } x^{2}+3 x-4=0 \text { ) How } \\
\text { can I solve for } x \text { ? How many ways are there? }\end{array}$ \\
\hline & & Melissa: Five \\
\hline
\end{tabular}




\begin{tabular}{cll}
\hline \multicolumn{1}{c}{ Code } & \multicolumn{1}{c}{ Definition } & \multicolumn{1}{c}{ Example of code application } \\
\hline Teacher-teacher & $\begin{array}{l}\text { Instance in which a teacher was engaged with another } \\
\text { teacher. }\end{array}$ & $\begin{array}{l}\text { From the inservice day: } \\
\text { Jean mentioned that Rudy's students had not seen proof } \\
\text { anywhere yet. She suggested he start with proofs. She } \\
\text { also mentioned that the students had no geometry. Rudy } \\
\text { asked if he needed to do algebraic proofs. Jean said they } \\
\text { did proofs last year with Rudy's students a lot. Julie } \\
\text { suggested a review of proof and a review of properties. }\end{array}$ \\
\cline { 2 - 3 } & $\begin{array}{l}\text { Instance in which a teacher engaged in practice with an } \\
\text { administrator or other non-teaching school personnel. }\end{array}$ & $\begin{array}{l}\text { From Rudy's initial interview: } \\
\text { The Principal at the time and the other two math teachers } \\
\text { wanted all three of us math teachers to teach one class, or } \\
\text { each class of each subject... I told them all, "you're nuts." } \\
\text { This is the first year going integrated, changing our } \\
\text { curriculum, we don't know our pacing guides. This is } \\
\text { going to be way too much. }\end{array}$ \\
\hline
\end{tabular}


Table F-2

\section{Joint Enterprise Codes}

\begin{tabular}{|c|c|c|}
\hline Code & Definition & Example of code application \\
\hline \multirow[t]{2}{*}{ Negotiating } & \multirow{2}{*}{$\begin{array}{l}\text { Instance in which parties in the community are negotiating } \\
\text { the joint enterprise of the community through mutual } \\
\text { engagement. }\end{array}$} & From the first lesson, fourth hour: \\
\hline & & $\begin{array}{l}\text { Rudy: Alright, notes (students flipped sections in five- } \\
\text { subject notebooks). This next unit we're just gonna focus } \\
\text { on two sections. It's not a complete chapter, and really it's } \\
\text { just gonna be one chapter. One point ten, (Rudy wrote } \\
1.10 \text { roots and zeros on board) roots and zeros. Who } \\
\text { remembers what a root is? }\end{array}$ \\
\hline \multirow[t]{2}{*}{ Indigenizing } & \multirow{2}{*}{$\begin{array}{l}\text { Instance in which parties in the community are responding to } \\
\text { external influences as they instantiate the joint enterprise } \\
\text { within their practice. }\end{array}$} & From the second lesson, fifth hour: \\
\hline & & $\begin{array}{l}\text { Rudy: Just like the first semester, I'm not gonna put } \\
\text { grades into [the online grading system] until you have } \\
\text { three, four, five different assignments in there. So, those } \\
\text { that are constantly looking on [the online grading system], } \\
\text { tell your parents that when there is an assignment it will } \\
\text { go out to [the online grading system] but there's not going } \\
\text { to be any numbers in yet. }\end{array}$ \\
\hline \multirow[t]{2}{*}{ Accountability } & \multirow{2}{*}{$\begin{array}{l}\text { Instance in which parties are holding each other accountable } \\
\text { to pursue the joint enterprise of the community, or feeling the } \\
\text { pressure (perceived or otherwise) of accountability to pursue } \\
\text { the joint enterprise. }\end{array}$} & From the second lesson, fifth hour: \\
\hline & & $\begin{array}{l}\text { Rudy: I want to go over the homework. We have a couple } \\
\text { of things that we're gonna do in terms of notes, then I } \\
\text { want to get you all on the board. I wanna see some of } \\
\text { your work, some of your answers. }\end{array}$ \\
\hline
\end{tabular}


Table F-3

\section{Shared Repertoire Codes}

Code $\quad$ Definition $\quad$ Example of code application

Content

Classroom Non-mathematical element of the classroom shared repertoire including tools, artifacts, norms.

Mathematical Mathematical elements of the shared repertoire could include mathematical definitions, postulates, theorems, procedures, strategies, norms, sayings, notations, visuals, representations, and possibly other mathematical elements. Answers to mathematical problems, when the problem and solution process are not discussed, or directions that involve minimal mathematical information are not considered elements of the repertoire.

From the first lesson, fourth hour:

Rudy: Let's open up to our warm ups.

All students opened their five-subject notebooks.

From the first lesson, fourth hour:

Rudy: So, all the quadratics that we graphed and really broke it down. What is the graph of it called?

Several students: Parabola.

Rudy: Parabola! What does it look like?

Brady: U (motioning with his hand)

Rudy: Like a horseshoe. They can open what directions?

Several students: Up and down.

Rudy: Up or down. Sideways?

Sidney: No 


\begin{tabular}{|c|c|c|}
\hline Code & Definition & Example of code application \\
\hline \multirow[t]{3}{*}{ Educational } & \multirow{3}{*}{$\begin{array}{l}\text { Educational elements are related to the educational sphere } \\
\text { and shared by those involved in education (e.g., } \\
\text { mathematics teachers, or the local community of } \\
\text { educators) }\end{array}$} & From the inservice day: \\
\hline & & $\begin{array}{l}\text { Rudy started the meeting by explaining his short } \\
\text { imaginary numbers unit. He explained that he planned } \\
\text { to give a brief introduction to imaginary and complex } \\
\text { numbers and that it would really only be like half a } \\
\text { unit. Then, he asked how in depth he should go with } \\
\text { parallel lines. }\end{array}$ \\
\hline & & $\begin{array}{l}\text { Jean made the comment that the complex number stuff } \\
\text { can be time consuming. She talked about using the } \\
\text { quadratic formula with } i \text { 's. She told him not to teach } \\
\text { Descartes's rule of signs. }\end{array}$ \\
\hline \multirow[t]{5}{*}{ Global } & \multirow{5}{*}{$\begin{array}{l}\text { Shared cultural experiences based on larger societal } \\
\text { memberships (e.g., movie references, pop-culture, social } \\
\text { media) }\end{array}$} & From the first lesson, fifth hour: \\
\hline & & $\begin{array}{l}\text { Rudy: Ben, you like quests don't you? Have you seen } \\
\text { the new Star Wars movie? }\end{array}$ \\
\hline & & Ben nodded. \\
\hline & & Rudy: How many times? \\
\hline & & Ben: Once, opening night. \\
\hline \multirow[t]{2}{*}{ Local } & \multirow[t]{2}{*}{ Part of local or school culture } & From the fourth lesson, fourth hour: \\
\hline & & $\begin{array}{l}\text { Rudy: At the end of the week I'm gonna put grades into } \\
\text { [the online grading system]. }\end{array}$ \\
\hline
\end{tabular}




\begin{tabular}{ccc}
\hline Code & Definition & Example of code application \\
\hline
\end{tabular}

Stage

Emerging Element of a shared repertoire that is being initially established by one or more members of a given community participating in an interaction. Mathematical elements of the shared repertoire that fit this categorization must be part of the teacher's lesson objective for the day.

Establish with discrepancies

Established
Element of a shared repertoire that is partially established for community members participating in a given interaction. Partial establishment of a mathematical element is evidenced when both of the following are true: (a) the element is no longer the expressed objective of the given lesson for the teacher, (b) discrepancies in the understandings of various community members were observed in the interaction (implied discrepancies are not significant evidence the discrepancy must be observable).

Element of a shared repertoire that is established for community members participating in a given interaction. No discrepancies in understandings were observed in the interaction and the element is not the objective for the day.
From the first lesson, fourth hour:

Rudy: The largest degree in the equation represents the total number of zeros or roots. (Rudy wrote three examples on the board.) These aren't meant to be tricky or hard or anything like that. Example number one, what's the largest exponent or what's the largest degree?

\section{Melissa: Two}

Rudy: Largest degree's two, so the total number of zeros is gonna be two.

From the second lesson, fourth hour:

Rudy: Reese got negative 36i...raise your hand if you agree.

Cory laughed and most of the class raised their hands.

Rudy: Raise your hand if you do not agree.

Cory and a couple other students raised their hands.

From the first lesson, fourth hour:

Rudy: Let's open up to our warm ups.

All students opened their five-subject notebooks. 


\begin{tabular}{cll}
\hline Code & \multicolumn{1}{c}{ Definition } & \multicolumn{1}{c}{ Example of code application } \\
\hline Unnecessary & $\begin{array}{l}\text { A possible element of the shared repertoire that the teacher } \\
\text { dismisses as unnecessary to establish in the community. }\end{array}$ & $\begin{array}{l}\text { From the first lesson, fourth hour: } \\
\text { Rudy: Remember that } i \text { is equal to the square root of } \\
\text { negative one. You'll get more in depth on what it } \\
\text { actually is or how it's actually used, like word problems } \\
\text { and all that once you get to Algebra 2. }\end{array}$ \\
\hline
\end{tabular}

Table F-4

Participation Codes

$\stackrel{\text { Code }}{\mathscr{\infty}_{0}}$

Allaying fears Instance of the teacher trying to calm the students and mitigate fear or anxiety, particularly in a mathematical situation.

From the first lesson, fourth hour:

Rudy: It's a little confusing. I will help you out.

Answering Instance of the teacher answering students for instructional purposes.

From the second lesson, fifth hour:

Sahara: Why'd we do that? Is it so that way we can, it's like easier to tell if we have to reduce or?

Rudy: That, but also this $a$ plus $b i$ is gonna be used with vectors and Algebra 2 stuff. 


\begin{tabular}{|c|c|c|}
\hline Code & Definition & Example of code application \\
\hline \multirow[t]{3}{*}{ Directing } & \multirow{3}{*}{$\begin{array}{l}\text { Instance of the teacher giving directions, managing } \\
\text { behavior, or engaging in other authoritative non- } \\
\text { mathematical interaction. }\end{array}$} & From the first lesson, fourth hour: \\
\hline & & Rudy: Let's open up to our warm ups. \\
\hline & & All students opened their five-subject notebooks \\
\hline \multirow[t]{2}{*}{ Evaluating } & \multirow{2}{*}{$\begin{array}{l}\text { Instance of the teacher evaluating student work and } \\
\text { responses for instructional purposes. }\end{array}$} & From the first lesson, fourth hour: \\
\hline & & $\begin{array}{l}\text { Liz and Brady raised their hands. Rudy went over and } \\
\text { looked as Liz's paper. Without commenting, Rudy } \\
\text { proceeded to check Brady’s work. Callie raised her } \\
\text { hand. Without commenting on Brady's work, Rudy } \\
\text { proceeded to check Callie’s work and without } \\
\text { commenting proceeded to check two more students } \\
\text { who had not raised their hands. }\end{array}$ \\
\hline \multirow{2}{*}{$\begin{array}{l}\text { Facilitating } \\
\text { peer-to-peer } \\
\text { engagement }\end{array}$} & \multirow{2}{*}{$\begin{array}{l}\text { Instance in which teacher's participation encourages } \\
\text { peers to engage with one another in a process of } \\
\text { evaluation, support, discussion. }\end{array}$} & From the second lesson, fourth hour: \\
\hline & & $\begin{array}{l}\text { Rudy: I'll give you a minute and a half to see if you } \\
\text { can do three. You can work on 'em with a partner } \\
\text { check your answers with a partner. Raise your hand } \\
\text { when you have an answer. The only hint I'll give you, } \\
\text { you do not want to distribute first. }\end{array}$ \\
\hline
\end{tabular}




\begin{tabular}{ll}
\hline Code & \multicolumn{1}{c}{ Definition } \\
\hline $\begin{array}{l}\text { Facilitating self- } \\
\text { evaluation }\end{array}$ & $\begin{array}{l}\text { Instance of the teacher creating space for students to } \\
\text { reflect on their own work, check their solutions, or learn } \\
\text { from their participation in the community (especially in } \\
\text { regards to mathematics) }\end{array}$
\end{tabular}
regards to mathematics).

Example of code application

From the second lesson, fifth hour:

Rudy: Okay, let's start going over these. If you were one that got these wrong, as we're going over these make sure we're correcting our mistakes. I want to point out a few things. Don't multiply them together first. In this case it does work out that you'll get the correct answer but I don't want you getting into bad habits. You want to take your i's out first so you'll have the square root of 7 times $i$ square root of 14 .

Hinting Instance of the teacher providing hints to help students.

From the second lesson, fourth hour:

Rudy: The only hint I'll give you, you do not want to distribute first.

Using humor Instance of the teacher using humor in an interaction.

From the first lesson, fourth hour:

Rudy: Mama says negatives underneath the square root are the devil. Just like negative exponents are the devil.

Coordinating

Instance of the teacher participating in classroom activity logistics through logistical arrangements and other non-interactive contributions to community activity.

From the first lesson, fourth hour:

Rudy prepared to begin class by taking attendance, turning on the projector, and writing a warm up on the interactive whiteboard. 


\begin{tabular}{|c|c|c|}
\hline Code & Definition & Example of code application \\
\hline \multirow{2}{*}{$\begin{array}{l}\text { Mathematical } \\
\text { telling }\end{array}$} & \multirow{2}{*}{$\begin{array}{l}\text { Instance of the teacher making a statement that is both } \\
\text { mathematical and instructional. }\end{array}$} & From the first lesson, fourth hour: \\
\hline & & $\begin{array}{l}\text { Rudy: Could this be one of them (ways to solve a } \\
\text { quadratic)? (Rudy wrote }()(\text { ) then filled in the } \\
\left.\text { factored form of } x^{2}+3 x-4=0\right) x, x \text {, positive times } \\
\text { a negatives is a negative, positive four times negative } \\
\text { one is negative four, if you add them together you get } \\
\text { a positive three. Then, you would use the zero product } \\
\text { property to get negative four and positive one. These } \\
\text { numbers are the roots. These numbers are the zeros. } \\
\text { What did I do with my } y \text { ? Put a zero in its place. So in } \\
\text { this case we have two answers. }\end{array}$ \\
\hline \multirow[t]{2}{*}{ Motivating } & \multirow{2}{*}{$\begin{array}{l}\text { Instance of the teacher attempting to motivate students. } \\
\text { Or an instance in which students are motivated by the } \\
\text { teacher's actions regardless of the teacher's intent. }\end{array}$} & From the second lesson, fifth hour: \\
\hline & & $\begin{array}{l}\text { Rudy: Raise your hand if you got this correct. Pat } \\
\text { yourselves on the back. }\end{array}$ \\
\hline \multirow[t]{2}{*}{ Questioning } & \multirow{2}{*}{$\begin{array}{l}\text { Instance of the teacher questioning students for } \\
\text { instructional purposes. }\end{array}$} & From the first lesson, fourth hour: \\
\hline & & $\begin{array}{l}\text { Rudy: Can you break } 10 \text { down, the square root of } 10 \\
\text { down? Perfect squares. Four go into it evenly? Nine? } \\
\text { No, so this is our answer. } i \text { times the square root of } 10 . \\
\text { See it's not that different. What about two? Negative } \\
\text { underneath the root, what do we have to do first? Take } \\
\text { your } i \text { 's out. (Rudy wrote as he talked.) } i \text { times the } \\
\text { square root of } 28 \text {. Is that our answer? }\end{array}$ \\
\hline
\end{tabular}

Kale: No.

Rudy: No, why not? Stacy, do any perfect squares go into 28? 


\begin{tabular}{|c|c|c|}
\hline Code & Definition & Example of code application \\
\hline \multirow[t]{7}{*}{ Story telling } & \multirow{7}{*}{$\begin{array}{l}\text { Instance of the teacher sharing information in a narrative } \\
\text { fashion not intended as instructional. }\end{array}$} & From the first lesson, fifth hour: \\
\hline & & Rudy nodded: Have you tasted this water? \\
\hline & & George: I live here so, I'm fine with it. \\
\hline & & $\begin{array}{l}\text { Rudy: The day I interviewed I almost didn't accept this } \\
\text { job because the water tasted so bad and no one warned } \\
\text { me. I thought I was gonna drive back to college } \\
\text { pregnant or something. }\end{array}$ \\
\hline & & George: It's not even that bad. \\
\hline & & $\begin{array}{l}\text { Kayla: The elementary school and the Chemistry room } \\
\text { water doesn't taste that bad. }\end{array}$ \\
\hline & & Rudy: I would rather lick a skunk than drink the water. \\
\hline \multirow{3}{*}{$\begin{array}{l}\text { Uncategorized } \\
\text { participation }\end{array}$} & \multirow{3}{*}{$\begin{array}{l}\text { Instance of the teacher's participation in the classroom } \\
\text { activity that does not fit a currently defined code. }\end{array}$} & Examples vary widely \\
\hline & & From the first lesson, fifth hour: \\
\hline & & $\begin{array}{l}\text { Rudy distributed worksheets one by one while walking } \\
\text { through the rows of desks. }\end{array}$ \\
\hline $\begin{array}{l}\text { Using a } \\
\text { nickname }\end{array}$ & $\begin{array}{l}\text { Instance of the teacher using a student's last name or a } \\
\text { nickname to address the student instead of his or her first } \\
\text { name. }\end{array}$ & $\begin{array}{l}\text { Actual nicknames are confidential but most instances } \\
\text { were the use of a last name }\end{array}$ \\
\hline
\end{tabular}




\begin{tabular}{|c|c|c|}
\hline Code & Definition & Example of code application \\
\hline Withdrawing & $\begin{array}{l}\text { Instance of the teacher purposefully disengaging from } \\
\text { interactions for a period of time. For instance, leaving the } \\
\text { classroom or sitting behind a desk may be indicative of } \\
\text { withdrawing (note that this need not be construed } \\
\text { negatively). }\end{array}$ & $\begin{array}{l}\text { From the first lesson, fifth hour: } \\
\text { Rudy started writing examples from his notes. He } \\
\text { stopped and went into the hall to talk with someone. } \\
\text { The students started talking with each other and } \\
\text { continued when he came back in and finished writing } \\
\text { the examples. }\end{array}$ \\
\hline \multicolumn{3}{|l|}{$\begin{array}{l}\text { Participation in the } \\
\text { teaching community }\end{array}$} \\
\hline \multirow{2}{*}{$\begin{array}{l}\text { Developing } \\
\text { instructional } \\
\text { materials }\end{array}$} & \multirow[t]{2}{*}{ Instance of the teacher developing plans for instruction } & From the initial interview: \\
\hline & & $\begin{array}{l}\text { Rudy: My first year I locked myself in my room. I } \\
\text { worked through my preps, my lunches, I'd come in on } \\
\text { Sundays, lesson plan, things like that. I didn't have } \\
\text { time to collaborate. }\end{array}$ \\
\hline \multirow{2}{*}{$\begin{array}{l}\text { Influencing } \\
\text { change }\end{array}$} & \multirow{2}{*}{$\begin{array}{l}\text { Instance of the teacher participating with colleagues in } \\
\text { the process of making large scale changes including } \\
\text { curricular changes, class sequence changes, and other } \\
\text { large scale changes. }\end{array}$} & From the initial interview: \\
\hline & & $\begin{array}{l}\text { Rudy: But we kind of did away with that (an RTI } \\
\text { approach) cause that's more at the lower level, like } \\
\text { elementary school, and we did away with the track } \\
\text { system altogether. We really only have one track now. } \\
\text { There isn't a higher level lower level. We created a } \\
\text { separate class that includes the lower level kids, which } \\
\text { is like an essentials class. So, we created that when we } \\
\text { changed our curriculum to integrated, so this will be } \\
\text { the third year now. }\end{array}$ \\
\hline
\end{tabular}

table continued 


\begin{tabular}{cll}
\hline Code & \multicolumn{1}{c}{ Definition } & \multicolumn{1}{c}{ Example of code application } \\
\hline $\begin{array}{l}\text { Uncategorized } \\
\text { participation }\end{array}$ & $\begin{array}{l}\text { Instance of the teacher's participation in the teaching } \\
\text { community that does not fit a currently defined code. }\end{array}$ & $\begin{array}{l}\text { Examples vary widely } \\
\text { From the initial interview: }\end{array}$ \\
& & $\begin{array}{l}\text { Rudy: I was kind of integrating certain concepts in } \\
\text { with my traditional teaching. Whether it be a warm up } \\
\text { or maybe it was a project trying to bring algebra } \\
\text { concepts into the geometry. }\end{array}$ \\
\hline
\end{tabular}

Table F-5

\section{$\stackrel{\omega}{\infty}$ Reification Codes}

\begin{tabular}{lll}
\hline Code & \multicolumn{1}{c}{ Definition } & \multicolumn{1}{c}{ Example of code application } \\
\hline CCSS-M & $\begin{array}{ll}\text { Reference to the Common Core State Standards for } \\
\text { Mathematics (National Governors Association, 2010) }\end{array}$ & $\begin{array}{l}\text { From the initial interview: } \\
\text { Rudy: And common core was a big reason. And I think } \\
\end{array}$ \\
& $\begin{array}{l}\text { Common Core is the biggest reason why a lot of the, } \\
\text { how we teach it, how our approach is to relate to the } \\
\text { students, get the material across, I think has a bigger } \\
\text { influence than the integrated. }\end{array}$
\end{tabular}

table continued 


\begin{tabular}{ll}
\hline \multicolumn{1}{c}{ Code } & \multicolumn{1}{c}{ Definition } \\
\hline Course & $\begin{array}{l}\text { Reference to a particular course (not the general subject, } \\
\text { not a particular class, not an hour in the school day) }\end{array}$ \\
$\begin{array}{l}\text { Five-subject } \\
\text { notebook }\end{array}$ & $\begin{array}{l}\text { Reference to or use of a five subject notebook as the } \\
\text { specifically defined tool in Rudy’s classes }\end{array}$ \\
Homework & $\begin{array}{l}\text { Reference to homework, assignment of homework, } \\
\text { grading of homework, checking of homework, collecting } \\
\text { of homework, or other engagement in the system of } \\
\text { homework. }\end{array}$
\end{tabular}

Lesson objective

Reference to an objective, goal, or focus of a given lesson

Lesson plan
Reference to a lesson plan or the planning of a lesson
Example of code application

From the first lesson, fourth hour:

Rudy: Remember that $i$ is equal to the square root of negative one. You'll get more in depth on what it actually is or how it's actually used, like word problems and all that once you get to Algebra 2.

From the first lesson, fourth hour:

Students flipped sections in five-subject notebooks.

From the first lesson, fourth hour:

Rudy: Homework. I'm gonna hand out two worksheets. We're gonna refer back to them for the next couple of days.

From the lesson plans:

Listed under the word objective: Determine the number and type of roots for a polynomial equation.

From the initial interview:

Rudy: There really wasn't a curriculum or there really isn't a whole lot of stuff out there as far as high school level RTI. I just basically made stuff up myself like fractions, decimals, simpler things. 


\begin{tabular}{cl}
\hline \multicolumn{1}{c}{ Code } & \multicolumn{1}{c}{ Definition } \\
\hline Mathematical Object & $\begin{array}{l}\text { Reference to a mathematical concept, procedure, or topic } \\
\text { that takes on a form of existence that helps organize } \\
\text { classroom experiences for the teacher and students (these } \\
\text { were only coded at the first use of the object in a particular } \\
\text { episode of activity (within one conversation, example } \\
\text { problem, or other episode) }\end{array}$
\end{tabular}

Notes

Reference to notes, taking of notes, use of notes

Reference to, grading of, completing of, or developing of short, but formal evaluation

$\underset{\infty}{\infty}$

Schoolwide

reification

Social norm

Technology
Any reification that is standard in the school, beyond the classroom context and is non-mathematical

Reference to, use of, or establishment of a classroom social norm

An element of technology that is part of participation
Example of code application

From the first lesson, fourth hour:

Rudy: So, all the quadratics that we graphed and really broke it down. What is the graph of it called?

Several students: Parabola

Rudy: Parabola! What does it look like?

From the first lesson, fifth hour:

Rudy: That was fun wasn't it? Alright, let's get to our notes.

From the first lesson, fifth hour:

Rudy: You're not going to have a test over this it's going to be more like a quiz or a quest

From the first lesson, fifth hour:

Students started gathering their things and after about 30 seconds the bell rang.

From the first lesson, fourth hour:

Rudy: Raise your hand if you think you have an answer.

From the fourth lesson, fourth hour:

Rudy: Can you use your graphing calculator to figure out the solutions to this? 


\begin{tabular}{|c|c|c|}
\hline Code & Definition & Example of code application \\
\hline \multirow[t]{2}{*}{ Test } & \multirow{2}{*}{$\begin{array}{l}\text { Reference to, completing of, grading of, or developing } \\
\text { of a classroom assessment referred to as a test }\end{array}$} & From the fourth lesson, fifth hour: \\
\hline & & $\begin{array}{l}\text { Rudy: I know for a fact, previous quizzes, previous } \\
\text { tests, I think both, there was a problem where we did } \\
\text { something like this and we used no solution. }\end{array}$ \\
\hline \multirow[t]{2}{*}{ Textbook } & \multirow{2}{*}{$\begin{array}{l}\text { Reference to or use of the textbook for a course (Carter } \\
\text { et al., 2012) }\end{array}$} & From the fourth lesson, fifth hour: \\
\hline & & $\begin{array}{l}\text { Rudy: Page 187, one through nine. We've already } \\
\text { done or gone over a lot of questions from } 182 \text { to } 183\end{array}$ \\
\hline \multirow{3}{*}{$\begin{array}{l}\text { Uncategorized } \\
\text { reification }\end{array}$} & \multirow{3}{*}{$\begin{array}{l}\text { Reference to a reification that is not described by one of } \\
\text { the current codes }\end{array}$} & Examples vary widely \\
\hline & & From the fourth lesson, fourth hour: \\
\hline & & $\begin{array}{l}\text { Rudy proceeded to look at each students paper } \\
\text { between the first two rows on the left side of the } \\
\text { classroom. He wrote something in his gradebook } \\
\text { periodically. }\end{array}$ \\
\hline \multirow[t]{2}{*}{ Warm up } & \multirow{2}{*}{$\begin{array}{l}\text { Reference to, completion of, development of a warm up } \\
\text { as defined by the participant using the term }\end{array}$} & From the first lesson, fourth hour: \\
\hline & & Rudy: Let's open up to our warm ups. \\
\hline
\end{tabular}




\section{APPENDIX G}

\section{TEACHER LETTER AND CONSENT FORM}

Dear Mr. Ruettiger,

You are invited to participate in a study of mathematics teacher learning conducted by Ted Rupnow for his dissertation at A University. The purpose of the study is to investigate how secondary mathematics teachers learn through their classroom experiences. If you choose to participate you will be asked to share your experiences teaching one of your courses during a period of approximately three-weeks. You will be asked to participate in two interviews: one prior to the two-week teaching period and one after the two-week teaching period. Each interview will be approximately 45 minutes in length. You will also be asked to share your lesson plans, record your lesson planning process, videotape your lessons, be observed during the lessons, and record a reflection for each lesson. The amount of extra time you spend recording your lesson planning process and a reflection should not exceed one hour per teaching day. In addition, I would like to act as a volunteer in your classroom for one week prior to the two-week observation. At a later time I would like to share some of my results with you in a short session to check that I have told your story accurately.

As a participant in the study you will be asked to choose a course that you are teaching for the first time during the 2015-2016 school year. You may have any experience level in general, but the course that you share should be one you have not taught at any time in your career. In addition, you should be teaching two sections of this course and be willing to have both sections observed and videotaped.

Your participation in this study is entirely voluntary and there are no negative consequences for non-participation. If you decide to participate you may withdraw from the study at any time by contacting the researcher. Should you decide to participate your identity will be kept confidential in all publications of the research. Only the researcher and his committee chair will view any of the raw data. Although the data will be kept confidential, your students, their parents, and select district representatives will know that you are participating in this study. In addition, the limited pool of possible participants in this geographic region may imply a greater risk of the loss of confidentiality.

Participation will require additional time for planning and reflection as well as two interview sessions. This could result in extra stress or other consequences of time spent on these activities. In addition, you may feel some emotional strain when having your classes observed and videotaped. Students may also become uncomfortable due to the presence of the video camera. This could impact your classroom environment causing 
disruption. Observations of collegial interactions and your responses to questions about collegial relationships in interviews may impact your employability. However, you may skip any question asked during an interview.

In compensation for your time the researcher is willing to provide services commensurate with your time spent on the project as determined by yourself and the researcher (not in excess of one hour per day). In addition, you will receive an $\$ 80$ stipend for participation. You will receive the first $\$ 40$ after the initial interview and the remainder at the conclusion of the final interview (withdrawal from the study will result in forfeiture of the second \$40). After the completion of the study I will also provide you with resources for your continued learning if you so desire.

Additional benefits of your participation include the opportunity to reflect on your own teaching and share your experiences with another professional. Your participation in this project will contribute to research that may help promote the use of practical experiences in teacher training and professional development.

If you wish to participate, please sign the attached consent form and return it in the addressed stamped envelope enclosed.

If you have any questions concerning the research study, please contact David Barker at xxxxx@xxxx, or at (xxx) xxx-xxxx, or postal mail XXXXXX. You may also contact Ted Rupnow at xxxx@xxx.xxx, or the same postal address. If you have any questions about your rights as a participant in this research, or if you feel you have been placed at risk, you can contact A University Research Ethics \& Compliance Office at (xxx) xxx-xxxx.

Sincerely,

Ted Rupnow

\section{Teacher Consent Form}

$\mathrm{I}$, consent to participate in the research

project investigating how secondary mathematics teachers learn through their classroom experiences. I consent to classroom lessons being video-taped.

Date 


\section{APPENDIX H}

\section{RUDY'S LESSON PLANS}

Geometry

1.10 - Roots \& Zeros [3 days]

Objectives

- Determine the number and type of roots for a polynomial equation.

- Find the zeros of a polynomial function.

Common Core State Standards

N.CN.9 Know the Fundamental Theorem of Algebra; show that it is true for quadratic polynomials.

A.APR.3 Identify zeros of polynomials when suitable factorizations are available, and use the zeros to construct a rough graph of the function defined by the polynomial.

Go over the homework

DAY1

Warm Up [SmartBoard] pg. 79; \#61

1. Imaginary Numbers

*Imaginary Numbers are used to simplify square roots of negative numbers

$$
\begin{aligned}
& i=\sqrt{-1} \quad i^{2}=-1 \\
& \text { Ex's: 1) } \sqrt{-10} \Rightarrow i \sqrt{10} \quad \text { 2) } \sqrt{-28} \Rightarrow i \sqrt{28} \\
& \text { 4) }(6 i)^{2} \Rightarrow(6 i)(6 i) \quad \frac{4 \sqrt{7}}{2 i \sqrt{7}} \\
& \begin{array}{l}
=36 i^{2} \\
=36(-1) \Rightarrow-36
\end{array} \\
& \text { 3) } 3 \sqrt{-12} \\
& 3 i \sqrt{12} \\
& \sqrt{4} \frac{1}{3} \\
& \frac{3 i \cdot 2 \cdot \sqrt{3}}{6 i \sqrt{3}}
\end{aligned}
$$

* Just how you have to rationalize the denominator when squared roots are in the denominator, you must rationallze the denominator when there is an " $\mu$ " in the denominator

$$
\begin{aligned}
& \text { Ex's: 1) } \frac{4}{5 i(i)}=\frac{4 i}{5 i^{2}}=\frac{4 i}{5(-1)}=\left|\frac{-4 i}{5}\right| \\
& \text { 2) } \frac{10}{\sqrt{-5}}=\frac{10}{i \sqrt{5}(i \sqrt{5})}=\frac{10 i \sqrt{5}}{i^{2} \cdot \sqrt{25}}=\frac{10 i \sqrt{5}}{(-1)(5)} \\
& =\frac{10 i \sqrt{5}}{-5} \\
& =-2 i v
\end{aligned}
$$

3. Complex Numbers:

"Adding/Subtracting using " $P$ "-- think about it as combining like terms when simplifying

$$
\text { Ex's: 1) } i+6 i=\overline{7 i} \quad \begin{array}{ll}
\text { 2) } & 4 \sqrt{-3}-\sqrt{-75} \\
& 4 i \sqrt{3}-i \sqrt{75} \\
& 4 i \sqrt{3}-5 i \sqrt{3}
\end{array}
$$

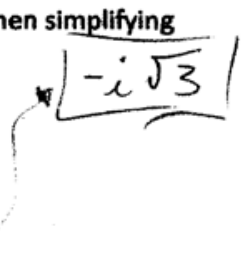


"Multiplying using " $r$ "-- remember, $t^{2}=-1$ Kcep answers in form of $\alpha+b i$

Ex's:

1) $2 i(4+7 i)$

$=8 i+14 i^{2}$

$=8 i+14(-1)$

$=-14+8 i$
2) $(2-5 i)(3+4 i)$

$6+8 i-15 i-20 i^{2}$

$6-7 i-20(-1)$

$6-7 i+20$

$26-7 i$

*Conjugates using " $r$-- keep answers in the form of $a+b i$

Ex's: $\frac{5}{2-5 i(2+5 i)}(2+5 i)=\frac{10+25 i}{4+5 i-5 i-25 i^{2}}=\frac{10+25 i}{4-25(-1)}=\frac{10+25 i}{4+25}=\frac{10+25 i}{29}$

2) $\frac{9}{-3+2 i(-3-2 i)}=\frac{-27-18 i}{9+6 i-6 i-4 i^{2}}=\frac{-27-18 i}{9-4(-1)}=\frac{-27-18 i}{9+4}=\frac{-27-18 i}{13}$

$\frac{\text { HOMEWORK: imaginary number W.s. }[1-19,27,29] \text { odds \& complex number w.s. [1-19] odds }}{\text { DAY } 2}$

Go over homework

Warm up: [Solve for $x$ ]

1) $x^{2}+100=0$

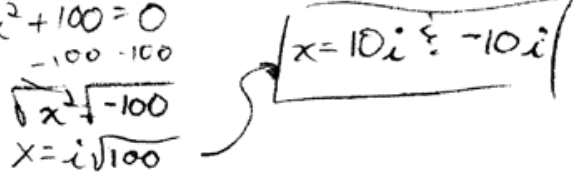

"Review what the term "degree" is

$$
\text { 2) } \begin{array}{rl}
4 x^{2}+78 & =6 \\
78 & 78 \\
4 x^{2} & =-\frac{72}{4} \\
\sqrt{x^{2}}=-18
\end{array} \quad \begin{gathered}
x=i \sqrt{18} \\
\sqrt{9} \sqrt{2}
\end{gathered}
$$

FUNDAMENTAL THEOREM OF ALGEBRA - All polynomial equations with degree greater than zero will have at least one root/zero [real or imaginary]

\section{DETERMINING THE TOTAL NUMBER OF ZEROS}

- The largest degree in the equation will allow you to determine how many roots/zeros there will be

Ex's:

1) $x^{2}+6 x+4=0$

Larges $x$ Degree $=2$

tif zeros $=2$

s) $4 x^{4}+5 x-3 x^{3}-6$

Laiges Degite $=4$

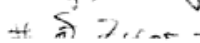

3) $8-3 x^{5}-5 x^{2}$

Largest Degree $=5$

\#tzeros $=5$

* ONLY \# ot Ziros 


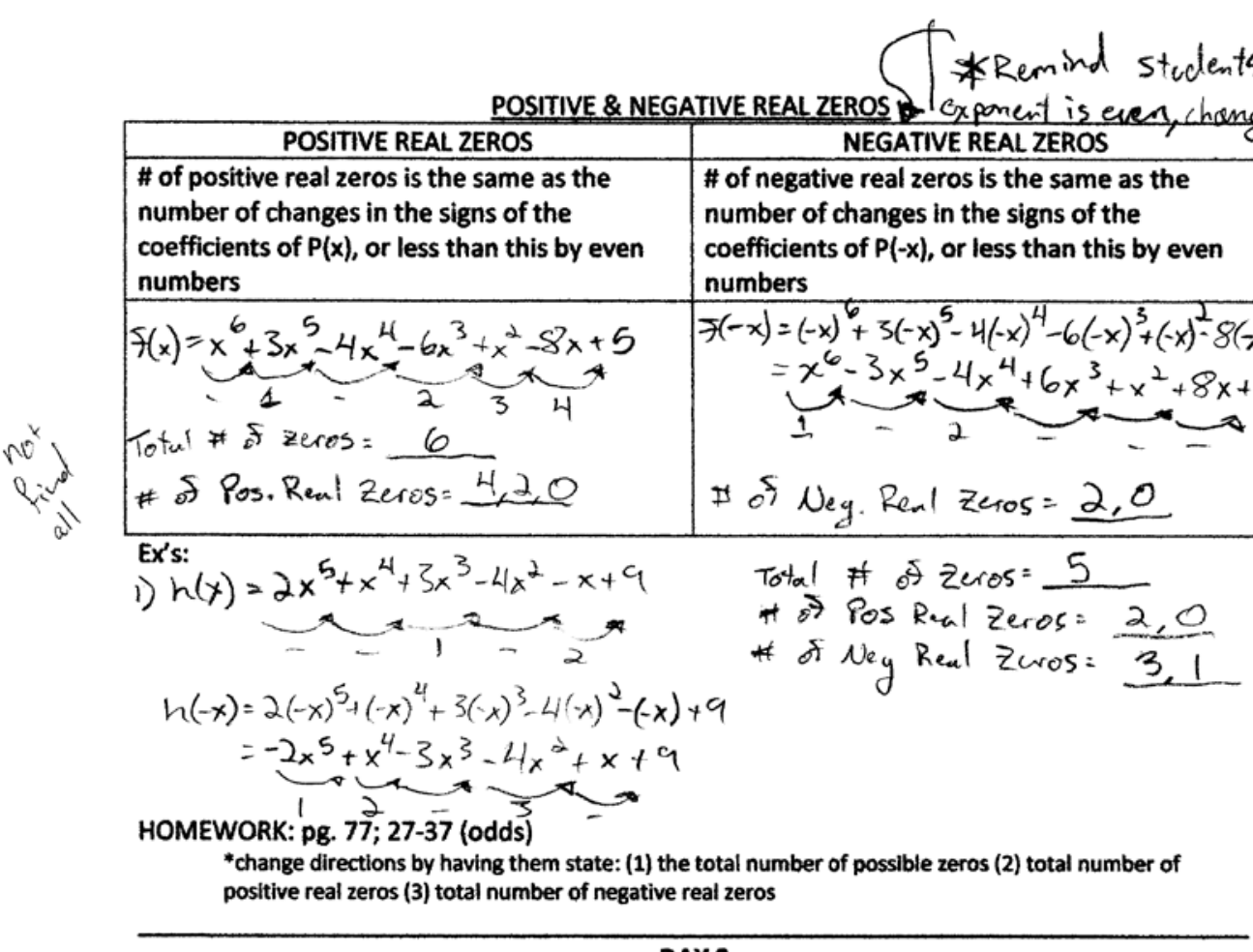

DAY 3

Go over the homework (have students put their work on the board

IMAGINARY ZEROS

*To determine how many imaginary zeros there will be, you have to:

$1^{\text {st }}$ : determine how many total zeros there are

$2^{\text {nd }}$ : determine how many positive real zeros there are \& how many negative real zeros there are

$3^{\text {rd }}$ : make a chart

Ex's:

$$
\begin{aligned}
& \text { 1) } f(x)=6 x^{4}+4 x^{3}-x^{2}-5 x-7 \\
& \begin{aligned}
f(-x) & =6(-x)^{4}+4(-x)^{3}-(-x)^{2}-5(-x)-7 \\
& =\underbrace{6 x^{4}-4 x^{3}-x^{2}+5 x-7}_{1}
\end{aligned} \\
& \begin{array}{l}
\text { Total \# of Zeros }=\frac{4}{1} \\
\text { \# of Pos Renl Zeros }=\frac{1}{3 \text { or } 1}
\end{array}
\end{aligned}
$$
positive real zeros (3) total number of negative real zeros (4) total number of imaginary zeros

Quiz over $2.6 \& 1.10$ 


\section{APPENDIX I}

\section{RUDY'S THINK-ALOUD RESPONSE}

\section{Reflection}

$|1 / 5 / 16|$

This unit will cover 1.10 (Zeros? Roots) \& 3.2 (Complex? Imaginary

- In the past I have gone into depth w/ 1.10

- Fundamental thecrem of Algebra - Stating i. determining total * of roots

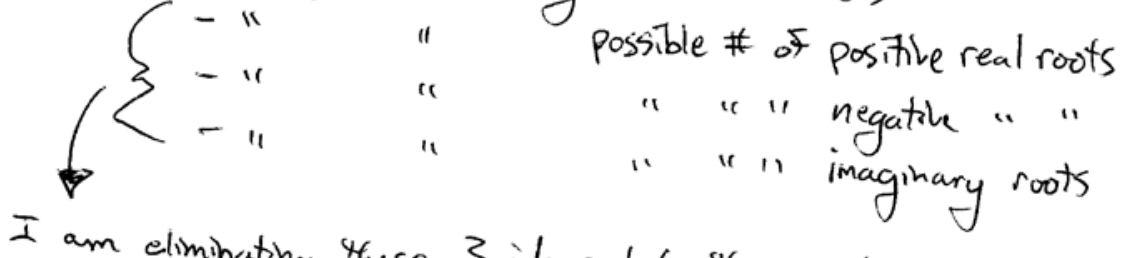

ing these 3 ideas b/c they will get this in Matulll

- I have rearranged the order in which I'

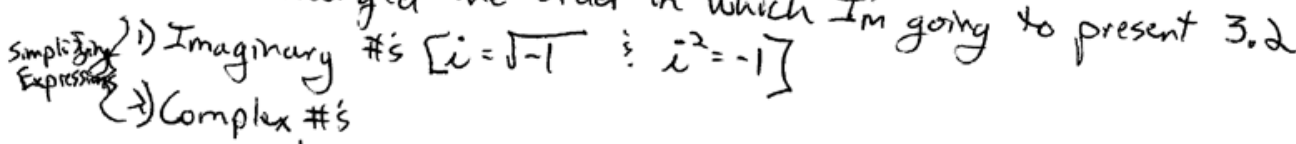

- Add/subr using $i$

- Mutiplying "I "

- Rationalizing the Denominutor

Solving 3) Imaginary Equans Complex $\# 5$

- They have done/solved quadratic eq's that have dealt w/ a neg. in the square root. up until now they havent been able to go any where from it.

- I want them to notice the similarities from what/how they're solved quadratic eqs (Rootiny both sides, factoring, completing the square, graphing
Calculator, Quad. Formula) in the past

- And how/what to do when they have a $\sqrt{-1}$.

- This unit is unique b/c the text book uses anly 2 sections? they aren't in the same ch.

- Instead of giving a Ch. Test after wards, they will thake a qyiz

- Pacing is still undetermined, will make note this year for future [I assume it is 24.5 days] 